University of New Mexico

UNM Digital Repository

Mechanical Engineering ETDs

Engineering ETDs

$12-9-1972$

\title{
A Probabilistic Approach to the Design of Heat Pipes
}

Charles C. Roberts Jr.

Follow this and additional works at: https://digitalrepository.unm.edu/me_etds

Part of the Mechanical Engineering Commons 
PROBAEIIST: APPRivinet 70 THE DES.AT OF WEAI PMES

Rogeris

LD

3781

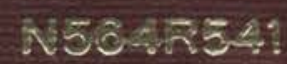

$60 x$ 


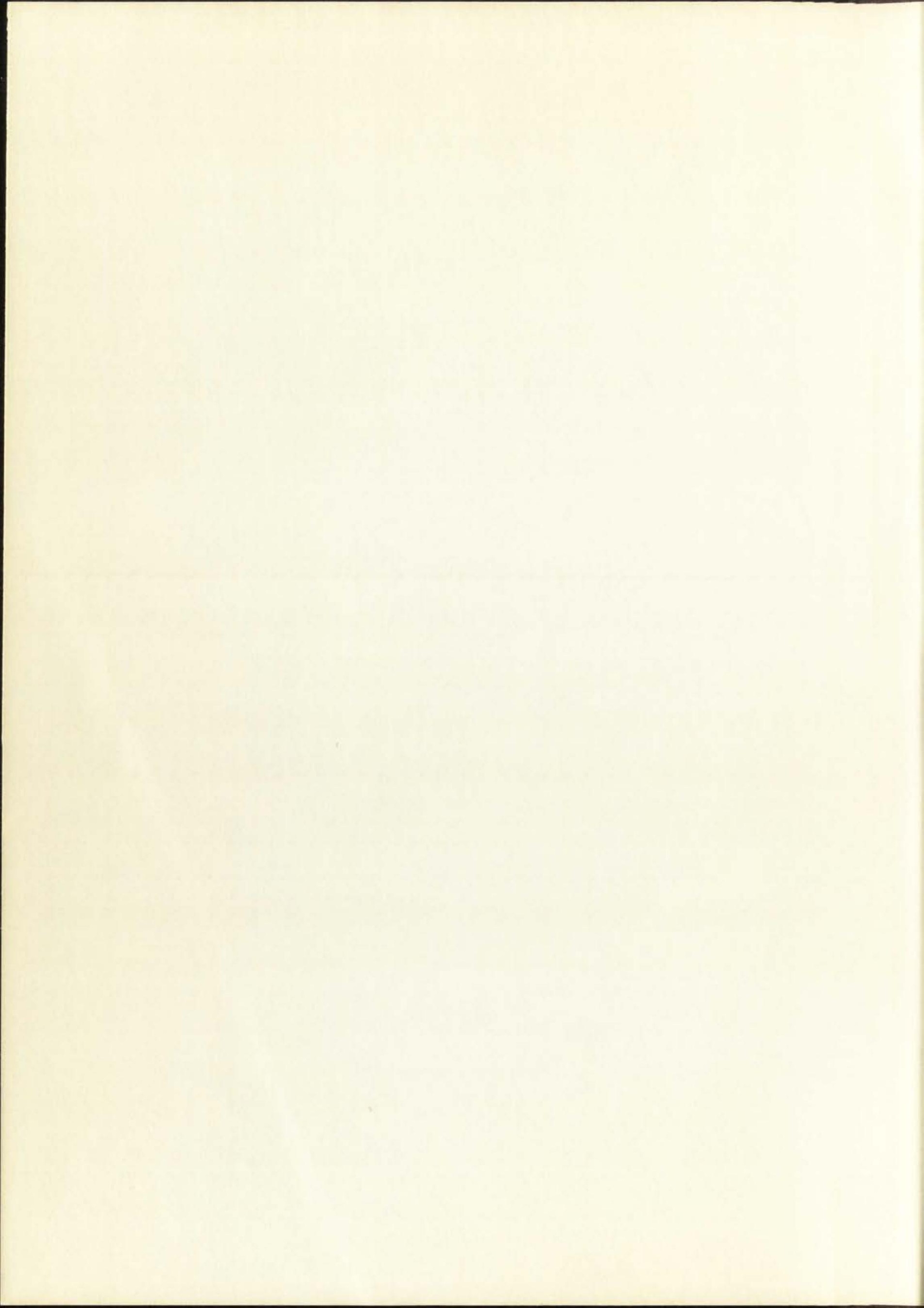




\section{THE UNIVERSITY OF NEW MEXICO \\ ALBUQUERQUE, NEW MEXICO 87106}

\section{Policy on Use of Theses and Dissertations}

Unpublished theses and dissertations accepted for master's and doctor's degrees and deposited in the University of New Mexico Library are open to the public for inspection and reference work. They are to be used only with due regard to the rights of the authors. The work of other authors should always be given full credit. Avoid quoting in amounts, over and beyond scholarly needs, such as might impair or destroy the property rights and financial benefits of another author.

To afford reasonable safeguards to authors, and consistent with the above principles, anyone quoting from theses and dissertations must observe the following conditions:

1. Direct quotations during the first two years after completion may be made only with the written permission of the author.

2. After a lapse of two years, theses and dissertations may be quoted without specific prior permission in works of original scholarship provided appropriate credit is given in the case of each quotation.

3. Quotations that are complete units in themselves (e.g., complete chapters or sections) in whatever form they may be reproduced and quotations of whatever length presented as primary material for their own sake (as in anthologies or books of readings) ALWAYS require consent of the authors.

4. The quoting author is responsible for determining "fair use" of material he uses.

This thesis/dissertation by Charles C. Roberts, Jr. has been used by the following persons whose signatures attest their acceptance of the above conditions. (A library which borrows this thesis/dissertation for use by its patrons is expected to secure the signature of each user.)

NAME AND ADDRESS

DATE

July $1971-1,000-$ GS 

This dissertation, directed and approved by the candidate's committee, has been accepted by the Graduate Committee of The University of New Mexico in partial fulfillment of the requiremints for the degree of

DOCTOR OF PHILOSOPHY

A PROBABILISTIC APPROACH

TO THE DESIGN OF HEAT PIPES

Title

CHARLES C. ROBERTS, JR.

Candidate

Department of Mechanical Engineering

Department
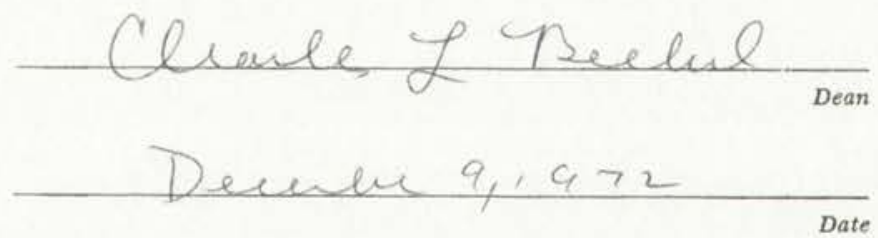

Committee

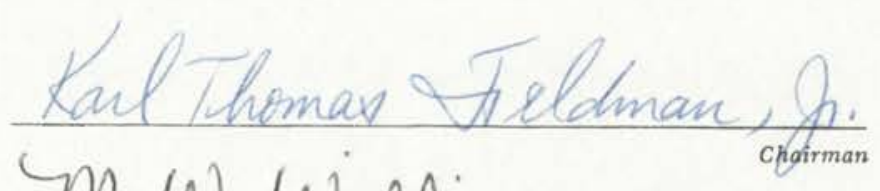

IM. W. Walden

Westing 


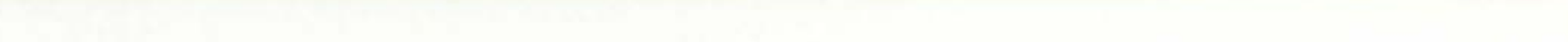

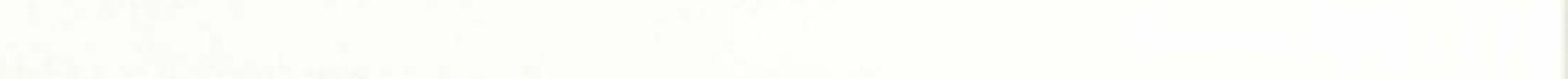

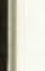

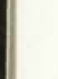

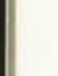

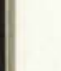

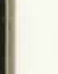

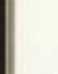

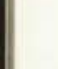

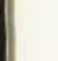

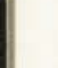

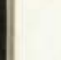

.
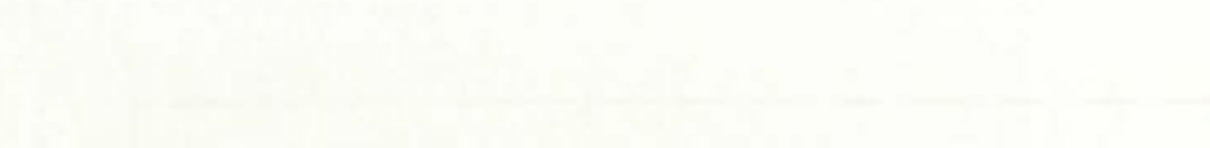

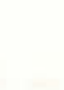
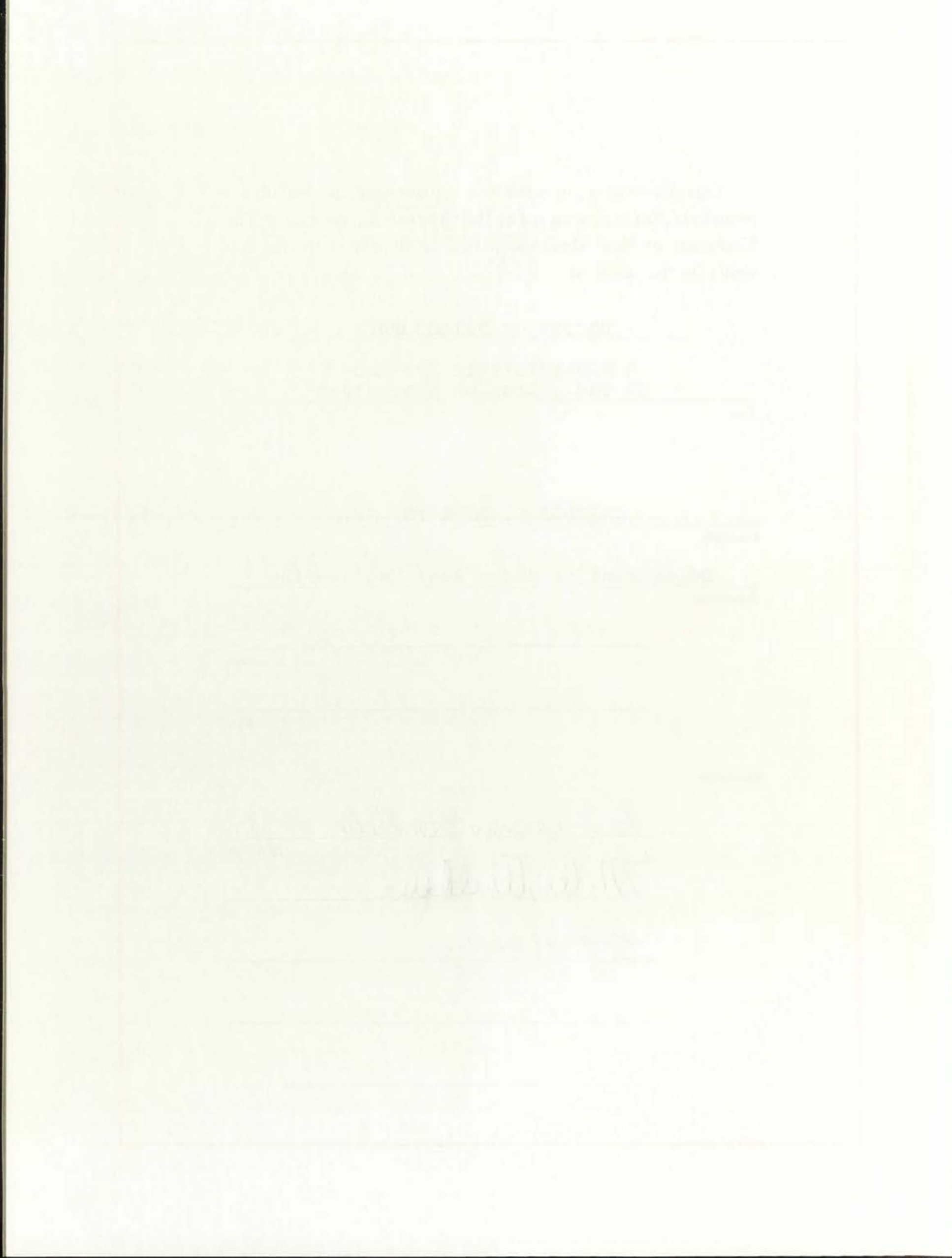


\section{A PROBABILISTIC APPROACH \\ TO THE DESIGN OF HEAT PIPES}

\section{BY}

CHARLES C. ROBERTS, JR.

B.S., Worcester Polytechnic Institute, 1966

M.S., Worcester Polytechnic Institute, 1967

\section{DISSERTATION}

Submitted in Partial Fulfillment of the

Requirements for the Degree of

Doctor of Philosophy in Mechanical Engineering in the Graduate School of

The University of New Mexico

Albuquerque, New Mexico

December, 1972 
I wish to express my deep appreciation to my advisors and friends, Dr. K. T. Feldman, Dr. H. Davis, and Joe Kemme, for guidance and counsel which led to the successful completion of this work.

I would also like to thank the Office of Naval Research for financial support on Contract N00014-68-A-0155-0002. 



\section{A PROBABILISTIC APPROACH \\ TO THE DESIGN OF HEAT PIPES}

BY

Charles C. Roberts Jr.

\section{ABSTRACT OF DISSERTATION}

Submitted in Partial Fulfillment of the

Requirements for the Degree of

Doctor of Philosophy in Mechanical Engineering in the Graduate School of

The University of New Mexico

Albuquerque, New Mexico

December, 1972 
$222 \ldots$ 
ABSTRACT

The design of heat pipes involves knowledge of phenomena such as surface tension forces, wick permeability, and fluid vaporization and condensation. Considerable variability in these phenomena has been observed in heat pipe experiments. Thus, a probabilistic design model for predicting heat pipe heat transfer rate has been developed taking into consideration uncertainty in the prediction of the above phenomena. The probabilistic model yields a mean, a standard deviation, and the distribution of heat transfer rate based on the means, standard deviations, and distributions of the design parameters. The probabilistic method is compared to experimental data from heat pipes with wire mesh wicks. Mean values, standard deviations, and distributions are presented for wick permeability, critical radius, area, porosity, tortuosity, and heat transfer rate. A technique is described for making wire mesh wicks. The probabilistic design model indicates the range of design without the use of safety factors. 


\section{TABLE OF CONTENTS}

chapter

Page

ACKNOWLEDGMENTS

iii

ABSTRACT

iv

LIST OF FIGURES

vii

NOMENCLATURE

1 INTRODUCTION

1.1 Design Methodology

1.2 Design of Heat Pipes

2.1 Deterministic Model of Heat Pipe Operation

2.2 Deterministic Model of Heat Pipe Operation with Partially Saturated Wick

2.3 The Probabilistic Model of Heat Pipe Operation

4 HEAT PIPE WICK PROPERTIES

4.1 Permeability

4.2 Critical Radius

4.3 Wick Cross Sectional Area

4.4 Porosity and Tortuosity

4.5 Summary of Wick Property Data

6 COMPUTATIONAL METHODOLOGY

6.1 Methodology

6.2 Application to Heat Pipe Design

7 THE PROBABILISTIC DESIGN EQUATION

7.1 Comparison of Probabilistic Model with Experimental Data

7.2 Results of the Probabilistic Design

7.3 Heat Pipe Temperature Drop

CONCLUSIONS

8.1 Probabilistic Design

8.2 Heat Pipe Design 

APPENDIX A BASIC RAW DATA

APPENDIX B COMPUTER PROGRAM

APPENDIX C HEAT PIPE EXPERIMENTAL TEST PROCEDURES

vii 



\section{LIST OF FIGURES}

Figure

Page

1.1 Design Methodology 1

1.2 Beta Distribution Model of Pore Radius in a Porous Medium

1.3 Permeability Distribution of 100-Mesh

Stainless steel Screen

1.4 Design Methodology Comparison 6

2.1 Operating Heat Pipe 10

2.2 Momentum Terms for a Differential Element of Wick

2.3 Energy Terms for a Differential Element of Wick

2.4 Mass Flow Distribution 18

2.5 Mass Flow Rate, Liquid Recession Distribution, and Liquid Pressure Distribution for Fully

Saturated and Partially Saturated Wicks

2.6 Liquid-Vapor Interface Distribution 25

2.7 Heat Pipe Configuration 28

2.8 Distribution of Heat Flow Capability of a Heat Pipe Whose Design Parameters are Assumed Random

3.1 Experimental Heat Pipe Apparatus 38

3.2 Stainless Steel Heat Pipe and Vapor Probes 39

3.3 Evaporator Section (Insulated) and Condenser \& Installed

3.4 Testing Configuration 39

3.5 Apparatus Used to Determine the Gravity Head at a Particular Inclination

3.6 Inserting Wire Mesh Wick into Heat Pipe 41

3.7 Testing Maximum Heat Transfer Rate 41

3.8 Determination of Liquid Head Loss Due to
Gravity

3.9 Apparatus for the Determination of Wick
Permeability

3.10 Heat Pipe Configuration for Wick Limiting Test 43

3.11 Permeability Test 43

3.12 Capillary Rise Capability Test Apparatus 44 
3.13 Checking Wire Mesh Thickness After Capillary Rise Test

3.14 Capillary Rise Height Apparatus 45

3.15 Basic Wick Wrapping Apparatus Structure 46

3.16 Apparatus Used to Wrap Wire Mesh Wicks 47

3.17 Wrapping Configuration for Wire Mesh Wicks 47

3.18 Initial Phase of Wire Mesh Wick Manufacture 48

3.19 Apparatus Ready for Wrapping 48

3.20 Mandrel and Wire Mesh Are Inserted into the

3.21 The Wrapping Is Initiated by Turning the collet and Lowering the Compression Jaws

3.22 Wick Seam Is Spot Welded and Excess Material Removed

3.23 Mandrel Is Removed and Wick Is Extracted by Removing Center

3.24 Heat Pipe Performance Test System 51

3.25 Wire Mesh Wick Cross Section of Typical Two Layer Wick

3.26 Illustration of the Permeability Error in Using Flexible Balloon

3.27 Additional Liquid Flow Paths in Wire Mesh Heat Pipes

4.1 Permeability Distribution for Data set 2

4.2 Critical Radius Distribution (two layer capability) for Data set 2

4.3 Cross Sectional Area Distribution for Data Set 2

4.4 Porosity Distribution for Data Set $2 \quad 83$

4.5 Tortuosity Distribution for Data Set $2 \quad 83$

5.1 Classical Wire Mesh Capillary Model 85

5.2 Recession and Dryout 85

5.3 Single Layer of Wire Mesh 86

5.4 Compressed Double Layer of Wire Mesh 86

5.5 Proposed Wire Mesh Capillary Model 86

5.6 Two Layers of Screen wick with Full Liquid
Saturation

5.7 Two Layers of Screen Wick with Liquid Recessed to the First Layer 

5.8 Two Layers of Screen Wick with Liquid Recessed to the Second Layer

5.9 Wire Mesh Structures for 200- and 100Mesh Stainless Steel Wicks

5.10 Wire Mesh Structures for 50-Mesh Stainless Steel and 100-Mesh Copper Wicks

5.11 Sequential Observation of Liquid Recession and Final Burnout for 100-Mesh Stainless Steel Two Layer Wick

5.12 Comparison of Random Intermeshing of Two Layers of 100-Mesh Stainless Steel Screen Compressed Together

5.13 Hypothesized Recession Model for Two Layer Square Weave Wire Mesh Wicks

5.14 The Three Possible Configurations of the Liquid Vapor Interface in 100-Mesh Square Weave Wire cloth

6.1 Simulation of Functional Variability

6.2 Computer Program Flow Diagram

7.1 Difference Distribution for Data set 2 (42-59 watts) Using Recession Model

7.2 Difference Distribution for Data set 2 (70-90 watts) Using Recession Model

7.3 Difference Distribution for Data set 2 (100-130 watts) Using Recession Model

7.4 Distribution of $Q_{\mathrm{Ca}}$ about Qob for 100-Mesh Stainless Steel, Two Layer Wicks at a Mean Wattage of 50.5666

7.5 Distribution of Qob about Qca for 100-Mesh Stainless Steel, Two Layer Wicks at a Mean Wattage of 81.333

7.6 Distribution of $Q_{\mathrm{Ob}}$ about $Q_{\mathrm{Ca}}$ for 100-Mesh Stainless Steel, Two Layer Wicks at a Mean Wattage of 116.799

7.7 Comparison of the Mean, Maximum Heat Transfer Rate with Experimental Data from Data Set 1 (100-mesh stainless

C steel two layer wicks, tight wrap)

7.8 Comparison for the Mean, Maximum Heat Transfer Rate with Experimental Data from Data set 2 (100-mesh stainless steel two layer wicks) 
7.9 Comparison of the Mean, Maximum Heat Transfer Rate with Experimental Data from Data set 2 (200-mesh stainless steel three layer wicks)

7.10 Comparison of the Mean, Maximum Heat Transfer Rate with Experimental Data from Data set 4 (50-mesh stainless steel two layer wicks)

7.11 Comparison of the Mean, Maximum Heat Transfer Rate with Experimental Data from Data Set 5 (100-mesh copper two layer wick)

7.12 Cross section of a Heat Pipe Showing the Temperature Distribution, Nomenclature, and the Corresponding Thermal Analog Circuit for Heat Flow

7.13 Wick Contact with Pipe Wall

7.14 General Heat Pipe Temperature Distribution 


\section{LIST OF TABLES}

Table

Page

4.1 PERMEABILITY DISTRIBUTION FROM DATA SET 1

4.2 PERMEABILITY DISTRIBUTION FROM DATA SET 2

4.3 PERMEABILITY DISTRIBUTION FROM DATA SET $3 \quad 64$

4.4 PERMEABILITY DISTRIBUTION FROM DATA SET $4 \quad 64$

4.5 PERMEABILITY DISTRIBUTION FROM DATA SET 5

4.6 CAPILLARY PRESSURE CAPABILITY OF ONE LAYER AND TWO LAYERS OF WIRE MESH

4.7 CAPILLARY PRESSURE CAPABILITY OF ONE LAYER $\begin{array}{ll}\text { AND TWO LAYERS OF WIRE MESH } & 67\end{array}$

4.8 CRITICAL RADIUS DISTRIBUTION FROM DATA SET $1 \quad 69$

4.9 CRITICAL RADIUS DISTRIBUTION FROM DATA SET $2 \quad 69$

4.10 CRITICAL RADIUS DISTRIBUTION FROM DATA SET $3 \quad 71$

4.11 CRITICAL RADIUS DISTRIBUTION FROM DATA SET $4 \quad 71$

4.12 CRITICAL RADIUS DISTRIBUTION FROM DATA SET $5 \quad 72$

4.13 WICK CROSS SECTIONAL AREA DISTRIBUTION 73

4.14 WICK CROSS SECTIONAL AREA DISTRIBUTION 73

4.15 WICK CROSS SECTIONAL AREA DISTRIBUTION 75

4.16 WICK CROSS SECTIONAL AREA DISTRIBUTION 75

4.17 WICK CROSS SECTIONAL AREA DISTRIBUTION 76

4.18 POROSITY AND TORTUOSITY DISTRIB UTIONS 77

4.19 POROSITY AND TORTUOSITY DISTRIBUTIONS 77

4.20 POROSITY AND TORTUOSITY DISTRIBUTIONS 79

4.21 POROSITY AND TORTUOSITY DISTRIBUTIONS 79

4.22 POROSITY AND TORTUOSITY DISTRIBUTIONS 80

4.23 SUMMARY OE HEAT PIPE WICK PROPERTIES 81

$\begin{array}{lll}6.1 & \text { MEANS AND STANDARD DEVIATIONS FOR SIMPLE } & \\ & \text { FUNCTIONS USING ALGEBRA OF EXPECTATIONS } & 103\end{array}$

6.2 COMPARISON OF THE MEAN AND STANDARD DEVIATION OF THE FUNCTION XX* USING SIMULATION, PARTIAL DERIVATIVE AND ALGEBRA OF MOMENTS METHOD

6.3 STANDARD DEVIATION GROWTH OF THE FUNCTION YY* USING SIMULATION, PARTIAL DERIVATIVE AND ALGEBRA OF MOMENTS METHOD 
6. 4 COMPARISON OF THE MEAN AND STANDARD DEVIATION OF THE FUNCTION ZZ* USING SIMULATION, PARTIAL DERIVATIVE AND ALGEBRA OF MOMENTS METHOD

7.1 COMPARISON OF OBSERVED AND CALCULATED DATA

7.2 THE OVERALL RESULTS OF THE PROBABILISTIC DESIGN EQUATION USING DESIGN PROPERTIES FROM TABLE 4.23

7.3 TEMPERATURE LOSS PREDICTION (Recession Model)

8.1 UNCERTAINTY OF WICK PROPERTIES AS A $\%$ OF THE MEAN PROPERTY 
A

cross sectional area of liquid saturated wick, $\mathrm{ft} \mathrm{t}^{2}, \mathrm{~cm}^{2}$

cross sectional area of vapor passage, $\mathrm{ft}^{2}, \mathrm{~cm}^{2}$ tortuosity or wick geometry constant, dimensionless diameter, $\mathrm{ft}, \mathrm{cm}$

characteristic dimension, ft, $\mathrm{cm}$ porosity of capillary structure or wick, dimensionless

force term

gravitational acceleration constant, $32.2 \mathrm{ft} / \mathrm{sec}^{2}$ dimensional conversion constant, $32.21 \mathrm{bm} \mathrm{ft/1bf} \mathrm{sec}^{2}$ gravity head, inches $\mathrm{H}_{2} \mathrm{O}$ elevation distance, ft, $\mathrm{cm}$ latent heat of vaporization, BTU/lbm, cal/gm mechanical equivalent of heat, $778 \mathrm{ft}$ lb/BTU thermal conductivity, BTU/hr $\mathrm{ft}^{2}{ }^{\circ} \mathrm{F}$, watts $/ \mathrm{cm}{ }^{\circ} \mathrm{C}$ permeability, $\mathrm{ft}^{2}, \mathrm{~cm}^{2}$ pipe length, ft, $\mathrm{cm}$ effective length, $\mathrm{L}_{e} / 2+\mathrm{L}_{\mathrm{a}}+\mathrm{L}_{\mathrm{c}} / 2, \mathrm{ft}, \mathrm{cm}$ mass flow rate, $1 \mathrm{bm} / \mathrm{hr}, \mathrm{gm} / \mathrm{sec}$ momentum, $1 \mathrm{bm} \mathrm{ft} / \mathrm{sec}$ liquid transport factor, BTU/hr $\mathrm{ft}^{2}$, watts $/ \mathrm{cm}^{2}$ pressure, $1 \mathrm{~b} / \mathrm{ft}^{2}$ dynes/ $\mathrm{cm}^{2} \mathrm{~mm} \mathrm{Hg}$ probability heat flux, BTU/hr $\mathrm{ft} \mathrm{t}^{2}$, watts $/ \mathrm{cm}^{2}$ maximum heat transfer rate, BTU/hr, watts radius or radial coordinate, $\mathrm{ft}, \mathrm{cm}$ 
$r_{e}$

$r_{\mathrm{C}}$

$r_{\mathrm{pi}}$

R

t

$t_{w}$

T

$\mathrm{u}$

v

$\mathrm{V}$

W

$\mathrm{x}$

Y

z

$\alpha$

$\gamma$

$\varepsilon$

$\Delta$

$\theta$

$\mu$

$\rho$

$\sigma$

$\phi$

pore radius in evaporator wick, ft, $\mathrm{cm}$

pore radius in condenser wick, ft, $\mathrm{cm}$

inside radius of heat pipe, $f t, \mathrm{~cm}$

miniscus radius of curvature at liquid vapor interface, $\mathrm{ft}, \mathrm{cm}$

thickness

wick thickness, ft, $\mathrm{cm}$

temperature, ${ }^{\circ} \mathrm{F},{ }^{\circ} \mathrm{C}$

axial velocity, ft/sec, $\mathrm{cm} / \mathrm{sec}$

radial velocity, ft/sec, $\mathrm{cm} / \mathrm{sec}$

volume, $\mathrm{ft} \mathrm{t}^{3}, \mathrm{~cm}^{3}$

work, $1 \mathrm{bf}$

axial coordinate

vertical coordinate

coordinate

accommodation coefficient

specific weight, $1 \mathrm{bf} / \mathrm{cu} . \mathrm{ft}$.

emissivity of radiation heat transfer

difference symbol

wetting angle, degrees

dynamic viscosity, $1 \mathrm{bm} / \mathrm{ft} \mathrm{sec}, \mathrm{gm} / \mathrm{cm}-\mathrm{sec}$

density, $\mathrm{ft} \mathrm{t}^{3} / \mathrm{lbm}, \mathrm{cm}^{3} / \mathrm{gm}$

surface tension, lbf/ft, dynes/cm

angle of inclination

$\underline{\text { Subscripts }}$

a

adiabatic

C

condenser

C

calculated 
v

w

$\mathrm{p}$

$r$

$\mathrm{P}_{i}$

○

$\mathrm{Ob}$

s

v

$\mathrm{w}$

evaporator, or arbitrary wick pore

gravity effect

inside

liquid

maximum

fully recessed

friction

dimension

vapor

wick

pressure

recessed

pipe

outside surface

observed

steel

vapor

wick or wall

STATISTICAL NOTATION

$\bar{x} \quad$ estimate of the mean of a population of random variables, $x$.

$\mathrm{S}_{\mathrm{x}}$ estimate of the standard deviation of a population of random variables, $\mathrm{x}$

$x_{i}$ a particular random variable $\left(K_{i}\right.$ is a random $\left.K\right)$

$\mu \quad$ the mean (general)

$\sigma \quad$ standard deviation (general)

n sample size 
E( ) expected value of

distributed

$N\left(\bar{x}, S_{x}\right)$ normal distribution with mean $\bar{x}$ and standard deviattion, $\mathrm{s}_{\mathrm{x}}$

$\mathrm{ZZ}\left(\overline{\mathrm{x}}, \mathrm{S}_{\mathrm{x}}\right) \mathrm{ZZ}$ distribution with mean $\overline{\mathrm{x}}$ and standard deviation $\mathrm{S}_{\mathrm{x}}$ 
1.1 Design Methodology

Optimization and reliability of design have been the topics of growing interest to engineers in recent years. A critical review of present design methodology, that based on arbitrary "ignorance factors" or safety factors, is under way. ${ }^{1}$ The realization that design parameters are usually characterized by some statistical distribution of values rather than by a single value indicates that probabilistic methodology is a logical alternative. The present deterministic (single valued) methods are special cases of the probabilistic methodology when the parameter variabilities are set equal to zero. Figure 1.1 shows a comparison between the conventional deterministic design and probabilistic design methodologies. In actual physical systems, the absence of design parameter variability is indeed a rare case.

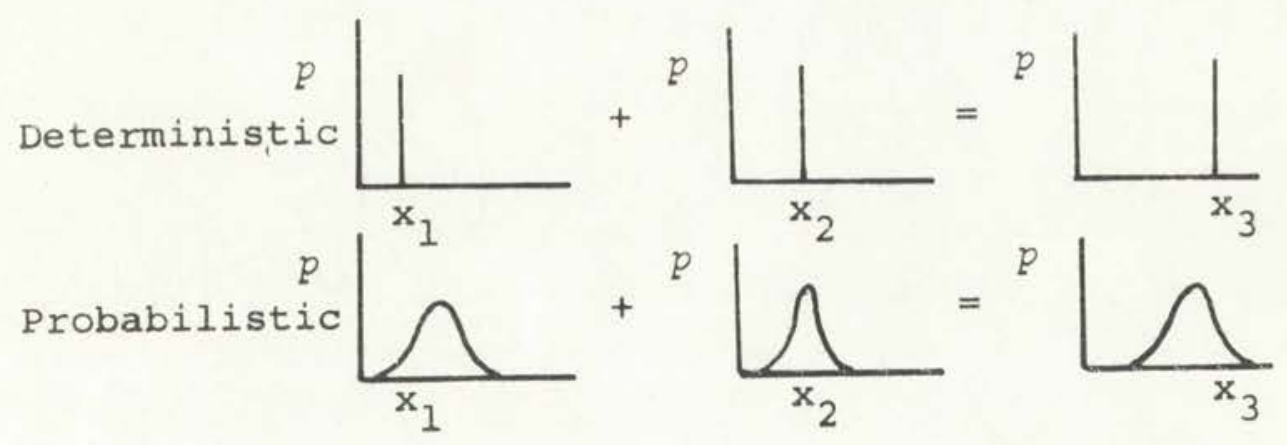

Figure 1.1. Design Methodology. 
It is not difficult to find examples of design parameter variation. For instance, in heat transfer we describe the rate of energy radiation from a body as

$$
\frac{Q}{A}=\varepsilon \sigma_{b} T^{4}
$$

where $Q$ is the rate of energy radiated, $T$ is the absolute temperature of the body, $\sigma_{b}$ is a universal physical constant, $\varepsilon$ is a property of an emitting surface, and $A$ is the surface area of the emitting body. Values of $\varepsilon$ are quite variable. ${ }^{2}$ Values of $\sigma_{b}$ and $T$ may depend on the accuracy of the instrumentation used. The functional variation of $Q$ will grow as the fourth power of the temperature variation. It is indeed optimistic to believe that the calculated $Q$ and actual $Q$ are identical. Yet that is what the deterministic model implies. The objective of this discussion is not to undermine the deterministic model but to improve upon it. The deterministic model has been an engineering tool for many years and has worked well. The probabilistic model uses the deterministic equation to find the mean value of the design result. But the added feature of the probabilistic methodology is that it yields a statistical distribution of the occurrence of the design result. This determines the expected range of the design result or, in the particular example mentioned (Equation 1.1), the probabilistic design yields a bound on the variation of $Q$. We are now able to determine a range in which the actual energy radiated, Q, may lie instead of calculating a single value 
of $Q$ and hoping that it is similar in magnitude to the actual Q. In many cases, an agreement of plus or minus $30 \%$ between the calculated result and the actual result is considered to be normal. This is in itself an admission of the uncertainty in modeling natural phenomenon. The probabilistic approach to design gives us a logical measure of this uncertainty.

\subsection{Design of Heat Pipes}

The application of deterministic design techniques to the design of heat pipes has indicated a need for an improved technique. Uncertainties in wick pore size, wick permeability, surface conditions, liquid inventory, and fluid properties has rendered the classical deterministic design approaches inaccurate. Probabilistic design, which treats the design parameters as random variables, has been used successfully to describe the integrity of structural components. ${ }^{1}$ Thus, it is logical to consider the use of probabilistic techniques in the design of heat pipes.

Haring and Greenkorn ${ }^{3}$ used a statistical distribution to describe the pore radius in a porous medium. Figure 1.2 shows the beta distribution which was used to model the uncertainty of pore radius in a porous medium. Pore radius is so variable that deterministic descriptions cannot be made. It is virtually impossible to randomly choose a particular pore and accurately calculate its radius. The probability distribution enables the researcher to do the next best thing. That is, one will be able to describe a range of radii in which a particular pore radius might be observed. One is able to observe 


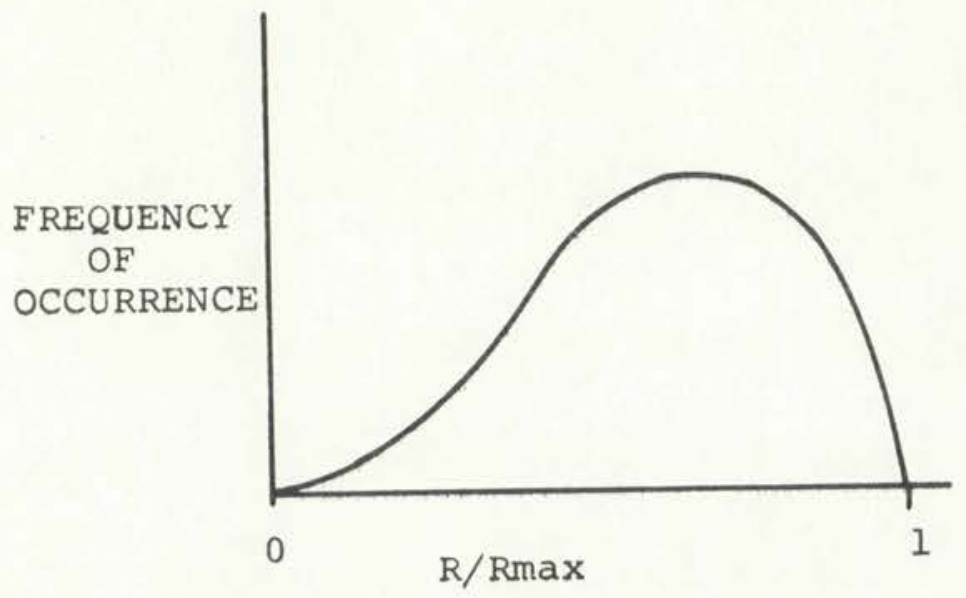

Figure 1.2. Beta Distribution Model of Pore Radius in a Porous Medium

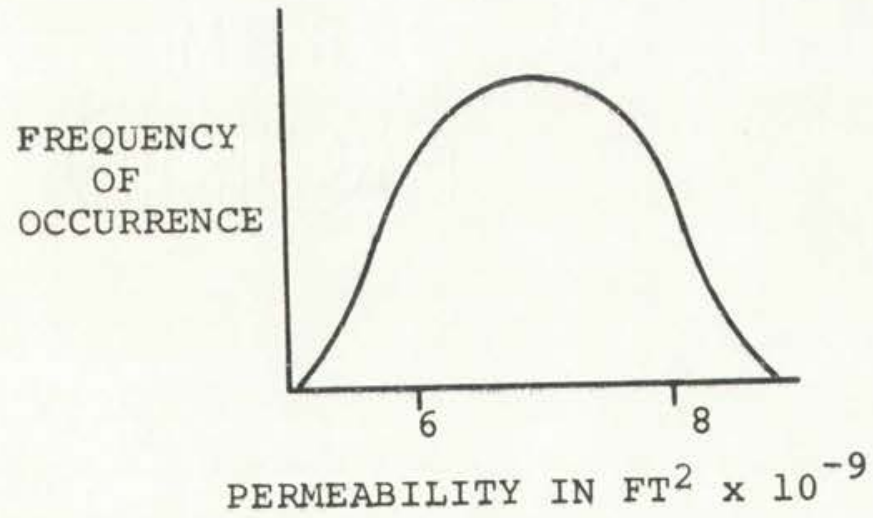

Figure 1.3. Permeability Distribution of 100 Mesh Stainless Steel Screen 
the range of variation and the probabilities of residing in certain locations of the range. Also, experiments at The University of New Mexico have shown the wide variability of wick permeability data. 20

Figure 1.3 is a plot of a continuous distribution approximation of experimental permeability data and illustrates the high variability in this heat pipe design variable. The measured permeability of wick samples taken from the same material is not exactly the same even though great care may be taken to uniformly clean and assemble each sample in an identical way. Choosing one particular value of wick permeability or even the average value would be erroneous in light of the high scatter between samples. Therefore, it is more correct to describe wick permeability using the average of all samples as an estimate of the mean permeability, $\bar{K}$, and the standard deviation, $\mathrm{S}_{\mathrm{k}}$, as a measure of scatter.

Heat pipe operation is a function of permeability, surface tension, wetting angle, fluid properties and geometrical configuration. ${ }^{6}$ If any of these parameters are distributed and, therefore, described by a probability distribution, the resulting heat flux capability of the heat pipe will be distributed with a mean heat flux, $\bar{Q}$, and a standard deviation, $\mathrm{S}_{\mathrm{q}^{\prime}}$ as a measure of variability.

Plotting of typical design results, as in Figure 1.4, shows the power of the probabilistic design method. The deterministic method gives an acceptable answer and a factor of safety while the probabilistic method indicates 

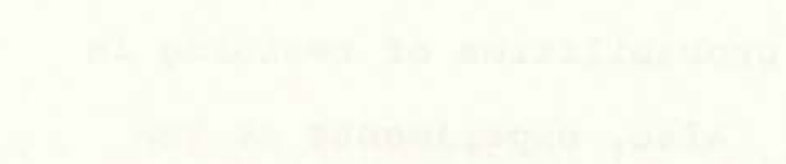
(1) 
a finite probability of failure. One minus the probability of failure $(1-p)$ is the probability of a successful design. The probability of obtaining a successful design is usually termed the reliability

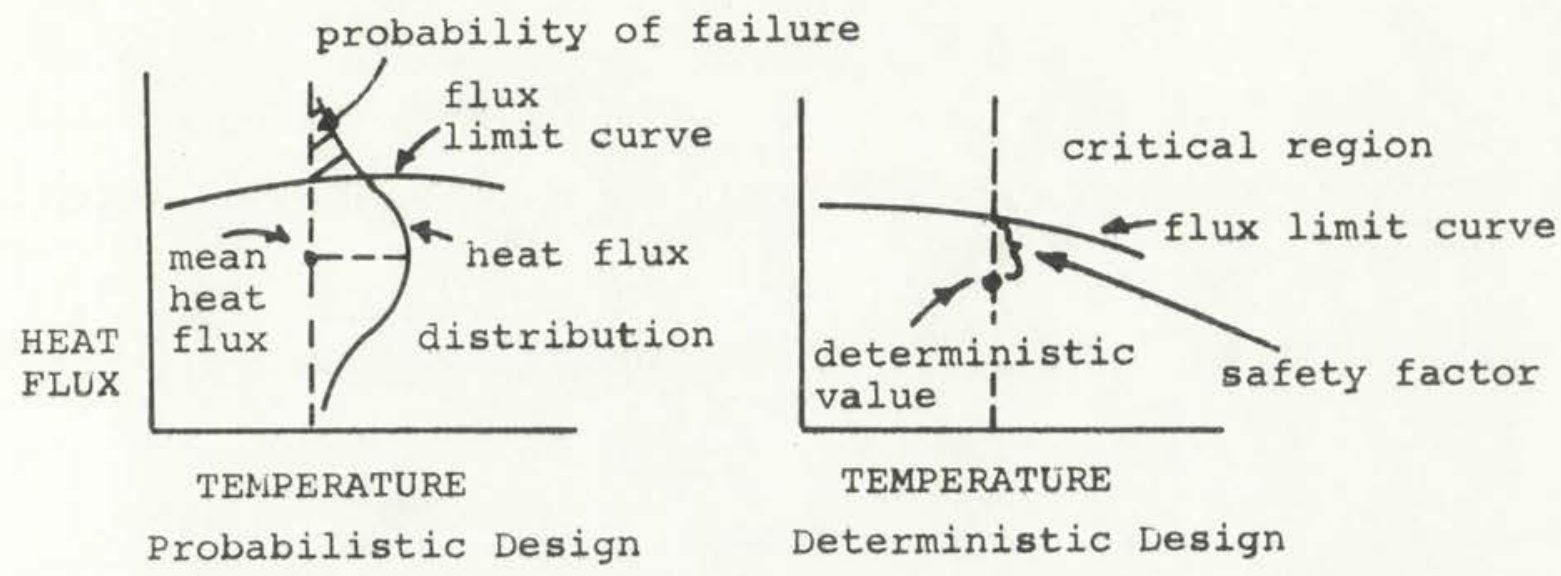

Figure 1.4. Design Methodology Comparison

The usefulness of the probabilistic design technique may be extended to heat exchanger design. There may be hundreds of heat pipes in a heat exchanger system, each having a different heat transfer capability. Conventional deterministic design dictates that the minimum heat transfer capability be used as characteristic of each heat pipe. This is essentially a "worst case" analysis. Another conventional design technique uses the mean heat transfer rate multiplied by a safety factor based on experience. The calculated performance of the heat exchanger, using either the "worst case" values or the mean values with a safety factor, no doubt will give a design safety factor which works. But typically, such 
a design is very conservative and the overdesigned heat exchanger is larger and more expensive than necessary. The probability of manufacturing one hundred heat pipes that have a performance decidedly worse than average, and, therefore, a "worst case," may be very small. For example, if the probability of occurrence of the worst case is .05, then the probability of manufacturing a heat exchanger with 100 "worst case" heat pipes is $(.05)^{100}$, which is a very rare event.

The purpose of this research project is to:

1. Measure statistical data on water heat pipes using wire mesh wicks.

2. Develop a probabilistic model of heat pipe operation. Based on the literature, it appears that heat pipe design considerations have been purely deterministic. The publication of Holm ${ }^{4}$ indicates some realization of experimental uncertainty in the collection of data. Holm presents his data using an error bound but does not mention anything about repeatability and distribution theory. Phillips ${ }^{5}$ presents data on nominal pore diameter for 200 mesh stainless steel screen. It is optimistic to hope that this deterministic pore diameter value is representative of the sample. A mean pore diameter, standard deviation and distribution will better represent the physical characteristics of this wick. Also, it has been observed at UNM that permeabilities of screen samples have large standard deviations despite many efforts to obtain uniform samples. 20 
A survey of the literature reveals no effort to account for parameter variability in the field of heat transfer. Little information is available on the statistical behavior of heat transfer parameters such as convection coefficient, conductivity, and permeability. The author has not yet found any literature which applies probabilistic approaches to heat transfer design. 
CHAPTER 2

THEORY

To develop the probabilistic theory for heat pipe design, it is necessary to derive the deterministic model on which the probabilistic model is based. The classic derivation of the heat pipe design equation appears in the literature. 8 In this chapter, the classic derivation of the fully saturated wick model is described. This derivation is based on the principles of conservation of momentum, energy, and mass for a differential element in the wick. The fully saturated wick model is later modified for the partially saturated wick condition and will be used as the basis of the probabilistic design equation.

\subsection{Deterministic Model of Heat Pipe Operation}

The heat pipe to be considered in this work is cylindrical in shape with an annular wick, as shown in Figure 2.1. The major assumptions used in the development of the deterministic model are:

1. The system is treated as one-dimensional.

2. The wick is fully saturated with liquid.

3. The heat flux is uniform over the evaporator and condenser sections.

4. The liquid-vapor interface meniscus can be characterized by one radius of curvature.

5. The liquid and vapor are at the same temperature along the entire length of the pipe.

6. Wick properties are isotropic. 


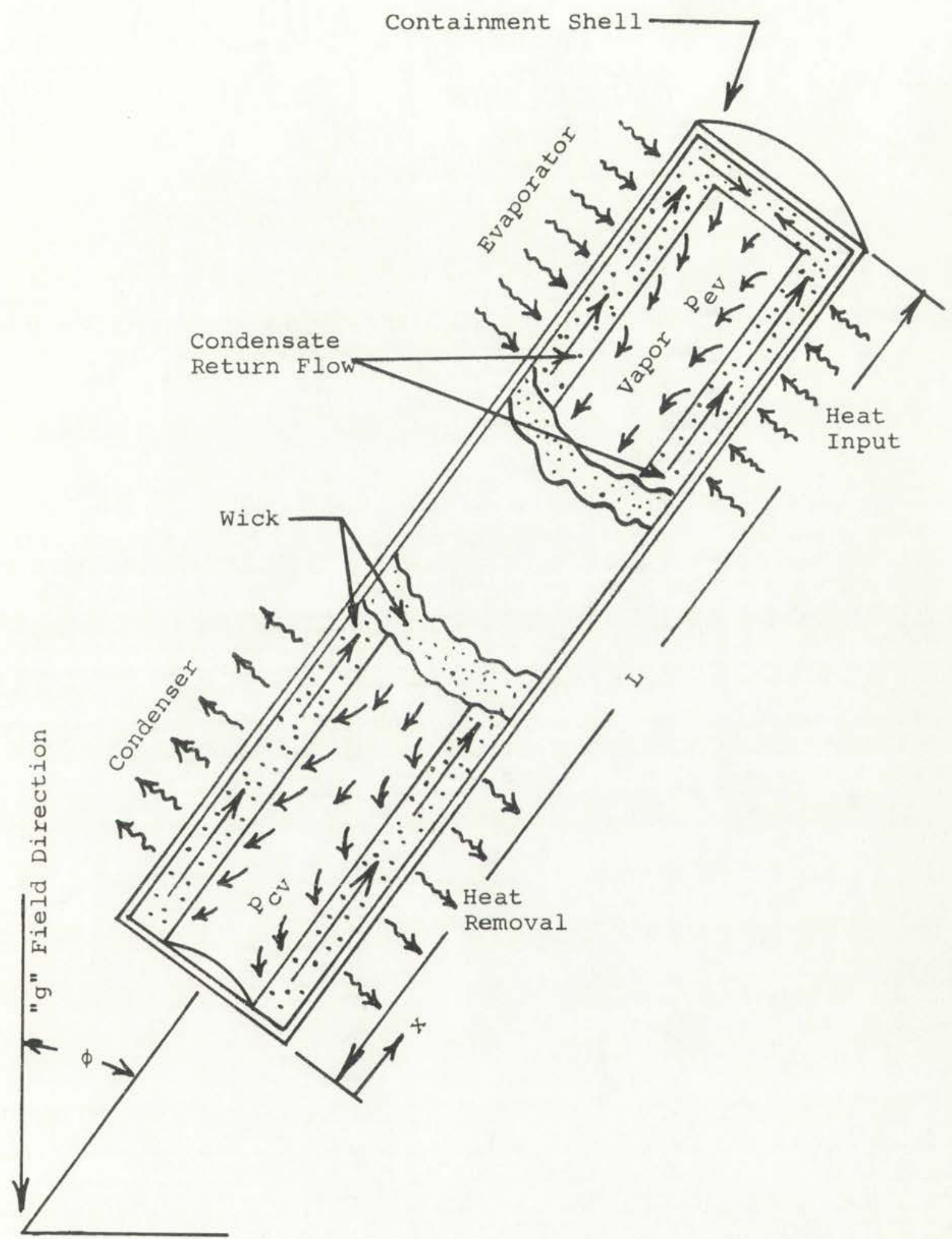

Figure 2.1. Operating Heat Pipe 
7. Differentials raised to the second or higher powers are neglected.

8. The heat pipe is wick limited, that is, viscous pressure drops in the liquid saturated wick are so much larger than those in the vapor that the viscous pressure drop in the vapor is negligible.

9. The vapor condensing on the liquid-vapor interface has a velocity in the $y$ direction only. Therefore, there is no contribution to momentum changes in the $x$ and $z$ directions.

A differential fluid element taken in the condenser section of the heat pipe wick may be used for the analysis. Applying conservation of mass to the element shown in Figure 2.2 , the relationship between liquid and vapor flow rates is obtained

$$
\dot{\mathrm{m}}_{\ell \mathrm{x}}+\dot{\mathrm{m}}_{\mathrm{v}}=\dot{\mathrm{m}}_{\ell(\mathrm{x}+\mathrm{dx})}
$$

where

$$
\begin{aligned}
& \dot{\mathrm{m}}_{\ell_{\mathrm{x}}}=\rho_{\ell} \mathrm{e}\left(E_{w{ }_{w}}\right) \mathrm{u}_{\ell} \\
& \dot{\mathrm{m}}_{\ell(x+d x)}=\rho_{\ell} e\left(\bar{t}_{w} z_{w}\right)\left(u_{\ell}+\frac{d u_{\ell}}{d x} d x\right) \text { * }
\end{aligned}
$$

Combining Equations $2.1,2.2$, and 2.3 , and solving for $\dot{m}_{v}$

$$
\dot{\mathrm{m}}_{\mathrm{v}}=\rho_{\ell} \frac{\mathrm{du}}{\mathrm{dx}} \mathrm{dxe}\left(\bar{t}_{\mathrm{w}} \mathrm{z}_{\mathrm{w}}\right)
$$

From the liquid-vapor interface of the differential element

$$
\dot{\mathrm{m}}_{\mathrm{v}}=\rho_{\mathrm{v}} \mathrm{u}_{\mathrm{v}} \mathrm{z}_{\mathrm{w}} \mathrm{dx}
$$

*where $\bar{t}_{\mathrm{w}}$ is the average wick thickness as would be measured by a micrometer. 


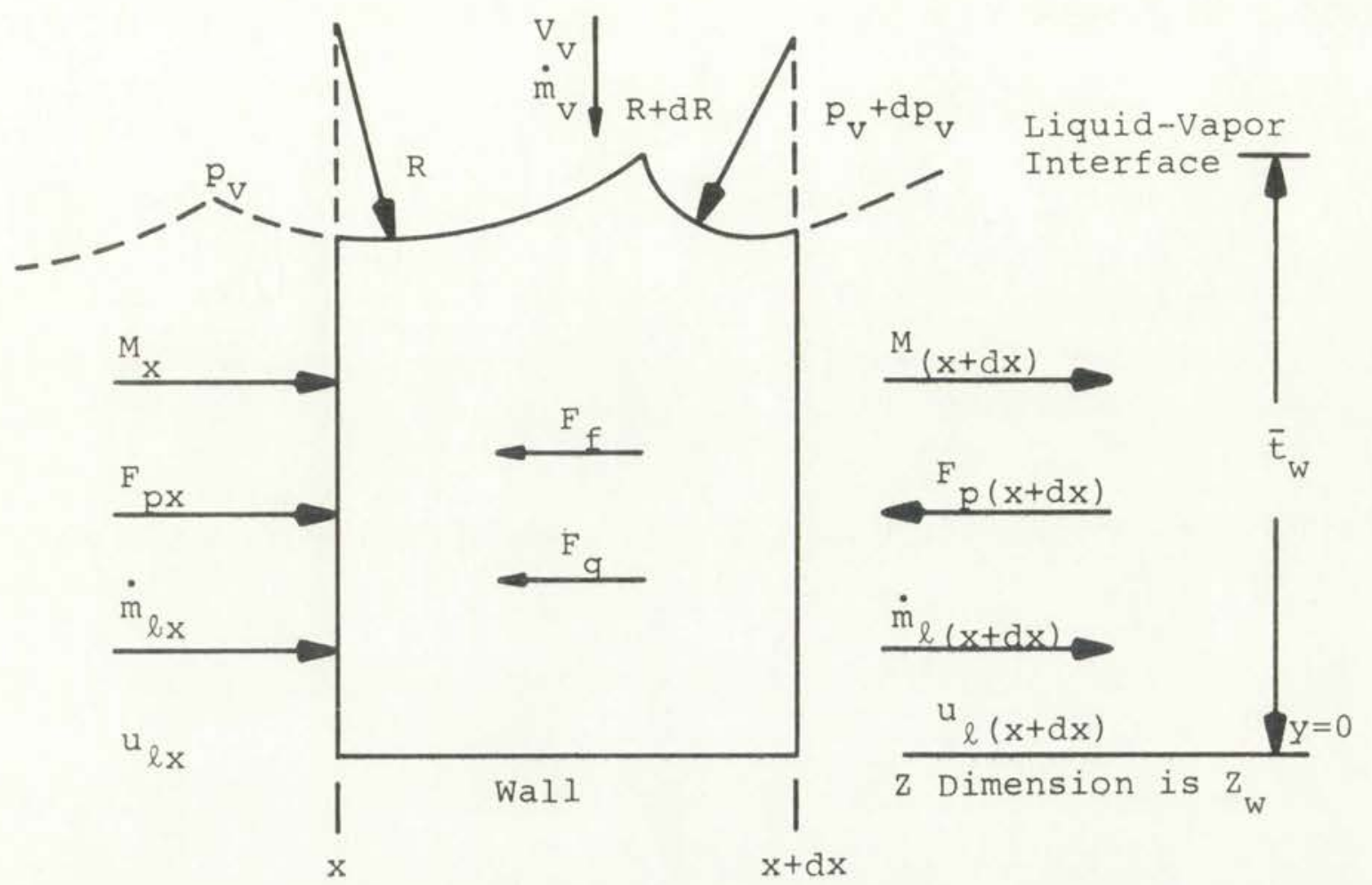

Figure 2.2. Momentum Terms for a Differential Element of Wick

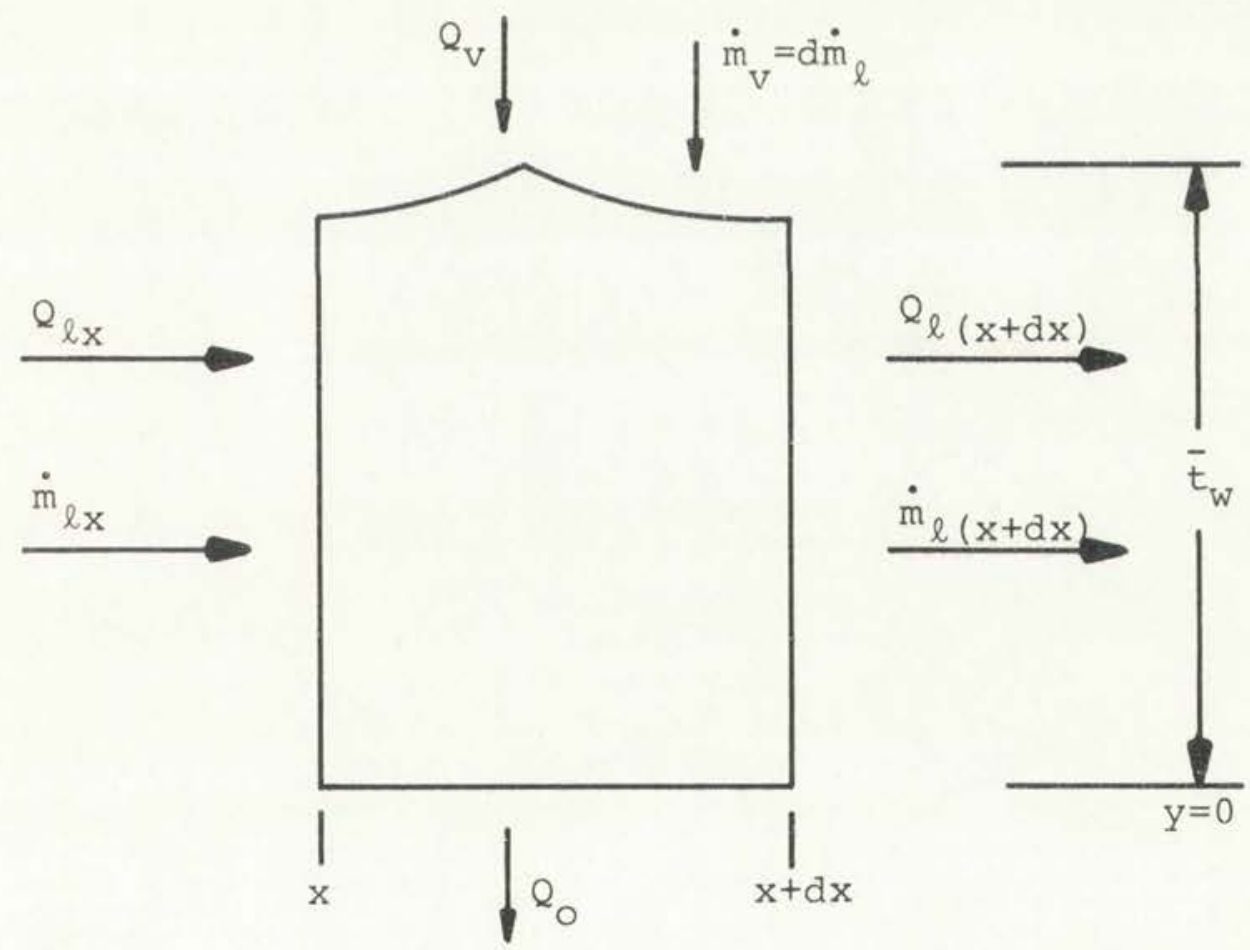

Figure 2.3. Energy Terms for a Differential Element of Wick 
Application of conservation of momentum in the $\mathrm{x}$ direction to the element of Figure 2.2 yields

$$
\sum F_{x}=M_{x}+d x-M_{x}
$$

where the momentum terms are

$$
\begin{aligned}
& M_{x}=\frac{\rho_{\ell}}{g_{c}} u_{l}^{2} \text { e } \bar{t}_{w} Z_{w} \\
& M_{x+d x}=\frac{\rho_{l}}{g_{C}} u_{\ell}^{2} \text { e } \bar{t}_{w} z_{w}+\frac{\rho_{\ell}}{g_{C}} \frac{d\left(u_{l}^{2}\right)}{d x} d x \varepsilon \bar{t}_{w} Z_{w}
\end{aligned}
$$

where no contribution is made to momentum in the $\mathrm{x}$ direction by the vapor as it enters the element as a result of assumption 9 .

The force terms are composed of the capillary pressure forces as described by the Laplace-Young equation

$$
\Delta \mathrm{p}=\sigma\left(\frac{1}{\mathrm{R}_{1}}+\frac{1}{\mathrm{R}_{2}}\right)
$$

By assumption 4 , this equation reduces to

$$
\Delta \mathrm{p}=\frac{2 \sigma}{\mathrm{R}}
$$

where $\Delta p$ is the pressure drop across the liquid vapor interface at $\mathrm{x}$. The pressure forces are

$$
\begin{aligned}
& F_{p_{x}}=\left(p_{v}-\frac{2 \sigma}{R}\right) \text { e } \bar{t}_{w} z_{w} \\
& F_{p_{x}+d x}=\left(p_{v}+d p_{v}-\frac{2 \sigma}{R+d R}\right) \text { e } \bar{t}_{w} z_{w}
\end{aligned}
$$



For the heat pipe with an annular wick with large vapor passage, a low density vapor and low vapor flow rate, $\mathrm{p}_{\mathrm{v}}$ is constant and $d p_{v}$ is zero. The force on the element is found by the summation of Equations 2.11 and 2.12

$$
F_{p x}-F_{p(x+d x)}=-e \bar{t}_{w} z_{w} 2 \sigma \frac{d R}{R^{2}+R d R}
$$

RaR will be neglected when compared to $\mathrm{R}^{2}$.

Because of the low flow rates and velocities that occur in capillary wicks, the flow is free of inertial effects, is laminar, is described by Darcy's law

$$
\frac{\mathrm{dp}}{\mathrm{dx}}=\frac{\dot{\mathrm{m}}_{\ell^{\mu}}{ }_{\mathrm{K}}}{\mathrm{K} \rho_{\ell} \mathrm{A}_{\mathrm{w}}}
$$

and viscous forces on the element are given by

$$
F_{f}=\frac{d p}{d x} d x\left[e\left(\bar{t}_{w} z_{w}\right)\right]
$$

The net viscous force on the element is obtained by combining Equations $2.2,2.14$, and 2.15

$$
F_{f}=\frac{e^{2}}{K} E_{w} z_{w} \mu_{\ell} u_{\ell} d x
$$

If the heat pipe operates in a gravitational field (or acceleration field), another force term must be added which is the weight component of the fluid element along the direction of flow

$$
F_{g}=\frac{g}{g_{c}} \rho_{l} \text { e } \bar{t}_{w} z_{w} \cos \phi d x
$$


The gravity component force may be plus or minus depending on the orientation of the heat pipe. In this analysis, as shown in Figure 2.1, the heat pipe is oriented so that the evaporator is above the condenser and the gravity force opposes the liquid flow. The summation of forces on the element is

$$
\sum F_{x}=F_{p(x)}-F_{p}(x+d x)-F_{f}-F_{g}
$$

Combining Equations 2.6, 2.7, 2.8, 2.13, 2.16, 2.17, and 2.18, we obtain the differential momentum equation for the fluid element

$$
\begin{aligned}
-2 \sigma & \frac{d R}{R^{2}}-\frac{e}{K} \mu_{\ell} u_{\ell} d x-\frac{g}{g_{C}} \rho_{\ell} \cos \phi d x \\
& =\frac{\rho_{\ell}}{g_{C}} \frac{d\left(u_{\ell}\right)^{2}}{d x} d x
\end{aligned}
$$

Conservation of energy must also be satisfied. Referring to Figure 2.3, neglecting kinetic energy effects the energy terms are

$$
\begin{array}{ll}
\frac{\text { Energy in }}{\mathrm{Q}_{\mathrm{v}}=\dot{\mathrm{m}}_{\mathrm{v}} \mathrm{h}_{\mathrm{v}}} & \frac{\text { Energy out }}{Q_{\ell}(\mathrm{x}+\mathrm{dx})}=\dot{\mathrm{m}}_{\ell} \mathrm{h}_{\ell}+\frac{\mathrm{d}\left(\dot{\mathrm{m}}_{\ell} \mathrm{h}_{\ell}\right)}{\mathrm{dx}} \mathrm{dx} \\
\mathrm{Q}_{\ell}=\dot{\mathrm{m}}_{\ell} \mathrm{h}_{\ell} & -\mathrm{k}_{\ell}\left(\overline{\mathrm{t}}_{\mathrm{w}} \mathrm{z}_{\mathrm{w}}\right)\left[\frac{\mathrm{dT} \ell}{\mathrm{dx}}+\frac{\mathrm{d}^{2} \mathrm{~T}_{\ell}}{\mathrm{dx} \mathrm{x}^{2}} \mathrm{dx}\right] \\
-\mathrm{k}_{\ell}\left(\mathrm{t}_{\mathrm{w}} \mathrm{z}_{\mathrm{w}}\right) \frac{\mathrm{T}_{\ell}}{\mathrm{dx}} & Q_{O} \text { (heat removed externally) } \\
& \mathrm{w}_{\mathrm{g}} \text { (work against gravity) }
\end{array}
$$

From assumption 5, the conduction terms are negligible and the energy equation becomes, 


$$
Q_{v}+Q_{\ell}=Q_{\ell(x+d x)}+Q_{0}-w_{g}
$$

replacing $\dot{\mathrm{m}}$ with Equation 2.4

$$
Q_{v}=h_{v} \rho_{\ell} \frac{d u_{\ell}}{d x} d x \text { e } \bar{t}_{w} z_{w}
$$

combining Equations 2.21 and 2.22,

$$
h_{v} \rho_{\ell} \frac{d u_{\ell}}{d x}+\frac{d\left(\dot{m}_{\ell} h_{\ell}\right)}{d x}-\frac{Q_{0}}{\bar{e}_{w} z_{w} d x}+\frac{w_{g}}{e \bar{t}_{w} z_{w} d x}=0
$$

and simplifying the derivative

$$
h_{v} \rho_{\ell} \frac{d u_{\ell}}{d x}-h_{\ell} \rho_{\ell} \frac{d u_{\ell}}{d x}-u_{\ell} \rho_{\ell} \frac{d h_{\ell}}{d x}-\frac{\ell_{0}}{d x \bar{e}^{\bar{t}} z_{w}}+\frac{w_{g}}{e \bar{t}_{w} z_{w} d x}=0
$$

From assumption 5, axial temperature gradients are negligible and assuming axial pressure gradients are small for the water heat pipe

$$
\frac{\mathrm{dh} l}{\mathrm{dx}} \approx 0
$$

Combining Equations 2.24 and 2.25

$$
\rho_{\ell}\left(h_{v}-h_{\ell}\right) \frac{d u_{\ell}}{d x}-\frac{Q_{o}}{e \bar{t}_{w} z_{w} d x}+\frac{w_{g}}{e \bar{t}_{w} z_{w} d x}=0
$$

where

$$
\begin{aligned}
& w_{g}=+\frac{\rho_{\ell}^{u} \ell}{J} \frac{g}{g_{C}} \cos \phi e \bar{t}_{w} z_{w} d x \\
& Q_{0}=+q d x z_{w} \\
& h_{v}-h_{l}=h_{f g}
\end{aligned}
$$


Combining Equations 2.26, 2.27, and 2.28

$$
\rho_{\ell} h_{f g} \frac{d u_{\ell}}{d x}-\frac{q}{e \bar{t}_{w}}+\frac{\rho_{\ell} u_{\ell}}{J} \frac{g}{g_{c}} \cos \phi=0
$$

and simplifying

$$
\frac{d u_{l}}{d x}=\frac{q}{e^{t} \rho_{l} h_{f g}}-\frac{g}{g_{C}} \frac{\cos \phi}{J_{f g}} u_{\ell}
$$

Solving for the average velocity and integrating over the length of the condenser, the energy equation becomes

$$
u_{\ell}=\frac{q}{h_{f g}{ }^{e \bar{t}_{w}} \rho_{\ell}}-\frac{g}{g_{c}} \frac{\cos \phi}{J h_{f g}} \int_{0}^{x} u_{\ell} d x
$$

Integrating to a position $x$ along the condenser and rearranging terms

$$
\frac{q x}{u_{\ell} h_{f g}{ }^{e \bar{t}_{w} \rho_{l}}}=\left(1+\frac{g}{2 g_{c}} \frac{x}{J h_{f g}}\right)
$$

The gravity term inside the bracket is much smaller than 1 and can be neglected, resulting in the following simplified form of the energy equation

$$
u_{\ell}=\frac{q}{h_{f g} e \bar{t}_{w} \rho_{\ell}}
$$

Combining Equations 2.34 and 2.19 to form the energy-continuitymomentum integral equation

$$
\begin{aligned}
& -\int_{R_{x}=0}^{R} 2 \sigma \frac{d R}{R^{2}}-\int_{0}^{x} \frac{1}{\bar{K}} \frac{g}{h_{f g} \bar{t}_{w}} \frac{u_{\ell}}{\rho_{l}} x d x-\int_{0}^{x} \frac{g}{g_{C}} \rho_{\ell} \cos \phi d x \\
& =\int_{0}^{x} \frac{2 q^{2}}{g_{c} h_{f g}^{2} \rho_{\ell} \varepsilon^{2} \bar{t}_{w}^{2}} x d x \\
& \text { (at } x=0 R \rightarrow \infty \text {, at } x=x_{\text {max }} R \rightarrow R_{\text {min }}=r \text { ) }
\end{aligned}
$$



The mass flow distribution resulting from the assumption of uniform heat flux in the evaporator and condenser is shown in Figure 2.4.

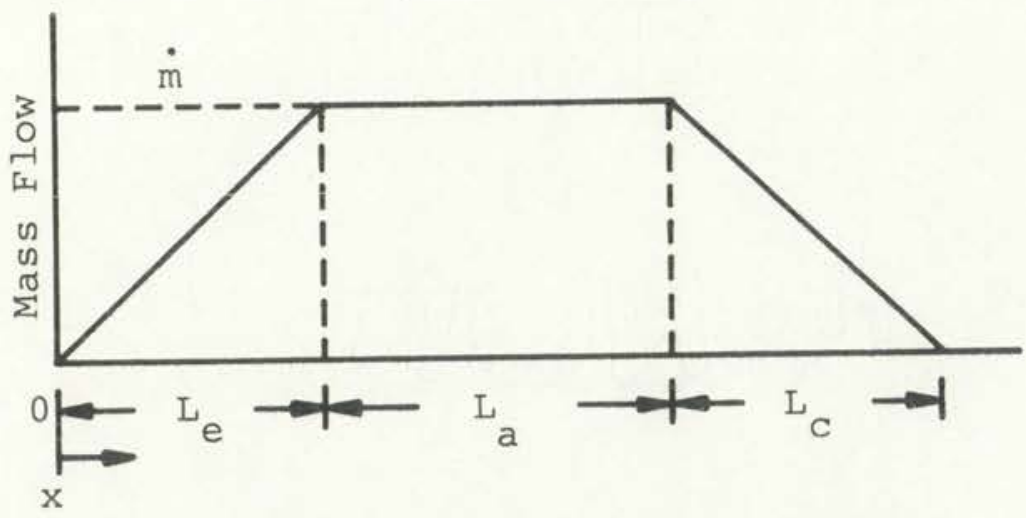

Figure 2.4. Mass Flow Distribution

Equation 2.35 is valid for the condenser region only and now a relation in the evaporator region is needed. To link the energy and momentum analysis between the condenser and evaporator, we will use the following boundary conditions

$$
\begin{aligned}
& u_{\max }=\frac{q_{c} L_{c}}{h_{f g} \bar{t}_{w}^{e \rho_{l}}}=u_{\max }=\frac{q_{e} L_{e}}{h_{f g} \bar{t}_{w} e \rho_{l}}
\end{aligned}
$$

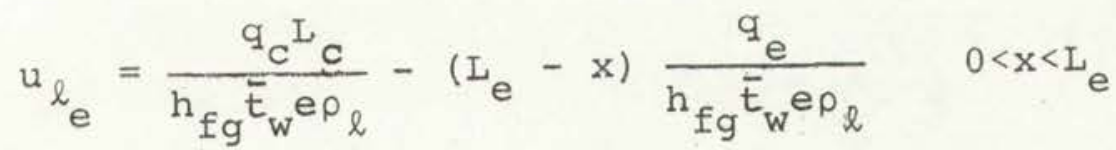

$$
\begin{aligned}
& q_{e}=\frac{q_{c} L_{c}}{L_{e}} \\
& u_{\ell_{e}}=\frac{{ }_{{ }_{c}} L_{c}}{h_{f g} \overline{t e} \rho_{\ell}}\left(1+\frac{\left(x-L_{e}\right)}{I_{e}}\right)
\end{aligned}
$$

Equation 2.39 is the link between the evaporator and condenser velocities and can be combined with Equation 2.35, resulting in the energy-continuity-momentum integral equation for the evaporator. The same but more simplified analysis may be 
applied to the adiabatic section since there the heat flux term is zero and the only forces entering into the equation are fluid friction and capillary pressure rise. Addition of the three momentum-continuity-energy equations yields

$$
\begin{aligned}
& Q_{\max }=\frac{\rho_{l^{h} g^{\circ}}}{\mu_{l}}\left(\frac{K Z_{w} \bar{t}_{w}}{\frac{L_{e}}{2}+L_{a}+\frac{L_{c}}{2}}\right)\left(\frac{2}{r_{e}}-\frac{\rho_{l^{g}}}{g_{c}} \frac{\left(L_{e}+L_{a}+L_{a}\right)}{\sigma} \cos \phi\right) \\
& Q_{\max }=\frac{\rho_{\ell} h_{f g} \sigma}{\mu_{\ell}}\left(\frac{K A}{L^{T}}\right)\left(\frac{2}{r_{e}}-\frac{\rho_{\ell} g}{\sigma g_{C}} H\right)
\end{aligned}
$$

Equation 2.41 is the basic deterministic maximum heat transfer rate equation for the heat pipe considered in this work. The term $(\rho h \sigma / \mu)$ is commonly referred to as the liquid transport factor, which is a group of fluid properties. The term $\left(K A / L^{\prime}\right)$ is a group of wick properties where $L^{\prime}$ is the effective flow length or average flow length of a given liquid particle in the wick. $L^{\prime}$ is obtained from the integration of Darcy's law, Equation 2.14, according to the mass flow distribution of Figure 2.4. The mass flow equations for the heat pipe considered in this work are given by

$$
\begin{aligned}
& \dot{\mathrm{m}}_{e}(\mathrm{x})=\dot{\mathrm{m}} \frac{\mathrm{x}}{\mathrm{L}_{e}}\left(0 \leq x \leq \mathrm{L}_{e}\right) \\
& \dot{\mathrm{m}}_{\mathrm{a}}(\mathrm{x})=\dot{\mathrm{m}}\left(\mathrm{L}_{e} \leq \mathrm{x} \leq \mathrm{L}_{e}+\mathrm{L}_{a}\right) \\
& \dot{\mathrm{m}}_{\mathrm{c}}(\mathrm{x})=\dot{\mathrm{m}}\left(1-\frac{\left(x-L_{e}-L_{a}\right)}{L}\right)\left(L_{e}+L_{a}<x<L\right)
\end{aligned}
$$

The mechanics of the integration of Darcy's law are shown in Equation 2.43 resulting in the expression for I'. 


$$
\begin{aligned}
& \int_{0}^{L} d p=\frac{\mu}{K A \rho}\left[\int_{0}^{L} e \dot{m}_{e}(x) d x+\int_{L_{e}}^{L_{e}+L a} \dot{m}_{a}(x) d x\right. \\
& \left.+\int_{L_{e}+L_{a}}^{L} \dot{m}_{c}(x) d x\right] \\
& \Delta \mathrm{p}_{\mathrm{W}}=\frac{\mu_{\ell^{\dot{m}^{\prime}}}}{\rho_{\ell^{K A}}} \\
& L^{\prime}=\frac{L_{e}}{2}+L_{a}+\frac{L_{c}}{2} \text { (for fully saturated wick) }
\end{aligned}
$$

Equation 2.45 appears as part of Equation 2.40 as a result of the combination and integration of the momentumenergy-continuity equation. The reason for the reiteration of the derivation of Equation 2.45 is that we will modify this integration step to obtain the design equation for the partially saturated wick condition.

\subsection{Deterministic Model of Heat Pipe operation with Par- tially saturated Wick \\ one of the major assumptions in the preceding analysis} was assumption 2 which stated that the heat pipe wick was fully saturated. Many times this is not the case. The liquid-vapor interface may recede into the wick resulting in performance different from that predicted by Equation 2.40. An attempt to modify Equation 2.40 for the partially saturated wick condition follows.

Modifying assumptions for a partially saturated wick analysis are: 
1. Capillary force properties are non-uniform across the wick as the result of the variation of critical capillary radius in the wick. Critical radius will be a function of $\bar{t}$; therefore, critical radius will decrease in the direction towards the heat pipe wall.

2. Permeability is assumed uniform across the wick.

3. Uniform heat flux in the evaporator and condenser is maintained during the partially saturated (desaturated) mode of operation.

4. The effect of the desaturation is to increase viscous liquid flow losses in the wick due to higher liquid velocities in the desaturated wick. The higher liquid velocities are required to maintain the mass flow in a smaller area.

5. A heat pipe functioning at non-equilibrium during the desaturation or recession process will reestablish equilibrium only if the receding liquid vapor interface encounters a smaller pore size resulting in sufficient additional capillary force. Figure 2.5 graphically illustrates the assumptions of the recession or desaturation mode of heat pipe operation. Figure $2.5(a)$ shows the mass flow distribution for the saturated and partially saturated mode of operation. The shape of the distribution is a result of the assumption that the 

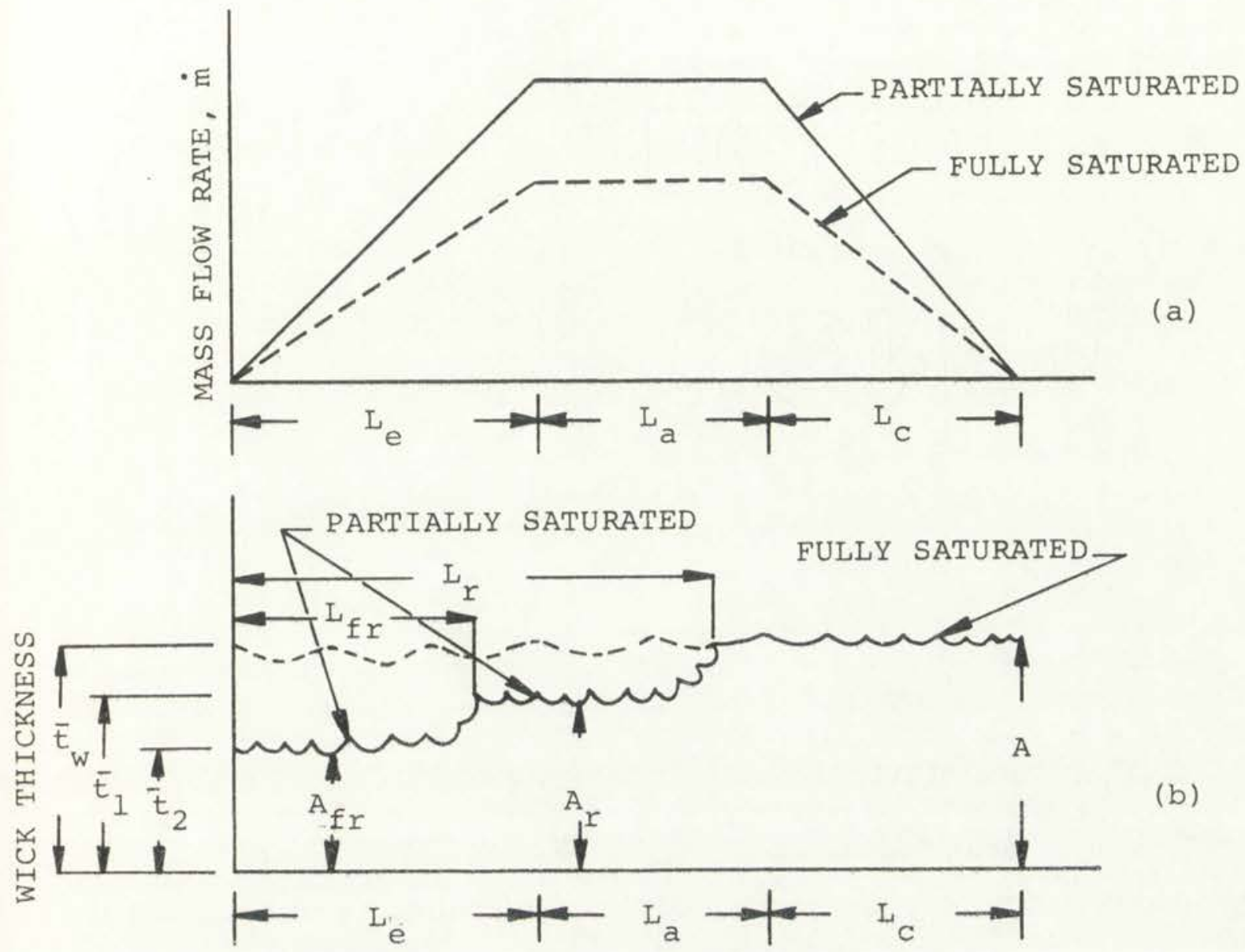

(b)

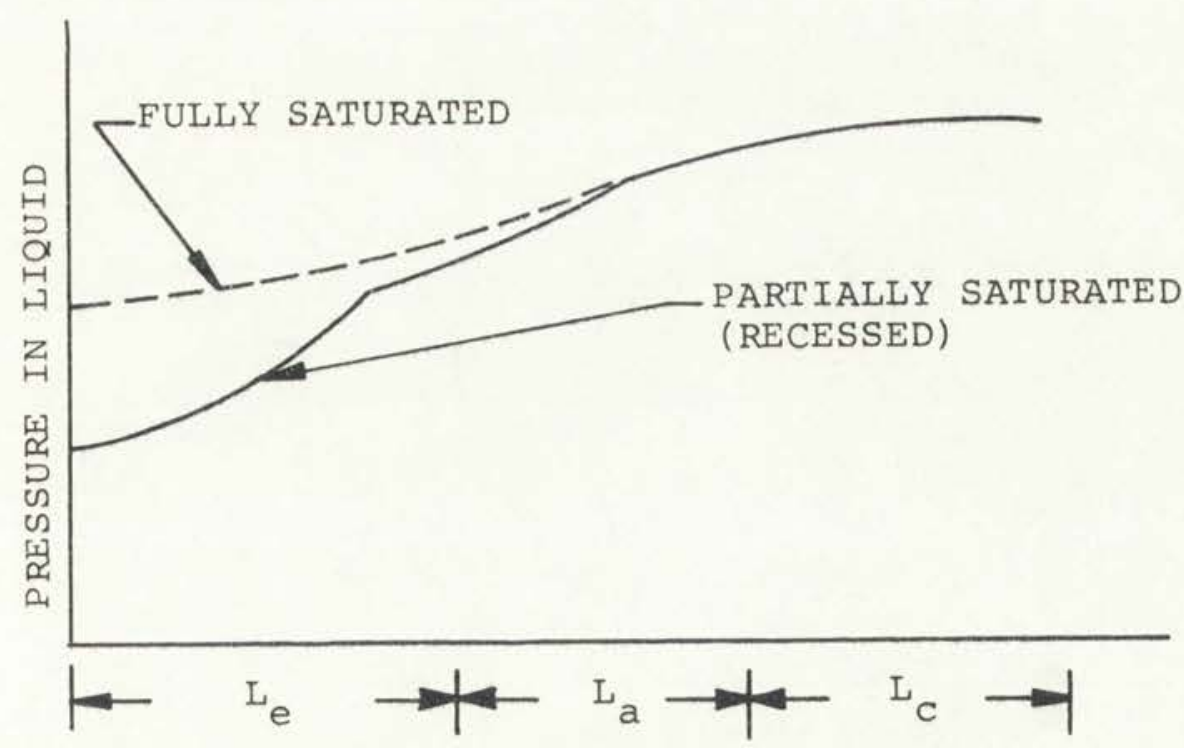

DISTANCE ALONG THE HEAT PIPE, $x$

Figure 2.5. Mass Flow Rate, Liquid Recession Distribution, and Liquid Pressure Distribution for Fully Saturated and Partially Saturated Wicks 
heat flux in the condenser and evaporator are uniform. Figure 2.5 (b) shows the liquid-vapor interface for the fully saturated and partially saturated modes of operation. The fully saturated condition of Figure $2.5(\mathrm{~b})$ indicates that there is sufficient capillary force at the upper $\bar{t}_{w}$ level in the wick to sustain the frictional and gravitational losses of the system. If this balance cannot be maintained by the capillary forces, liquid will be depleted due to evaporation in the evaporator more quickly than it can be restored by the capillary forces at the given liquid-vapor interface. The result is a non-equilibrium condition in which the liquid-vapor interface recedes into the wick. Now that the fluid is receding, there are two possible outcomes:
1. The fluid will recede until it encounters a stronger capillary force which will reestablish an equilib- rium condition.
2. The fluid will recede until it encounters the heat pipe wall resulting in the dryout and failure of the heat pipe.

For the analysis of recession, we will assume that the liquidvapor interface will reestablish an equilibrium condition at some level in the wick. Returning to Figure $2.5(\mathrm{~b})$, we see a hypothetical liquid-vapor interface distribution for a partially saturated wick. The $\bar{t}_{2}$ level in the wick is assumed to have the highest capillary force capability and, therefore, the smallest critical radius. The $\bar{t}_{1}$ level has a higher capillary force capability than the $\bar{t}_{w}$ level but a smaller capability than the $\bar{E}_{2}$ level. 
Referring to Figure $2.5(\mathrm{~b}$ and $\mathrm{c}$ ), the mechanics of the recession will be described. Starting at the condenser end of the heat pipe, we observe the liquid pressure and liquid level (position of vapor-liquid interface). Moving from right to left in the condenser region, the liquid pressure begines to decrease due to gravity and viscous forces. This pressure loss can still be maintained, however, by the capillary pressure at the $\bar{t}_{w}$ level in the wick. Moving into the adiabatic region, the pressure loss in the liquid has exceeded the capillary pressure capability of the $\bar{t}_{W}$ level pores and the fluid recedes. The $\bar{t}_{1}$ level pores have sufficient capillary force to maintain the liquid pressure loss and the liquid level remains at $\bar{t}_{1}$. Moving into the evaporator region with ever increasing liquid pressure loss, it is observed that the $\bar{E}_{1}$ level pores cannot sustain any more pressure loss and the 1iquid level recedes to the next level, $\bar{t}_{2}$. At the $\bar{t}_{2}$ level, capillary forces are sufficient to maintain the viscous and gravitational losses of the system. The $\bar{t}_{2}$ level has the highest capillary pressure capability and any additional recession will result in burnout. The difficulty in this analysis is the determination of the capillary properties at different levels if such a situation exists. In this work, the above theory is applied to wire mesh wicks whose capillary properties can be determined at the various levels. This may be a difficult matter for powder metal or other types of wicks. 
The preceding analysis indicated that the liquid-vapor interface recedes into the wick, resulting in a decreased flow area and increased liquid pressure loss. The only difference this introduces into the combined energy-continuity-momentum equation, 2.35, is the thickness of the liquid element. All other terms of Equation 2.35 must be maintained at their present values, consistent with Figure $2.5(\mathrm{a})$, except the liquid pressure loss term given by Equation 2.14, Darcy's law, which will be used to form the integral equation for the pressure loss in the liquid. For the recessed liquid-vapor interface, Equation 2.45 does not apply because the liquid flow area is not constant with length. This is shown in Figure 2.6

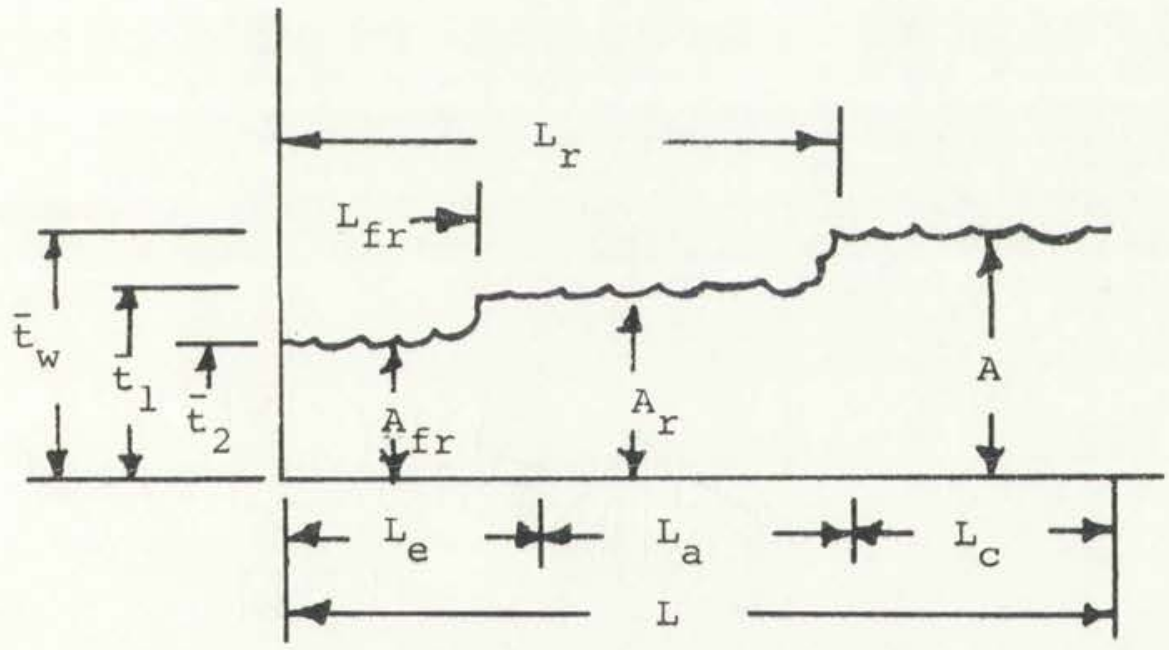

Figure 2.6. Liquid-Vapor Interface Distribution

Figure 2.6 is a redrawing of Figure 2.4(b) and will be used to determine the total liquid pressure loss for the recessed liquid level condition. Application of Equations 2.14 and 2.42 to Figure 2.6 the total pressure loss is 


$$
\begin{aligned}
\int_{0}^{L} d p_{r}= & \frac{\mu_{l}}{K_{p_{l}}}\left[\int_{0}^{L_{f r}} \frac{\dot{m}_{e}(x) d x}{A_{f r}}+\int_{L_{f r}}^{L_{e}} \frac{\dot{m}_{e}(x) d x}{A_{r}}\right. \\
& +\int_{L_{e}}^{L_{r}} \frac{\dot{m}_{a}(x) \cdot d x}{A_{r}}+\int_{L_{r}}^{L_{e} e_{a}^{L} \frac{\dot{m}_{a}(x) d x}{A}}+\int_{L_{e}+L_{a}}^{L_{c}} \frac{\dot{m}_{c}(x) d x}{A}
\end{aligned}
$$

Simplifying, we obtain

$$
\Delta \mathrm{p}_{r}=\frac{\mu \dot{m}_{L^{\prime}}(A)}{\rho_{l} \bar{K}}
$$

where

$$
\begin{aligned}
L^{\prime}(A)_{r}= & \left(\frac{L_{f r}}{2 A_{f r}}+\frac{\left(L_{e}-L_{f r}\right)}{2 A_{r}}+\frac{\left(L_{r}-L_{e}\right)}{A_{r}}+\frac{\left(L_{a}+L_{e}-L_{r}\right)}{A}\right. \\
& \left.+\frac{L_{C}}{2 A}\right)
\end{aligned}
$$

and the resulting model for heat pipe operation in the desaturated or recessed wick condition is

$$
Q_{\text {max }}=\frac{\rho_{\ell} h_{f g}{ }^{\sigma}}{\mu_{\ell}}\left(\frac{K}{L^{\prime}(A)_{r}}\right)\left(\frac{2}{r_{f r}}-\frac{\rho_{\ell} g H}{\sigma_{g_{C}}}\right)
$$

The only difference between Equation 2.49 and 2.41 is the $L^{\prime}(A) r$ term (Darcy flow length) and the critical radius, $r_{c}$. In Equation 2.49, we use the $L^{\prime}\left(A_{r}\right.$ to account for the additional pressure loss due to the recession and $r_{f r}$ to account for the increased capillary force at the fully recessed level, therefore, level $\bar{t}_{2}$ in Figure 2.5. Figure 2.6 may be interpreted as a general case of fluid recession and does not imply that there are always three distinct levels of constant pore size, 
r. The integration of Equation 2.46 may be applied to any amount of recession "steps" as long as one integrates between the discontinuities. The discontinuities of Figure 2.6 are at $\mathrm{L}_{f x^{\prime}} \mathrm{L}_{e^{\prime}} \mathrm{L}_{r^{\prime}}$ and $\mathrm{L}_{\mathrm{e}}+\mathrm{L}_{\mathrm{a}}$.

In the design of heat pipes operating under the desaturated wick condition, the recession lengths, therefore, $L_{f r}$ and $L_{r}$ of Figure 2.6 , must be determined to insert into Equation 2.48. Also, one must know the variation of $r_{C}$ as a function of the $t$ dimension of Figure 2.6. The $r_{c}$ variation may be theoretically hypothesized or experimentally determined. In this work, $r_{C}$ as a function of $\bar{t}$ is determined experimentally. Given that the $r_{C}$ variation is known, one can calculate the recession lengths by plotting the pressure distribution along the wick and observing where the liquid pressure loss exceeds the capillary pressure rise of a given pore. The pressure loss in the wick is a combination of viscous and gravity effects and is given by

$$
\frac{d p}{d x}=-\frac{\dot{m}(x) \mu_{\ell}}{K A(x) \rho_{\ell}}-\frac{\rho_{\ell}}{g_{C}} \frac{H}{L}
$$

Integration of Equation 2.50 results in the pressure distribution along the wick of a heat pipe shown in Figure 2.7.

$$
p_{(x)}-p_{(0)}=-\frac{\mu_{\ell}}{K_{\ell}} \int_{0}^{x} \frac{\dot{m}(x) x d x}{A(x)}-\frac{\rho_{\ell} g H x}{g_{0}} \frac{1}{L}+H_{0}
$$

If one has no excess liquid in a pipe and neglects the effect of the diameter of the pipe, Equation 2.51 becomes 


$$
p_{x}-p_{0}=\frac{\mu_{\ell}}{K \rho_{\ell}} \int_{0}^{x} \frac{\dot{m}(x) x d x}{A(x)}-\frac{p_{\ell}}{g_{0}} \cos \phi
$$

where $\dot{\mathrm{m}}(\mathrm{x})$ is defined by Equation 2.42 .

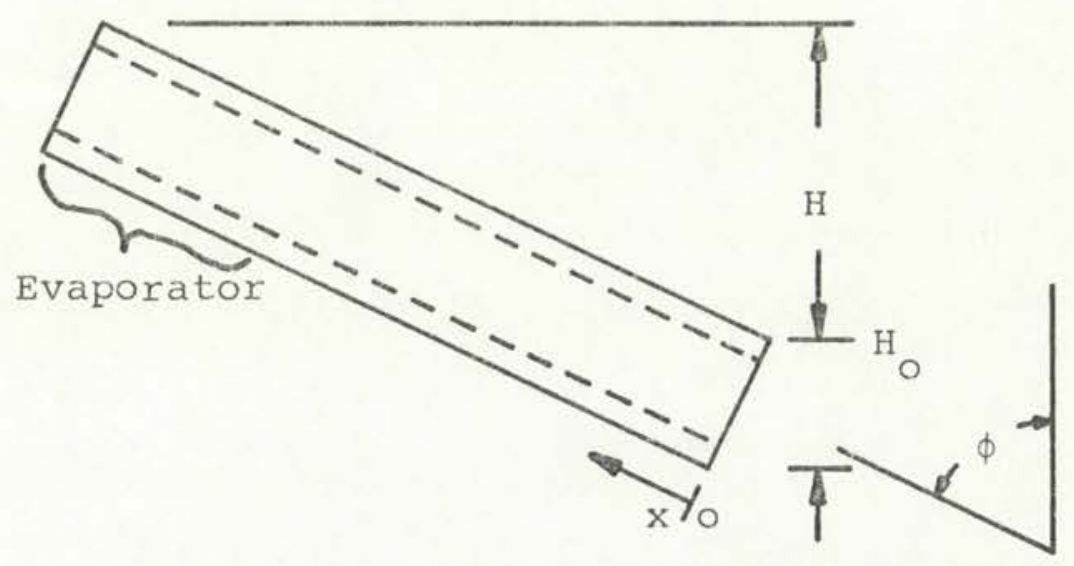

Figure 2.7. Heat Pipe Configuration

Equation 2.52 is difficult to solve in closed form because the area term is a function of $\mathrm{x}$. A trial and error solution is proposed using Equations 2.49, 2.50, 2.52, and 2.53.

$$
\mathrm{Q}_{\text {max }}=\dot{\mathrm{m}}_{\max } \mathrm{h}_{\mathrm{fg}}
$$

First, compute $Q_{\max }$ using Equation 2.49, initially setting $L^{\prime}(A)_{r}$ equal to $\mathrm{L}^{\prime} / \mathrm{A}$. Second, compute $\dot{\mathrm{m}}$ using Equation 2.53. Then, using Equation 2.52, start plotting $p_{x}$, beginning at the condenser end at $\mathrm{x}$ equal $o$. Increment, using small $\mathrm{x}$ until the term $\left(p_{x}-p_{0}\right)$ exceeds the capillary pressure rise of the pores at the inside diameter of the wick. At this point, set $A(x)$ equal to the new and smaller recessed area as a result of the fluid recession and record the $x$ position. Referring to Figure 2.6 , the new area will be $A_{r}$. Continue to plot pressure along the entire length of the pipe in like manner, 
always observing the mass flow distribution of Figure 2.5(a). From this pressure plot, one can calculate the recessed lengths of the wick and, therefore, calculate $L^{\prime}(A)_{r^{*}}$ The new $L^{\prime}(A) r$ from Equation 2.48 is inserted into Equation 2.49 and the procedure is repeated until the $Q_{\max }$ value converges, which usually takes about four iterations. A computer program was written to perform this computation and is discussed in Chapter 6 .

2.3 The Probabilistic Nodel of Heat Pipe Operation

Many of the design parameters of Equation 2.49 are extremely variable. Experiments show that the wicking properties, $K, A$, and $r_{C}$ may vary plus or minus $30 \%$ of the absolute mean value. The reasons for the variability or uncertainty in the determination of these variables result from variability of materials, variability of manufacturing, and, to some extent, experimental measurement variability. Generally, the uncertainty in these design variables is too large to be neglected. The probabilistic model of heat pipe operation incorporates the variability of the design parameters so that the variability of the design result, $Q_{\text {max }}$ can be determined. Given that the design variables of a particular system are described by a distribution of values rather than a single deterministic point, we may be able to fit certain functions to data to describe the variability of design variables. These functions are called probability distributions. The permeability, $K$, may be described by a certain probability distribution while the critical radius, $r_{c}$, may be described by another. 

The first step in the analysis of the probabilistic model will be the following assumptions:

1. Q, $K, r_{e}, H, L^{\prime}(A)_{r^{\prime}}$ and $A$ are assumed to be independent random variables described by a continuous probability distribution.

2. The continuous probability distributions will be described by two parameters, the mean and standard deviation.

3. All other variables will be considered deterministic since their variabilities are comparatively small. The notation for a given random variable using these assumptions will be $\left(\mu_{z z}, \sigma_{z z}\right)$ where $z z$ is the random variable, $\mu$ is the mean and $\sigma_{z z}$ is the standard deviation. The permeability variate pair being $\left(\mu_{K}, \sigma_{K}\right)$.

The probabilistic design equation is the deterministic design equation with the random variate pairs inserted. The probabilistic design equation is

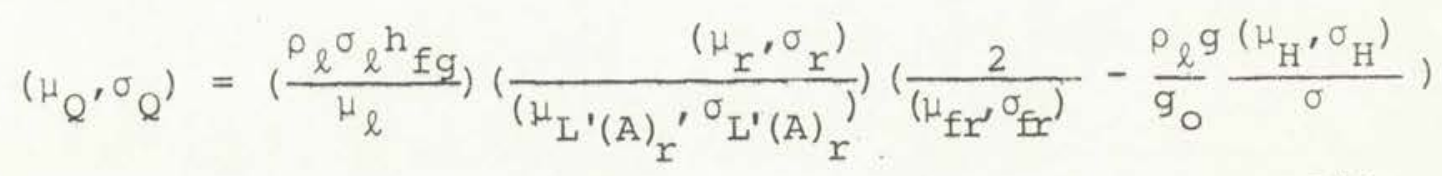

Equation 2.54 represents the functional relationship between the random variates of the probabilistic design model. Many times, the distribution parameters (the mean and standard deviation in this analysis) must be estimated from experimental data. The consistent and unbiased estimator for the mean of a random variable, $x$, is defined by Miller and Freund $^{17}$ as 



$$
\bar{x}=\sum_{i=1}^{n} \frac{x_{i}}{n}
$$

where $\mathrm{n}$ is the number of readings and the estimator for the standard deviation is

$$
s_{x}=\sqrt{\sum_{i=1}^{n} \frac{\left(x_{i}-\bar{x}\right)^{2}}{n-1}}
$$

Since all the random variates will be determined using experimental data, their parameter will be estimated and Equation 2.54 for the case of partially saturated wick becomes

$$
\begin{aligned}
& \left(\bar{Q}, S_{Q}\right)=\left(\frac{\rho_{\ell} \sigma_{0} h_{f g}}{\mu_{\ell}}\right)\left(\frac{\left(\bar{K}, S_{K}\right)}{\left(\bar{L}^{\prime}(A)_{r}, S_{I^{\prime}(A)_{r}}\right)}\right)\left(\frac{2}{\left(\bar{r}_{f r^{\prime} S_{I_{f r}}}\right)}\right. \\
& \left.-\frac{\rho_{\ell} g}{g_{O} \sigma_{\ell}}\left(\bar{H}, S_{H}\right)\right)
\end{aligned}
$$

The solution of Equation 2.57 is the random variate $\left(\bar{Q}, S_{Q}\right)$, which may be translated into a probability distribution function such as the normal distribution. Figure 2.8 shows a hypothetical distribution of maximum heat transfer rate for a given heat pipe design. The designer may determine the variability of the design and decide if it meets or exceeds the specified minimum value, $Q_{s}$. The area to the right of $Q_{S}$ indicates the probability that a heat pipe, with the given variable properties, will exceed $Q_{S}{ }$. The design engineer can adjust the $Q_{\max }$ distribution by changing the distribution of the heat pipe properties so that a very small portion of the distribution lies below $Q_{s}$ in the failure region. 


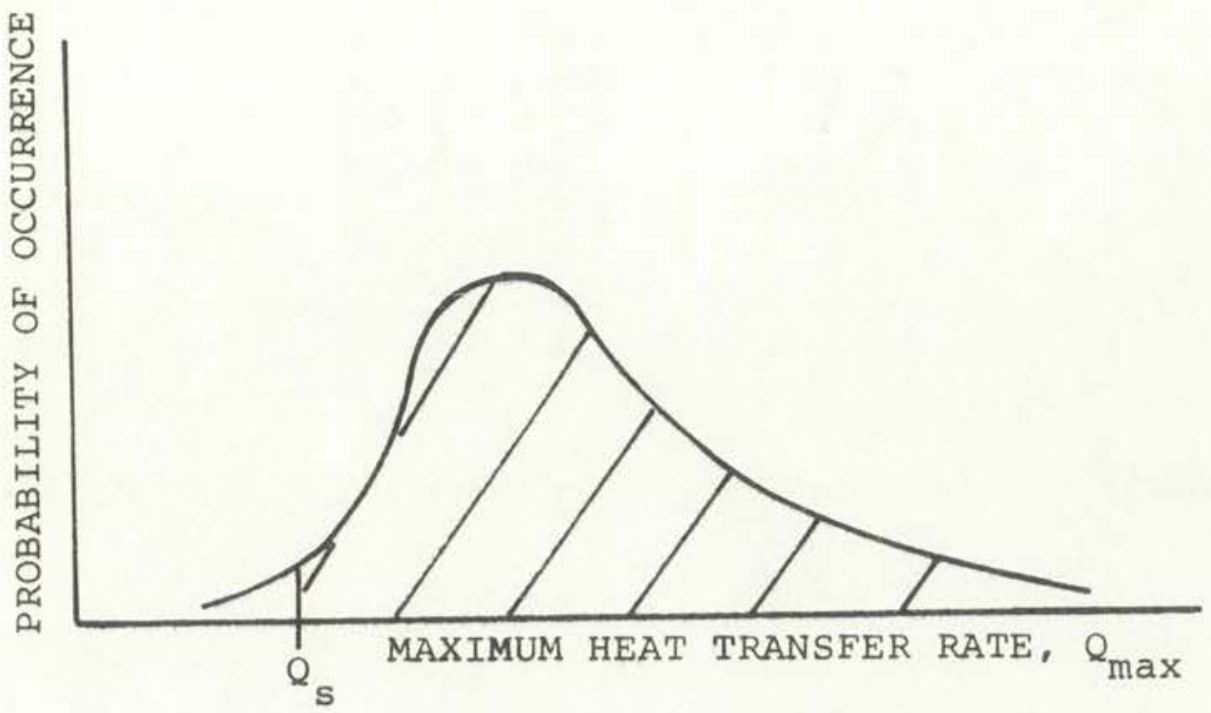

Figure 2.8. Distribution of Heat Flow Capability of a Heat Pipe Whose Design Parameters Are Assumed Random

Solution techniques will be discussed in depth in Chapter 6 for Equation 2.57 .

The basic argument behind the probabilistic design approach is that we can obtain a quantitative measure of the uncertainty of the system performing as required. Many times we may obtain a set of measurements that, when inserted into the deterministic equation (Equation 2.49, or any equation for that matter), give a vastly different result from reality. The conclusion may be that the particular deterministic equation is poor, but this may not be a proper conclusion. One must look at the distribution of functional solution variables to determine the validity of the model. It may be highly possible to obtain a calculated result relatively far from the observed mean result yet still lie in the range of the distribution. 
Chapters 6 and 7 will analyze the probabilistic design methodology in depth and comparisons will be made with actual test data. In Chapter 3, the details of experimental techniques for the measurement of our design variables, K, A, L', $r_{e}$, and $H$, are presented. 
CHAPTER 3

APPARATUS

The heat pipe design used as a basis for obtaining data on a typical wire mesh wick heat pipe is shown in Figure 3.1. The material used in the construction of the wicks and pipe was 304 stainless steel. The dimensions shown in Figure 3.1 were chosen as typical for a wire mesh heat pipe of this design with an annular wick. The active length of the heat pipe was 22 inches and the evaporator was 13.5 inches. The evaporator was chosen to be large (a significant portion of the pipe) to insure low radial heat transfer and therefore little chance of vapor blockage in the wick as a result of high radial heat fluxes. The inside diameter of the heat pipe was .743 inches and the outside diameter was $13 / 16$ inches. Thermocouples were placed along the outside surface of the heat pipe to monitor axial temperature loss. The end caps on the heat pipe were removable to facilitate the testing of many different wicks without the additional labor and expense of constructing a new heat pipe for each wick. Vapor thermocouples were attached to the removable end caps to monitor vapor temperature. Four different sizes of wire mesh were used to obtain four variations in the design equation.

Figure 3.2 shows the stainless steel heat pipe with end caps. The thermocouple wiring harness was attached and bonding cement was applied to the thermocouple junctions. Figure 3.3 shows the same heat pipe of Figure 3.2 after insulation, heater wire, and calorimeter have been installed. Excessive insulation 

was added to the evaporator to maximize the input heater effectiveness. Figure 3.4 shows the experimental heat pipe mounted and ready for testing. The heat pipe is tested with the evaporator higher than the condenser so that the wick limited condition can be reached without excessive heat flux. The apparatus used to measure the gravity effect is shown in Figure 3.5 . A sliding probe two feet in length is inserted into the heat pipe until electrical contact is made with the excess working fluid in the bottom of the pipe. Contact is indicated by a reading on a microammeter. The length of the probe, Lp, is measured and the pressure drop due to gravity, $\Delta \mathbf{p}_{\ell g}$, is calculated using Equation 3.1. Figure 3.6 shows the wire mesh wick being inserted into a heat pipe. The wicks were manufactured to fit as tight as possible and were inserted through the condenser end and pressed tightly into the evaporator. Figure 3.7 shows the heat pipe under test. Figure 3.24 is a simplified drawing of the heat pipe operating at steady

$$
\Delta \mathrm{p}_{\ell \mathrm{g}}=\mathrm{L}_{\mathrm{p}_{i}} \sin \theta+\mathrm{r}_{\mathrm{pi}}
$$

state and temperature recorder monitoring temperature distributions along the pipe and the calorimeter temperature rise. Figure 3.9 shows the technique used to experimentally determine wick permeability. A balloon approximately two feet in length was inserted into the vapor cavity of the heat pipe and pressurized to $50 \mathrm{psi}$. This pressure was chosen to ensure a sufficient force to press the balloon against the wick as shown in Figure 3.26. The objective of the measurement is to force fluid through the wick in a 

manner similar to the actual operation of the heat pipe. Figure 3.26 shows the small error that will result in the permeability test due to the inability of the balloon to seal off a small area near the seam. This error is considered insignificant since that seam void carries a small amount of fluid by the meniscus shown in Figure 3.27. A pressure head of six inches of water was used to drive the fluid through the wick. The liquid flow velocity resulting from this driving pressure was approximately $.015 \mathrm{ft} / \mathrm{sec}(.015 \mathrm{ft} / \mathrm{sec}$ was calculated to be the maximum flow encountered during operation of these heat pipes and is in the Darcy flow regime) and the pressure loss was taken across the wick structure only. Permeability was calculated using Equation 2.14. Figure 3.11 shows the preparation for a permeability test with the balloon ready to be pressurized.

$$
\frac{2}{r_{e}}=\frac{\rho g}{g_{0}} H
$$

The apparatus used in the determination of capillary critical radius is shown in Figure 3.14 . Wick samples were pressed between two o-rings and submerged in a reservoir of working fluid. The sample covered a 2.25 inch hole which was attached to a 2.25 inch plastic tube. The tube acted as a fluid container so that the liquid head could be supported by the capillary forces of the wick sample structure. The fluid level was then lowered until the wick sample could no longer support the fluid inside the plastic cylinder by surface tension forces. At that instant the capillary rise height was measured. Critical radius, $r_{e}$, was determined 
using Equation 3.2. Figure 3.12 shows the capillary rise height apparatus broken down and in the testing configuration. Figure 3.13 shows the measurement of wire mesh thickness after the capillary rise test. The wire mesh thickness data will be used in Chapter 5 to determine liquid recession depths.

Figure 3.15 shows the apparatus used to manufacture the wire mesh wicks. The wrapping mandrel twenty-five inches in length is mounted between spring loaded jaws which press against the wire mesh as it is wrapped. Figure 3.16 shows the initial phase of manufacture. A piece of wire mesh is cut to size and a retainer rod is spot welded at the edge. The wire mesh is inserted into the mandrel and placed into the apparatus. The wire mesh is then wrapped on the mandrel with the spring loaded jaws pressing against the wire mesh to produce a tight fit as shown in Figure 3.17. Figures 3.18 through 3.23 reiterate this sequence in detail. Figure 3.25 shows the final result of the wick manufacture. The $1 / 4$ inch overlap at the edge of the wick is necessary to insure strong spot welds. The resultant structure is quite strong and incompressible which gave accurate and repeatable readings in the permeability test.

The procedure for testing is given in the appendix. Chapter 4 will deal with properties of heat pipe wicks measured using the apparatus just described. 



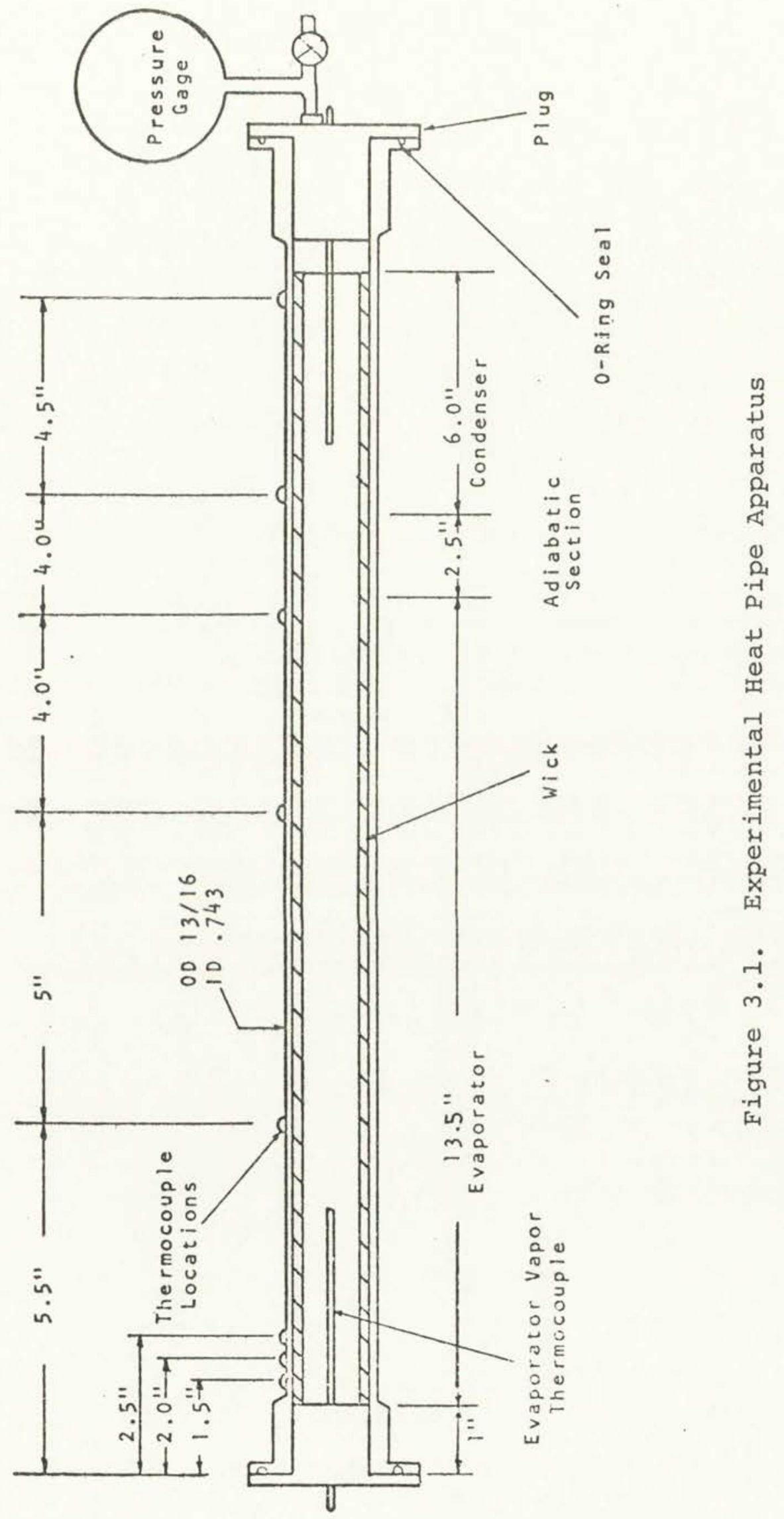





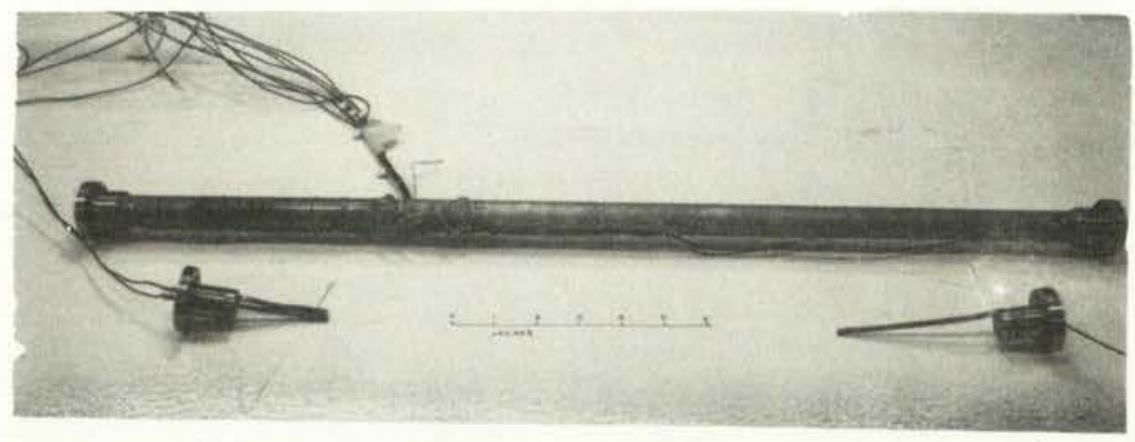

Figure 3.2. Stainless Steel Heat Pipe and Vapor Probes

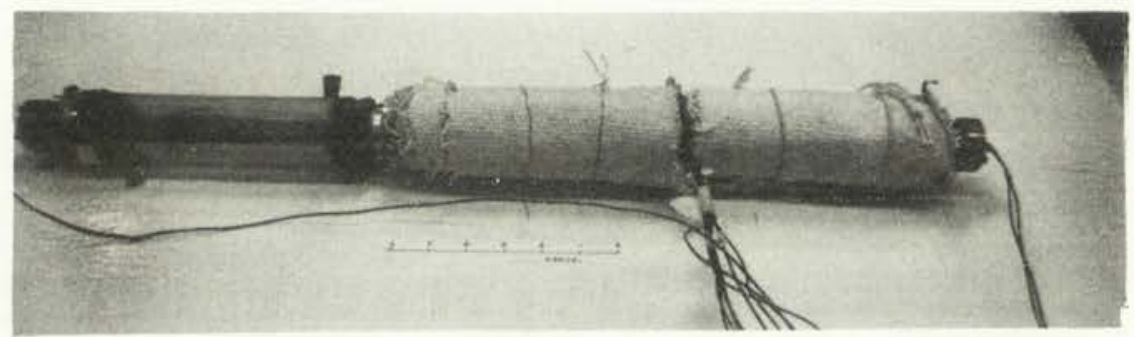

Figure 3.3. Evaporator Section (insulated) and Condenser Installed

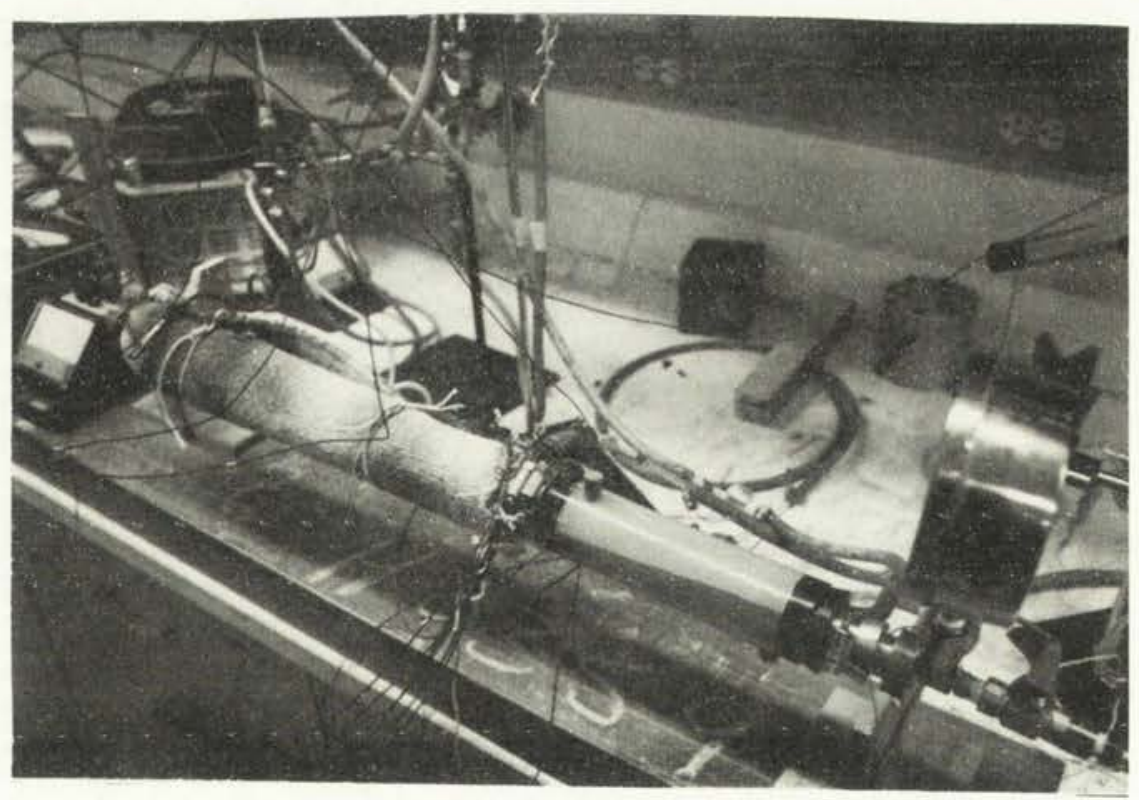

Figure 3.4. Testing Configuration 



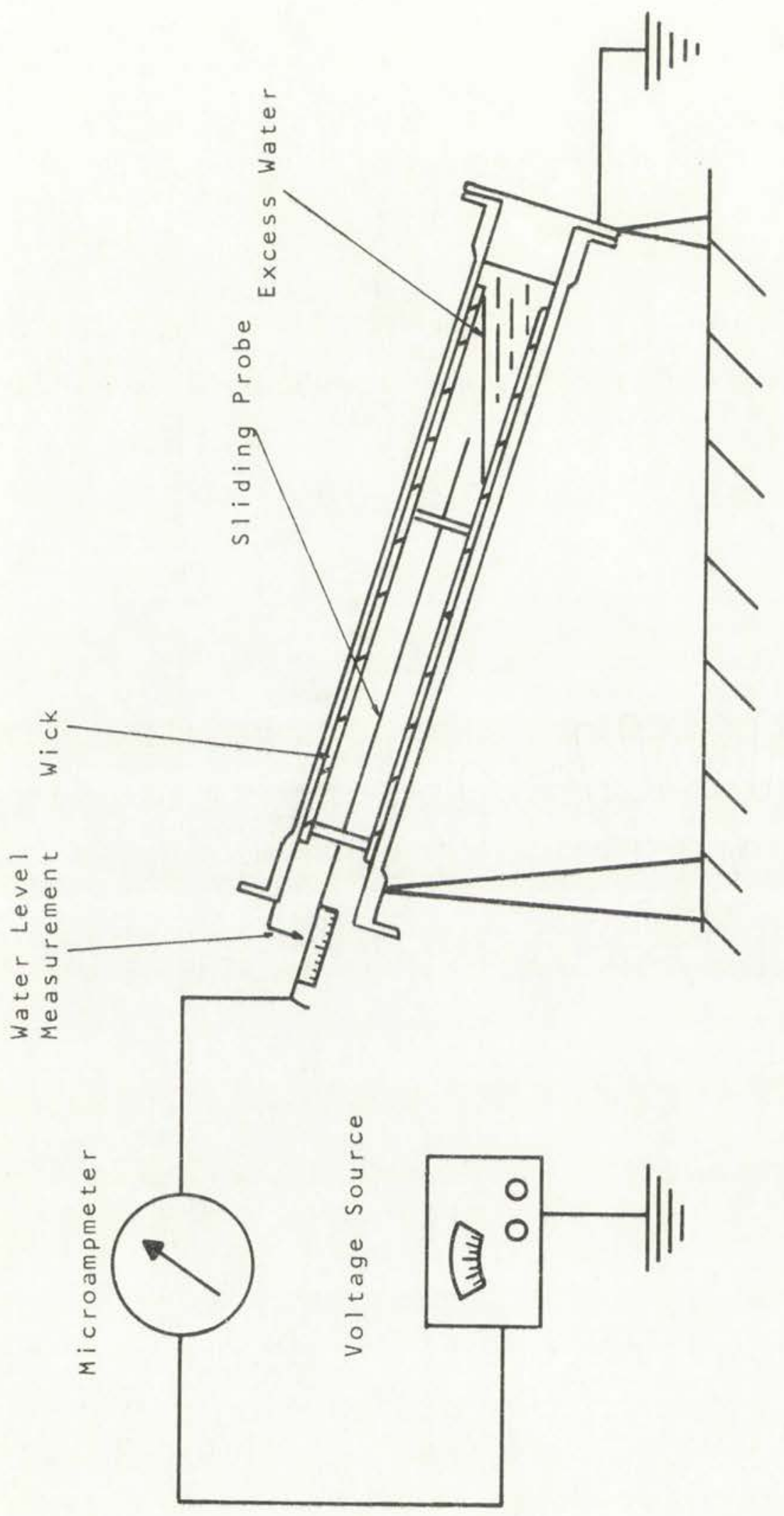

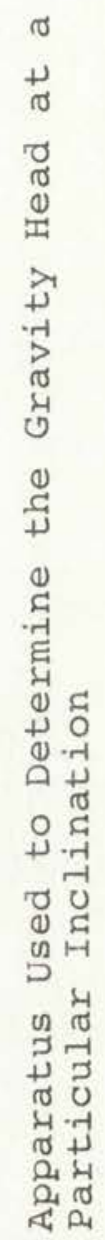

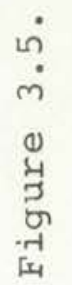




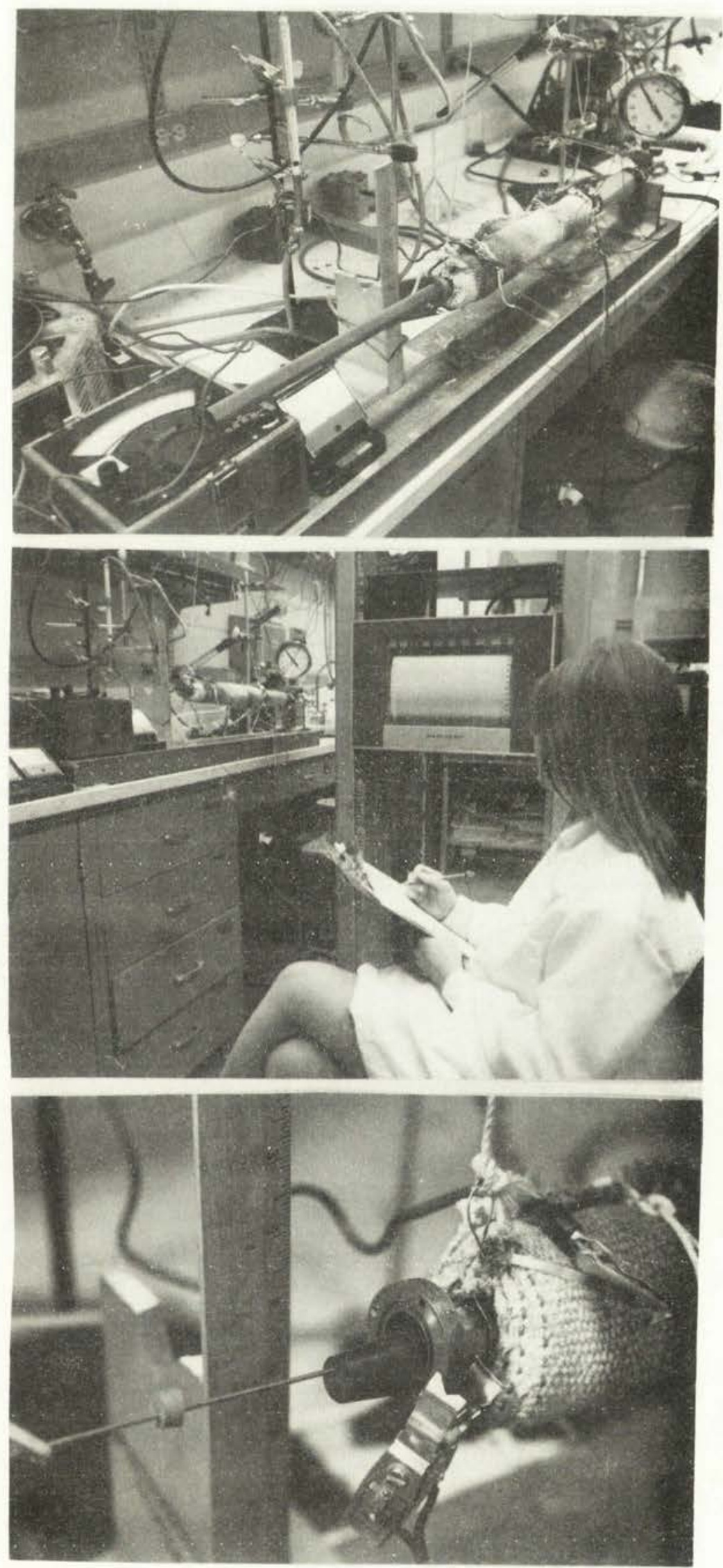

Figure 3.6 . Inserting Wire Mesh Wick into Heat Pipe

Figure 3.7 .

Testing Maximum Heat Transfer Rate

Fiqure 3.8. Determination of Liquid Heat Loss Due to Gravity 



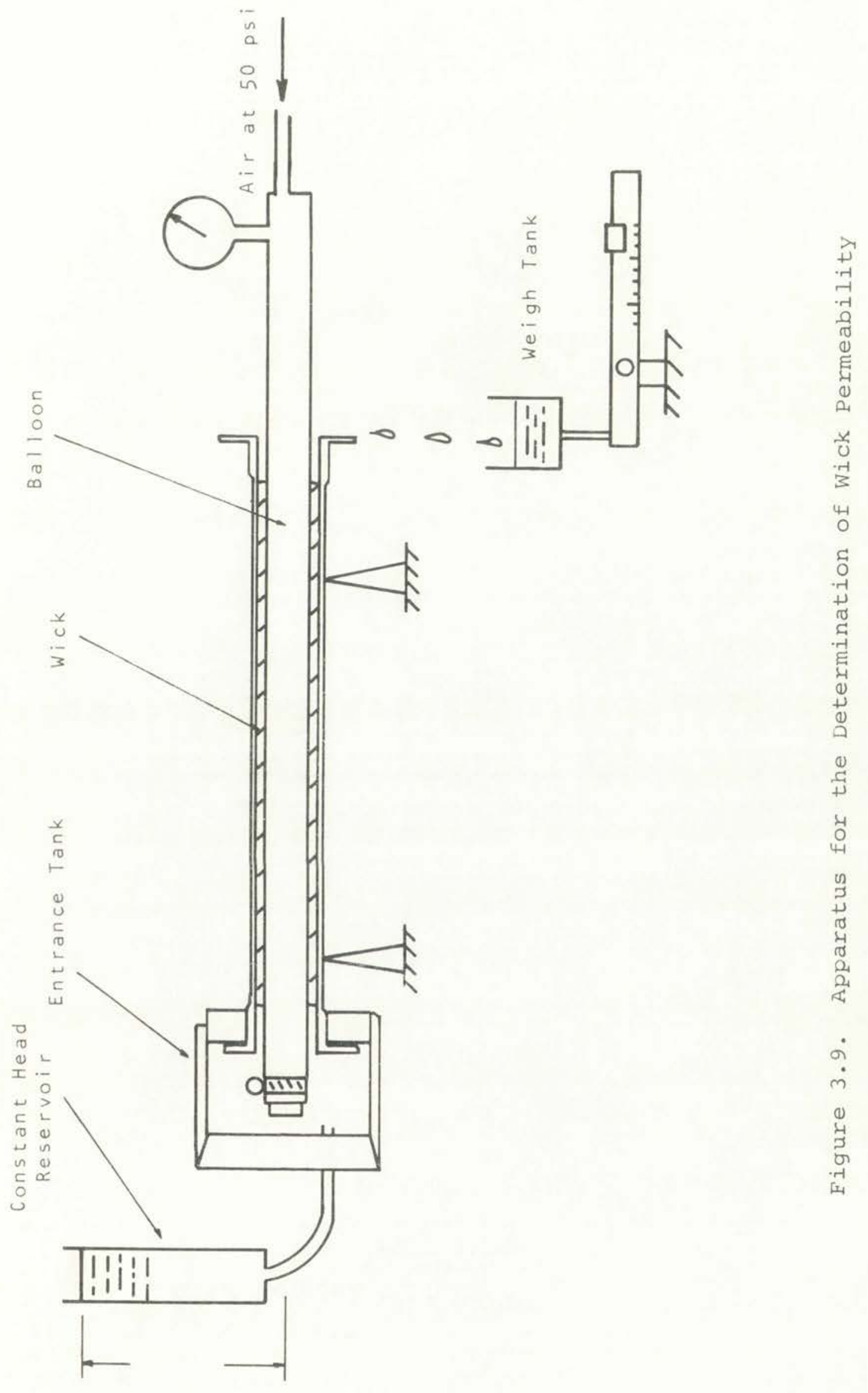



Tr8 $\quad . \quad 72$

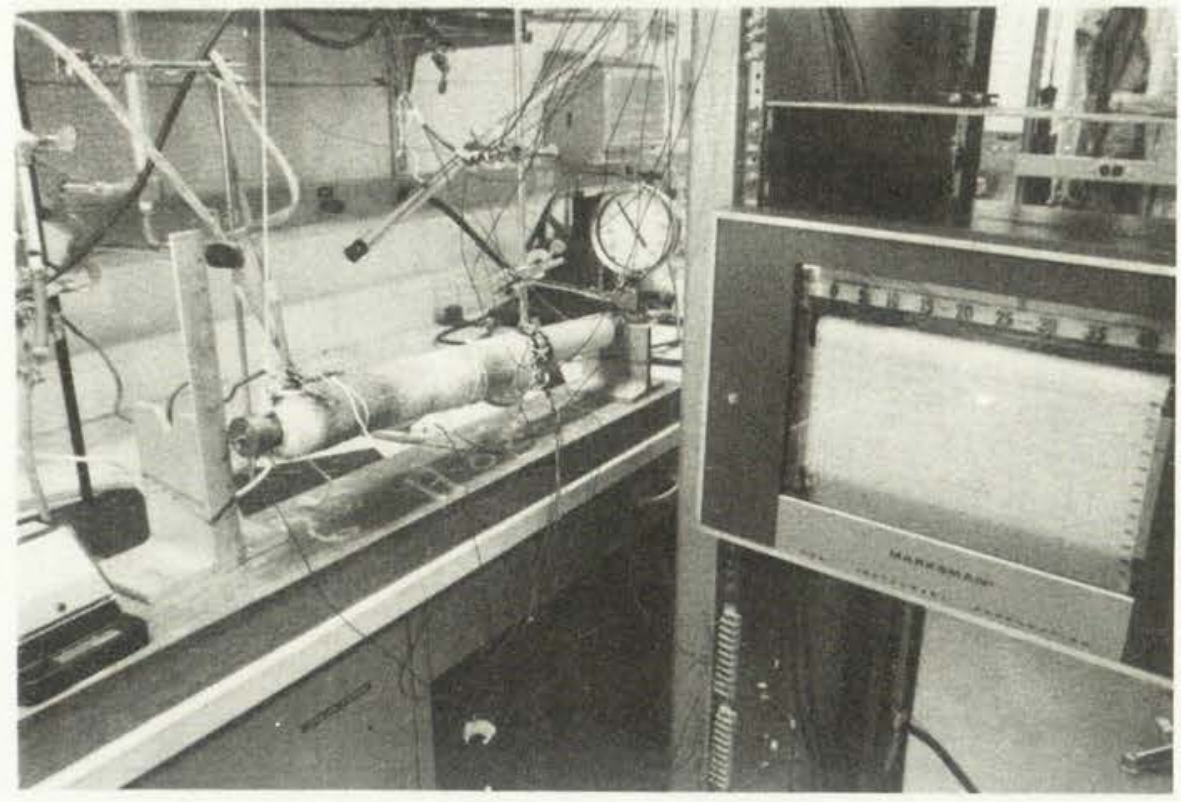

Figure 3.10. Heat pipe configuration for wick limiting test

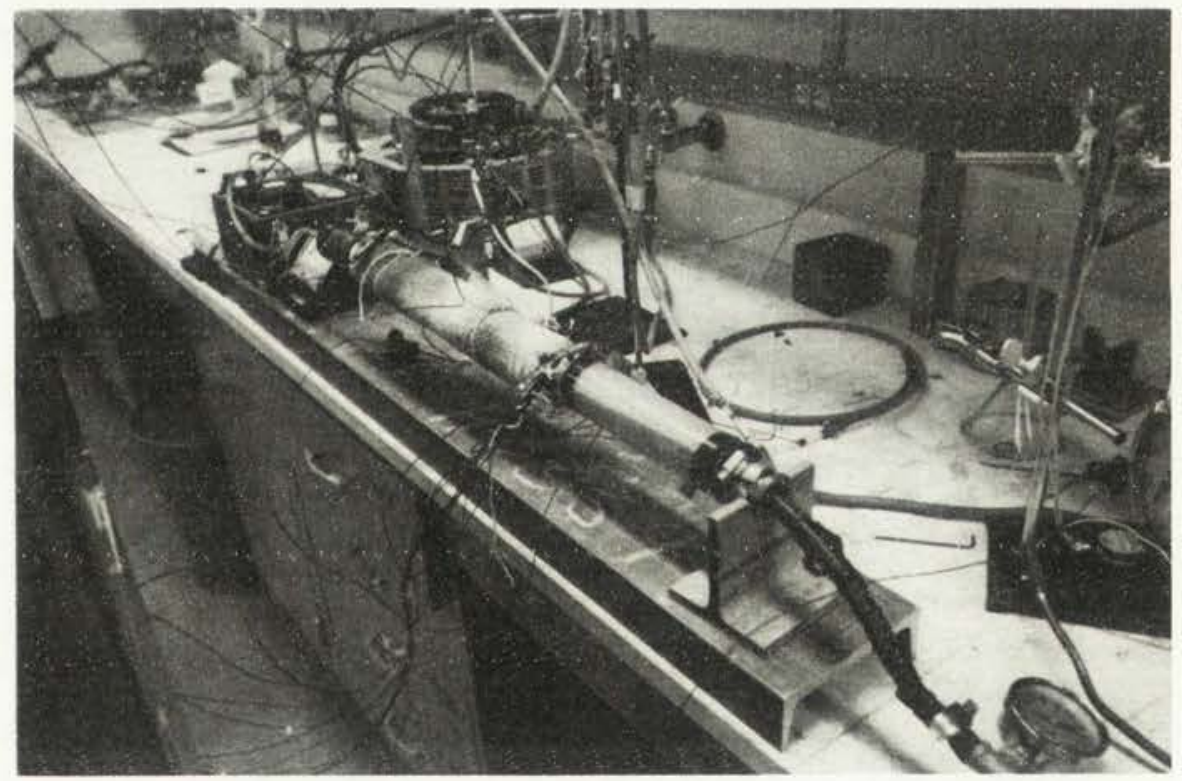

Figure 3.11. Permeability test 


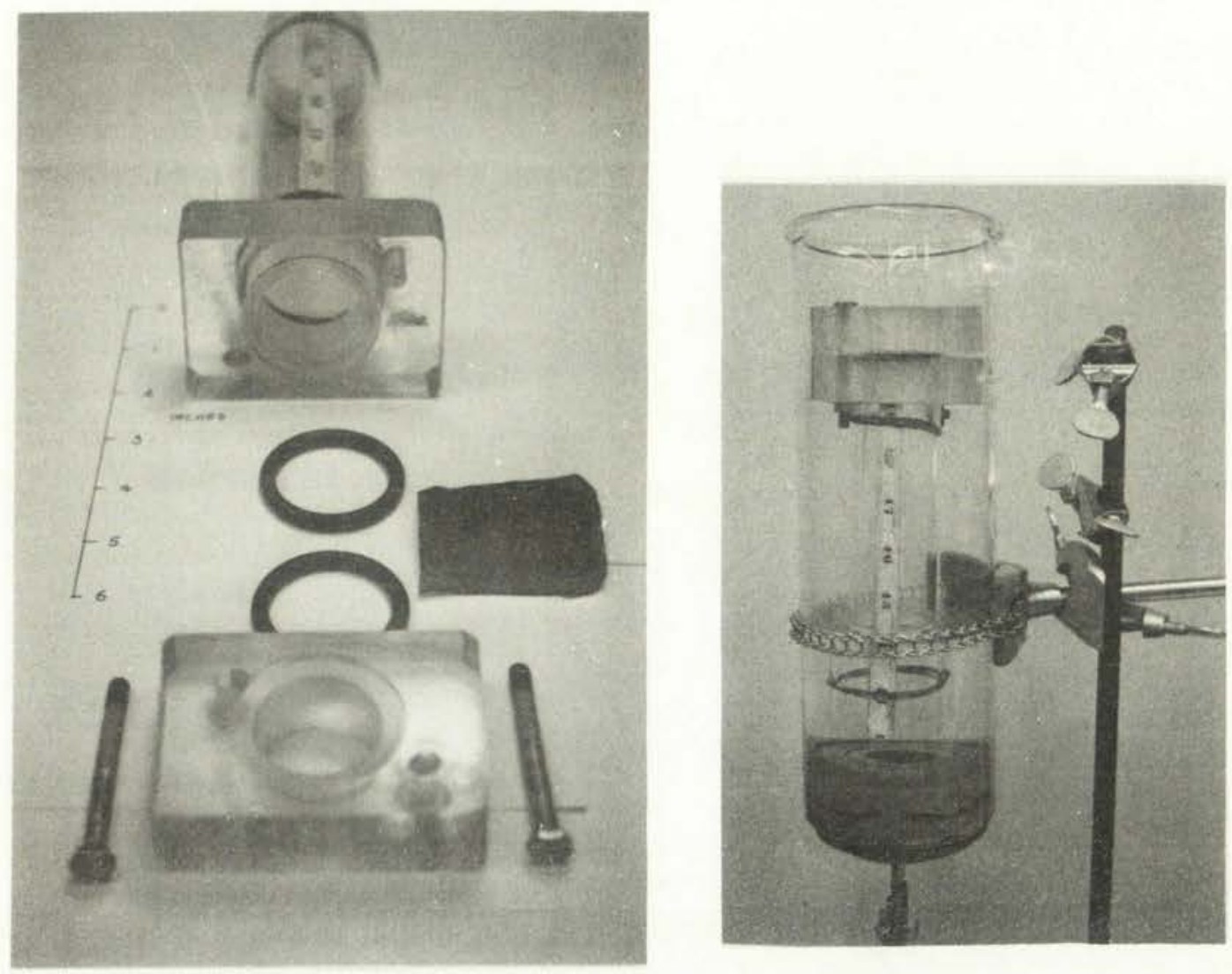

Figure 3.12. Capillary Rise Capability Test Apparatus

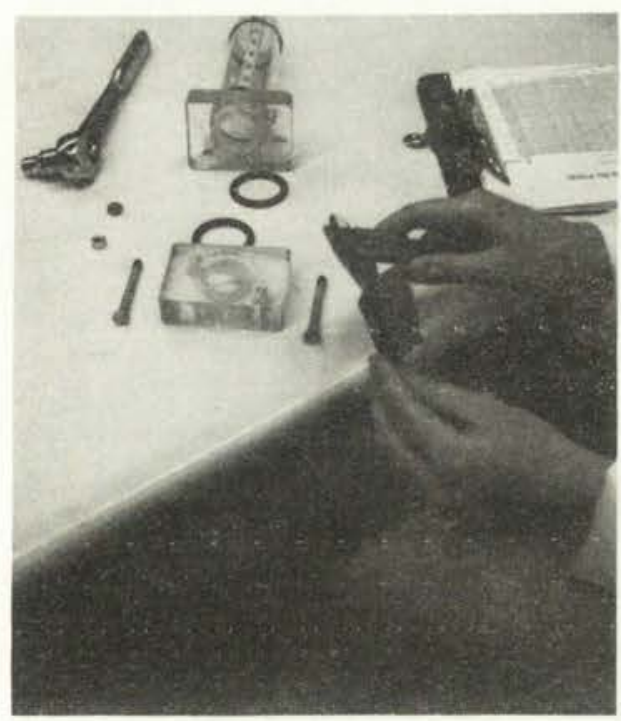

Figure 3.13 Checking wire Mesh Thickness after Capillary Rise Test 



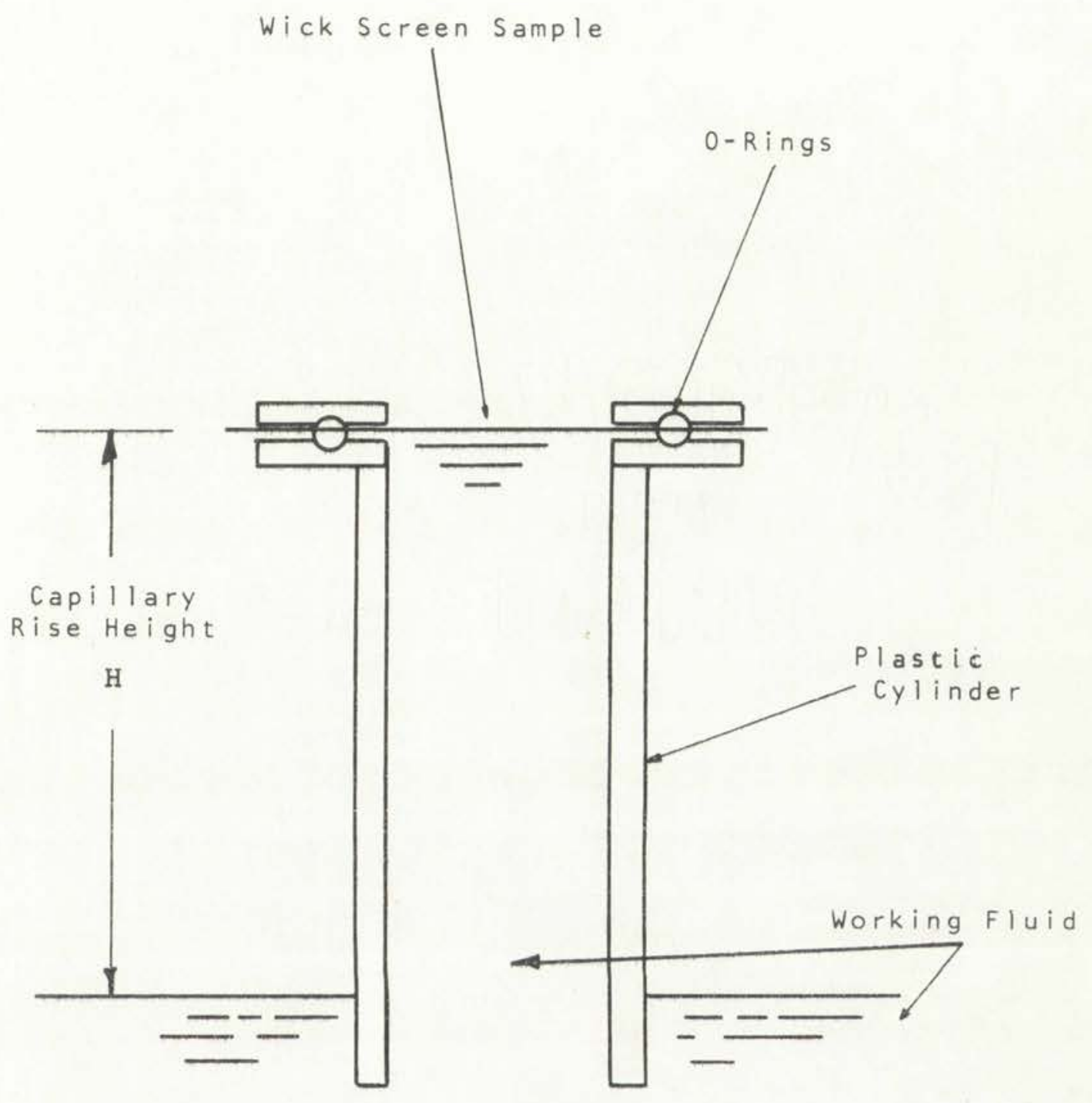

Figure 3.14. Capillary Rise Height Apparatus 


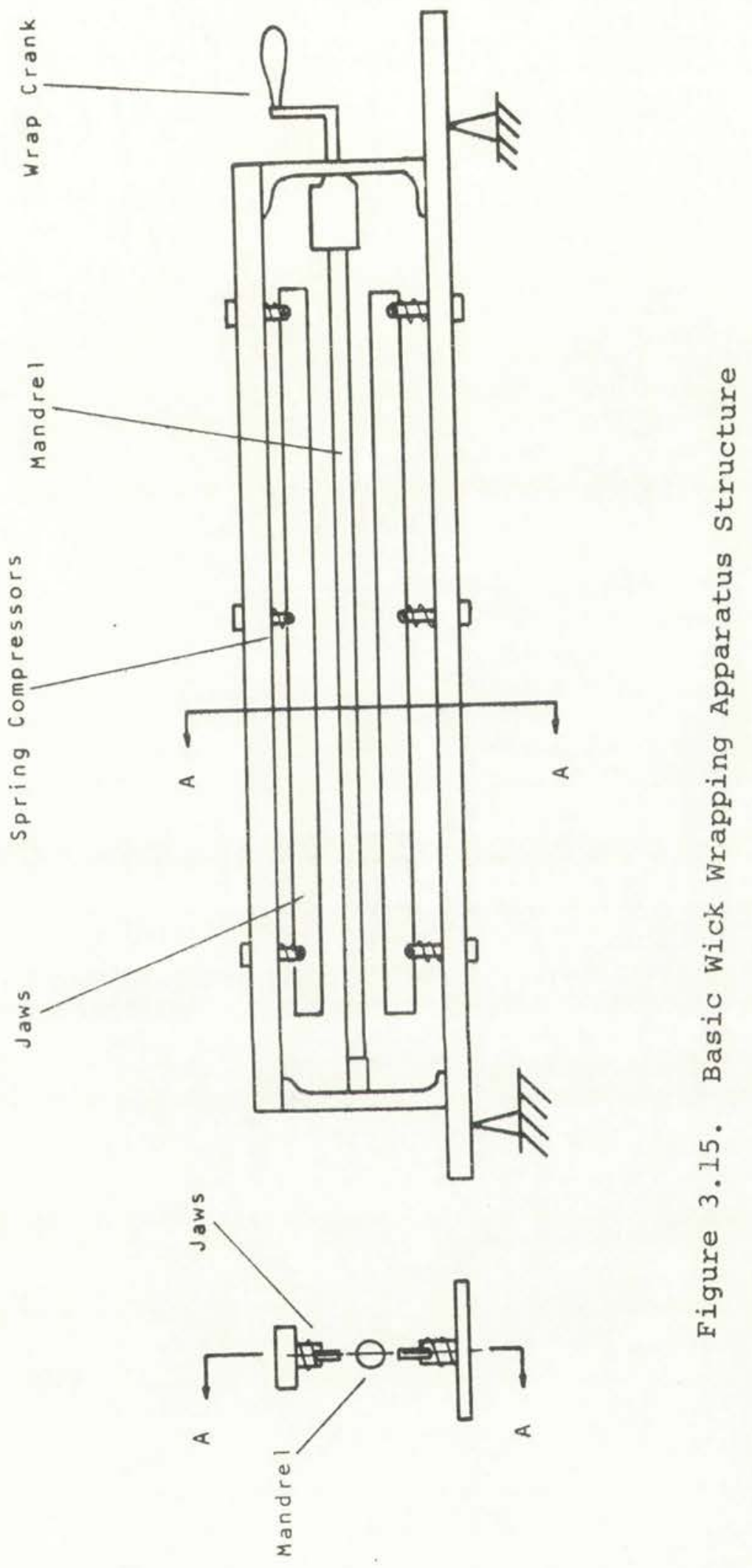




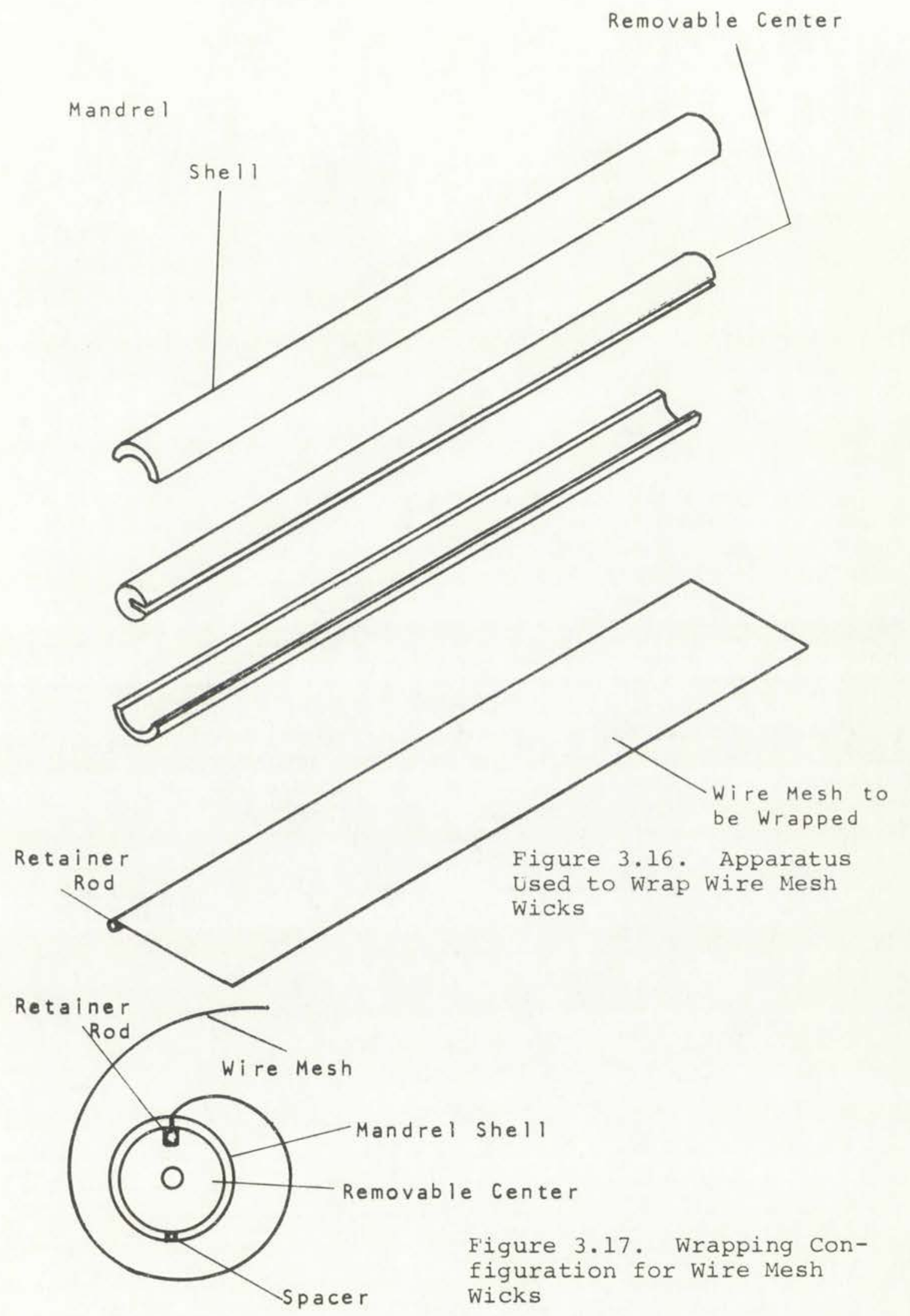




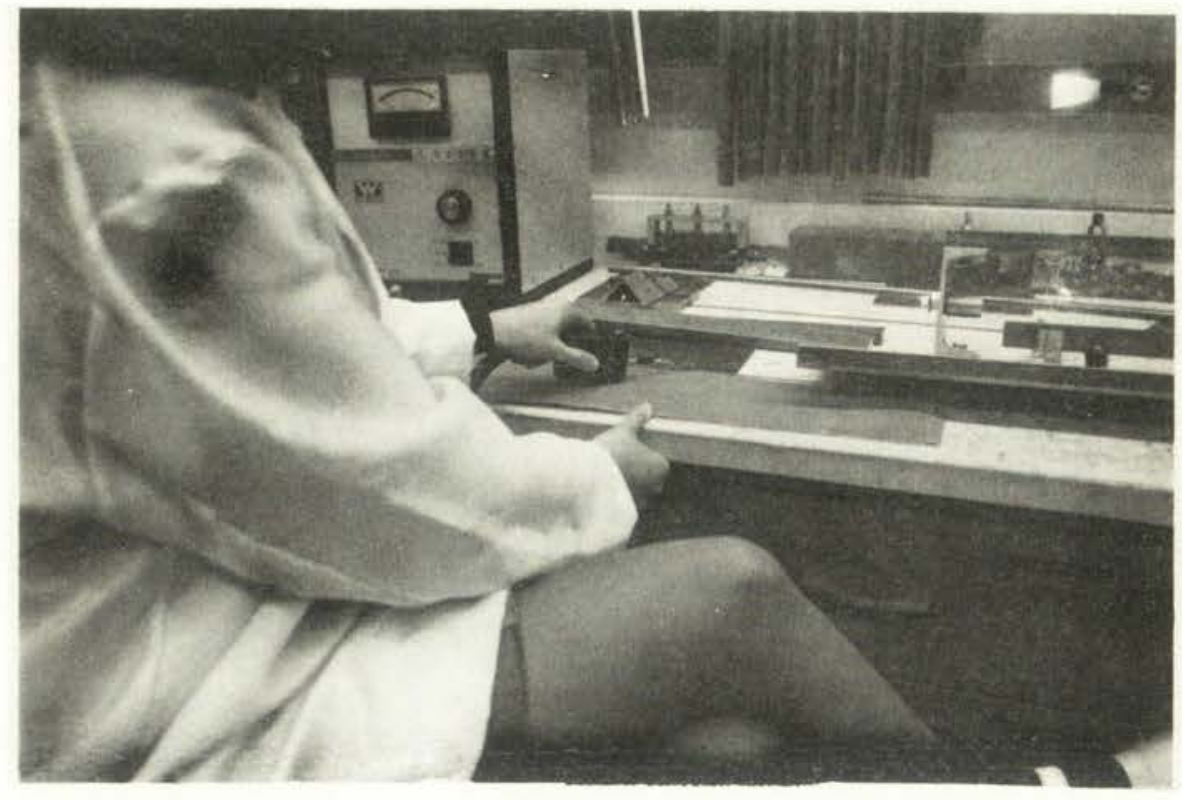

Figure 3.18. Initial Phase of Wire Mesh Wick Manufacture

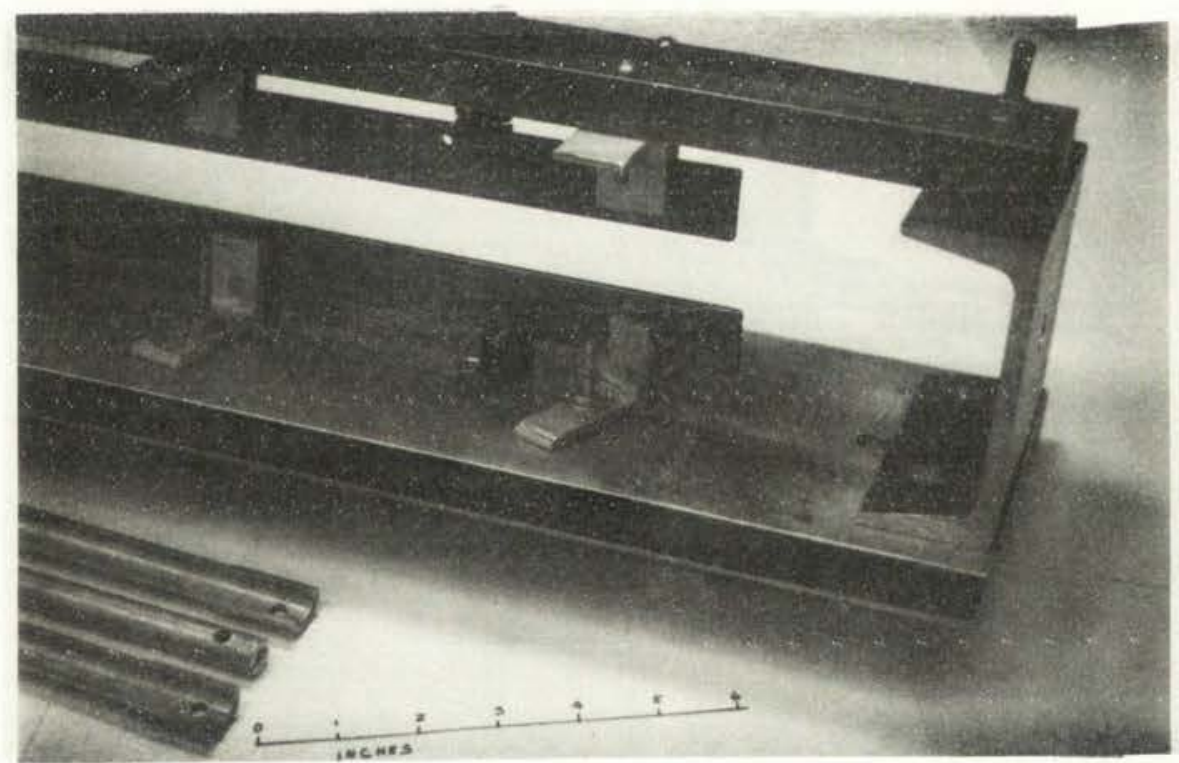

Figure 3.19. Apparatus Ready for Wrapping 



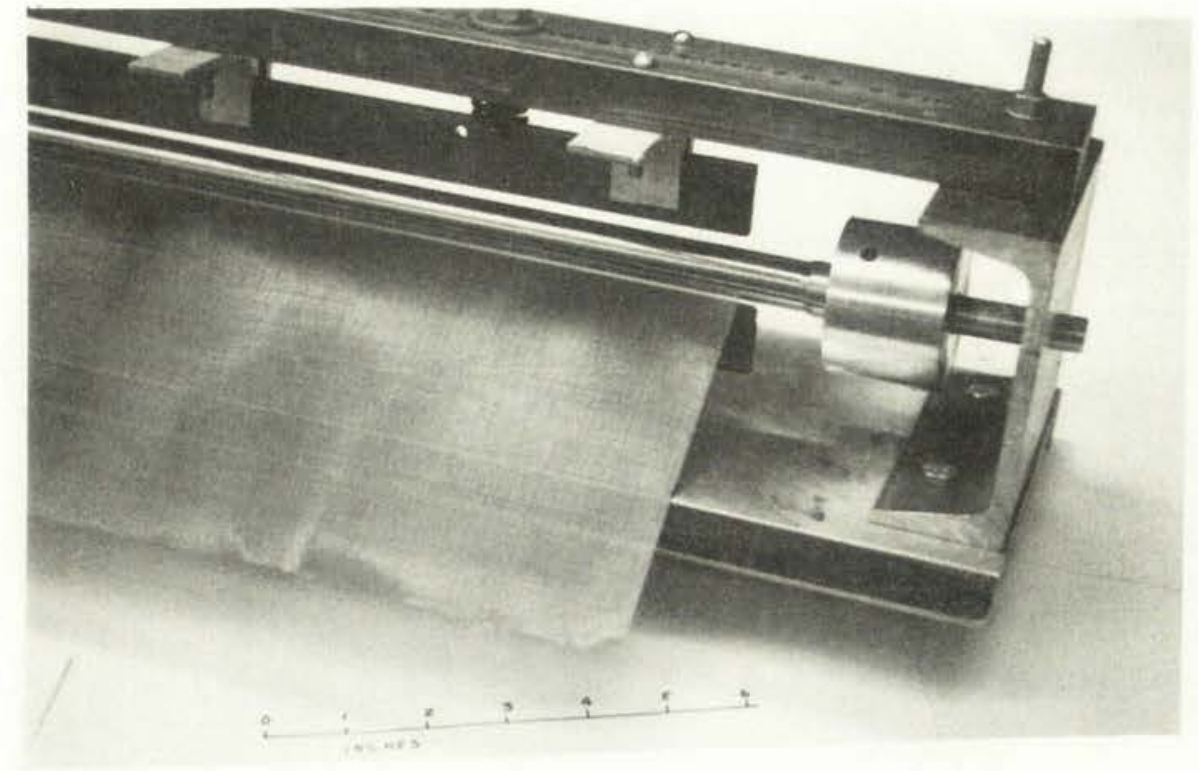

Figure 3.20. $\begin{aligned} & \text { Mandrel and Wire Mesh Are In- } \\ & \text { serted into the Apparatus }\end{aligned}$

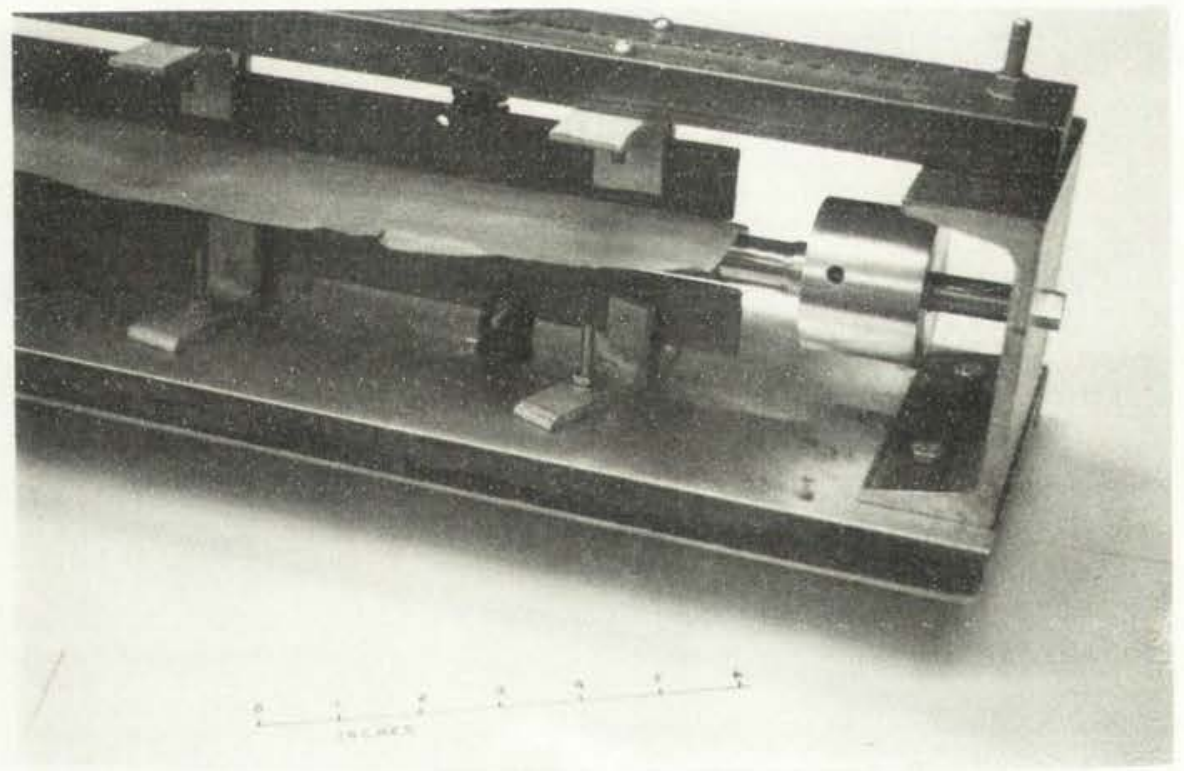

Figure 3.21. The Wrapping Is Initiated by Turning the collet and Lowering the Compression Jaws 


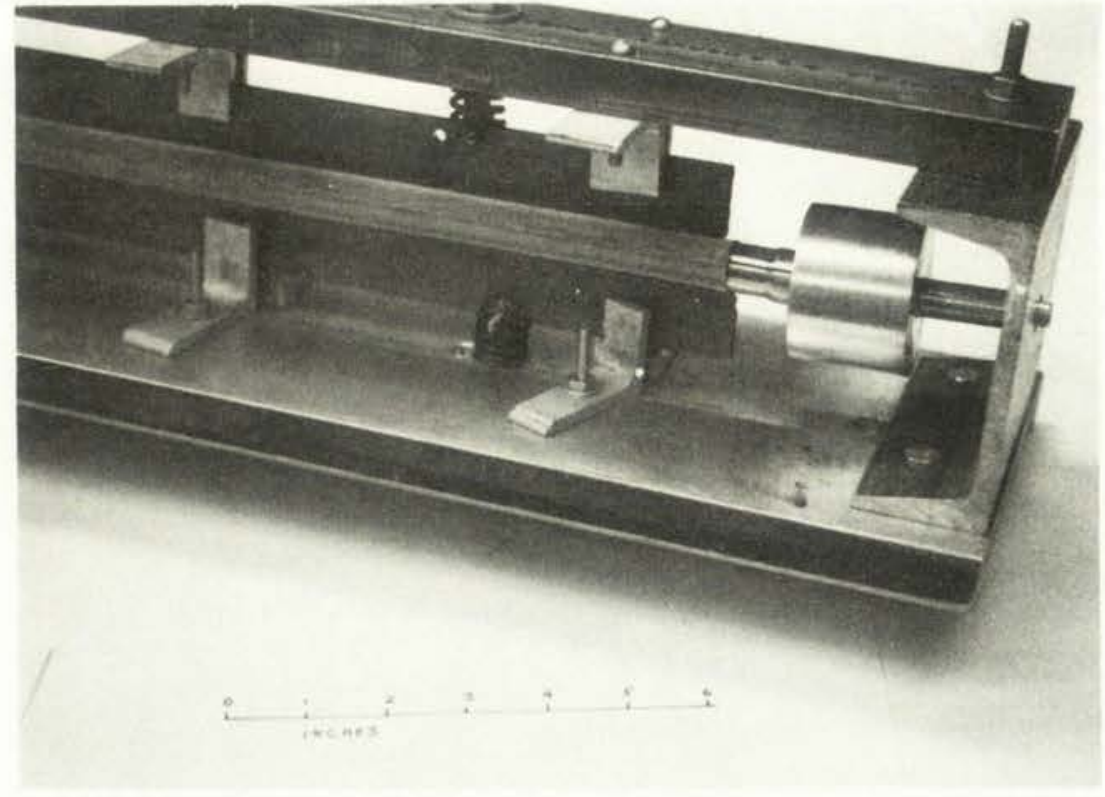

Figure 3.22 . Wick Seam Is spot Welded and Excess Material Removed

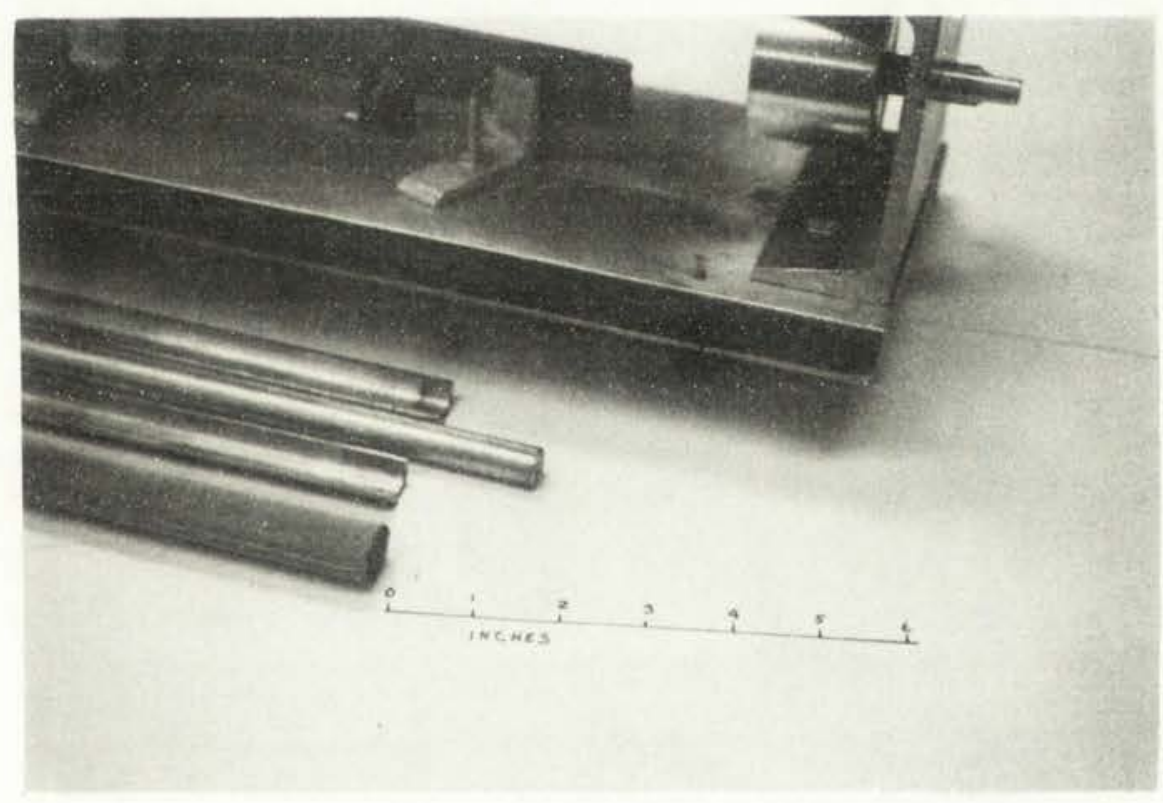

Figure 3.23. Mandrel Is Removed and Wick Is Extracted by Removing Center 



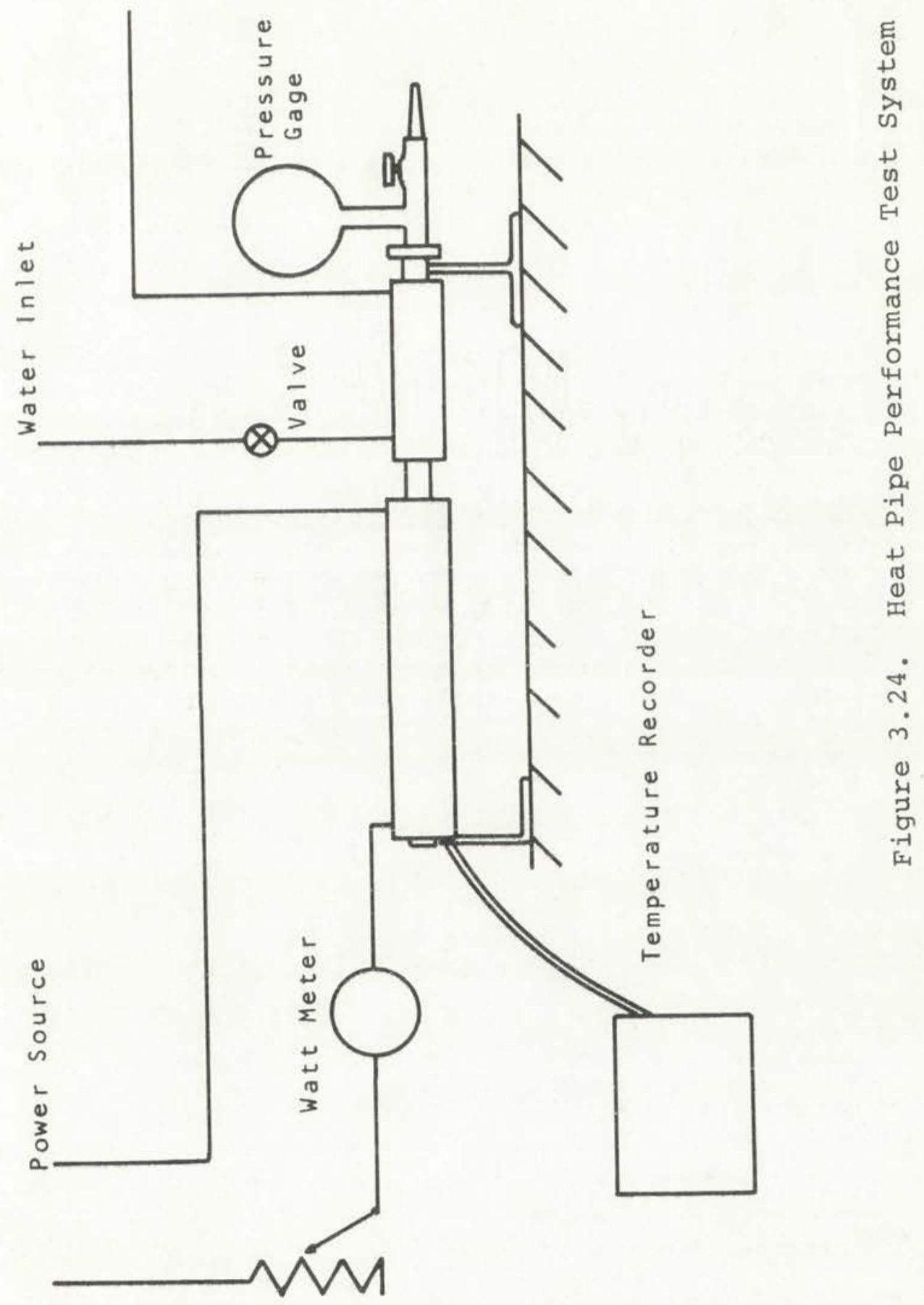




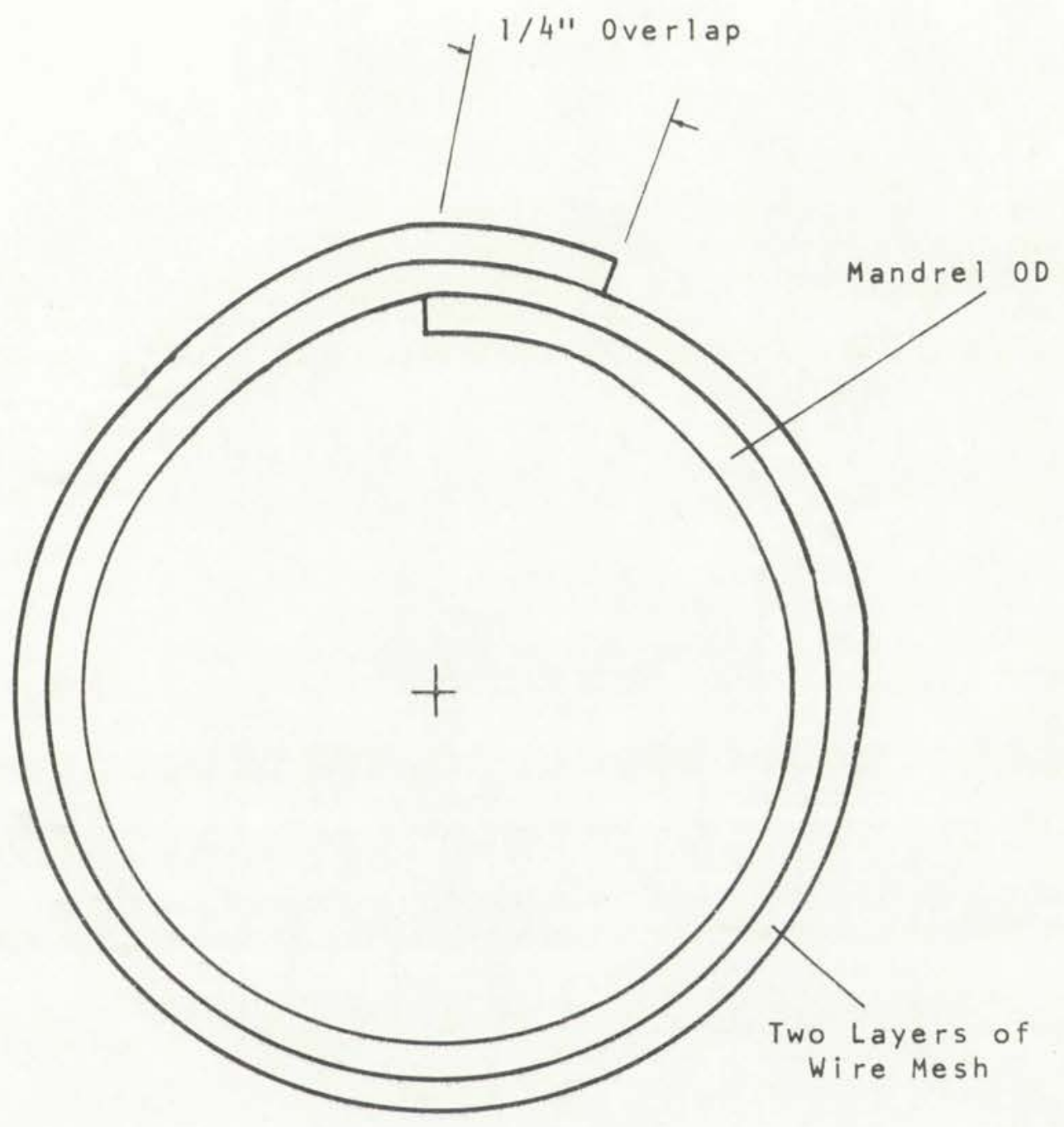

Figure 3.25. Wire Mesh Wick Cross Section of Typical Two Layer Wick 



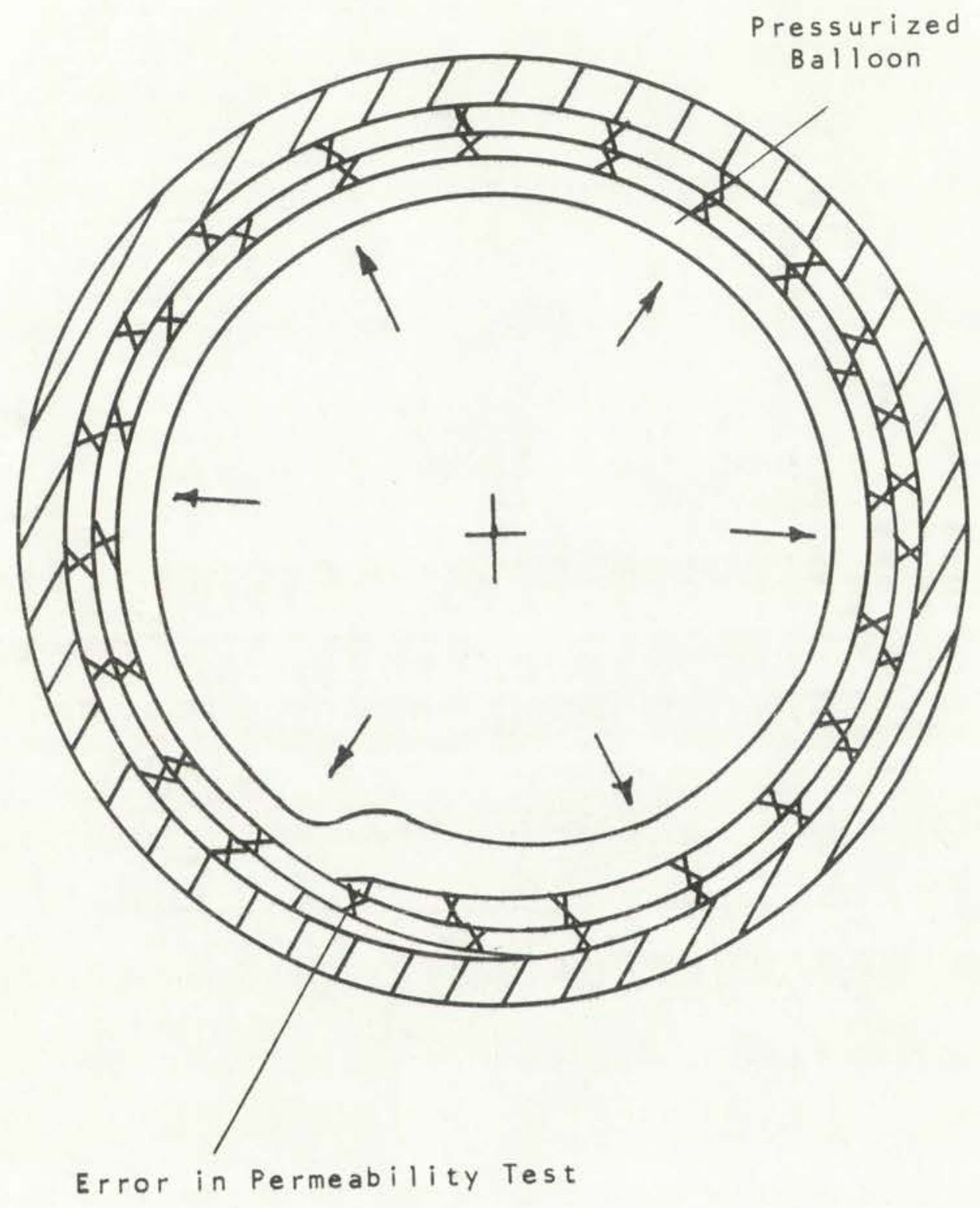

Figure 3.26. Illustration of the Permeability
Error in Using Flexible Balloon 


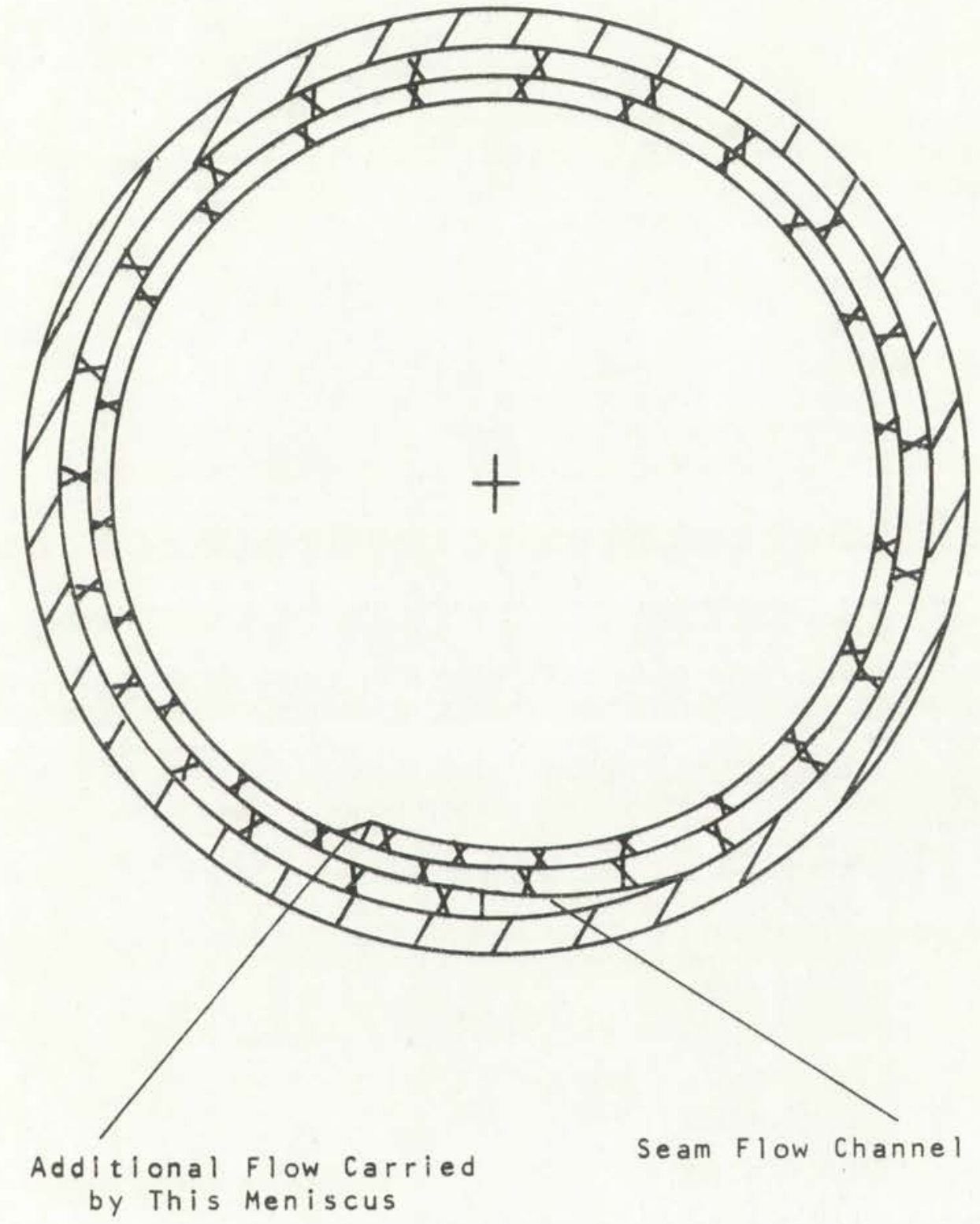

Figure 3.27. Additional Liquid Flow Paths in Wire Mesh Heat Pipes 



\section{CHAPTER 4}

\section{HEAT PIPE WICK PROPERTIES}

The properties of heat pipe wicking materials are extremely variable. Wick properties such as porosity, critical radius, wetting angles, and cross sectional area are not identical for the same type of wicks manufactured from the same materials under carefully controlled uniform conditions. In order to measure the extent of such variability a total of 50 square weave wire mesh wicks were tested in the following categories

\section{Type of Wick}

100 Mesh 304 Stainless Steel

(tight wrap)

100 Mesh 304 Stainless steel (moderately tight wrap)

200 Mesh 304 Stainless Steel

50 Mesh 304 Stainless Steel

\section{Mesh Copper}

Five properties were measured for each wick. These properties were permeability $(K)$, critical radius $\left(r_{e}\right)$, wick cross sectional area (A), porosity (e), and tortuosity (b).

In this chapter tabular values of the experimental data used to determine the heat pipe wick properties are presented. The reason for presentation of this data is to show the extreme variability of the readings and to show how one incorporates these readings into estimates of the random variates used in design. 



\subsection{Permeability}

Permeability measurements for each of the 50 wire mesh wicks tested are shown in Figures 4.1 through 4.5 . Each mean value and standard deviation was generated using Equations 2.55 and 2.56 using the number of replicated points which is designated as the sample size. The individual means and standard deviations result from experimental error in observing the data. The overall mean is the mean of all the individual means and the overall standard deviation is calculated using Equation 2.56 for all the data points in the data set. (Note: Each data set is data for a specific type of wick.) The overall mean and overall standard deviation are used as the parameters of the random variate pair to describe variability of the manufacturing process. According to Data set 1, the permeability variate, $\left(\bar{K}, S_{k}\right)$, for the 100 mesh stainless steel wicks, is $\left(5.243 \times 10^{-9}, 1.096 \times 10^{-9}\right)$. Now that the distribution parameter estimates are known, it is helpful to assume a probability distribution for the given random variable. Since these data are repeated readings, one generally chooses the normal distribution to model variability of the design variable. All of the data were tested for normality and did not reject the Kolomogorov-Smirnov Significance Test ${ }^{17}$ at the $99 \%$ significance level; thus, the data are considered normally distributed.

Factors contributing to the uncertainty in prediction of the permeability are: 

1. Variability of wire diameter in the mesh and between mesh lots

2. Weave manufacture variability

3. Wrapping manufacture variability

a) Weights of wire mesh wicks are not identical indicating more wire mesh on certain wicks.

b) Wrap compression is not completely consistent due to change alignment of the two screen layers.

c) Tightness of wick fit in the pipe may vary resulting in a variable seam channel flow path.

One may notice the significant difference between the permeability in data sets 1 and 2 shown in Tables 4.1 and 4.2 Although each of the wicks had identical mesh sizes, the wicks of data set 1 were wrapped to fit very tightly in the heat pipe. This tight fit compressed the screen structure which resulted in a low permeability. This demonstrates the sensitivity of the permeability measurement to compression of the wick layers against the pipe wall.

The uncertainty in the prediction of heat flow capability for a heat pipe with the above permeability characteristic is directly proportional to the variability of the permeability.

\subsection{Critical Radius}

Capillary critical radius readings are affected by

1. Wetting angle

2. Width of wire mesh openings

3. Compression of the two or multiple layers of wire mesh The data of Table 4.6 shows the uncertainty in the measurement of capillary pressure capability of one and two layers of wire 

mesh. Here capillary pressure capability is the pressure rise measurement using the apparatus of Figure 3.14.

The data of Table 4.6 are taken from data set 1 and 2 * since 100 mesh stainless steel screen was used in both sets. The equality of standard deviations between the two layer and one layer data indicates the consistency of the capillary pressure measuring device. All of the single layer capillary pressure measurements proved to be statistically different from the two layer measurements according to a hypothesis test. 17 It should be pointed out that the difference between the one and two layer capillary pressure capabilities may vary depending on the degree of compression and distortion of the two layers. If the two layers of wire mesh were compressed tightly together, a rather large difference in capillary pressure capability would be expected between the compressed two layer structure and the single layer of wire mesh due to the smaller capillary pores formed between the two layers. If the two layer structure was loose, very little difference would be expected. The wick structures mentioned in chapter 3 are compressed sufficiently to cause intermeshing of the multiple layers of wire mesh.

The difference in capillary pressure capability of one and two layers of the same wire mesh is an important factor in the recession theory analysis of these types of wicks. During the two layer capillary pressure tests, the liquid receded into the two layer structure and encountered higher capillary force resulting in the difference between one and *Reference Appendix A 

two layer readings. This will be discussed in detail in Chapter 5 .

Table 4.7 shows small samples of data from other tests and in every case the one and two layer capillary pressure capabilities proved to be different, statistically.

Tables $4.8,4.9,4.10,4.11$, and 4.12 show the critical radius values, $r_{f r}$, for all the data.

Uncertainty of the widths of wire mesh openings (due to the manufacturing) are considered the prime variabilities in the measurement of this property. Wetting angle was assumed constant throughout the structure since the wicks were cleaned uniformly.

\subsection{Wick Cross Sectional Area}

The wick cross sectional area distributions proved to be very consistent with low standard deviations. Tables 4.13, $4.14,4.15,4.16$, and 4.17 show cross sectional area data for all of the area tests. The low standard deviations indicate a consistent intermeshing of the multiple layers of wire mesh. Uncertainties in the measurement of this property arise from

a) Differences in wire mesh lots

b) Measurement variations for the wick inside diameter (one must avoid additional compression of the wick structure while making the measurement)

\subsection{Porosity and Tortuosity}

Porosity and tortuosity for all 50 wicks were calculated from measured values according to the following definitions 
porosity $\quad \mathrm{e}=\frac{\text { Void Vol }}{\text { Total VoI }}=1-\frac{\text { Weight of Wick }}{\rho_{\mathrm{W}}(\mathrm{A}) \text { (L) }}$

tortuosity $\quad b=\frac{\text { er }_{\text {fr }}^{2}}{K}$

The porosity distributions proved to be almost identical from wick to wick. Tables $4.18,4.19,4.20,4.21$, and 4.22 show the porosity and tortuosity data. The tortuosity data were almost independent of wire mesh size except for data set 1 which had a very low permeability. One might expect higher tortuosity for these wicks but looking at the variables for the calculation of $b$ we are able to see the opposite. The $r_{e}$ used in the calculation was the value of the two layer wick, $\left(r_{f r}\right)$, which was about $20 \%$ smaller than that for the single layer. The permeability for this wick design is higher than other designs because of the additional flow through the seam flow channel (see Figure 3.26). This tends to lower the tortuosity, b, somewhat as compared to other wire mesh structures since the permeability seems to have dominated the tortuosity calculation. The standard deviations for $e$ and $b$ were calculated from the input variabilities into the equations using the algebra of moments method. ${ }^{7}$ The uncertainty in the calculation of $b$ was rather high as a result of the high uncertainties of the input properties $e, r_{e}$, and $k$.

\subsection{Summary of Wick Property Data}

Table 4.23 summarizes the uncertainties in predicting properties of wire mesh wicks of this particular design. Many of the properties may vary considerably depending on 

the type of manufacture methods used. Since all of the data distributions are considered normal, one can quote the mean property value plus or minus three standard deviations and be assured that $99.7 \%$ of the property values will lie within these bounds. ${ }^{7}$ (For small sample sizes, tolerances should be placed on this probability.) Figures $4.1-4.5$ show discrete probability plots of the various design variables which were assumed normally distributed. 

TABLE 4.1

\section{PERMEABILITY DISTRIBUTION FROM \\ DATA SET 1

$$
\begin{aligned}
& \text { (100 mesh, stainless } \\
& \text { steel, } 3042 \text { layer) }
\end{aligned}
$$

Mean $K\left(f t^{2}\right)$

$3.584 \times 10^{-9}$

5. $244 \times 10^{-9}$

$5.246 \times 10^{-9}$

$5.407 \times 10^{-9}$

$6.654 \times 10^{-9}$
Standard Deviation $\mathrm{K}\left(\mathrm{ft} \mathrm{t}^{2}\right)$

$1.926 \times 10^{-10}$

$2.685 \times 10^{-10}$

$2.874 \times 10^{-10}$

$1.495 \times 10^{-10}$

$42.158 \times 10^{-10}$
Sample Size 30

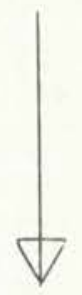

\section{Overall Mean $5.243 \times 10^{-9}$}

Overall Standard Deviation $1.096 \times 10^{-9}$

*Note: These standard deviations are a result of experimental error in the determination of each individual $\mathrm{K}$ reading. The sample sizes are the number of replications per $\mathrm{K}$ reading.

TABLE 4.2

PERMEABILITY DISTRIBUTION FROM

DATA SET 2

(100 mesh stainless steel, 3042 layer wrap mandral .001" smaller diameter than Data set 1)

Mean $K\left(f t^{2}\right)$

$5.951 \times 10^{-9}$

$6.080 \times 10^{-9}$

$6.081 \times 10^{-9}$

$6.204 \times 10^{-9}$ $\underline{\text { Standard Deviation } \mathrm{K}\left(\mathrm{ft} \mathrm{t}^{2}\right)}$

$4.467 \times 10^{-10}$

$3.364 \times 10^{-10}$

$2.297 \times 10^{-10}$

$2.575 \times 10^{-10}$
Sample Size

10

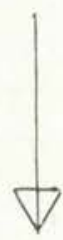



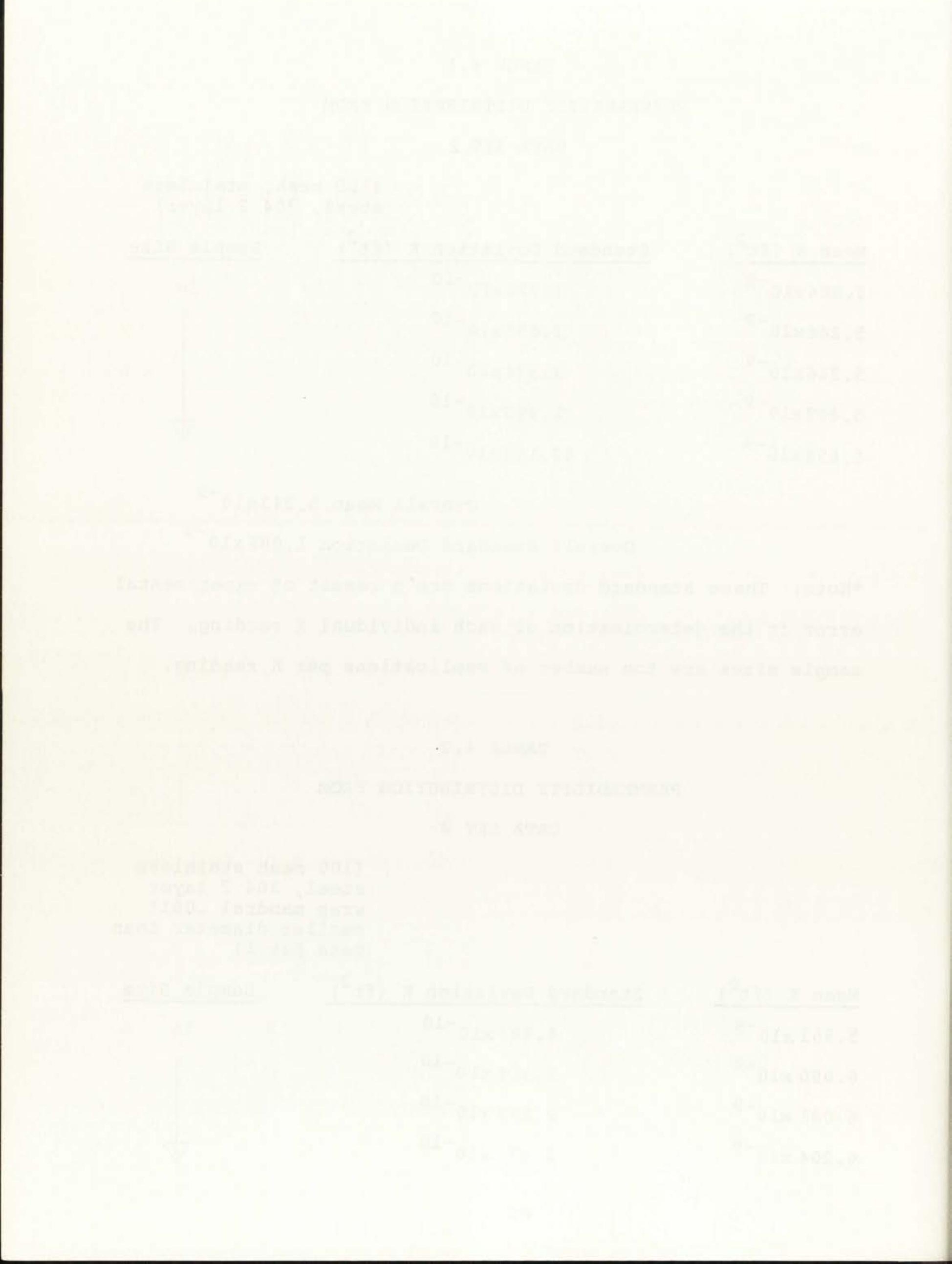
TABLE 4.2 continued
$6.234 \times 10^{-9}$
$2.833 \times 10^{-10}$
$6.250 \times 10^{-9}$
$4.356 \times 10^{-10}$
$6.326 \times 10^{-9}$
$2.176 \times 10^{-10}$
$6.412 \times 10^{-9}$
$1.968 \times 10^{-10}$
$6.427 \times 10^{-9}$
$3.795 \times 10^{-10}$
$6.566 \times 10^{-9}$
$3.085 \times 10^{-10}$
$6.698 \times 10^{-9}$
$3.641 \times 10^{-10}$
$6.850 \times 10^{-9}$
3. $748 \times 10^{-10}$
$6.909 \times 10^{-9}$
4. $862 \times 10^{-10}$
$6.953 \times 10^{-9}$
3. $122 \times 10^{-10}$
$7.184 \times 10^{-9}$
3. $601 \times 10^{-10}$
$7.191 \times 10^{-9}$
3. $192 \times 10^{-10}$
7. $323 \times 10^{-9}$
$2.834 \times 10^{-10}$
7. $463 \times 10^{-9}$
1. $381 \times 10^{-10}$
$7.474 \times 10^{-9}$
$5.334 \times 10^{-10}$
$7.479 \times 10^{-9}$
$2.634 \times 10^{-10}$
$7.482 \times 10^{-9}$
4. $464 \times 10^{-10}$
$7.775 \times 10^{-9}$
3. $342 \times 10^{-10}$
$8.116 \times 10^{-9}$
$4.518 \times 10^{-10}$
$8.154 \times 10^{-9}$
$2.877 \times 10^{-10}$
$8.214 \times 10^{-9}$
$4.302 \times 10^{-10}$
$8.246 \times 10^{-9}$
$2.674 \times 10^{-10}$
$8.337 \times 10^{-9}$
$3.730 \times 10^{-10}$
$8.338 \times 10^{-9}$
$2.142 \times 10^{-10}$
$8.379 \times 10^{-9}$
$5.015 \times 10^{-10}$
$8.701 \times 10^{-9}$
$3.439 \times 10^{-10}$

Overall Mean $7.193 \times 10^{-9}$ sq. ft. overall standard Deviation $0.841 \times 10^{-9} \mathrm{sq}$. ft. 
TABLE 4.3

PERMEABILITY DISTRIBUTION FROM

DATA SET 3

(200 mesh stainless steel, 3163 layer)
$\frac{\text { Mean } K\left(f t^{2}\right)}{2.584 \times 10^{-9}}$
$\underline{\text { Standard Deviation } K\left(f t^{2}\right)}$
1. $483 \times 10^{-10}$
$\underline{\text { Sample Size }}$
$2.798 \times 10^{-9}$
$9.819 \times 10^{-10}$
$3.074 \times 10^{-9}$
$2.845 \times 10^{-10}$
$3.171 \times 10^{-9}$
$2.149 \times 10^{-10}$
$3.796 \times 10^{-9}$
$6.949 \times 10^{-10}$

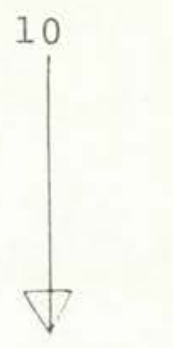

Overall Mean $3.084 \times 10^{-9} \mathrm{sq}$. ft.

Overall Standard Deviation $0.460 \times 10^{-9} \mathrm{sq}$. ft.

TABLE 4.4

PERMEABILITY DISTRIBUTION FROM

DATA SET 4

( 50 mesh stainiess

steel, 3042 layer)

$\begin{array}{lc}\text { Mean } K\left(\mathrm{ft}^{2}\right) & \text { Standard Deviation } K(\mathrm{ft}) \\ 2.739 \times 10^{-8} & 1.339 \times 10^{-9} \\ 2.822 \times 10^{-8} & 8.494 \times 10^{-9} \\ 3.209 \times 10^{-8} & 1.625 \times 10^{-9} \\ 3.230 \times 10^{-8} & 9.071 \times 10^{-9} \\ 3.290 \times 10^{-8} & 1.625 \times 10^{-9}\end{array}$

Sample Size

Overall Mean $3.056 \times 10^{-8} \mathrm{sq}$. ft.

Overall standard Deviation $0.260 \times 10^{-8} \mathrm{sq}$. ft. 

TABLE 4.5

PERMEABILITY DISTRIBUTION FROM

DATA SET 5

(100 mesh Cu 2 layer)

Mean $K\left(f t^{2}\right)$

$6.031 \times 10^{-9}$

$\underline{\text { Standard Deviation } K\left(f t^{2}\right)}$

Sample Size

$6.400 \times 10^{-9}$

$4.131 \times 10^{-10}$

$3.475 \times 10^{-10}$

$6.421 \times 10^{-9}$

$4.344 \times 10^{-10}$

$6.577 \times 10^{-9}$

$3.111 \times 10^{-10}$

$6.737 \times 10^{-9}$

$2.586 \times 10^{-10}$

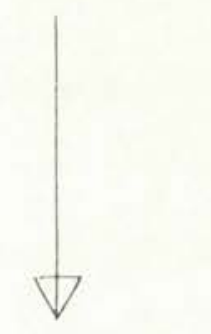

Overall Mean $6.433 \times 10^{-9} \mathrm{sq}$. ft.

Overall Standard Deviation $0.263 \times 10^{-9} \mathrm{sq}$. ft. 

TABLE 4.6

CAPILLARY PRESSURE CAPABILITY OF ONE LAYER AND TWO LAYERS OF WIRE MESH

(100 mesh stainless steel 304,35 readings taken from data set \#1 and \#2)

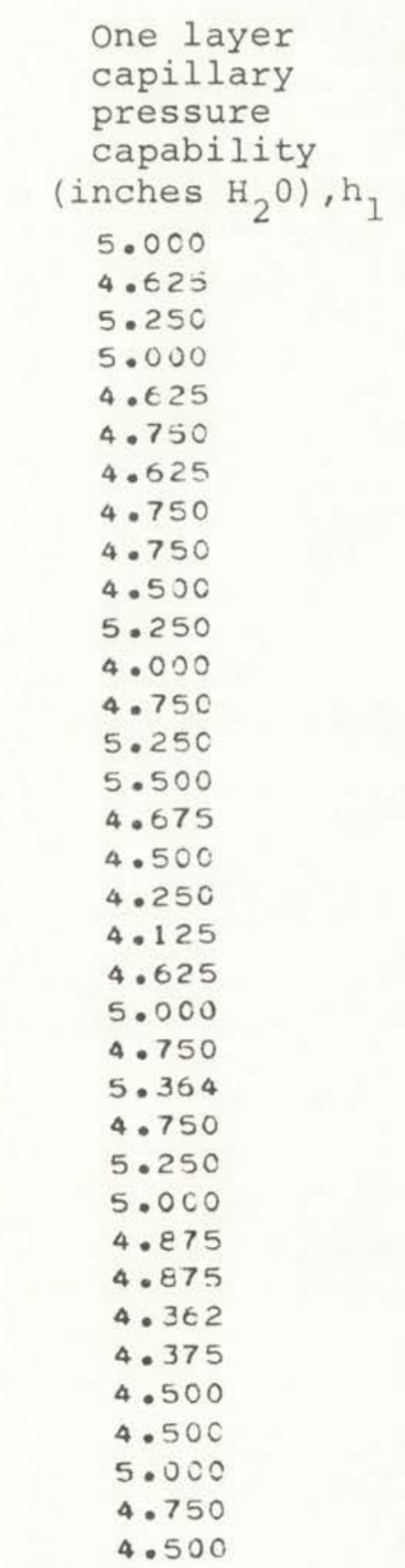

Mean 4.761

Stan- 0.349

dard

deviation

(all distributions Normal)

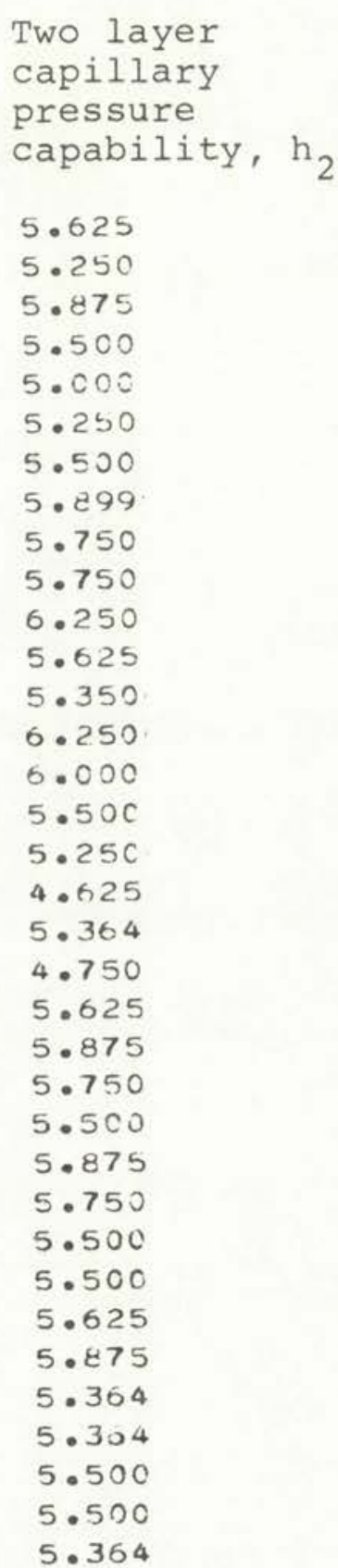

5.552

0.350
Difference data

$\mathrm{h}_{2}-\mathrm{h}_{1}$

0.625

0.625

0.625

0.500

0.375

0.500

0.875

1.149

1.000

1.250

1.000

1.625

0.600

1.000

0.500

0.824

0.750

0.375

1.239

0.125

0.625

1.125

0.385

0.750

0.625

0.750

0.025

0.625

1. 262

1.500

0.864

0.854

0.500

0.750

0.864

0.790

0.332 

TABLE 4.7

CAPILLARY PRESSURE CAPABILITY OF ONE LAYER AND TWO LAYERS OF WIRE MESH

(data taken from data sets $3,4,5$ )

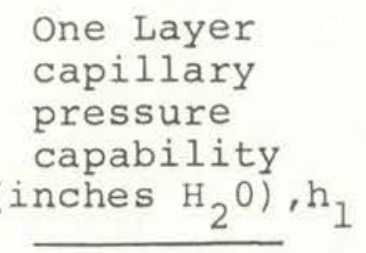
(Data set 3 , 200 mesh
stainless
steel,
3 layer)
8.000
7.000

7.500

9.250

7.350

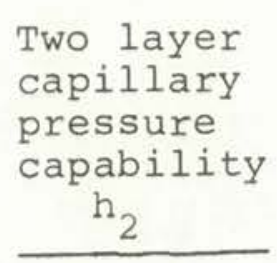

Two layer

capillary

pressure

2

(note: for

data set 3 ,

this is 3

layer capability)
Difference data

$\mathrm{h}_{2}-\mathrm{h}_{1}$
1.750

2.500

1.500

1.000

1. 400

7.819 (Overall Mean) 9.450

1.630

$0.876 \begin{gathered}\text { (Overall Stan- } \\ \text { dard Deviation) } 0.597\end{gathered}$

0.556

(Data set 4 ,

50 mesh

stainless

steel,

2 layer)

2. 364

2.875

0.510

2. 364

2. 750

0.385

2. 000

2.625

0.625

1. 875

2. 625

0.750 
TABLE 4.7 (continued)
2. 250
2. 625
0.375

2.171 (Overall Mean) 2.700

0.529

0.223 (Overall Stan- 0.112

0.160

(Data set 5 ,

100 mesh

$\mathrm{Cu}, 2$ layer)
5. 250
5.875
0.625
5. 250
5.875
0.625
5.164
5.750
0.585
5. 250
5.875
0.625
5. 250
5.875
0.625

5.233 (Overall Mean) 5.850

0.617

$0.038 \begin{aligned} & \text { (Overall Stan- } 0.056 \\ & \text { dard Devia- }\end{aligned}$

0.018 tion) 
TABLE 4.8

CRITICAL RADIUS DISTRIBUTION

FROM DATA SET 1

(100 mesh stainless steel, two layer)

Mean $r_{f r}$ inches) Standard Deviation $r_{f r}$ (inches) Sample Size

$4.055 \times 10^{-3}$

$1.000 \times 10^{-4}$

$4.247 \times 10^{-3}$

$4.337 \times 10^{-3}$

$4.809 \times 10^{-3}$

$4.906 \times 10^{-3}$

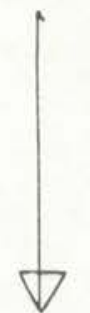

Overall Mean $4.470 \times 10^{-3}$ inches

Overall standard Deviation $0.369 \times 10^{-3}$ inches

TABLE 4.9

CRITICAL RADIUS DISTRIBUTION

FROM DATA SET 2

(100 mesh stainless steel, two layer)

Mean $r_{f r}($ inches $)$

Standard Deviation $r_{f r}$ (inches)

Sample Size

$3.639 \times 10^{-3}$

$1.000 \times 10^{-4}$

5

3. $645 \times 10^{-3}$

3. $786 \times 10^{-3}$

3. $858 \times 10^{-3}$

$3.870 \times 10^{-3}$

$3.877 \times 10^{-3}$

$3.878 \times 10^{-3}$

$3.887 \times 10^{-3}$
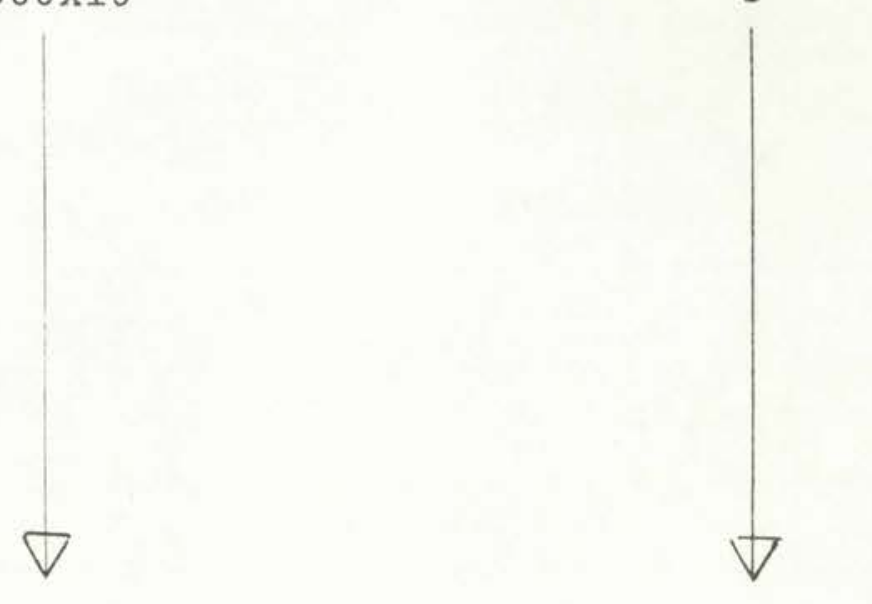


\section{TABLE 4.9 (continued)}

$3.958 \times 10^{-3}$

$3.961 \times 10^{-3}$

$3.969 \times 10^{-3}$

$3.969 \times 10^{-3}$

$5.051 \times 10^{-3}$

$5.051 \times 10^{-3}$

$5.053 \times 10^{-3}$

$4.139 \times 10^{-3}$

$5.140 \times 10^{-3}$

$4.140 \times 10^{-3}$

$4.140 \times 10^{-3}$

$4.140 \times 10^{-3}$

$4.140 \times 10^{-3}$

$4.141 \times 10^{-3}$

$4.143 \times 10^{-3}$

$4.245 \times 10^{-3}$

$4.257 \times 10^{-3}$

$4.257 \times 10^{-3}$

$4.265 \times 10^{-3}$

$4.337 \times 10^{-3}$

$4.337 \times 10^{-3}$

$4.539 \times 10^{-3}$

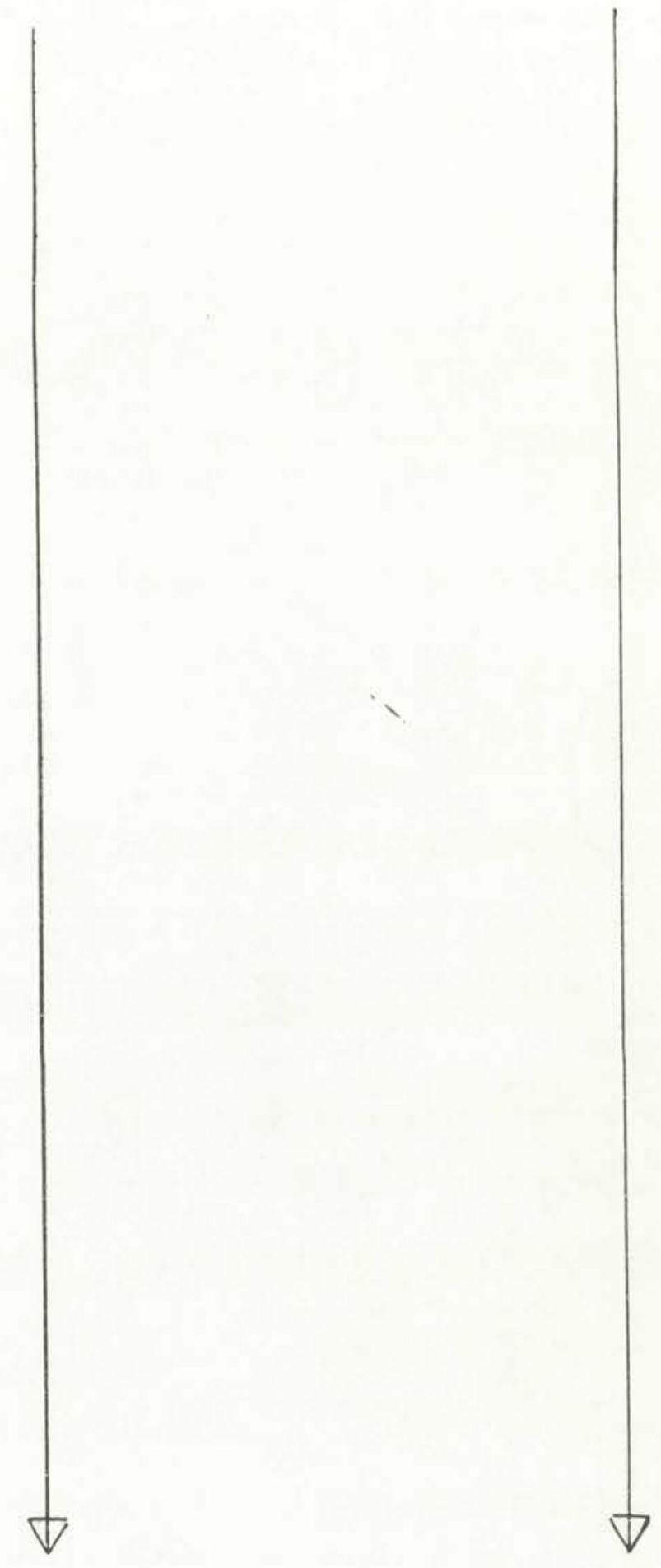

Overall Mean $4.069 \times 10^{-3}$ inches

Overall standard Deviation $0.214 \times 10^{-3}$ inches Note: All $r_{f r}$ readings are those of the multiple layers of screen. 
TABLE 4.10

CRITICAL RADIUS DISTRIBUTION

FROM DATA SET 3

(200 mesh stainless

steel, 3 layer)

Mean $r_{f r}$ (inches)

$2.162 \times 10^{-3}$

$\frac{\text { Standard Deviation } r_{f r} \text { (inches) }}{1.000 \times 10^{-4}}$

Sample Size

$2.336 \times 10^{-3}$

2. $396 \times 10^{-3}$

$3.575 \times 10^{-3}$

$2.603 \times 10^{-3}$

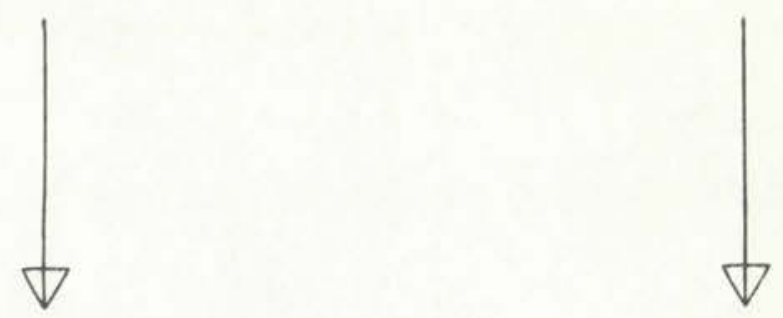

Overall Mean $2.414 \times 10^{-3}$ inches

Overall Standard Deviation $0.181 \times 10^{-4}$ inches

TABLE 4.11

CRITICAL RADIUS DISTRIBUTION

FROM DATA SET 4

(50 mesh stainless steel, two layer)

Mean $r_{f r}$ (inches)

$7.921 \times 10^{-3}$

Standard Deviation $r_{\mathrm{fr}}$ (inches)

$1.000 \times 10^{-4}$

Sample Size

$8.278 \times 10^{-3}$

$8.278 \times 10^{-3}$

$8.278 \times 10^{-3}$

$8,675 \times 10^{-3}$

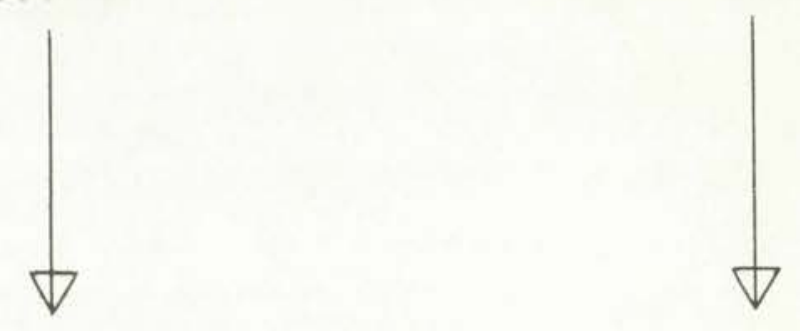

Overall Mean $8.444 \times 10^{-3}$ inches

Overall Standard Deviation $0.339 \times 10^{-3}$ inches 
TABLE 4.12

\section{CRITICAL RADIUS DISTRIBUTION}

FROM DATA SET 5

(100 mesh copper, two layer)

$$
\begin{aligned}
& \frac{\text { Mean } r_{\mathrm{fr}} \text { (inches) }}{3.888 \times 10^{-3}} \\
& 3.888 \times 10^{-3} \\
& 3.888 \times 10^{-3} \\
& 3.888 \times 10^{-3} \\
& 3.971 \times 10^{-3}
\end{aligned}
$$
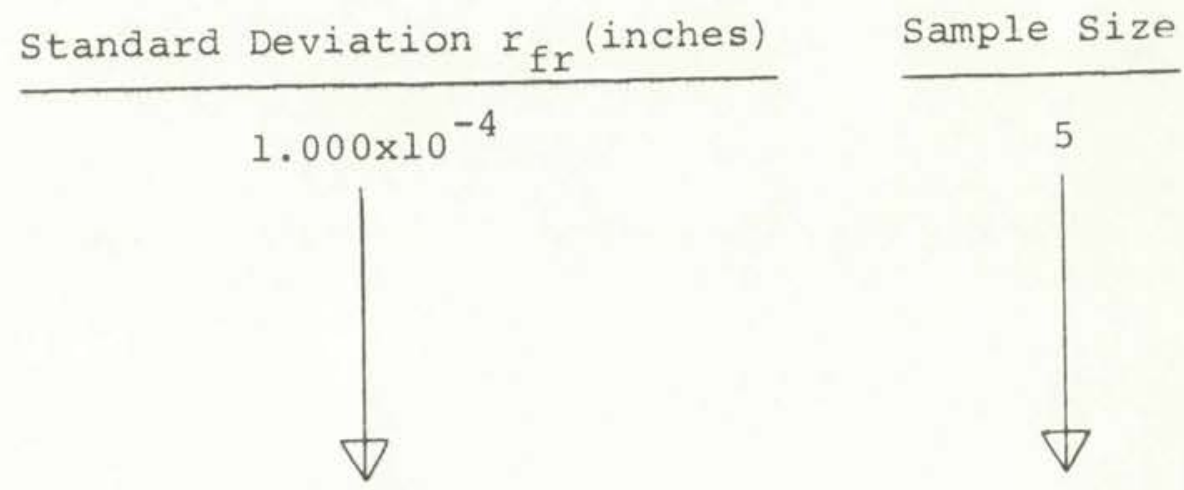

Overall Mean $3.904 \times 10^{-3}$

Overall Standard Deviation $1.000 \times 10^{-4}$ 

TABLE 4.13

WICK CROSS SECTIONAL AREA DISTRIBUTION

(Data from data set 1, 100 mess stainless steel, two layer)

\begin{tabular}{|c|c|c|}
\hline Mean $A(s q . f t)$. & Standard Deviation A & Sample Size \\
\hline $2.285 \times 10^{-4}$ & $5.040 \times 10^{-5}$ & 16 \\
\hline $2.354 \times 10^{-4}$ & $6.289 \times 10^{-5}$ & \\
\hline $2.375 \times 10^{-4}$ & $5.250 \times 10^{-5}$ & \\
\hline $2.445 \times 10^{-4}$ & $4.790 \times 10^{-5}$ & \\
\hline $2.503 \times 10^{-4}$ & $1.104 \times 10^{-5}$ & \\
\hline
\end{tabular}

Overall Mean $2.392 \times 10^{-4} \mathrm{sq}$. ft.

Overall Standard Deviation $0.848 \times 10^{-5} \mathrm{sq}$. ft.

TABLE 4.14

WICK CROSS SECTIONAL AREA DISTRIBUTION

(Data from data set 2, 100 mesh stainless steel, two layer)

Mean A(sq.ft.)

$2.236 \times 10^{-4}$

$2.261 \times 10^{-4}$

2. $270 \times 10^{-4}$

2. $294 \times 10^{-4}$

2. $324 \times 10^{-4}$

2. $334 \times 10^{-4}$

$2.336 \times 10^{-4}$

$2.337 \times 10^{-4}$

2. $353 \times 10^{-4}$

2. $359 \times 10^{-4}$
Standard Deviation A (sq.ft)

$6.790 \times 10^{-6}$

7. $510 \times 10^{-6}$

$4.900 \times 10^{-6}$

$2.294 \times 10^{-6}$

$5.370 \times 10^{-6}$

6. $270 \times 10^{-6}$

1. $124 \times 10^{-5}$

$6.280 \times 10^{-6}$

$7.900 \times 10^{-6}$

$7.890 \times 10^{-6}$
Sample Size

\section{6}

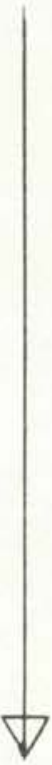



$2.363 \times 10^{-4}$
$7.780 \times 10^{-6}$
2. $373 \times 10^{-4}$
$6.270 \times 10^{-6}$
2. $382 \times 10^{-4}$
1. $236 \times 10^{-5}$
2. $387 \times 10^{-4}$
$1.001 \times 10^{-5}$
2. $387 \times 10^{-4}$
$6.00010^{-6}$
2. $392 \times 10^{-4}$
$9.78010^{-6}$
2. $392 \times 10^{-4}$
$6.880 \times 10^{-6}$
2. $401 \times 10^{-4}$
$8.750 \times 10^{-6}$
2. $402 \times 10^{-4}$
$9.200 \times 10^{-6}$
$2.416 \times 10^{-4}$
$1.022 \times 10^{-5}$
$2.416 \times 10^{-4}$
$1.134 \times 10^{-5}$
$2.421 \times 10^{-4}$
1. $300 \times 10^{-5}$
$2.426 \times 10^{-4}$
$8.500 \times 10^{-6}$
$2.426 \times 10^{-4}$
$1.169 \times 10^{-5}$
$2.441 \times 10^{-4}$
$1.117 \times 10^{-5}$
2. $469 \times 10^{-4}$
$1.674 \times 10^{-5}$
$2.475 \times 10^{-4}$
$1.479 \times 10^{-5}$
$2.555 \times 10^{-4}$
$1.190 \times 10^{-5}$
$2.558 \times 10^{-4}$
$1.189 \times 10^{-5}$
$2.584 \times 10^{-4}$
$6.540 \times 10^{-5}$

Overall Mean $2.393 \times 10^{-3} \mathrm{sq}$. ft. Overall Standard Deviation $0.816 \times 10^{-5} \mathrm{sq}$. ft. 

TABLE 4.15

WICK CROSS SECTIONAL AREA DISTRIBUTION

(Data from data set 3, 200 mesh, stainless steel, 3 layer)
Mean $A(s q$. ft. $)$
Standard Deviation A
$5.390 \times 10^{-6}$
Sample Size
$1.579 \times 10^{-4}$
$1.294 \times 10^{-5}$
$1.614 \times 10^{-4}$
$6.440 \times 10^{-6}$
$1.677 \times 10^{-4}$
$7.860 \times 10^{-6}$
$1.682 \times 10^{-4}$
$8.570 \times 10^{-6}$
16
$1.688 \times 10^{-4}$

Overall Mean $1.648 \times 10^{-4} \mathrm{sq}$. ft.

Overall Standard Deviation $0.487 \times 10^{-5} \mathrm{sq}$. ft.

TABLE 4.16

WICK CROSS SECTIONAL AREA DISTRIBUTION

(Data from data set 4,50 mesh stainless steel, 2 layer)

Mean S(sq. ft.)

$5.203 \times 10^{-5}$

$5.295 \times 10^{-5}$

$5.314 \times 10^{-5}$

$5.406 \times 10^{-5}$

$5.438 \times 10^{-5}$
Standard Deviation A

$2.091 \times 10^{-6}$

$1.100 \times 10^{-5}$

$1.890 \times 10^{-5}$

$1.860 \times 10^{-6}$

$1.001 \times 10^{-5}$
Sample Size 16

$\downarrow$

Overall Mean $5.331 \times 10^{-4} \mathrm{sq}$. ft.

Overall Standard Deviation $0.936 \times 10^{-5} \mathrm{sq}$. ft. 

TABLE 4.17

WICK CROSS SECTIONAL AREA DISTRIBUTION

(Data from data set 5, 100 mesh Cu 2 layer)

Mean A(sq. ft.)

$2.759 \times 10^{-4}$

$2.836 \times 10^{-4}$

$2.893 \times 10^{-4}$

$2.939 \times 10^{-4}$

$3.092 \times 10^{-4}$
Standard Deviation A

$1.719 \times 10^{-5}$

1. $474 \times 10^{-5}$

$1.037 \times 10^{-5}$

$1.053 \times 10^{-5}$

$9.650 \times 10^{-6}$
Sample Size

16

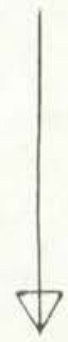

Overall Mean $2.903 \times 10^{-4} \mathrm{sq}$. ft.

Overall Standard Deviation $0.124 \times 10^{-4} \mathrm{sq}$. ft. 

TABLE 4.18

POROSITY AND TORTUOSITY DISTRIBUTIONS

(Data from data set 1, 100 mesh stainless steel, two layer)

Mean

Porosity

(dimensionless)

$$
\begin{aligned}
& 0.582 \\
& 0.577 \\
& 0.591 \\
& 0.614 \\
& 0.602
\end{aligned}
$$

Standard Deviation Porosity

$$
\begin{aligned}
& 0.0924 \\
& 0.113 \\
& 0.0898 \\
& 0.0180 \\
& 0.0782
\end{aligned}
$$

Mean

Tortuosity

Dimensionless)
Standard Devistion Tortuosity

Overall

Mean

$$
0.593
$$

16.098

Overall

Standard

Deviation

$$
0.0359
$$

3. 244

2.827

2.376

1. 403

2.016

TABLE 4.19

POROSITY AND TORTUOSITY DISTRIBUTIONS

(Data from data set 2, 100 mesh stainless steel, two layer)

$\begin{array}{llll}\begin{array}{l}\text { Mean } \\ \text { Porosity }\end{array} & \begin{array}{l}\text { Standard } \\ \text { Deviation } \\ \text { Porosity }\end{array} & \begin{array}{l}\text { Meari } \\ \text { Tortuosity }\end{array} & \begin{array}{l}\text { Standard } \\ \text { Deviation } \\ \text { Tortuosity }\end{array} \\ 0.596 & 0.0249 & 10.257 & 0.975 \\ 0.636 & 0.0107 & 8.472 & 0.557 \\ 0.611 & 0.0190 & 8.229 & 0.687 \\ 0.583 & 0.0210 & 8.794 & 0.740 \\ 0.619 & 0.0186 & 9.836 & 0.752 \\ 0.606 & 0.0273 & 8.927 & 0.888\end{array}$



TABLE 4.19 (continued)
0.607
0.0189
8.157
0.663
0.597
0.0166
10.688
0.772
0.594
0.0148
9.721
0.652
0.604
0.0151
8.757
0.661
0.578
0.0168
10.323
0.690
0.569
0.0132
9.984
0.610
0.582
0.0233
10.519
0.984
0.584
0.0186
9.106
0.742
0.585
0.0168
11.644
0.833
0.577
0.0137
9.136
0.645
0.574
0.0154
9.618
0.710
0.591
0.0206
9.300
0.707
0.580
0.0226
9.225
0.795
0.587
0.0203
10.312
0.866
0.573
0.0158
10.303
0.708
0.578
0.0130
7.924
0.525
0.568
0.0114
8.116
0.473
0.585
0.0184
10.375
0.863
0.584
0.0122
9.885
0.685
0.570
0.0157
1.704
0.551
0.552
0.0143
10.841
0.670
0.581
0.0127
8. 314
0.572
0.578
0.0116
9.219
0.511
0.589
0.0179
9.482
0.670

Overall

Mean

0.588

9.473

Overall

Standard

Deviation 0.0170

0.937 
TABLE 4.20

POROSITY AND TORTUOSITY DISTRIBUTIONS

(Data set 3, 200 mesh stainless steel, three layer)

Mean

Porosity

Standard

Deviation

Porosity

Mean

Tortuosity

0.0142

0.00588

0.00553

0.00844

0.00950
10.074

9.221

10.186

11.941

10.184
Standard

Deviation Tortuosity

$$
0.600
$$

0.463

0.562

0.361

0.287

Overall

Mean

0.634

10.321

Overall

0.00933

0.992

Standard

Deviation

TABLE 4.21

POROSITY AND TORTUOSITY DISTRIBUTIONS

(Data set 4,50 mesh stainless steel, two layer)

Mean P
Porosity

0.617

0.614

0.656

0.640

0.653
Standard Deviation Porosity

0.0312

0.0145

0.0183

0.0149

0.0171
Mean

Tortuosity

7.617

9.468

7.957

7. 428

9.696
Standard Deviation Tortuosity

1.035

0.985

1.598

2.701

1. 025

Overal1

Mean

0.636

8.433

Overall

0.0197

1.068

Standard

Deviation 
TABLE 4.22

POROSITY AND TORTUOSITY DISTRIBUTIONS

(Data set 5, 100 mesh, Cu 2 layer)

\begin{tabular}{|c|c|c|c|}
\hline $\begin{array}{l}\text { Mean } \\
\text { Porosity }\end{array}$ & $\begin{array}{l}\text { Standard } \\
\text { Deviation } \\
\text { Porosity }\end{array}$ & $\begin{array}{l}\text { Mean } \\
\text { Tortuosity }\end{array}$ & $\begin{array}{l}\text { Standard } \\
\text { Deviation } \\
\text { Tortuosity }\end{array}$ \\
\hline 0.648 & 0.0122 & 10.105 & 0.676 \\
\hline 0.600 & 0.0256 & 10.450 & 1.000 \\
\hline 0.634 & 0.0142 & 10.358 & 0.911 \\
\hline 0.626 & 0.0202 & 10.277 & 0.837 \\
\hline 0.623 & 0.0147 & 10.373 & 0.757 \\
\hline $\begin{array}{l}\text { Overal1 } \\
\text { Mean }\end{array}$ & 0.626 & & \\
\hline $\begin{array}{l}\text { Overall } \\
\text { Standard } \\
\text { Deviation }\end{array}$ & 0.0175 & & \\
\hline
\end{tabular}





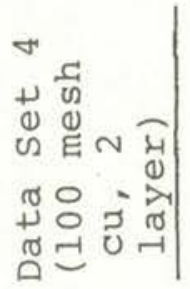

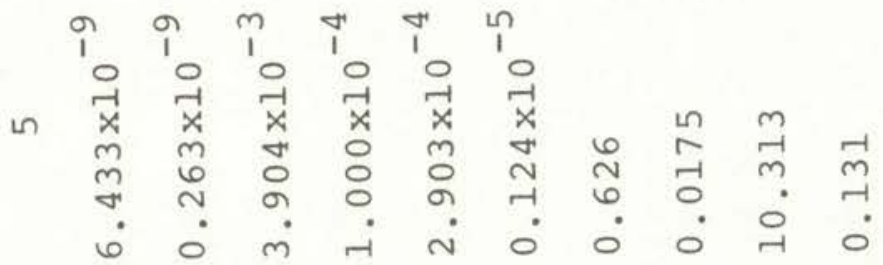



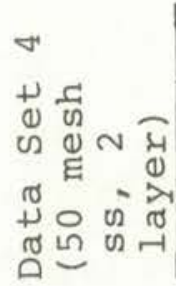

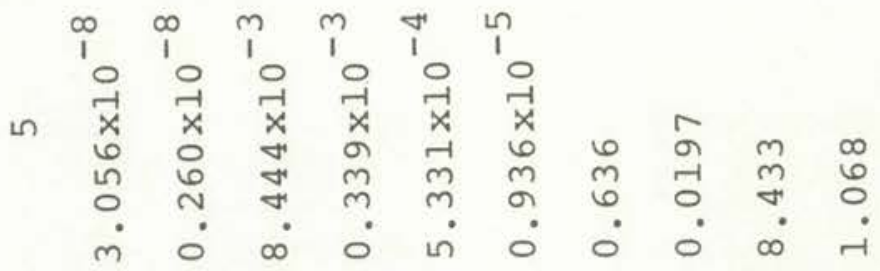

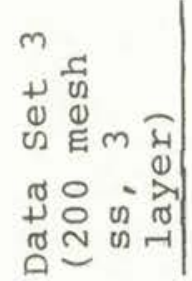

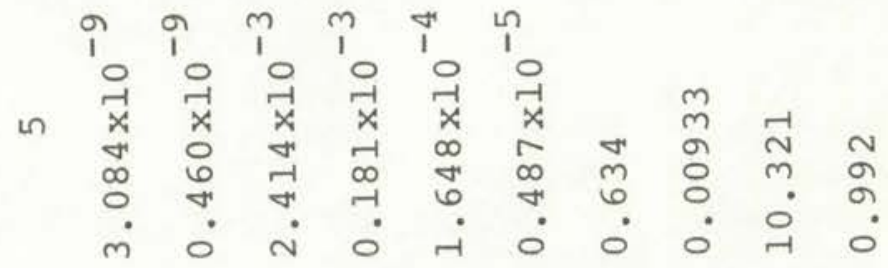

ह1

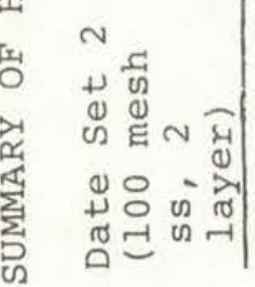

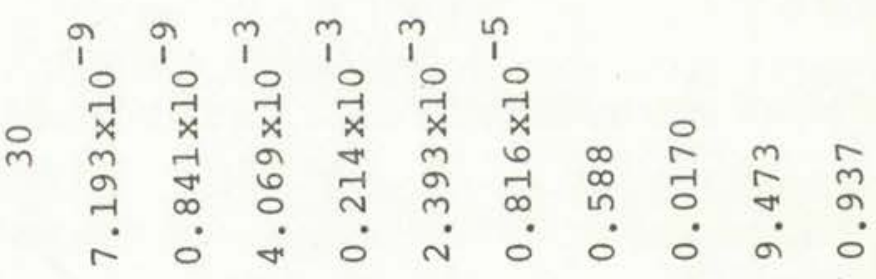

ก

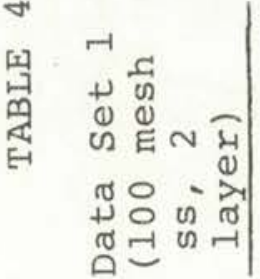

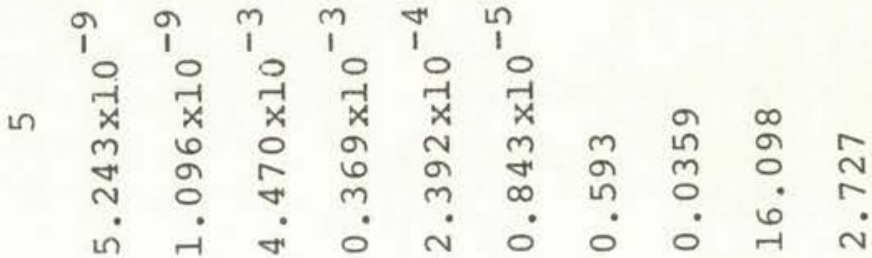

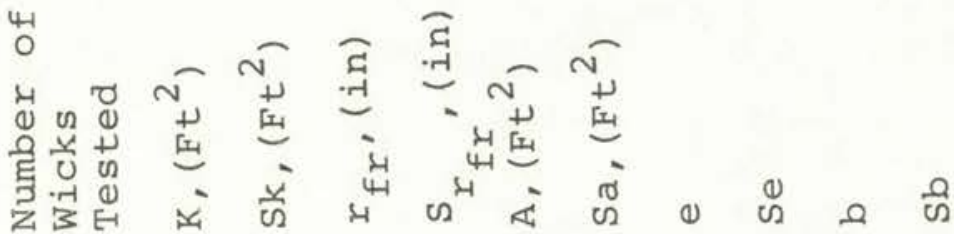





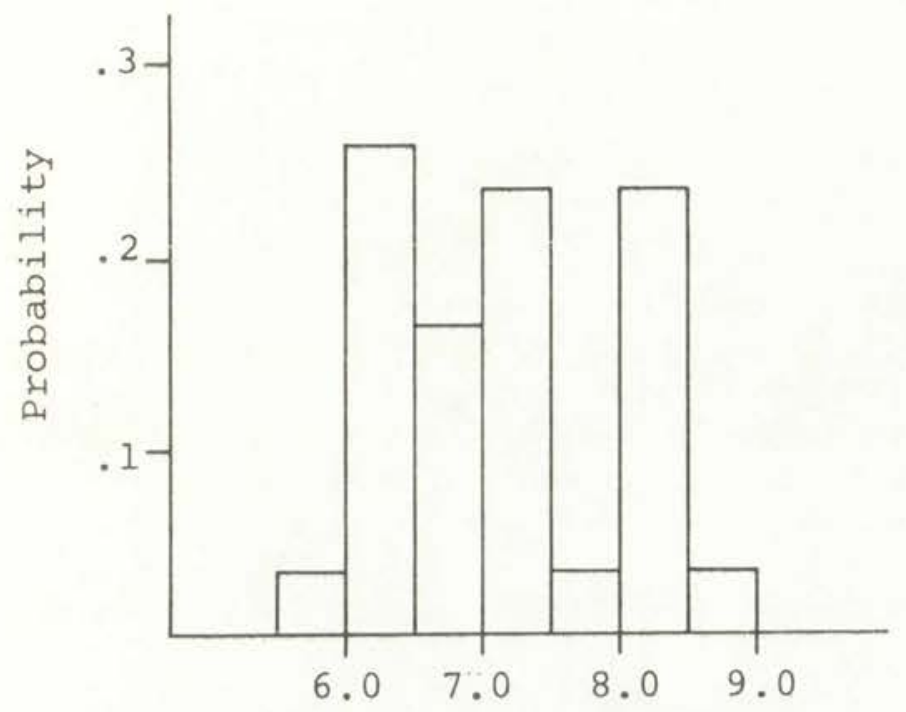

Permeability $\times 10^{9} \mathrm{sq}$. ft.

Figure 4.1. Permeability Distribution for Data set 2

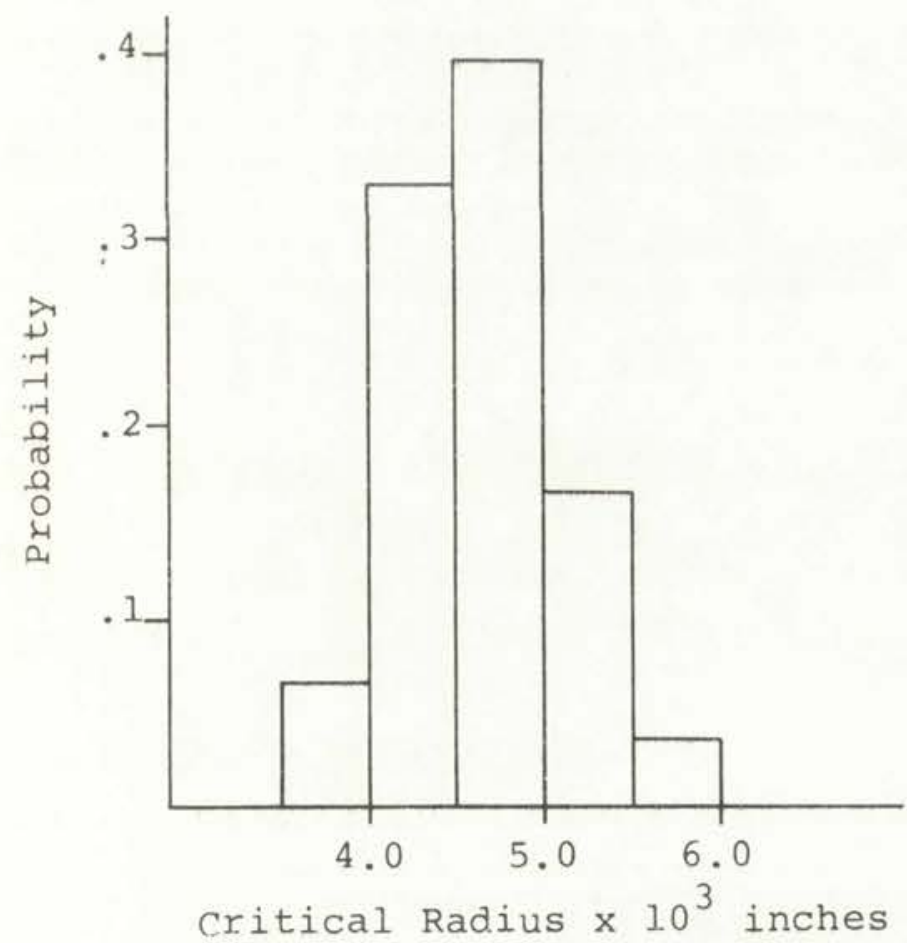

Figure 4.2. Critical Radius Distribution (two layer capability) for Data set 2 


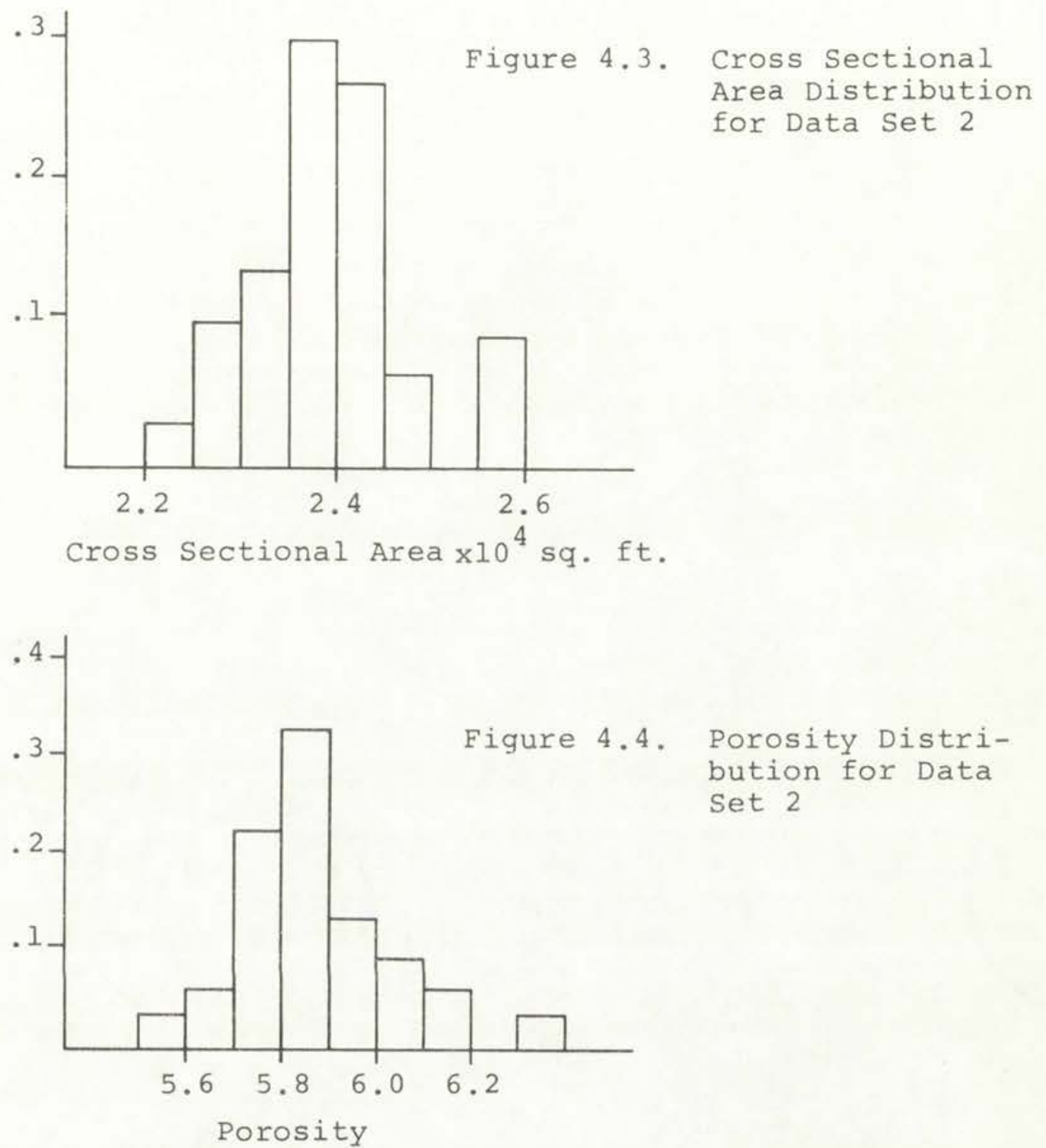

Porosity Distribution for Data set 2

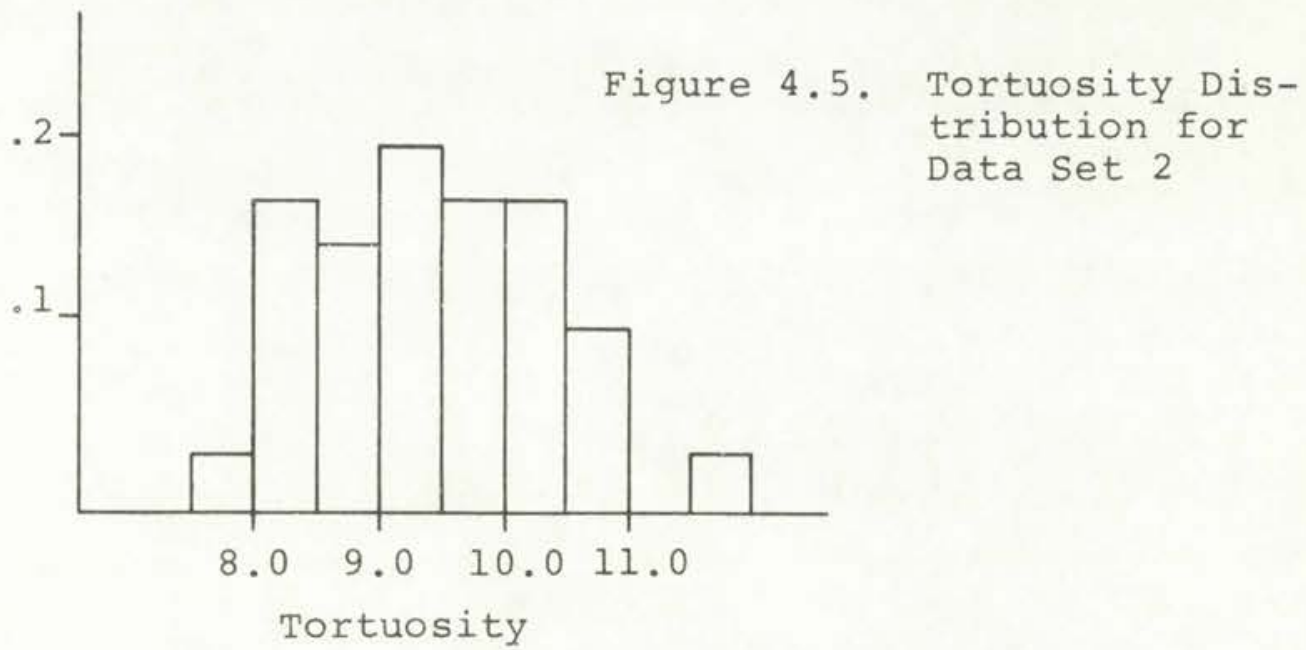



CHAPTER 5

RECESSION IN WIRE MESH WICKS

In Chapter 4 the basic determination of wire mesh wick properties was described. In this chapter the application of the recession theory of chapter 2 to the wire mesh wicks will be presented. The wire mesh wicks to be analyzed will be the two layer square weave type wicks that were used in the experimental measurements.

Many descriptions ${ }^{7}$ of wire mesh wick characteristics have modeled the surface tension phenomenon as shown in Figure 5.1. The screen layers are spaced one screen opening apart, and the radius is equal to one half the screen opening size. Liquid recession is shown in Figure $5.2(a)$. This desaturation process is unstable since the capillary forces have not increased due to the recession (Figures $5.2(\mathrm{a})$ and (b)). Using this physical model, the wick would dry out at relatively low heat transfer rate, yet experimentation shows this not to be the case. Many times fluid recession occurs down to the second layer and remains stable, and no dry out is observed at higher than expected heat transfer rates. Thus, a more accurate description of the wire mesh capillary structure is apparently required to help explain these observations.

Figure 5.3 shows a sketch of plain square weave wire cloth. Figure 5.4 shows a sketch of two layers of wire cloth compressed together as occurs in the construction of a heat pipe wick. Generally, when wicks are wrapped, the two layers do not align 


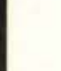


perfectly as suggested in Figure 5.1. Normally the wrapping results in the structure shown in Figure 5.5. The high points of the bottom layer of wire mesh tend to fit into openings of the top layer, resulting in a structure with a thickness less than the sums of the thicknesses of the individual layers.

Figures $5.6,5.7$, and 5.8 show a cross section view, $A-A$, of the compressed doube layer of wire mesh previously shown in Figure 5.4.

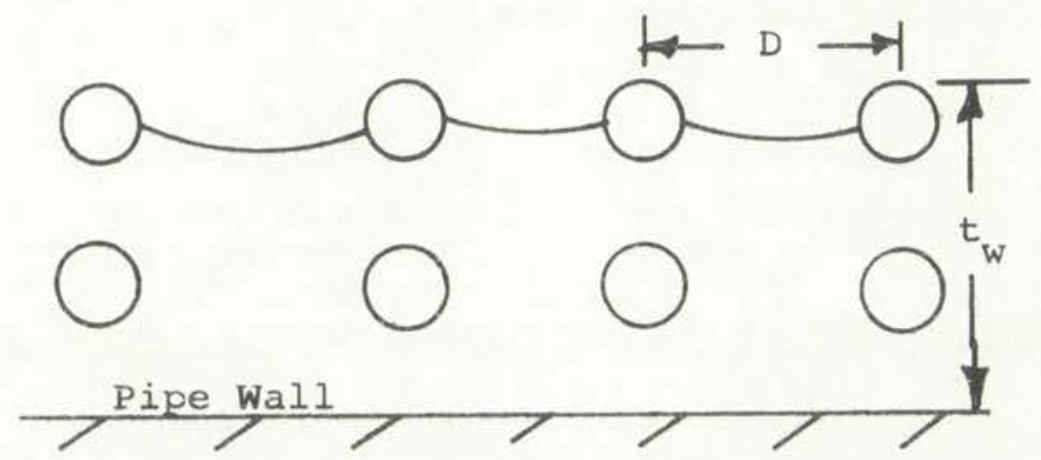

Figure 5.1. Classical Wire Mesh Capillary Model
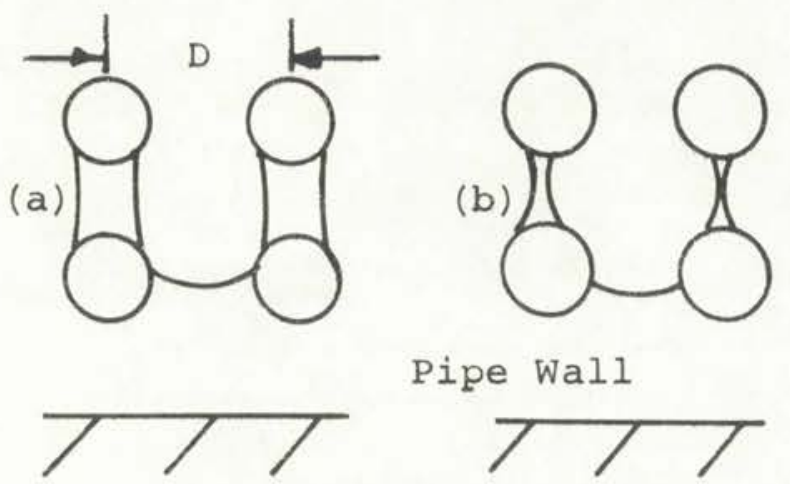

Pipe Wall

Figure 5.2. Recession and Dryout 



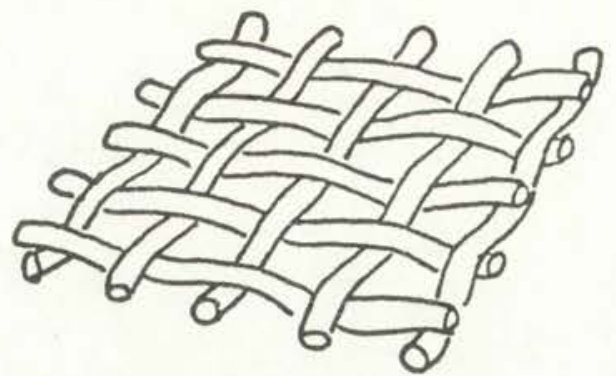

Figure 5.3. Single

Layer of Wire Mesh

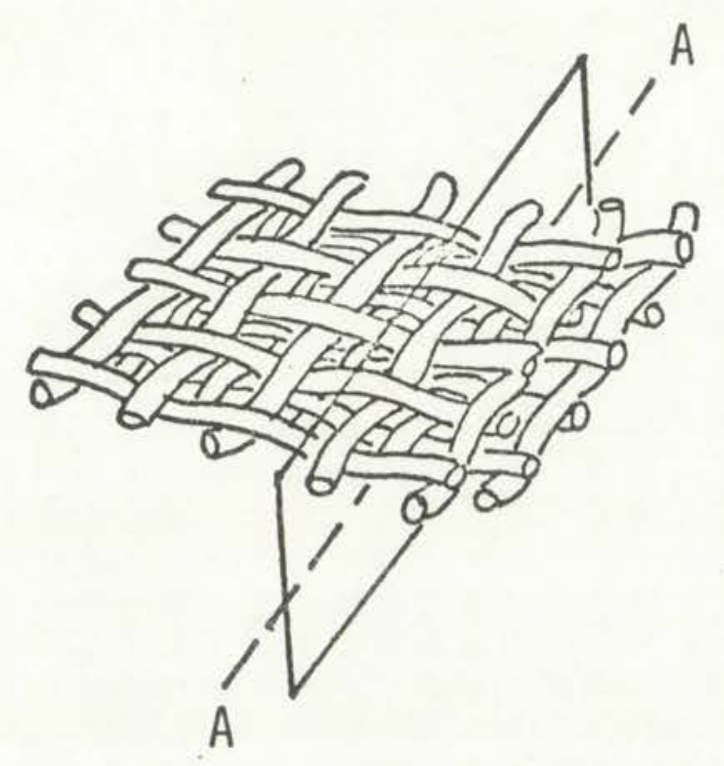

Figure 5.4. Compressed Double Layer of Wire Mesh
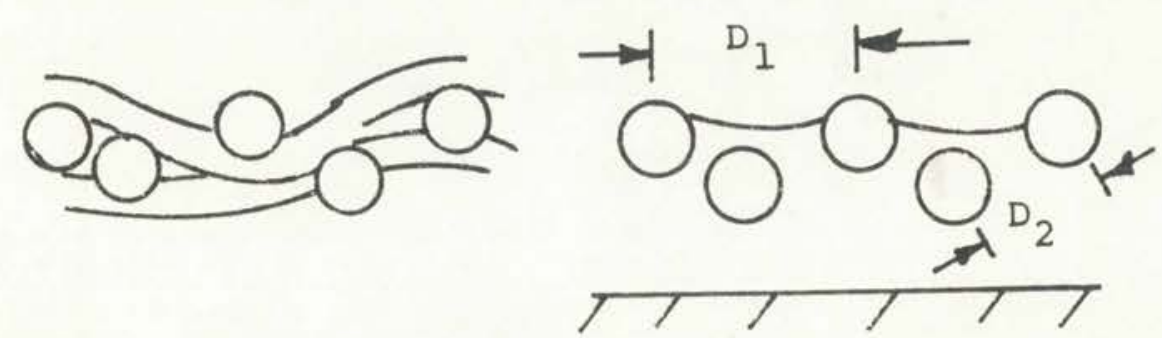

Figure 5.5. Proposed Wire Mesh Capillary Model 



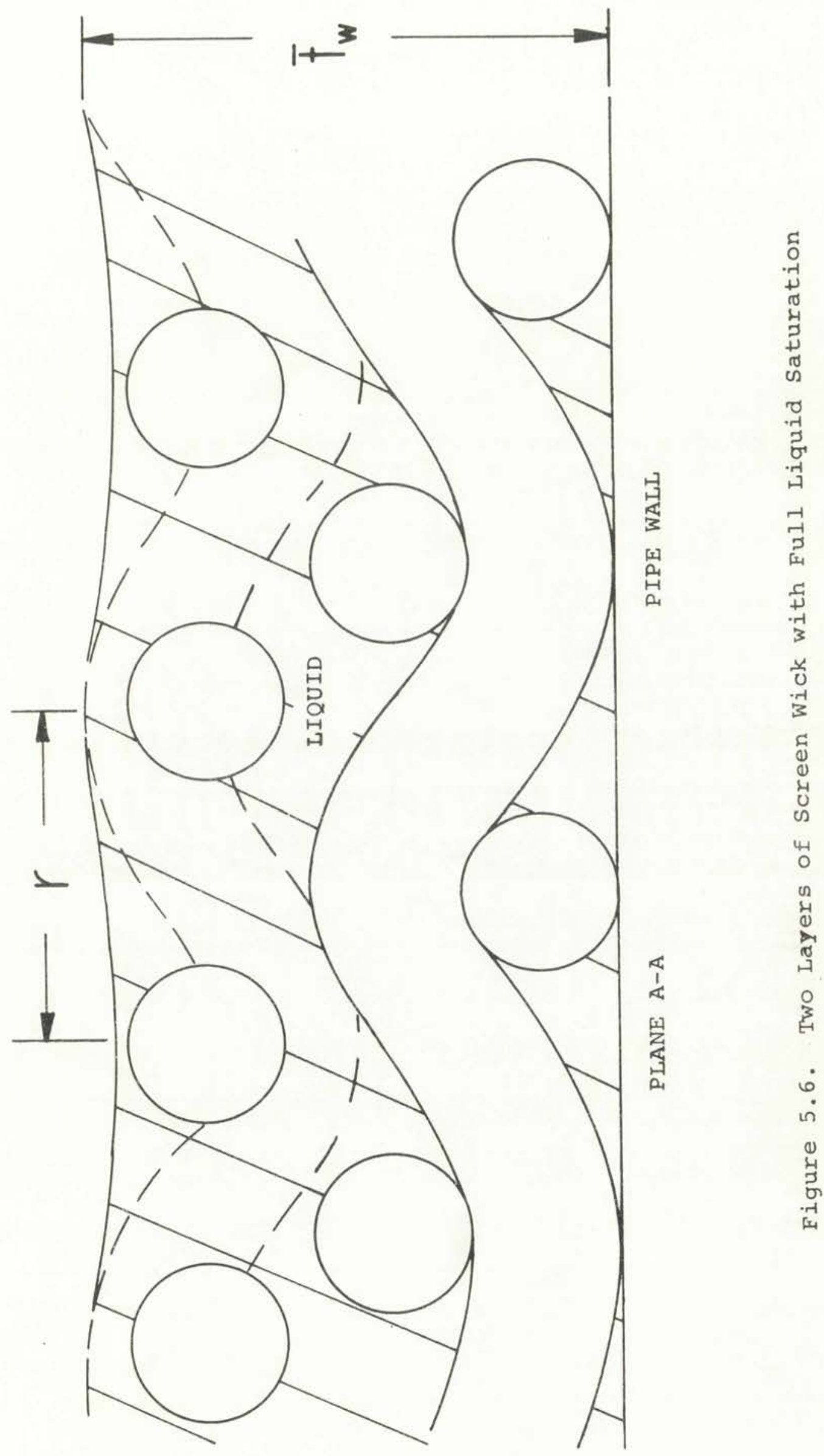




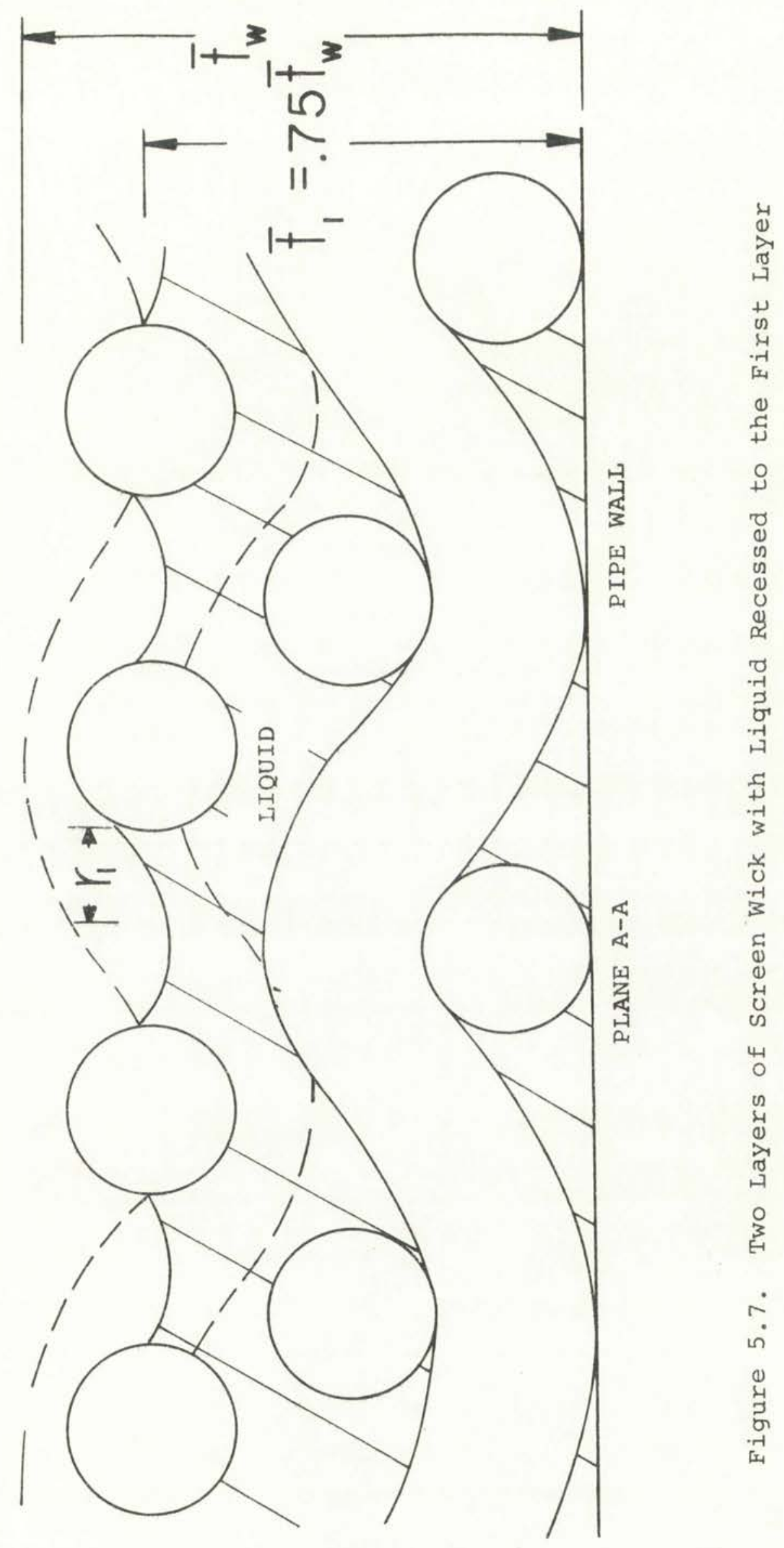





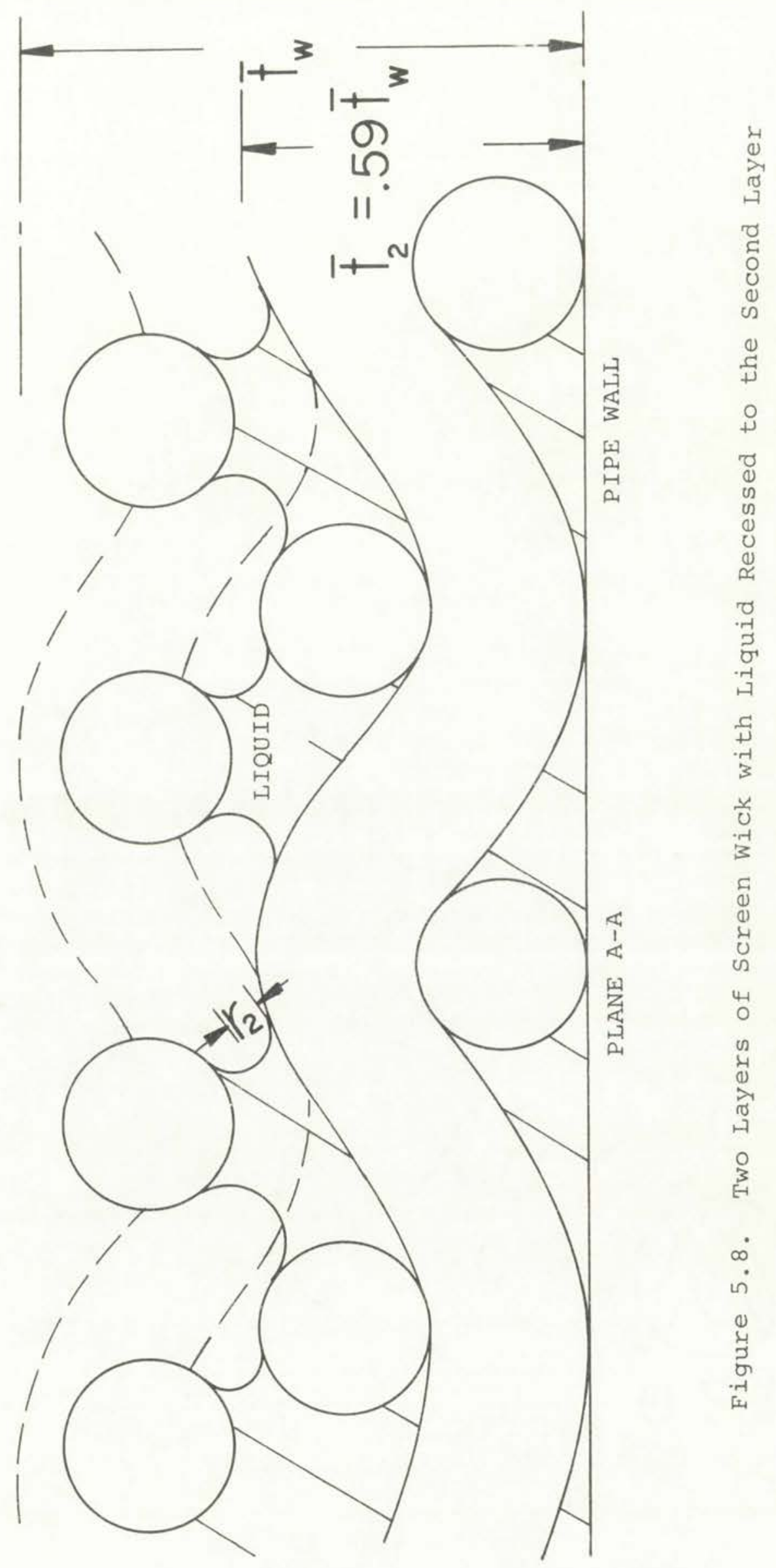


In Figure 5.5, the simplified drawing of the intermeshing of the two layers shows that a smaller capillary radius exists at the interface of the two layers. Figures 5.6, 5.7, and 5.8 are detailed drawings of Figure 5.5. The mean thickness of a double layer of 100 mesh stainless steel was .0160 inches with a standard deviation of .00107 inches based on 72 readings. In Figure 5.6, the fully saturated wick is shown with a large capillary radius at the $\bar{t}_{w}$ level. In Figure 5.7 , liquid is shown recessed to the first layer of wire mesh. This recessed level will be termed the first layer capillary pressure capability of the wick and, when the liquid-vapor interface recedes to that level, the fluid experiences a capillary force characteristic of the first layer. The distance from the wall of the first layer is called the recessed depth, $\bar{t}_{I^{\prime}}$, and is graphically determined from Figure 5.7. The graphical determination of $\bar{t}_{1}$ is performed by measuring the distance from the pipe wall to the hypothesized liquid level on a large cross sectional drawing of the wick. For the first layer, $\bar{t}_{1}$ is three fourths the thickness of the wick, $\bar{t}_{w}$ with the same standard deviation. Therefore, for a 100 mesh stainless steel wick, the liquid experiences a capillary force equivalent to the first layer capability at a distance .00120 inches from the wall with a standard deviation of .00107 inches. The first layer capillary pressure capability was determined experimentally and is tabulated in Tables 4.6 and 4.7 of Chapter 4 . 

If additional capillary force is required of the wick, the liquid level will receed to the configuration shown in Figure 5.8. The liquid-vapor interface has now encountered a smaller capillary radius, $r_{2}$. This configuration is termed the two layer capillary pressure capability, the data for this liquid level tabulated in Tables 4.6 and 4.7 . The recessed depth of this level of recession, $t_{2}$, is again determined graphically and averages $59 \%$ of the wick thickness with the standard deviation of the wick thickness. For the 100 mesh stainless steel wick the liquid level will encounter a capillary pressure equal to the two layer capillary pressure capability .0094 inches from the wall of the heat pipe with a standard deviation of .00107 inches. If additional capillary force is required of the wick, no smaller $r_{e}$ will be encountered during the recession and the wick will dry out.

To add to the information presented in Figures 4.7 and 4.8 we will refer to Figures 5.9 and 5.10 which are photographs of the wick structures tested in this work. The photograph of the 100 mesh two layer wick $(12.5 \mathrm{x})$ of Figure 5.9 shows the intermeshing of the two layers of wire mesh consistent with Figures 5.6 and 5.7. Figure 5.12 shows a top view of the intermeshing and illustrates how the high points of the lower layer tend to fill the openings of the top layer of wire mesh. Figure 5.11 is a sequential recession of fluid in a 100 mesh stainless steel two layer wick. High intensity lamps were used to observe the liquid vapor interface as it recedes. The liquid receded to a location between the two 



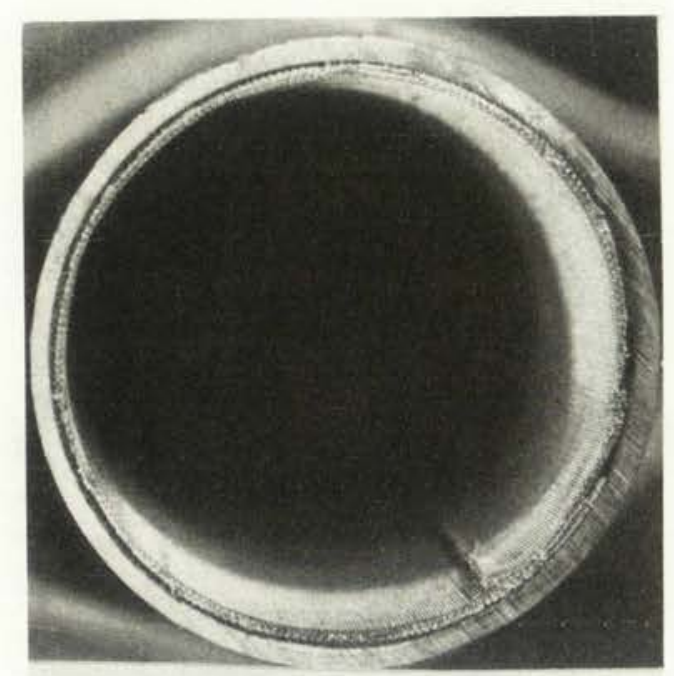

200-mesh stainless steel 3-layer wick $2 \mathrm{x}$

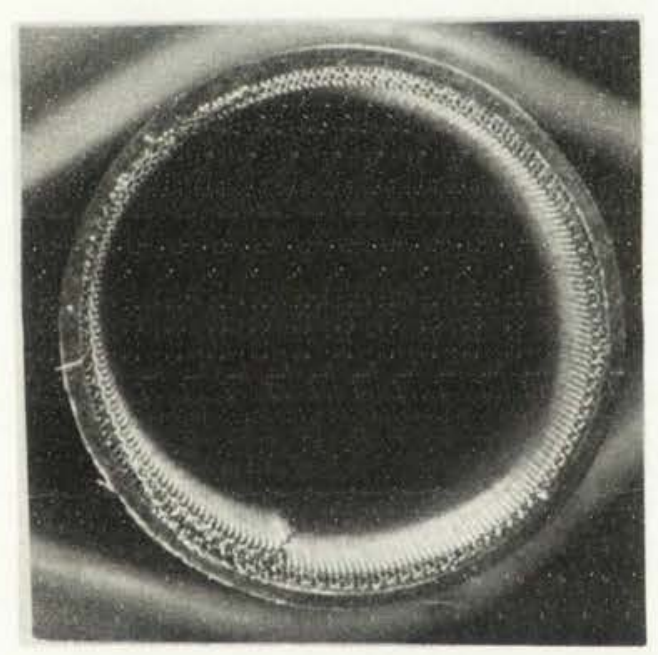

100-mesh stainless steel 2-layer wick $2 \mathrm{X}$

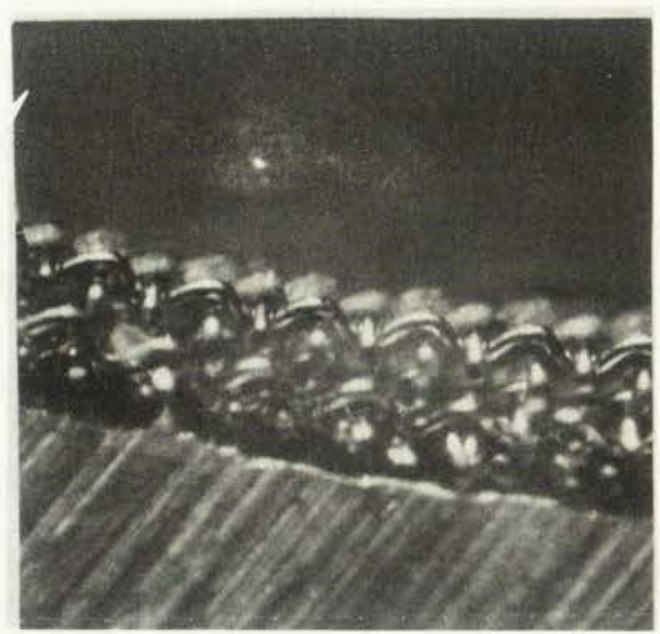

200-mesh stainless steel 3-layer wick $12.5 \mathrm{x}$

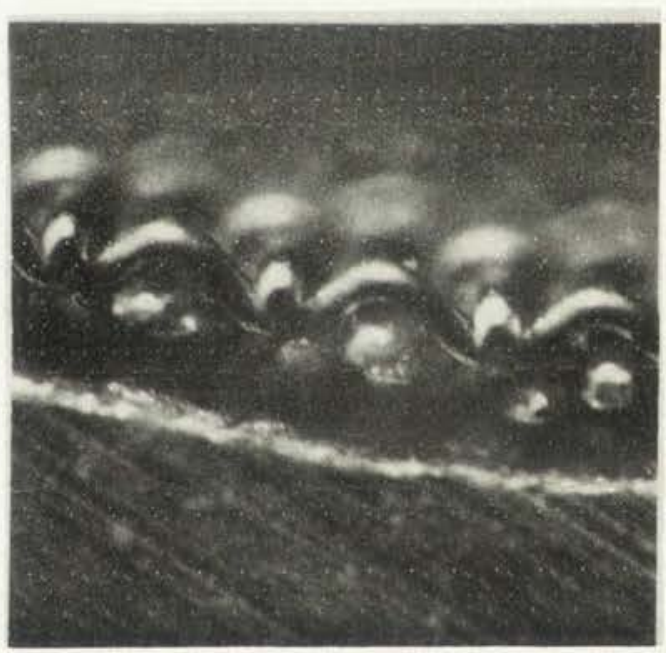

100-mesh stainless steel 2-layer wick $12.5 \mathrm{X}$

Figure 5.9. Wire mesh structures for 200- and 100mesh stainless steel wicks 


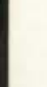

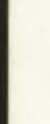
(an -

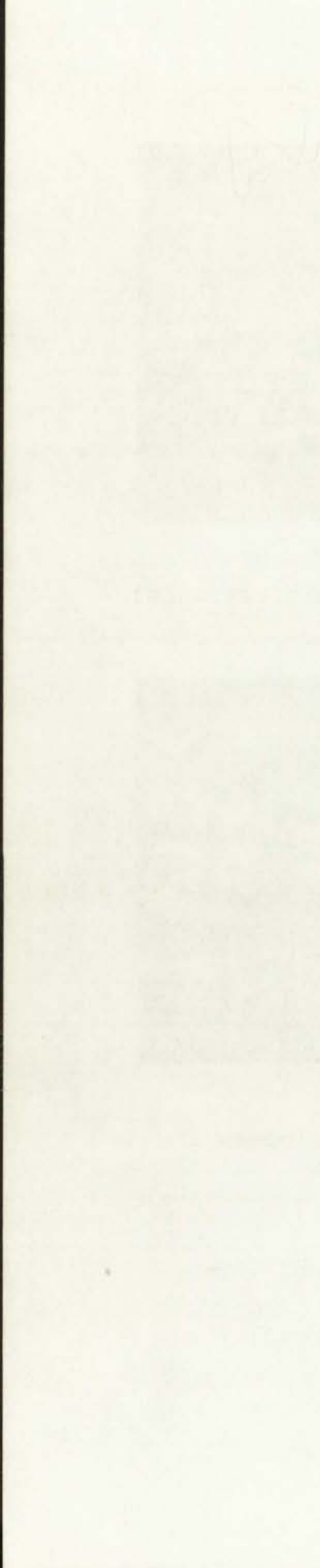



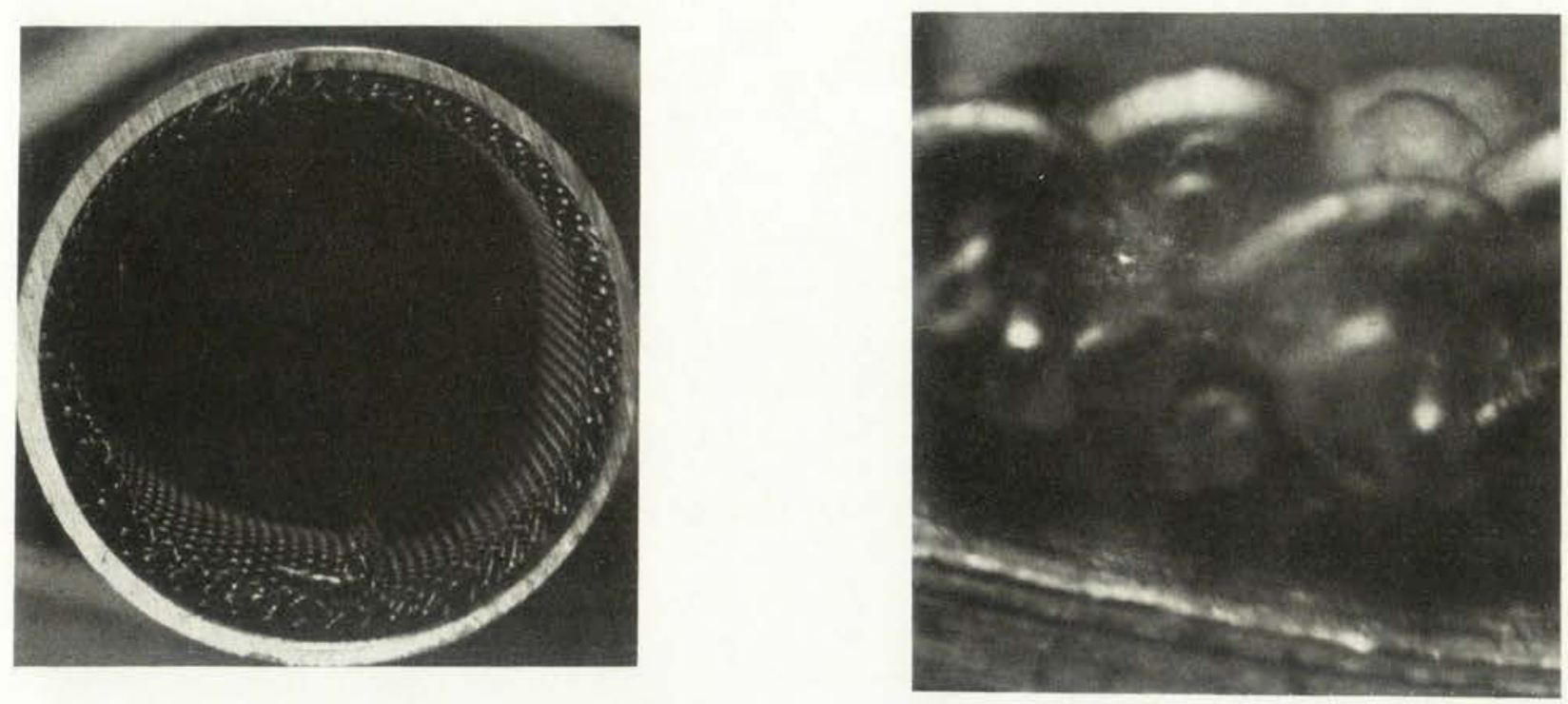

50-mesh stainless steel 2-layer wick $2 \mathrm{X}$

\author{
50-mesh stainless steel \\ 2 -layer wick $12.5 \mathrm{x}$
}

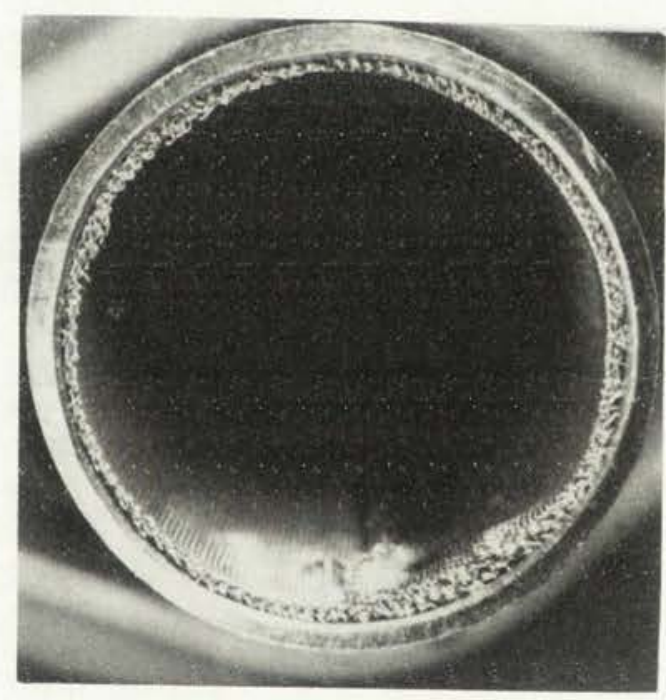

\title{
100-mesh copper \\ 2-layer wick $2 \mathrm{x}$
}

Figure 5.10. Wire mesh structures for 50-mesh stainless steel and 100-mesh copper wicks 


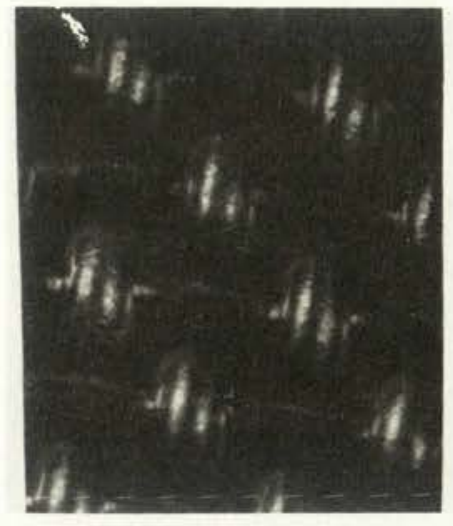

Fully saturated wick at low wattage

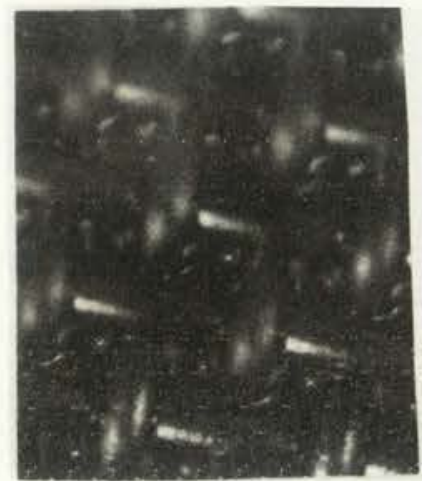

Liquid has rerecessed to minimum capillary radius

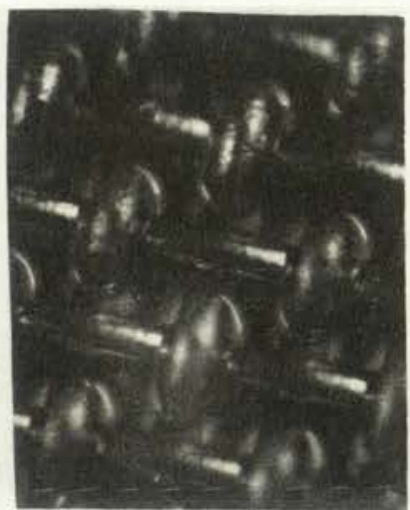

Wattage increased, recession begins

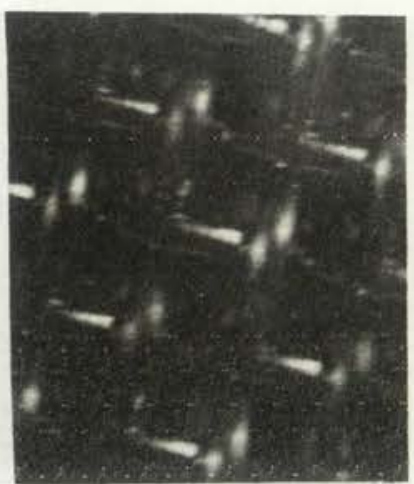

Burnout begins randomly

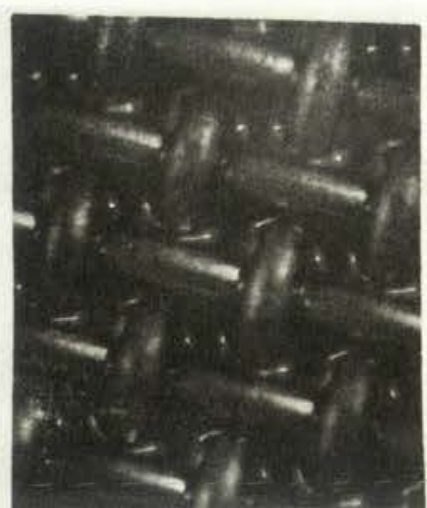

Recession

Increases

Figure 5.11. Sequential observation of liquid recession and final burnout for 100-mesh stainless steel 2-layer wick
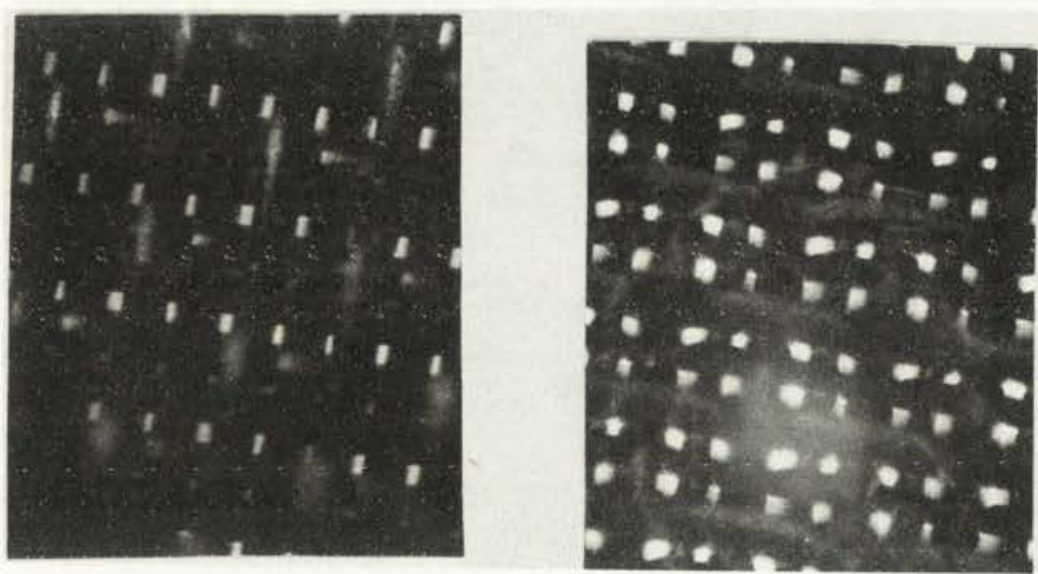

Figure 5.12.

Comparison of Randon Intermeshing of Two Layers of 100Mesh Stainless Steel Screen Compressed Together 

layers where maximum capillary forces were encountered. When the heat transfer rate was increased further, the liquid-vapor interface receded to dry out. Maximum capillary forces were encountered at the interface of the two screen layers which is illustrated in Figure 5.8. Tables 4.6 and 4.7 of Chapter 4 indicate a significant capillary force difference between one and two layers of wire mesh.

Figure 5.14 shows the three possible configurations of the liquid-vapor interface that will be observed in this analysis. Figure 5.14 (a) shows the fully saturated wick with large capillary radii at the $\bar{t}_{w}$ level. The capillary pressure capability of this level is small and will be neglected. This configuration of the liquid vapor interface is assumed for the condenser and adiabatic sections of the heat pipe considered here.

The partially recessed configuration of Figure 5.14 (b), where the wick is saturated at a level where $\bar{t}_{1}=.75 \bar{t}_{\mathrm{w}}$ is assumed to exist from $x=I_{f r}$ to $x=L_{e}$. The configuration of Figure 5.14 where the liquid is fully recessed to the level where $\bar{t}_{2}=.59 \bar{t}_{\mathrm{w}}$ is assumed to exist from $\mathrm{x}=0$ to $\mathrm{x}=\mathrm{L}_{\mathrm{fr}}$. The reason for this detailed analysis is to determine the actual saturation distribution as shown in Figure 5.13 (b), of the wick so that $L^{\prime}(A)_{\Upsilon}$ may be calculated. Now that the values of $r_{e}$ at various levels are specified, we can calculate $L^{\prime}(A)_{I}$ using Equation 2.52. Applying Equation 2.14 to the evaporator section of our heat pipe we obtain the expression for liquid pressure loss and 



$$
\begin{aligned}
& \Delta p_{\ell}=\frac{\mu_{\ell}}{K \rho_{\ell}} \int_{0}^{L_{e}} \frac{\dot{m}(x)}{\bar{A}(x)} d x+\frac{\mu \dot{m}}{\rho \overline{K A}}\left(L_{a}+\frac{L_{c}}{2}\right) \\
& \mathrm{A}_{\mathrm{fr}}=.59 \mathrm{~A} \quad 0 \leq \mathrm{x} \leq \mathrm{L}_{\mathrm{fr}} \\
& A_{r}=3 / 4 \mathrm{~A} \quad L_{f r}<x \leq L_{e} \\
& A=A \quad L_{e}<x \leq L \\
& \dot{m}(x)=\dot{m} \frac{x}{L_{e}} \quad 0<x \leq L_{e} \\
& \Delta \mathrm{p}_{r}=\frac{\mu_{\ell^{\dot{m}}}}{\rho_{\ell}} L^{\prime}(A)_{r} \\
& L^{\prime}(A)_{r}=\left[\frac{2}{3} L_{e}+\frac{L_{f r}}{5.25 L_{e}}+L a+\frac{L_{c}}{2}\right] \frac{1}{A}
\end{aligned}
$$

$L^{\prime}(A)_{r}$ is the expression that accounts for the reduction of flow area due to recession. Equation 5.2 can now be used in conjunction with Equations $2.49,2.53$, and 5.1 in the iterative solution discussed in Chapter 2.

This concludes discussion of the deterministic recession model. Chapter 6 will outline computation techniques for the solution of Equation 2.52 using probabilistic techniques. The analysis presented in this chapter is considered valid for any size square weave wire mesh wrapped according to the procedure shown in Chapter 3. Although this particular analysis was done with two layer wicks, the effects of multiple layers (greater than two) could be incorporated into this analysis. For instance, this analysis was used successfully on a three layer 200 mesh wick assuming no recession into the third layer. 


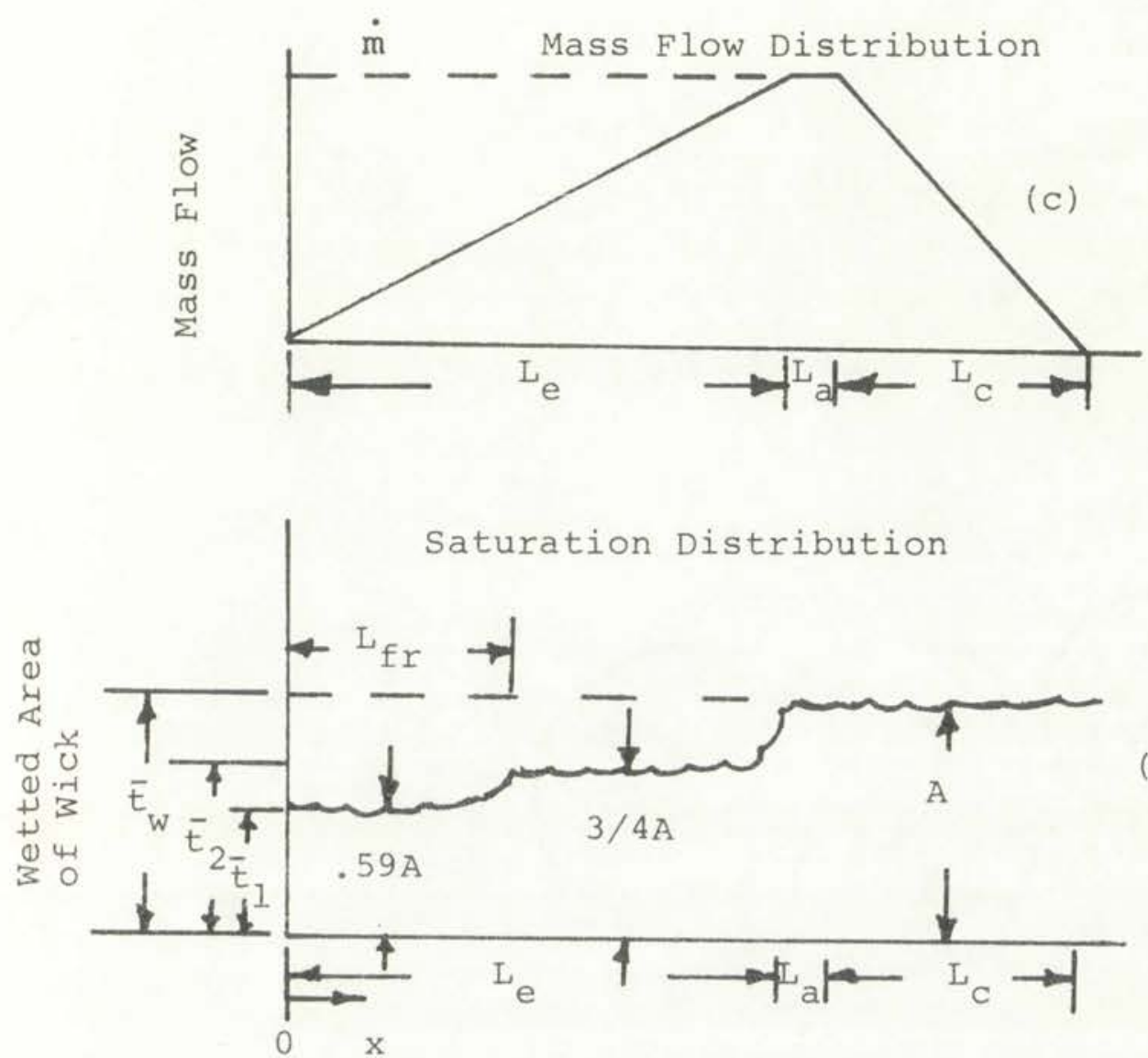

(b)

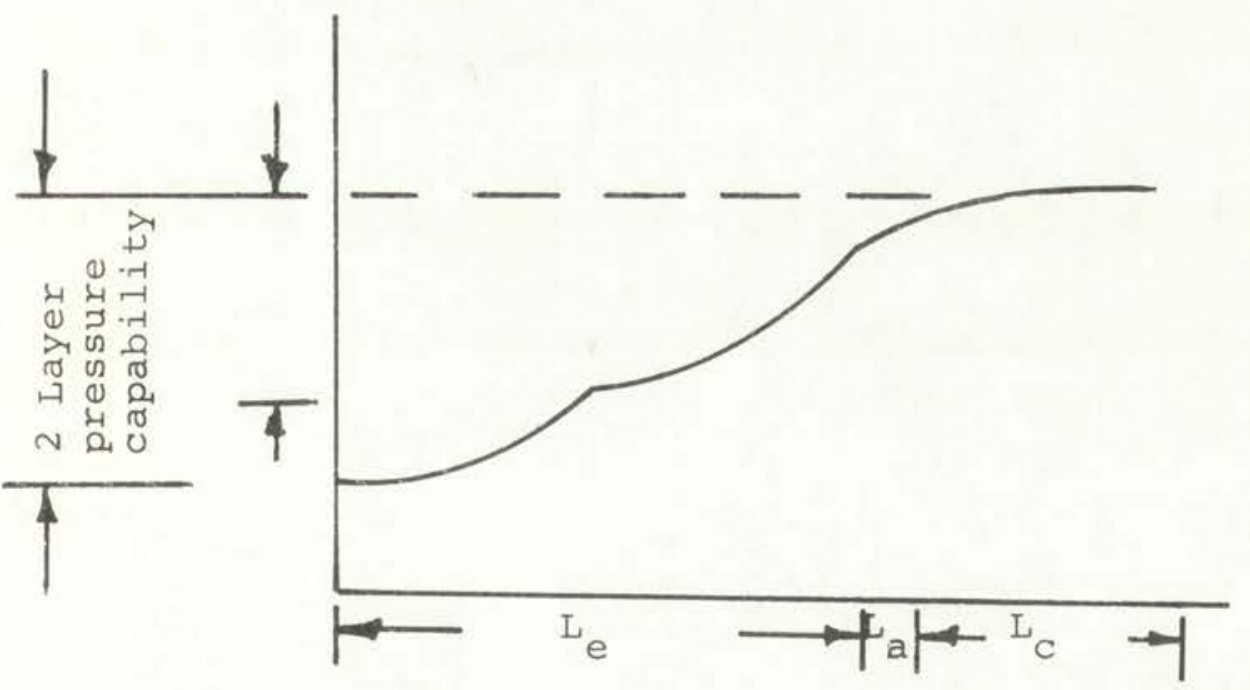

(a)

Figure 5.13. Hypothesized Recession Model for Two Layer Square Weave Wire Mesh Wicks 



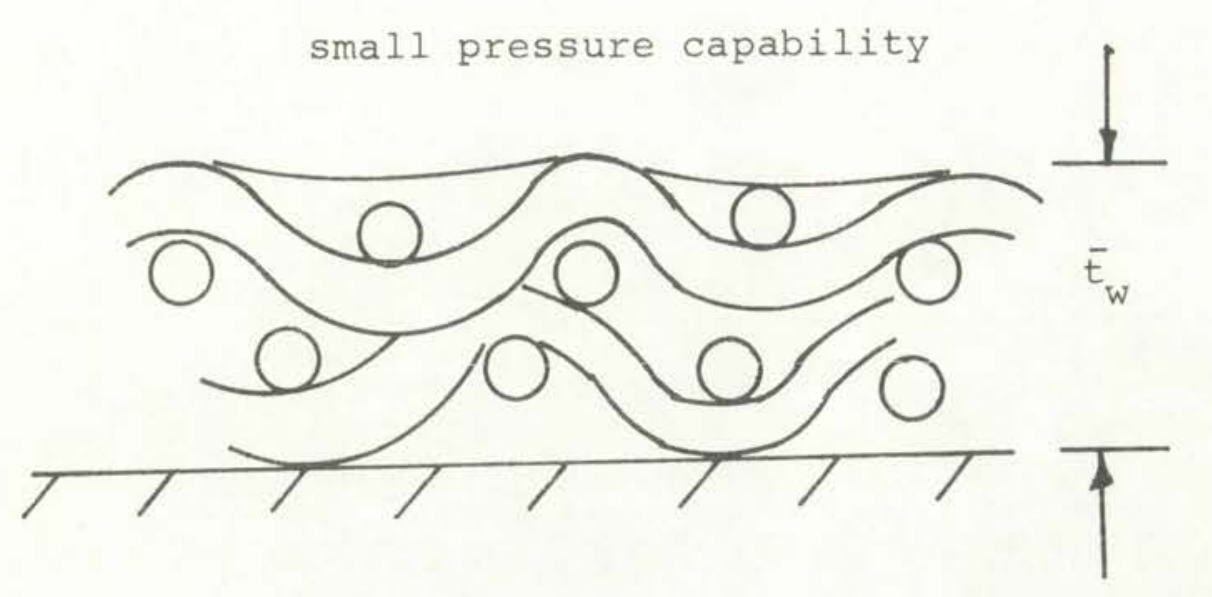

(a)
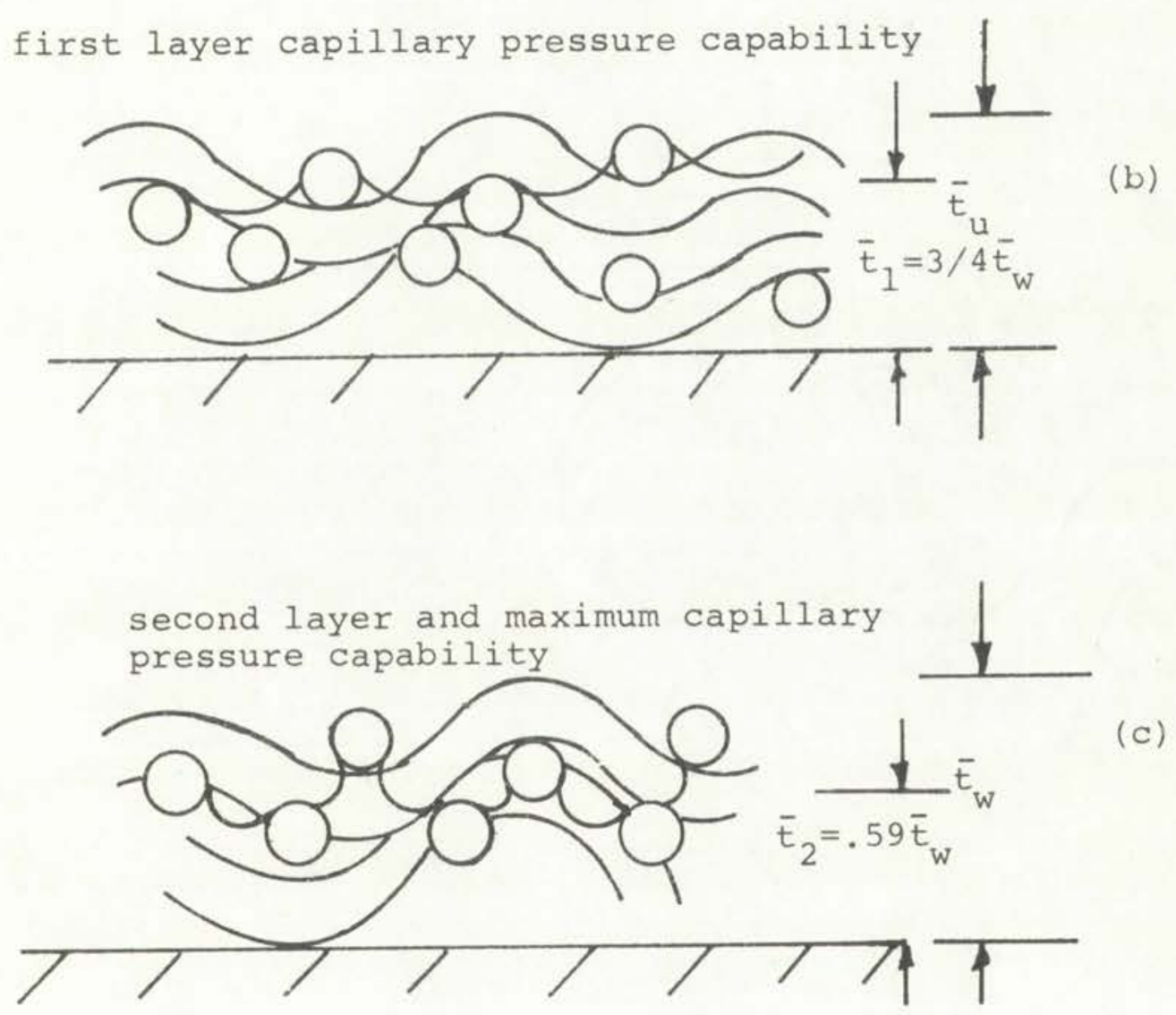

Figure 5.14. The Three Possible Configurations of the Liquid Vapor Interface in 100-Mesh Square Weave Wire Cloth 

CHAPTER 6

COMPUTATIONAL METHODOLOGY

\subsection{Methodology}

In this chapter the foundation is developed for the solution of Equation 2.57, the probabilistic model of heat pipe operation. Simple deterministic equations are used as examples of the formulation of a probabilistic design model. The probabilistic model uses the basic equation structure of the deterministic model. Probabilistic methodology is applied to account for the variability in the deterministic model.

To illustrate the solution to the probabilistic design equation, simple mathematical models will be used.

Many physical phenomena may be described by mathematical models. A simple example is shown below.

$$
\begin{aligned}
& Q_{3}=Q_{1}+Q_{2} \\
& Q=\text { Flow Rate }
\end{aligned}
$$

Assuming that this deterministic model describes the physical phenomena adequately, we may form a probabilistic model by transforming the deterministic variables into random variables which are governed by some statistical distribution

$$
\begin{aligned}
& \left(Q_{3} P_{1}, Q_{3} P_{2}, \ldots Q_{3} P_{n}\right)=\left(Q_{1} P_{1}, Q_{1} P_{2}, \ldots Q_{1} P_{n}\right) \\
& +\left(Q_{2} P_{1}, Q_{2} P_{2}, \ldots Q_{2} P_{n}\right) \\
& Q_{1}, Q_{2}, Q_{3}=\text { Random variables } \\
& Q P=\text { Random variable distribution parameters } \\
& Q_{1}, Q_{2}=\text { Independent }
\end{aligned}
$$

For our particular analysis, virtually all distributions of 
physical properties are two parameter. Therefore, the distribution is determined solely by the mean and standard deviation. We may now transform our general probabilistic model to that of simple two-parameter distributions and obtain

$$
\left(\overline{\mathrm{Q}}_{3}, \mathrm{~S}_{\mathrm{Q}_{3}}\right)=\left(\overline{\mathrm{Q}}_{1}, \mathrm{~S}_{\mathrm{Q}_{1}}\right)+\left(\mathrm{Q}_{2}, \mathrm{~S}_{\mathrm{Q}_{2}}\right)
$$

where $\left(\bar{Q}, S_{Q}\right)$ is a random variate pair.

The reason for changing the deterministic variable to a random variable is that most physical variables

may not be known precisely. If there is

uncertainty in describing these input variables, there will

be uncertainty in the functional result. Describing the uncertainty of the functional result may be the best way to describe the natural phenomenon.

There are three techniques for finding functional variability and they are discussed as follows:

a) Simulation: We will use the flow rate example to illustrate the procedure. We are given the following

$$
\begin{aligned}
& \mathrm{Q}_{3}=\mathrm{Q}_{1}+\mathrm{Q}_{2}=\text { Flow Rate } \sim \mathrm{ZZ}_{1}^{*}\left(\overline{\mathrm{Q}}_{1}, \mathrm{~S}_{\mathrm{Q}_{1}}\right) \\
& \mathrm{Q}_{2}=\text { Flow Rate } \sim \mathrm{ZZ}_{2}\left(\overline{\mathrm{Q}}_{2}\left(\overline{\mathrm{Q}}_{2}, \mathrm{~S}_{\mathrm{Q}_{2}}\right)\right.
\end{aligned}
$$

This solution technique uses a random number generator to supply a $\mathrm{ZZ}_{1}$ distributed flow rate, $\mathrm{Q}_{1}$, and a $\mathrm{ZZ}_{2}$ distributed flow rate, $Q_{2}$. These individual random numbers are inserted into the above equation and the random result, $Q_{3}$, is recorded. This procedure is repeated many times, and the $Q_{3}$ parameters and distribution can be determined using Equations 2.55 and 2.56 and a significance test.

* $\mathrm{ZZ}_{1}$ designates a particular two parameter distribution such as the normal distribution. 



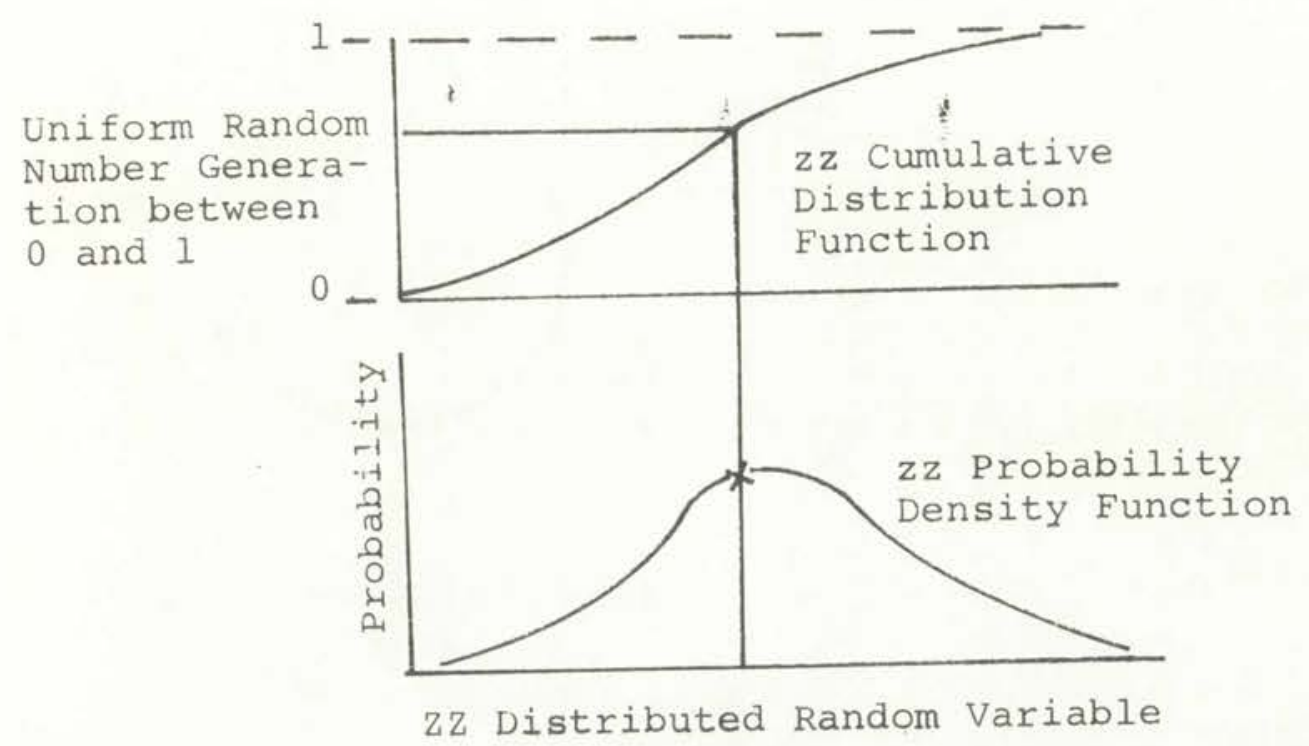

Figure 6.1. Simulation of Functional Variability

The simulation algorithm is as follows

Do down to and including 5 , $n$ times

$\operatorname{Call~} \mathrm{ZZ}_{1}$ Distributed Random $\mathrm{Q}_{1}$

Call $\mathrm{ZZ}_{2}$ Distributed Random $Q_{2}$

Random $Q_{3}=$ Random $Q_{1}+$ Random $Q_{2}$

Store Random $Q_{3}$

5 Continue

Call subroutine Parameter Estimation

Call Significance Test

End

From this technique we can determine the functional mean, variability (standard deviation) and distribution.

b) Partial Derivative Method: This method uses a Taylor approximation of functional variability and is derived in most 

elementary statistical texts. To find functional variability using this method we proceed as follows:

Given

$$
\begin{gathered}
F=f\left(x_{1}, x_{2} \ldots x_{n}\right) \\
E(F)=\bar{F}=f\left(E\left(x_{1}\right), E\left(x_{2}\right) \ldots E\left(x_{n}\right)\right)
\end{gathered}
$$

Al1 X Independent

$$
\bar{F}=f\left(\bar{x}_{1}, \bar{x}_{2} \ldots \bar{x}_{n}\right)
$$

(the mean function result is the computation of all the variables means in the given equation)

The functional variability (standard deviation) is derived from the Taylor approximation as,

$$
S_{F}^{2}=\left(\frac{\partial F}{\partial x_{1}}\right)^{2}\left(S_{x_{1}}\right)^{2}+\left(\frac{\partial F}{\partial x_{2}}\right)^{2}\left(S_{x_{2}}\right)^{2} \ldots+\left(\frac{\partial F}{\partial x_{n}}\right)^{2}\left(S_{x_{n}}\right)^{2}
$$

and for our example

$$
\begin{aligned}
& \overline{\mathrm{Q}}_{3}=\overline{\mathrm{Q}}_{1}=\overline{\mathrm{Q}}_{2} \\
& \mathrm{SQ}_{3}=\left(\mathrm{S}_{\mathrm{Q}_{1}}{ }^{2}+\mathrm{S}_{\mathrm{Q}_{2}}{ }^{2}\right)^{1 / 2}
\end{aligned}
$$

Note that this method yields a good approximation of the functional mean and standard deviation but indicates nothing of the functional distribution.

c) Algebra of moments: This method uses the algebra of moments or expectations to determine functional variability exactly. Unfortunately, algebra of expectations becomes difficult when functions contain many random variables and powers of random variables. Because of this difficulty this method is used only on simple functions and these results are shown in Table 6.1 . 

MEANS AND STANDARD DEVIATIONS FOR

SIMPLE FUNCTIONS USING ALGEBRA OF EXPECTATIONS

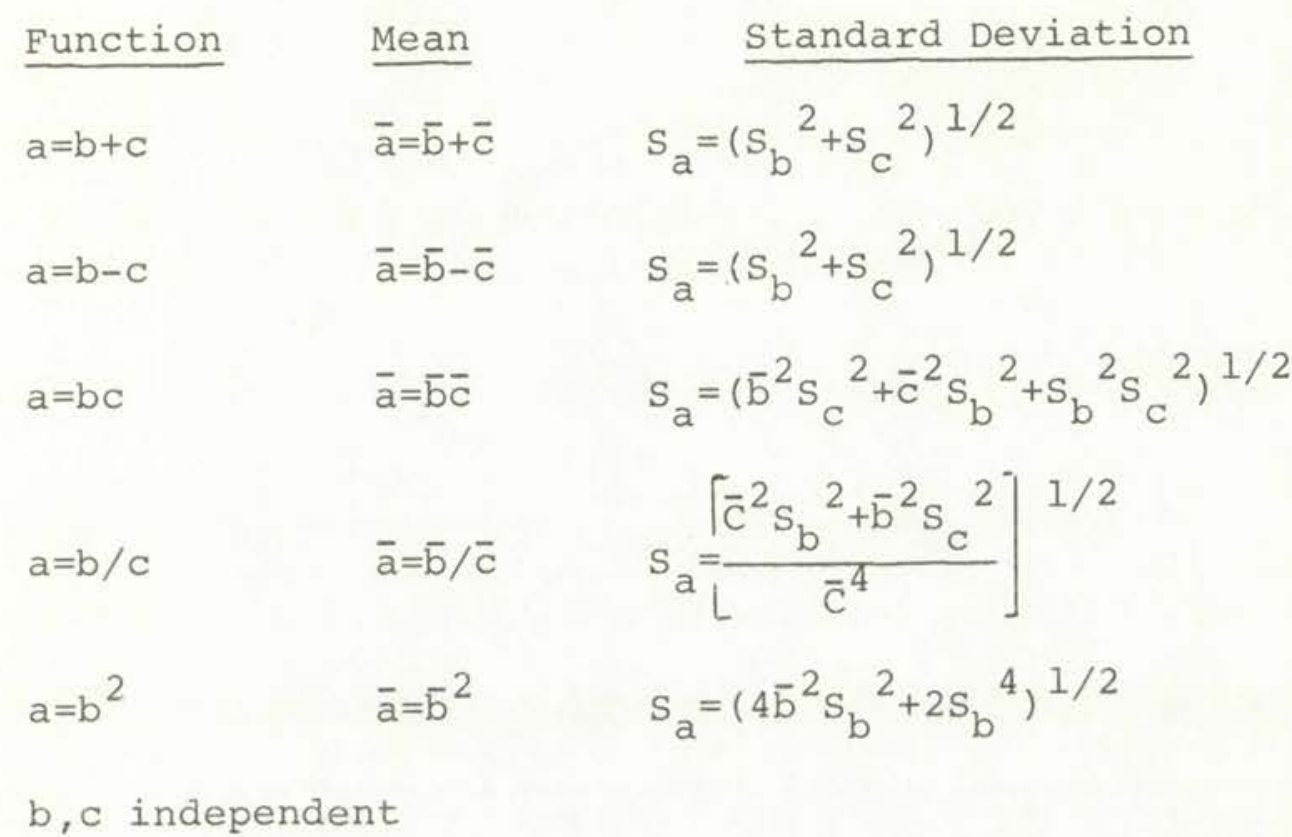

The algebra of expections gives the functional mean and the standard deviation but does not indicate the functional distribution. For example, the algebra of expectations gives the following exact result which is incidentally the same as the partial derivative result.

$$
\begin{aligned}
& \overline{\mathrm{Q}}_{3}=\overline{\mathrm{Q}}_{1}+\overline{\mathrm{Q}}_{2} \\
& \mathrm{~S}_{\mathrm{Q}_{3}}=\left(\mathrm{S}_{\mathrm{Q}_{1}}{ }^{2}+\mathrm{S}_{\mathrm{Q}_{2}}\right)^{1 / 2}
\end{aligned}
$$



The three sample functions we will investigate are*

$$
\begin{aligned}
& \text { 1) } Q_{3}=Q_{1}+Q_{2} \\
& \text { 2) } A=B-C \\
& \text { 3) } \quad V=Q / A
\end{aligned}
$$

The first function, $Q_{1}+Q_{2}$, appears in Table 6.2 . The standard deviation of the function was calculated using simulation, partial derivative and exact techniques at various standard deviations and sample sizes. Looking at the range of input variable standard deviations, one can conclude that this function is well behaved. The functional standard deviations are actually smaller, percentage wise, than the input variable standard deviations. Even at large input standard deviations this holds true and all techniques give the same resultant standard deviation.

The second function, $A=B-C$, is not so well behaved. Table 6.3 shows what can happen if the input variables, B \& , are nearly the same in magnitude with high standard deviations. This is the classic numerical problem of subtracting two numbers of almost equal magnitude. Notice that at moderate input standard deviations (say $9 \%$ of the input variable mean) the functional standard deviation grows to $225 \%$ of the functional result. The simulation mean becomes unstable at these high standard deviations as one might expect.

\footnotetext{
* The reason for choosing these simple functions is that they appear in many engineering applications and also form the basic structure of Equation 2.57 .
} 

능봉

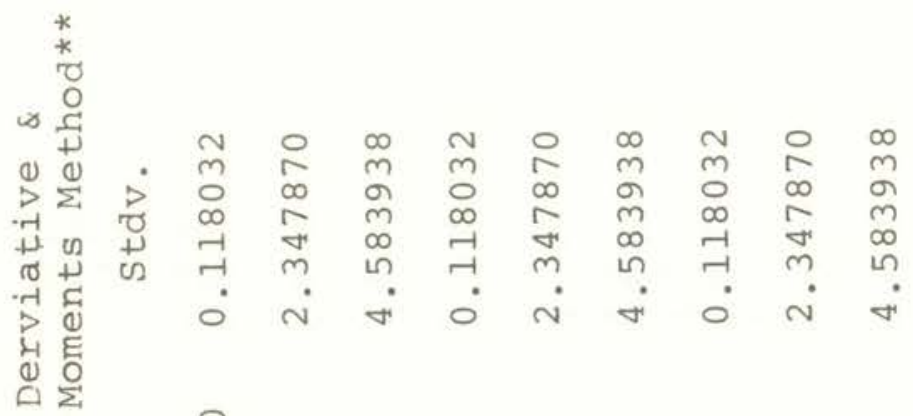

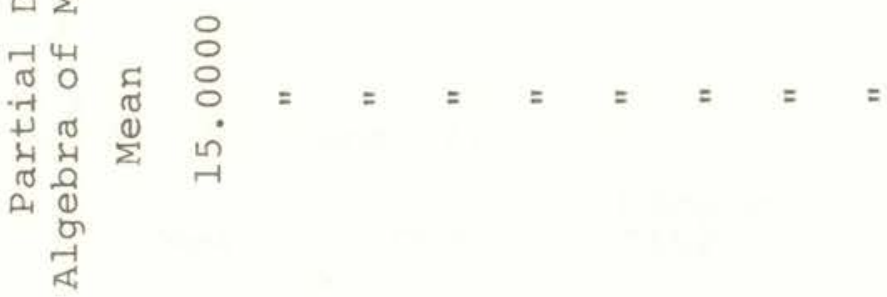

턴렁 近诖 $P_{101} D_{1}$ E-

结- 这

冚心

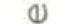

(1)

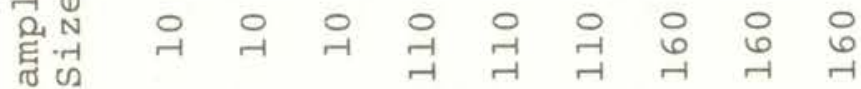

들

爷出舟

卆易只

ㄴ.

$x$

is

됙

要之会

म

텅 뫼 Z员占

红誳

되 닷

西叫

蛅

$\sum_{0}$

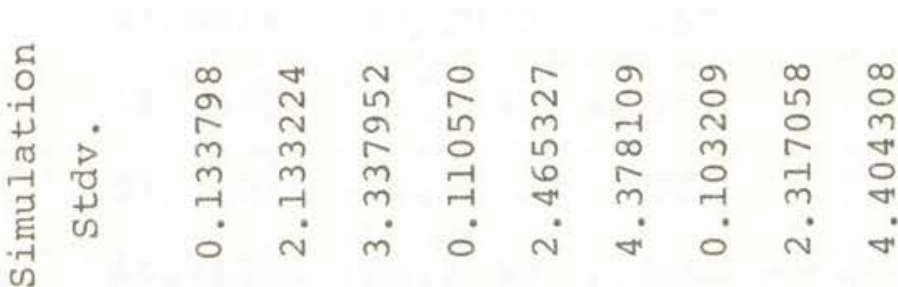

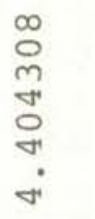

थ

$\stackrel{\alpha}{\alpha}$

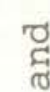

ర్

井

빔

㟔

00

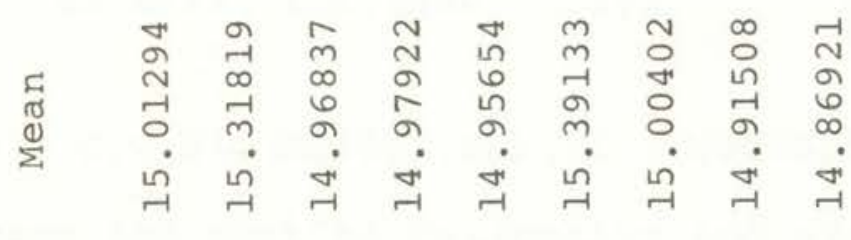

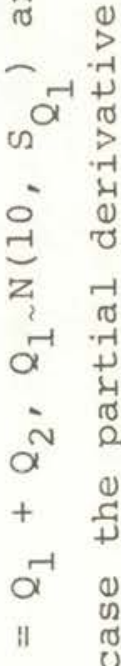

穴

(1) i⿱

为

त्

芹㟔

$\stackrel{0}{>}$

아 4

हี त्ठ

ते

需

त 25

म

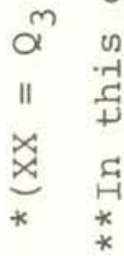


TABLE 6.3

\section{STANDARD DEVIATION GROWTH OF THE FUNCTION YY* USING SIMULATION, PARTIAL DERIVATIVE \\ AND ALGEBRA OF MOMENTS METHOD}

Random

Variable

Standard Deviation

(in $\%$ of mean)

.1

1

2

3

4

5

6

7

8

9
Simulation

Mean Stdv.

50.0098

1. 3278

48.6319

15.3096

51.6134

28.9453

48.6156

43.4557

47.0834

53.3973

$48.5659 \quad 70.2449$

53.0261

83.8806

44. 2171

99.3238

$51.4417 \quad 107.2407$

$53.8297 \quad 131.5490$
Sample

Size

300

300

300

300

300

300

300

300

300

300
Partial

Derivative \&

Algebra of

Moments Method**

Mean stdv.

$50.00 \quad 1.3793$

$50.00 \quad 15.1724$

$50.00 \quad 28.9655$

$50.00 \quad 42.7586$

$50.00 \quad 56.5571$

$50.00 \quad 70.3448$

$50.00 \quad 70.9831$

$50.00 \quad 97.9310$

$50.00 \quad 111.7231$

$50.00 \quad 125.5173$

$\star\left(Y Y=A=B-C, \quad B \sim N\left(1000, S_{b}\right), C \sim N\left(950, S_{C}\right)\right)$

** In this case the partial derivative and algebra of moments method are identical. 



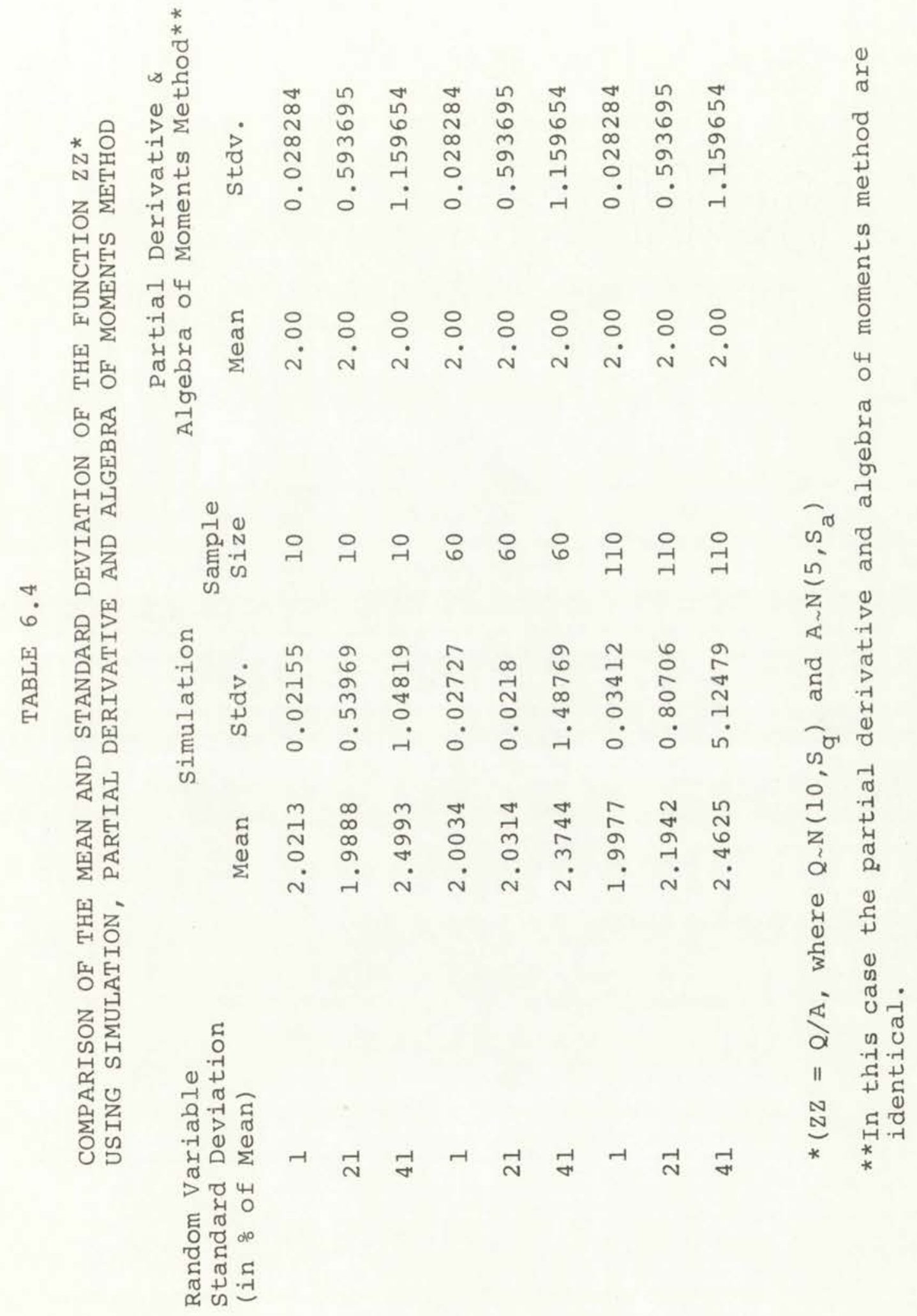



The third function, $V=Q / A$, presents a problem when denominator random variables approach zero. Table 6.4 shows the standard deviation growth of this function. Notice that in this case the partial derivative and exact method diverge from the simulation method. The simulation is affected considerably by random choices of $\mathrm{A}$ near zero while the other techniques are not. This divergence may be a good indicator of numerical problems in this function.

The purpose of these examples is to point out the numerical problems associated with the computation of the functional standard deviation. Caution must be observed in this calculation since the physical phenomenon variability may differ, significantly, from the calculation.

\subsection{Application to Heat Pipe Design}

In the next several pages the three techniques are presented for finding functional variability as applied to Equation 2.57 .

\section{a) Simulation}

The simulation technique is the most useful because the distribution of the heat transfer rate can be determined as well as the mean and variability. The mean heat transfer rate is

$$
\bar{Q}=\sum_{i=1}^{n} \frac{q_{i}}{n} \quad \begin{gathered}
\text { (estimate of mean heat transfer } \\
\text { rate) }
\end{gathered}
$$

where 



$$
\begin{gathered}
q_{i}=N_{\ell L} \frac{\left(K_{i}\right)}{{ }^{(A)_{r_{i}}}}\left(\frac{2}{r_{f r_{i}}}-\frac{\rho_{\ell} g\left(\overline{\mathrm{H}}_{i}\right)}{g_{C}^{\sigma}}\right) \\
\mathrm{N}_{\ell}=\frac{\rho_{\ell}{ }^{\sigma h_{f g}}}{\mu_{\ell}}
\end{gathered}
$$

The $q_{i}$ values are obtained by randomly choosing a value for each of the random variables $\left(r_{f r}, H, K, A, L^{\prime}(A)_{r}\right)$. The random values $\left(\mathrm{K}_{i}, \mathrm{r}_{\mathrm{fr}}{ }_{i} \mathrm{H}_{i}, \mathrm{~A}_{i}, \mathrm{~L}^{\prime}(\mathrm{A})_{r_{i}}\right)$ are chosen by entering the cumulative distribution functions of each of these parameters using a random number generation technique. The procedure for generating a random variable from a particular distribution is shown in Figure 6.1. The cumulative distribution functions are determined from experimental data using Equations 2.55 and 2.56 . The estimate of the heat transfer rate standard deviation is obtained from Equation 2.56 and is rewritten in Equation 6.11.

$$
\mathrm{S}_{\mathrm{Q}}=\sum_{i=1}^{\mathrm{n}} \frac{\left(\mathrm{q}_{i}-\overline{\mathrm{Q}}\right)^{2}}{\mathrm{n}-1} \quad \begin{aligned}
& \text { estimate of variability } \\
& \text { (standard deviation) }
\end{aligned}
$$

The parent distribution of $q_{i}$ is hypothesized using a goodness of fit test. This technique becomes accurate for large and moderate coefficients of variation.

\section{b) Partial Derivative Method}

The mean heat transfer rate is determined by introducing the means of the random variables into the deterministic design equation and solving for $\overline{\mathrm{Q}}$. 


$$
\bar{Q}=N_{\ell} \frac{\bar{K}}{\overline{L^{\prime}(A)_{r}}}\left(\frac{2}{\bar{r}_{f r}}-\frac{\rho_{\ell} g(\bar{H})}{g_{C}{ }^{\sigma}}\right)
$$

The standard deviation is given by an approximation using a Taylor expansion

$$
\begin{aligned}
& \left.\mathrm{F}=\mathrm{Fx}_{1}, \mathrm{x}_{2}, \ldots \mathrm{x}_{\mathrm{n}}\right) \\
& \mathrm{S}_{\mathrm{F}}=\left(\frac{\partial \mathrm{f}}{\partial \mathrm{x}_{1}}\right)^{2}\left(\mathrm{~s}_{\mathrm{x}_{1}}\right)^{2}+\left(\frac{\partial f}{\partial \mathrm{x}_{2}}\right)^{2}\left(\mathrm{~s}_{\mathrm{x}_{2}}\right)^{2} \cdots\left(\frac{\partial f}{\partial \mathrm{x}_{\mathrm{n}}}\right)^{2}\left(\mathrm{~s}_{\mathrm{x}_{\mathrm{n}}}\right)^{2}
\end{aligned}
$$

and in our case

$$
\begin{aligned}
S_{q}= & \left(\frac{\partial \bar{Q}}{\partial \bar{K}}\right)^{2} S_{k}{ }^{2}+\left(\frac{\partial \bar{Q}}{\partial r_{f I}}\right)^{2}\left(S_{r_{f r}}\right)^{2}+\left(\frac{\partial \bar{Q}}{\partial \bar{H}}\right)^{2}\left(S_{H}\right)^{2} \\
& +\left(\frac{\partial \bar{Q}}{\partial L^{\prime}(A)_{I}}\right)^{2}\left(S_{L^{\prime}(A)_{r}}\right)^{2}
\end{aligned}
$$

The distribution of $Q$ cannot be determined through significance tests and must be assumed or calculated in closed form.

\section{c) Algebra of Moments}

This technique, introduced by Haugen, ${ }^{1}$ is an exact technique for determining $\overline{\mathrm{Q}}, \mathrm{s}_{\mathrm{q}}$. The mean is calculated as in the partial derivative method

$$
\bar{Q}=N_{\ell} \frac{\overline{\bar{K}}}{\bar{L}^{\prime}(A)_{I}}\left(\frac{2}{\bar{r}_{f r}}-\frac{\rho_{\ell^{g(\bar{H})}}}{g_{C} \sigma}\right)
$$

(all random variables are independent)

The standard deviation is formulated using algebra of the first and second moments. For the functions

$$
\mathrm{z}_{1}=\mathrm{XY}
$$





$$
\begin{aligned}
& \mathrm{s}_{\mathrm{z}_{1}}=\sqrt{\overline{\mathrm{x}}^{2} \mathrm{~s}_{\mathrm{y}}+\overline{\mathrm{y}}^{2} \mathrm{~s}_{\mathrm{x}}{ }^{2}+\mathrm{s}_{\mathrm{x}}{ }^{2} \mathrm{~s}_{\mathrm{y}}{ }^{2}} \\
& \mathrm{z}_{2}=\mathrm{x}-\mathrm{y} \\
& \mathrm{s}_{\mathrm{z}_{2}}=\sqrt{\mathrm{s}_{\mathrm{x}}^{2}+\mathrm{s}_{\mathrm{y}}{ }^{2}}
\end{aligned}
$$

These formulae may be used in succession to obtain $\mathrm{S}_{\mathrm{q}}$. The distribution is determined in the same way as the partial derivative method.

The computer program block diagram is shown in Figure 6.1, and the actual listing appears in the appendix. The computer program is simply the iteration procedure mentioned in Chapter 2 using the three solution techniques of this chapter. 



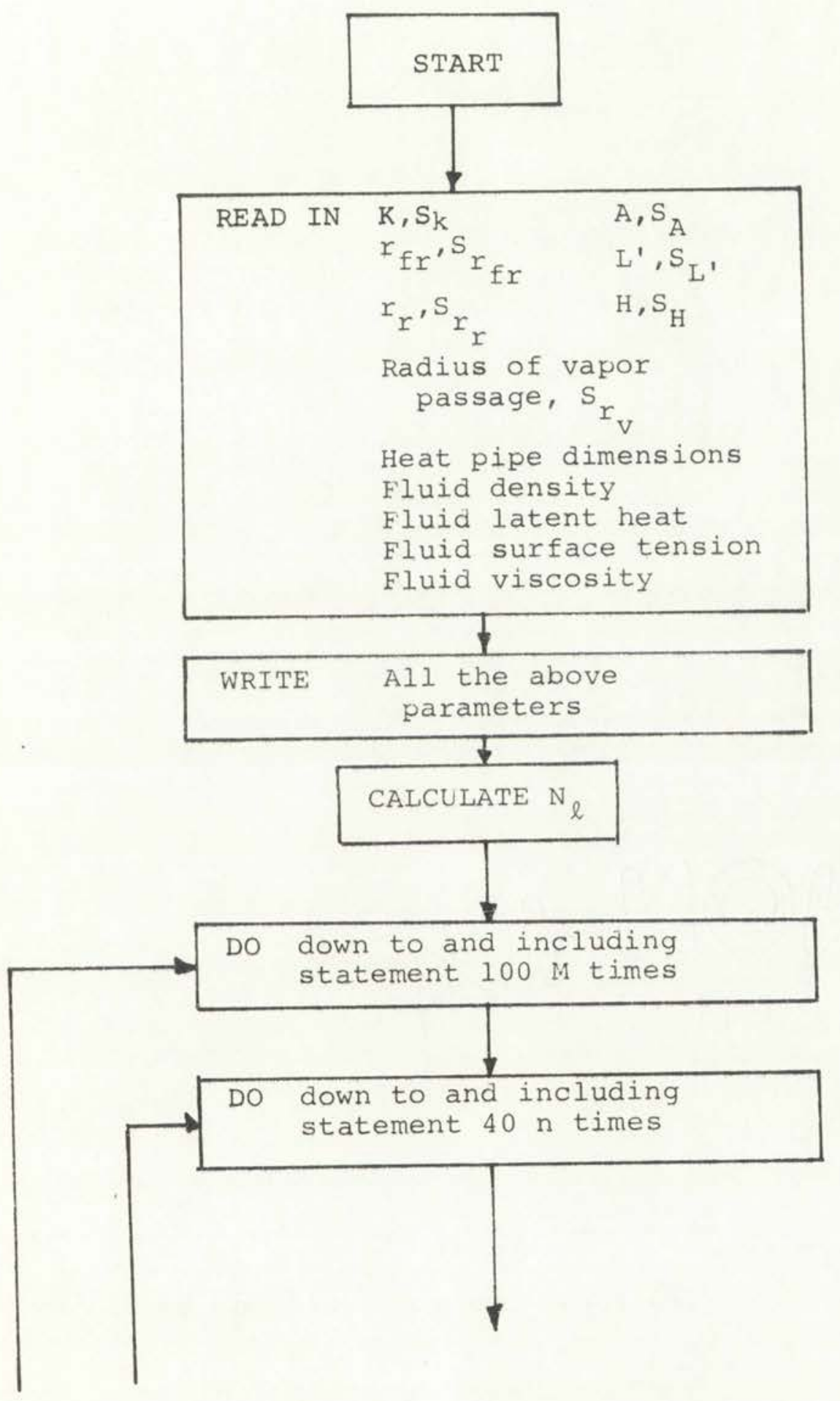

Figure 6.2. Computer Program Flow Diagram 



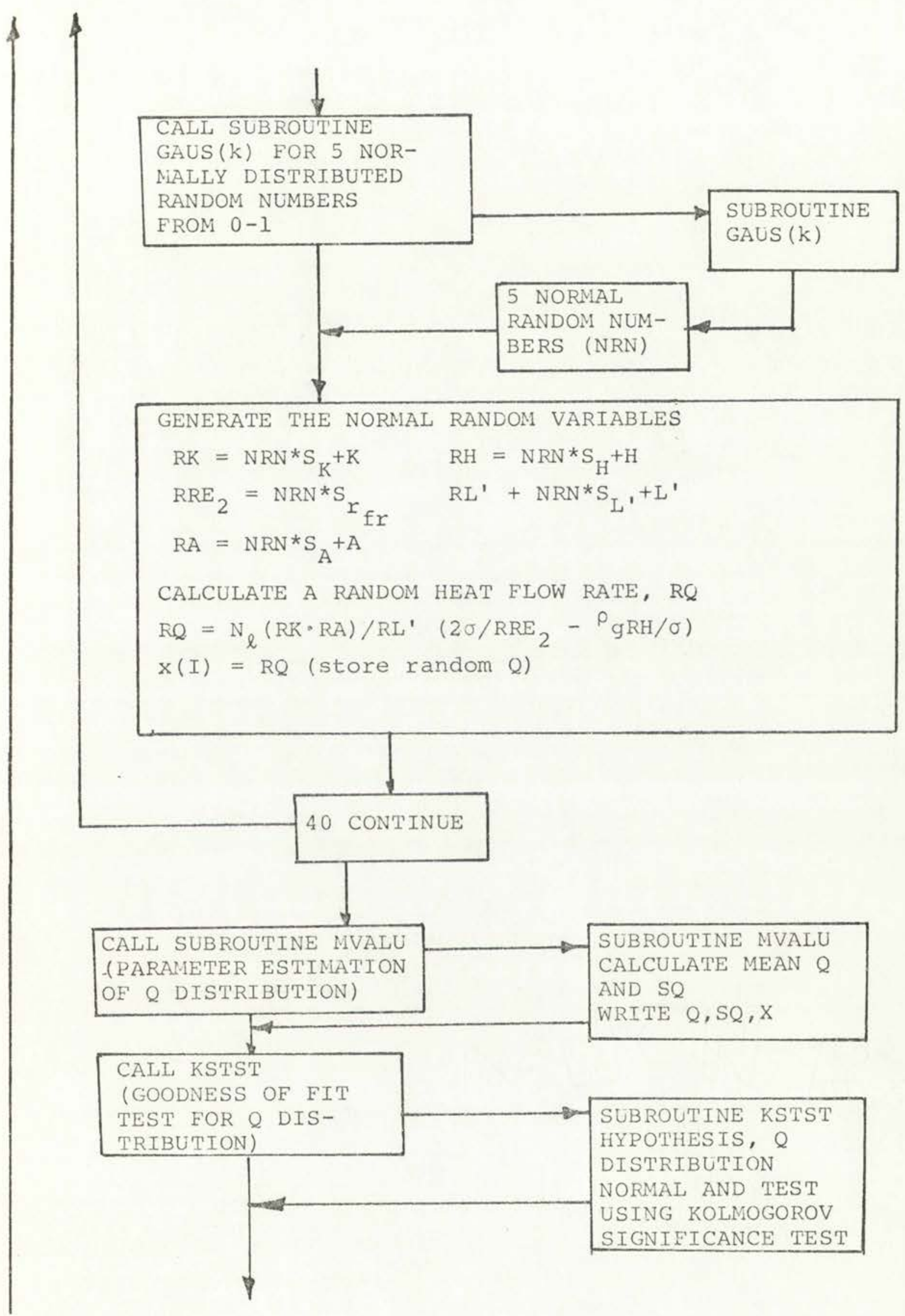

Figure 6.2. (continued) 


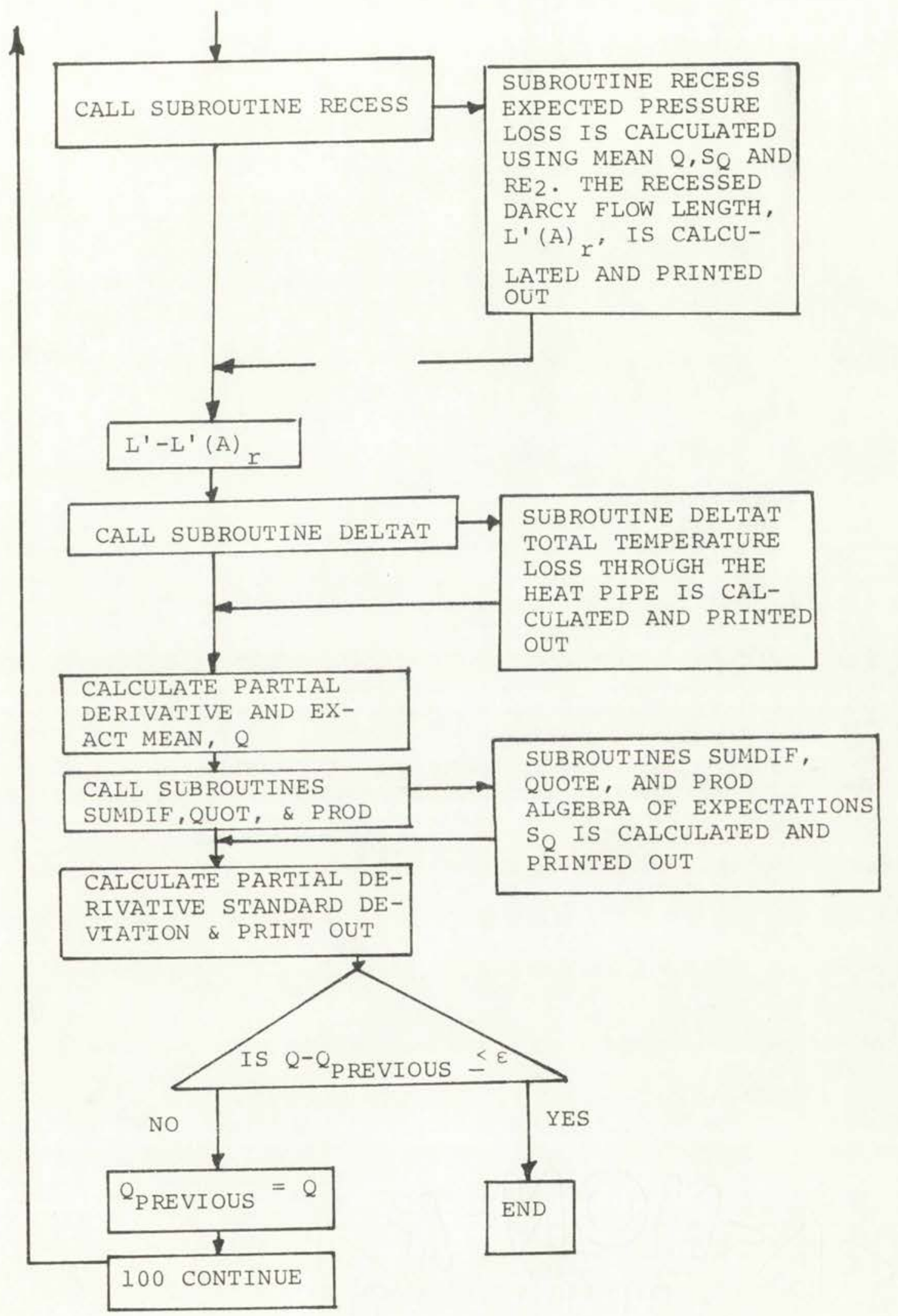

Figure 6.2. (continued) 

The probabilistic model was mentioned in Chapter 5 and is written below for the recessed condition

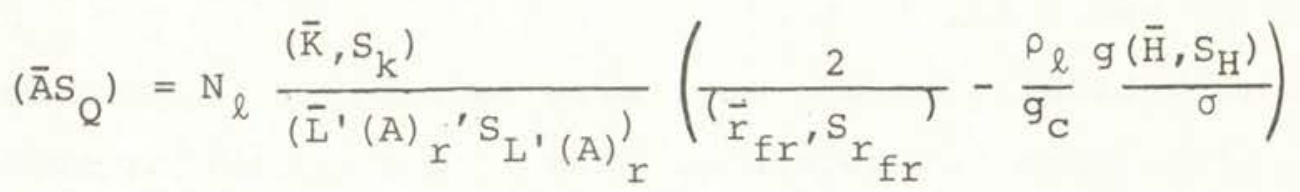

The assumptions are the same as the deterministic equation with the addition of the following:

a) $\mathrm{A}, \mathrm{K}, \mathrm{r}_{\mathrm{fr}} \mathrm{L}^{\prime}(\mathrm{A})_{r}$ and $\mathrm{H}$ are random variables and are described by simple two parameter continuous distributions.

b) Variabilities of all other parameters are considered small and are therefore deterministic

c) All random variables are independent

d) Coefficients of variation $\left(\bar{x} / s_{x}\right)$ are large (>7) for denominator random variables.

7.1 Comparison of Probabilistic Model with Experimental Data To test the validity of the probabilistic model, fifty heat pipe wicks were manufactured, tested, and their properties recorded in the Appendix and analyzed in Chapter 5. The following analysis will examine data set 2 in detail since this data set is composed of thirty tests and carries the most significance. The analysis for the other data sets are identical and will be mentioned throughout the discussion. For each of the fifty heat pipe wicks tested, K, A, L', and $r_{\text {fr }}$ were recorded. A steady state heat transfer rate was 

established and the evaporator section was raised until the wick began to dry out. The steady-state maximum heat transfer rate, $Q_{o b}$ ' was recorded along with the gravity effect, $H$, at dry out. The experimental values of $K, A, L^{\prime}, r_{f r}$ and $H$ were inserted into the recession design equation, Equation 2.57, and $Q_{\text {ca }}$ was calculated. The deviation of the observed experimental mean heat transfer rate from the calculated mean heat transfer rate, $Q_{C O}-Q_{o b}$ ' was calculated for each test. Table 7. 1 shows the mean and standard deviation of $Q_{C a}-Q_{o b}$. The mean difference, $Q_{C a}-Q_{O b}$, was small in all cases when compared to the standard deviation. We will test this hypothesis using the following Student's T Statistic, 17

$$
\begin{aligned}
T_{\text {calc. }} & =\frac{|\mathrm{D}|(\mathrm{n})^{1 / 2}}{\mathrm{~S}_{\overline{\mathrm{D}}}} \sim \mathrm{T} \alpha / 2(\mathrm{n}-1) \\
\overline{\mathrm{D}} & =\sum_{i=1}^{\mathrm{n}} \frac{\mathrm{Q}_{\mathrm{Ca}}-\mathrm{Q}_{\mathrm{Ob}}}{\mathrm{n}}
\end{aligned}
$$

If the calculated $T$ value, Tcalc., is less than the critical $T$ value at the $\alpha=.005$ significance level, we will accept the hypothesis that there is no significant difference between $Q_{C z}$ and $Q_{\text {ob }}$. Table 7.1 shows the results of the hypothesis test. At every heat transfer rate, the mean observed heat transfer rate was not significantly different from the mean calculated heat transfer rate. This indicates that Equation 2.57 is a good predictor of the mean heat transfer rate. Figures 7.7 through 7.11 show plots of the data from Table 7.2 and a comparison of the mean maximum calculated heat transfer rate with experimental data for each of the data sets. Figures 7.1 through 7.3 show the distribution of $Q_{c a}-Q_{o b}$, which is called the difference distribution. Appendix A shows values of $Q_{C a}$ and $\mathrm{S}_{\mathrm{Ca}_{\mathrm{C}}}$ for all the heat pipes tested. 



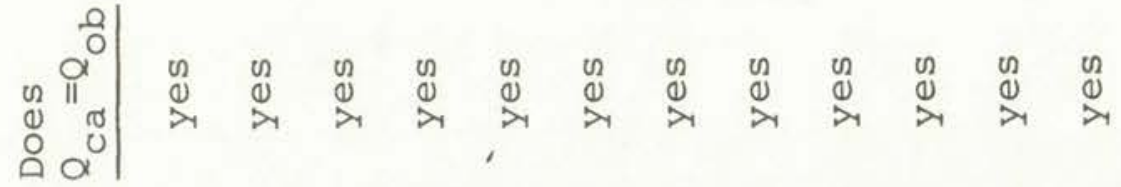

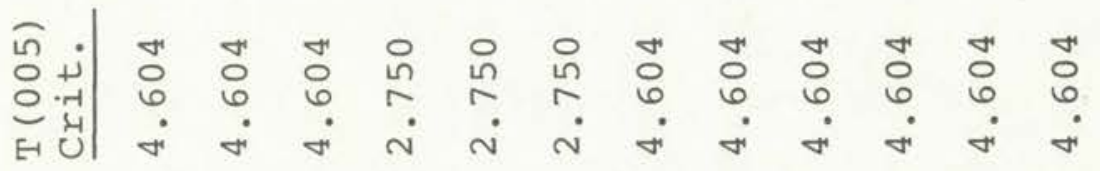

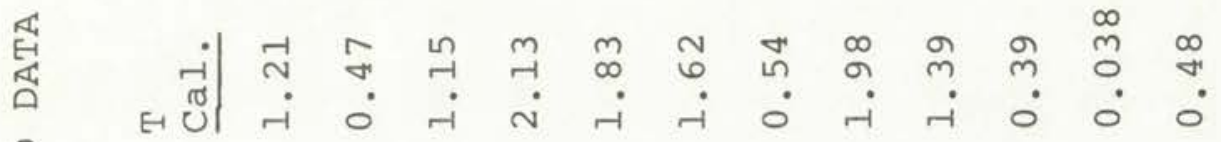

$$
\begin{aligned}
& \text { 焦 } \\
& \therefore \text { 叓 }
\end{aligned}
$$

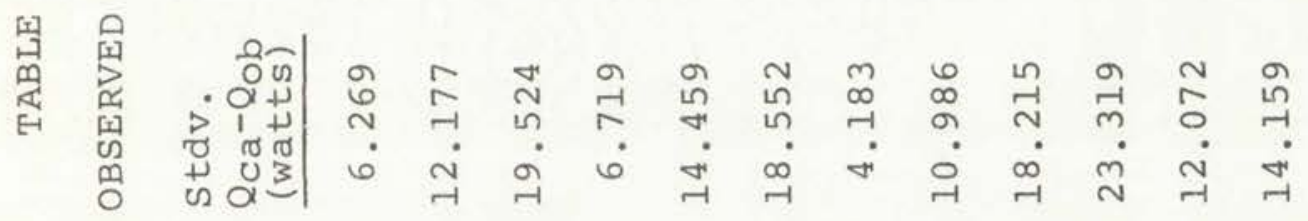

$$
\begin{aligned}
& \text { 떵 }
\end{aligned}
$$

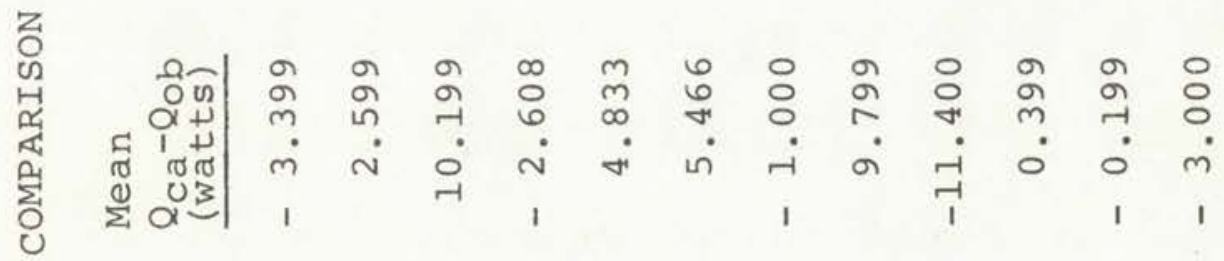

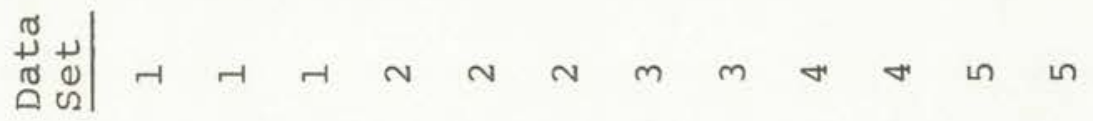

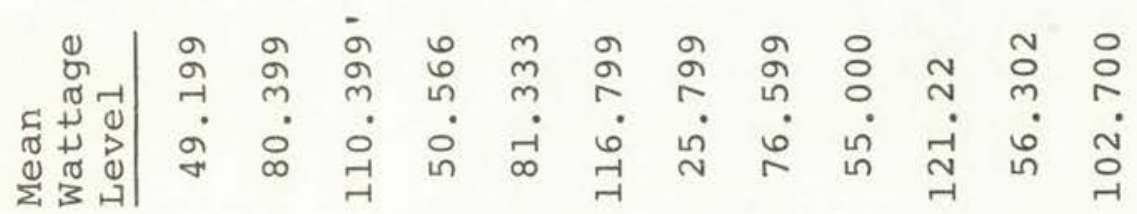




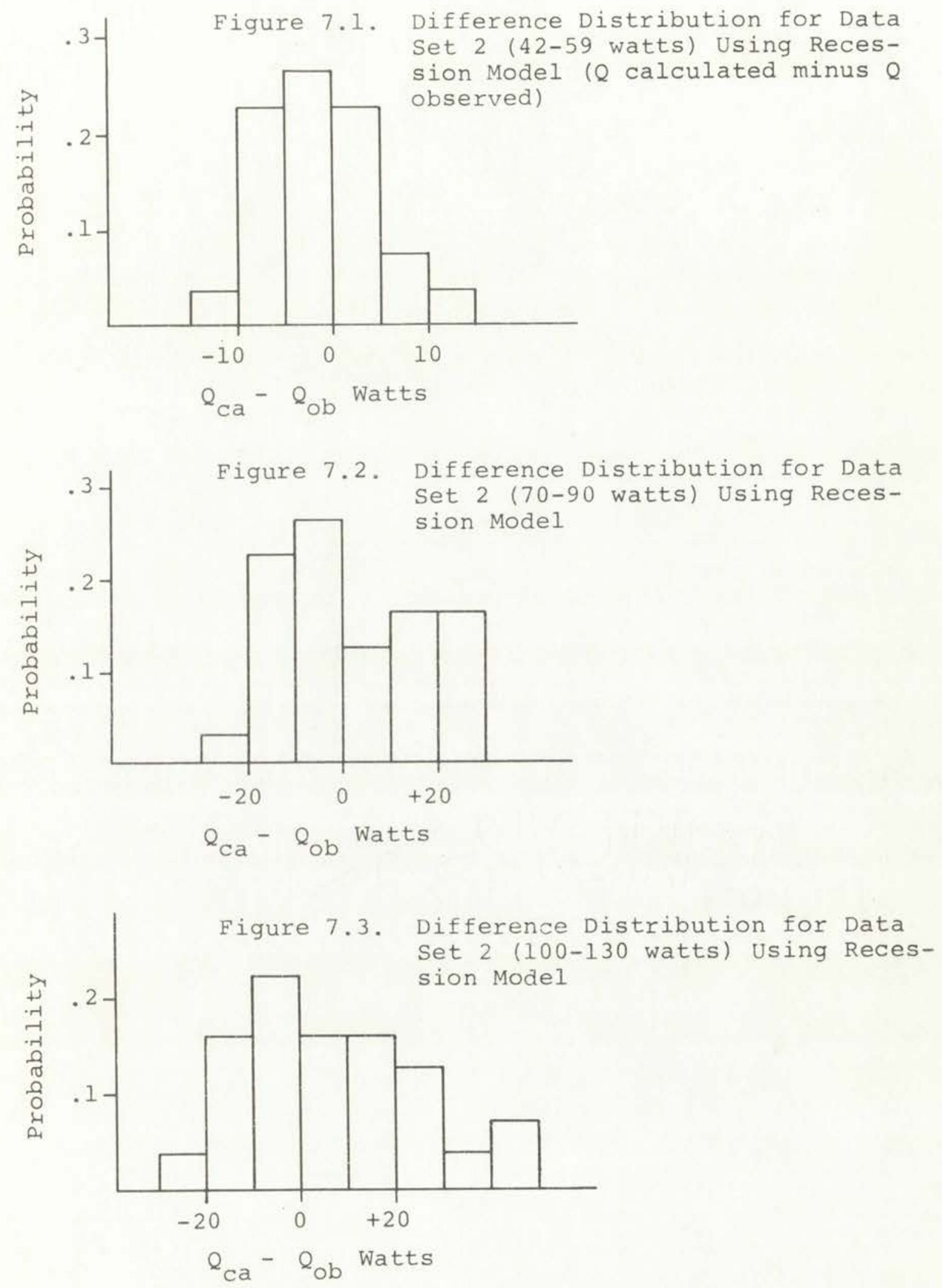

These values were calculated from Equation 2.57 using the simulation technique. 200 random variables were calculated for each simulation and the resultant $Q_{C a}$ distribution did not reject the Kolmogorov Smirnov significance test at $99 \%$ significance. The distribution of $Q_{\mathrm{Ca}}$ was hypothesized as normal. The uncertainty bound on the predicted heat transfer rates for each pipe will be plus or minus three standard deviations from the mean since these limits will encompass $99.7 \%$ of the $Q_{c a}$ Normally distributed random variables. If the observed heat transfer rate lies in this region of plus or minus three standard deviations of $Q_{\mathrm{ca}^{\prime}}$ the probabilistic design equation is credited as having predicted the occurrence of the experimental result, $Q_{o b}$. If $Q_{o b}$ falls outside the three standard deviation bounds, the probabilistic design equation will be considered inadequate in the prediction of the occurrence of $Q_{o b}$. Referring to the data of Appendix $B$, each of the 135 observed heat transfer rates, Q ob' were within the three standard deviations of $Q_{\mathrm{Ca}}$. If we assume that the three standard deviation bound on the variability of the calculated heat transfer rate to be correct, then the probability of observing $Q_{\text {ob }}$ within these bounds will be .9972 . From 135 tests, all the observed heat transfer rates were within these bounds. The probability of observing 135 observed heat transfer rates within the three standard deviation bound and 0 outside the bound is $(.9972)^{135}$ or .668 . This indicates a high probability that the calculated variability of the observed heat transfer rate, $\mathrm{s}_{\mathrm{q}}$ ' is correct 



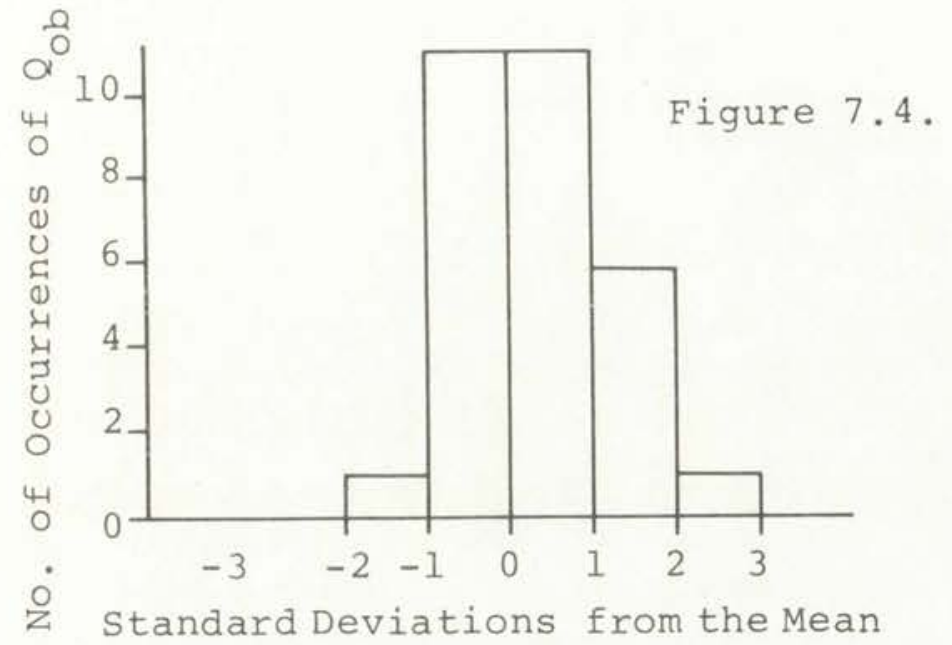

Distribution of $Q_{C a}$ about Qob for 100Mesh Stainless Steel, Two Layer Wicks at a Mean Wattage of 50.566
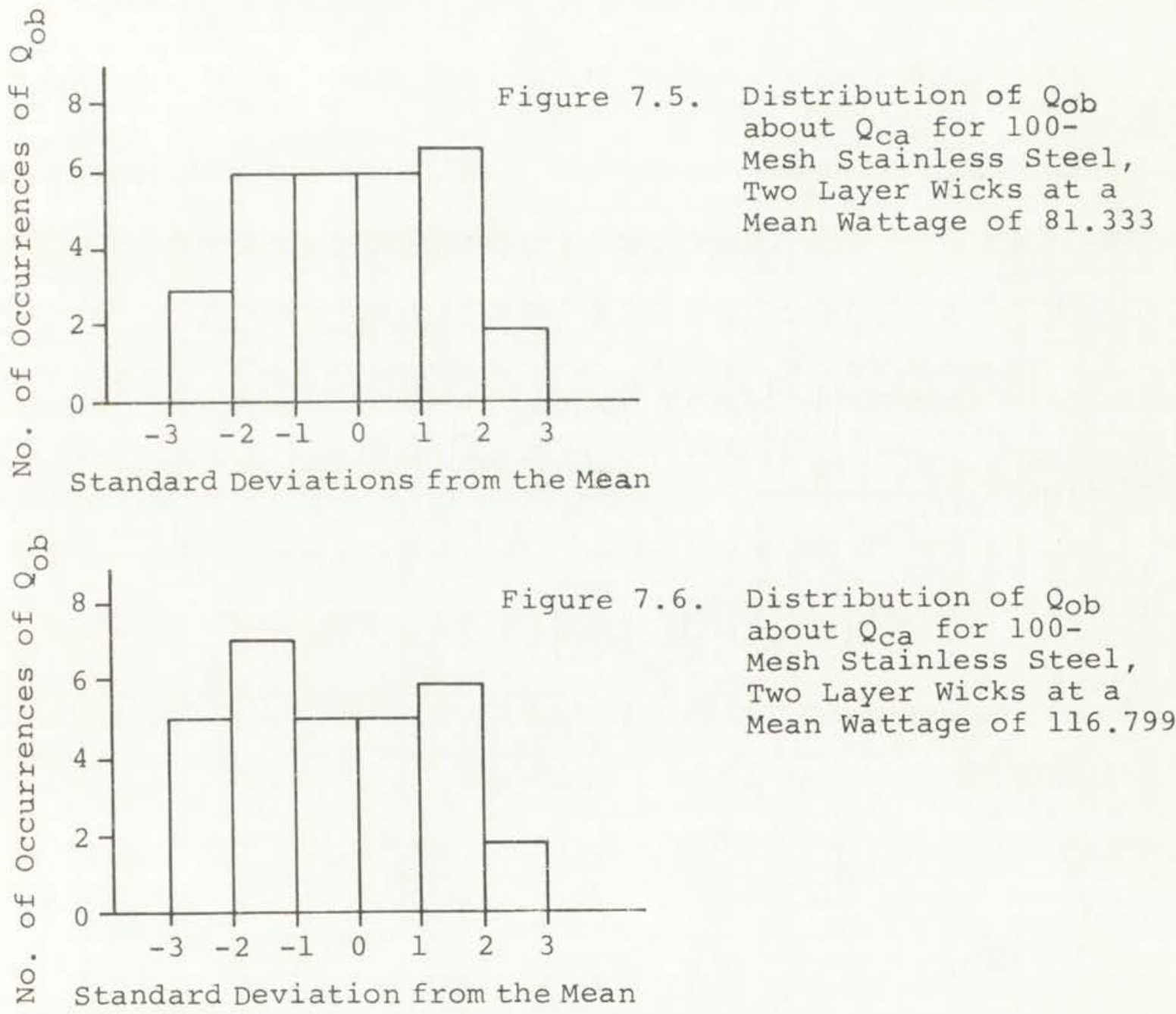


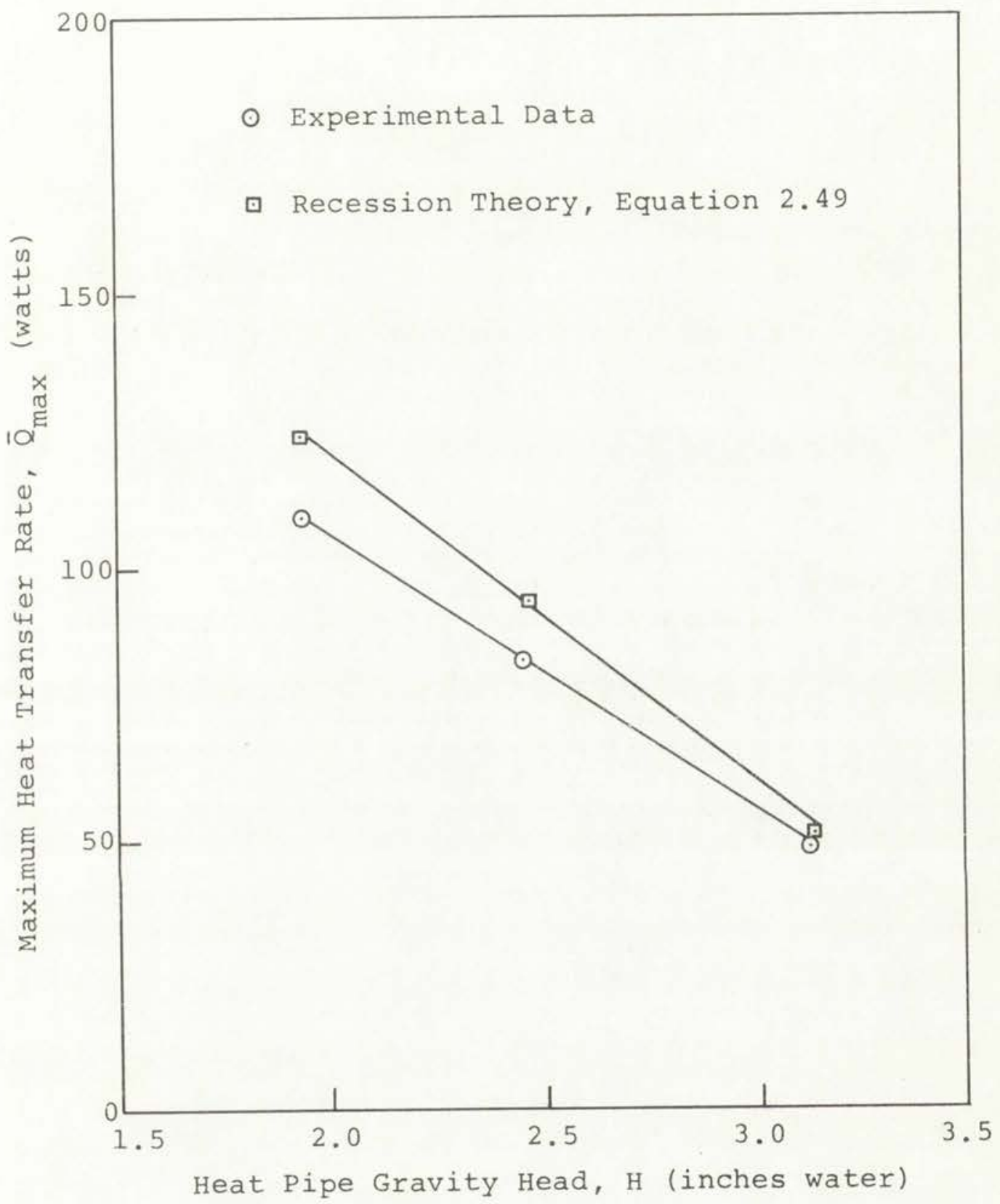

Figure 7.7. Comparison of the Mean, Maximum Heat Transfer Rate with Experimental Data from Data Set 1 (100 mesh stainless steel two layer wicks, tight wrap) 



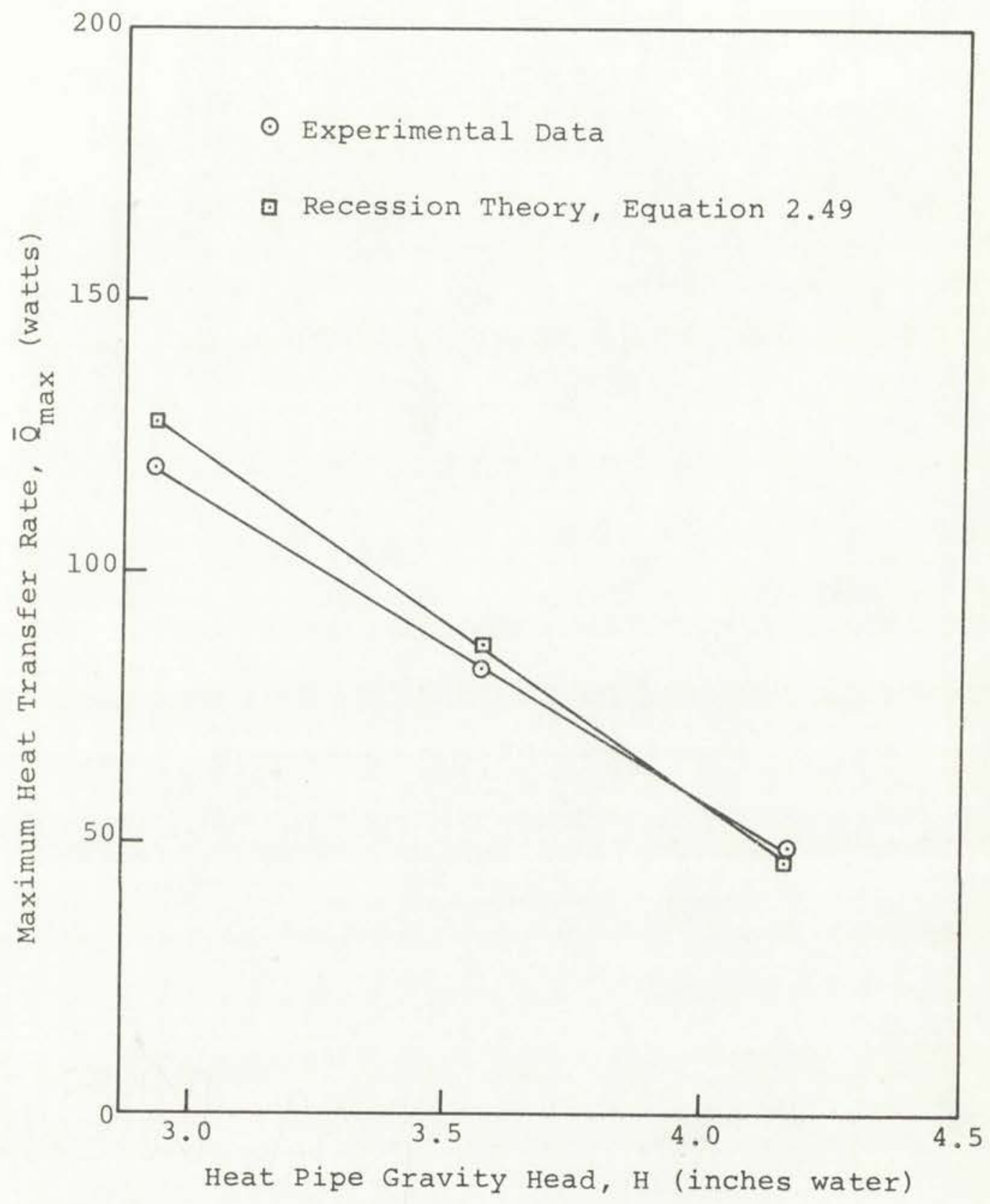

Figure 7.8. Comparison of the Mean, Maximum Heat Transfer Rate with Experimental Data from Data set 2 (100 mesh stainless steel two layer wicks) 



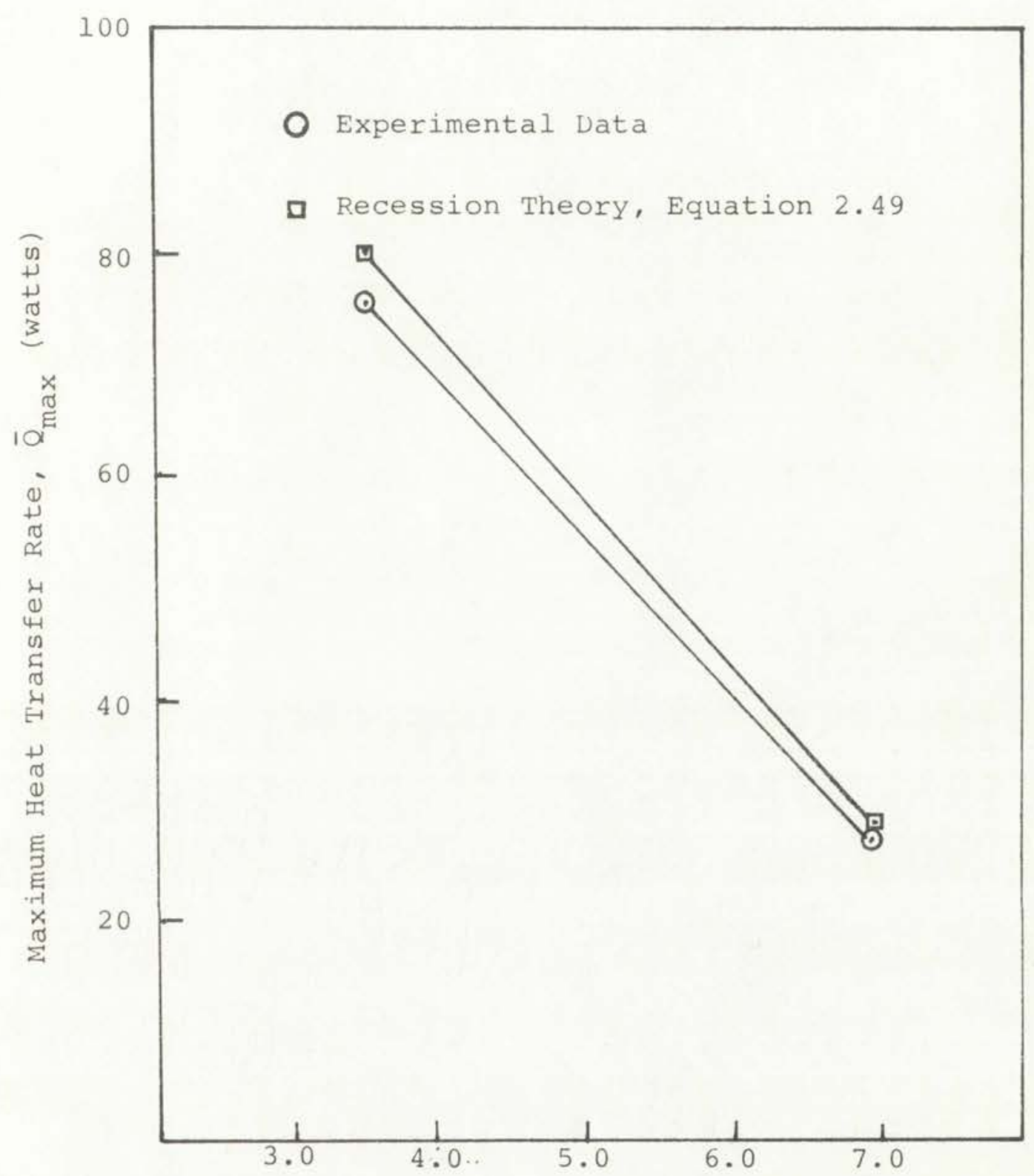

Figure 7.9. Comparison of the Mean, Maximum Heat Transfer Rate with Experimental Data from Data set 3 (200 mesh stainless steel 3 layer wicks) 



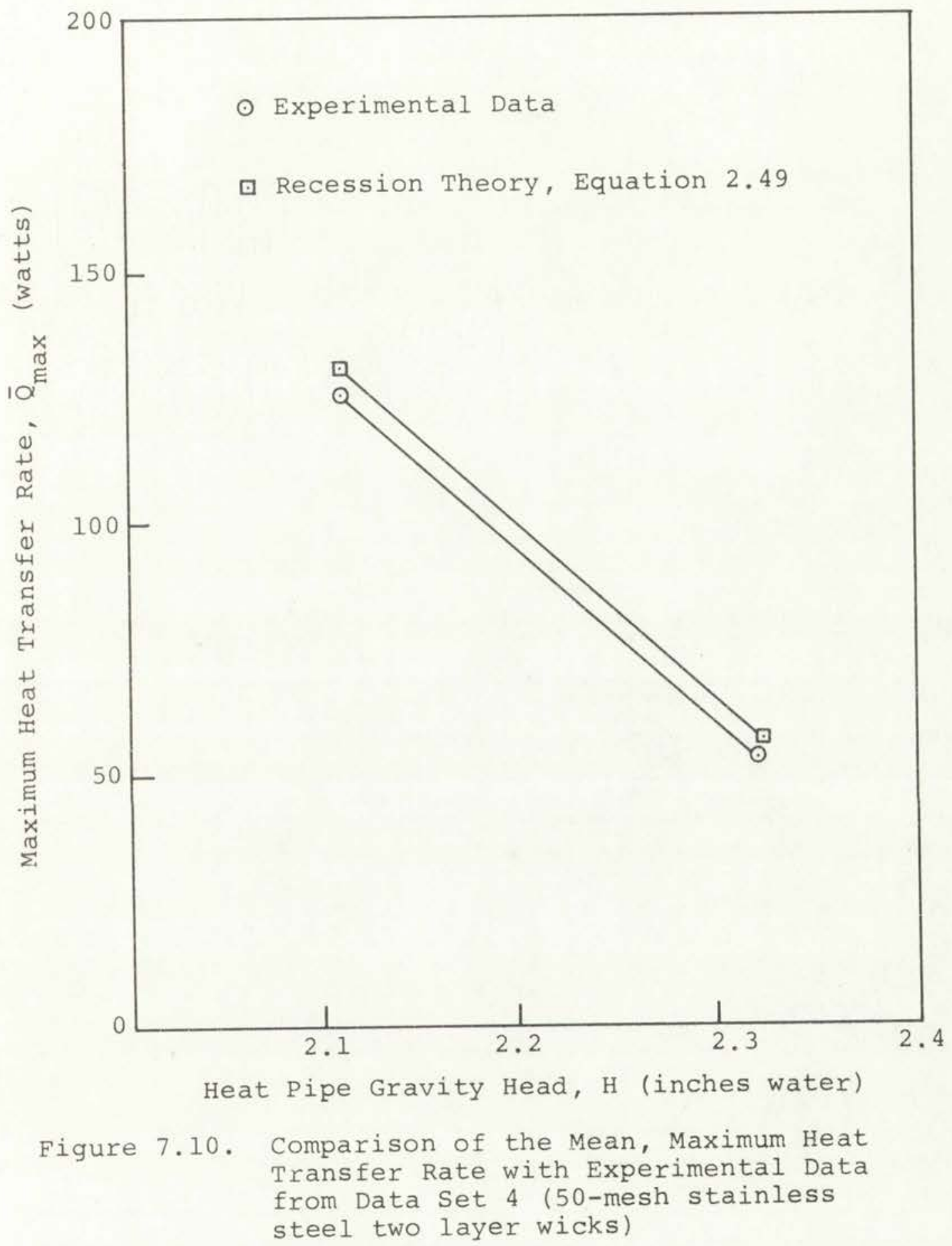





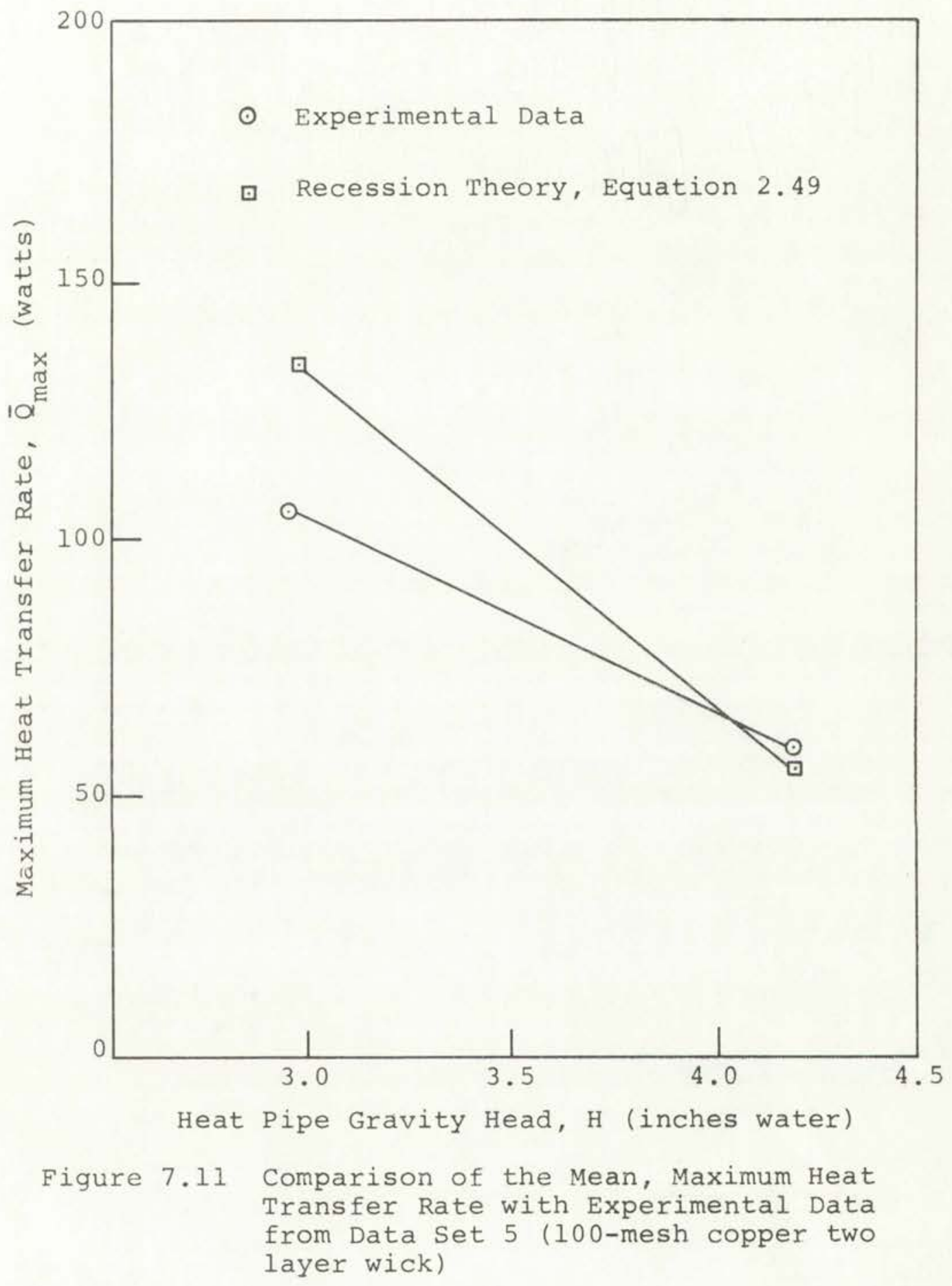



according to data from 135 tests. Figures 7.4, 7.5, and 7.6 show the distribution of the observed heat transfer rate, $Q_{o b}$, about the mean calculated heat transfer rate, $Q_{\text {ca }}$ for data set 2. The distribution of Figure 7.4 did not reject the Komogrov-Smirnov significance test when tested for Normality and neither did the distributions of Figures 7.5 and 7.6 . However, as heat transfer rate increased, the occurrence of Qob appeared more likely at the tails of the distributions and the resulting distributions became flatter than expected. The consistency of predicting the range of occurrence of Q ob using Equation 2.56 is evident. However, some basic numerical problems may result in applications to low heat transfer rates at high gravity effect and also to low heat transfer rates at high permeabilities. Upon examination of our mathematical model below, we can readily see how problems

$$
Q=N_{\ell} \frac{K}{L^{\prime}(A)_{r}}\left(\frac{2}{r_{f r}}-\frac{\rho_{\ell} g H}{g_{C}{ }^{\sigma}}\right)
$$

arise. Shown below are two sample calculations using data from data set 2 . One calculation has a high gravity head

$$
\begin{aligned}
Q & =N_{\ell} \frac{K}{L^{\prime}(A)_{r}}\left(\frac{24 .}{4.069 \times 10^{-3}}-\frac{62.4(2.96)}{4.4 \times 10^{-3}(12)}\right) \begin{array}{l}
\text { (Low } \\
\text { Gravity } \\
\text { Loss) }
\end{array} \\
Q & =N_{\ell} \frac{K}{L^{\prime}(A)_{r}}(5900-3500) \\
Q & =N_{\ell} \frac{K}{L^{\prime}(A)_{r}}\left(5900-\frac{62.4(4.21)}{4.4 \times 10^{-3}(1.2)}\right) \begin{array}{l}
\text { (High } \\
\text { Gravity } \\
\text { Loss) }
\end{array} \\
& =N_{\ell} \frac{K}{L^{\prime}(A)_{r}}(5900-5000)
\end{aligned}
$$

loss while the other has a low gravity loss. Notice at the 

high gravity head loss the subtraction of the two rather large numbers. This shows the classic numerical problem of loss of significance when subtracting two nearly identical numbers. Such a problem was discussed in Chapter 6 and if one refers to Table 6.3 of Chapter 6 the sensitivity of this computation to error at relatively small standard deviations can be realized. Input standard deviations for the surface tension term are on the order of $5 \%$ and the gravity terms are approximately $1 \%$. As shown on the previous page, these particular values of standard deviation lead to problems at low heat flow since the surface tension and gravity terms are on the order of magnitude of 5000. If one refers to Chapter 6 , Table 6.3, we can observe a reliable prediction of the mean of the difference function. Despite the high resultant standard deviation, the error in the mean (calculated by simulation) is small in comparison (about 10\%). We may conclude that although low heat flow (near wick dry out) standard deviation calculations may be unreliable, the mean heat flow calculation is quite good as indicated by the data discussed earlier in this chapter. If calculations must be made in the low heat flux range (less than 50 watts and near burn out), the resultant calculated standard deviations of heat flow will probably be conservative. Another numerical problem results at high permeabilities and low critical heat transfer rates. This is exemplified in data set 4 of the appendix (50 mesh stainless steel wicks). The permerability was large and the capillary pumping term was small resulting in a loss of significance in the difference term. 

This resulted in extremely large calculations of standard deviation and seemed too conservative as indicated by the data.

We have been examining the prediction of heat transfer rate knowing the properties of the particular wick tested. If one wishes to design a heat pipe using the manufacturing technique of Chapter 3, then the wick properties of Table 4.23 should be used. These property values give the range of occurrence of wick properties for a particular heat pipe manufactured. Table 7.2 shows the mean calculated wattage and standard deviation at various values of $\mathrm{H}$, using the three techniques mentioned in Chapter 6 . The wattage values of Table 7.2 give the range of maximum heat transfer rate one might expect if a heat pipe was designed and operated at the particular gravity effect, H. Notice that the calculated standard deviations are quite high due to the high standard deviations of the input properties of Table 4.23 . The three techniques used to solve the probabilistic design equation were quite close. The simulated results were slightly higher than the rest due to high variability in the denominator random variables. Now that the variability of the manufacturing process has been described, its applicability to design will be discussed.

\subsection{Results of the Probabilistic Design}

Assume that our design specification required that a particular heat pipe of this design operate at 75 watts at a gravity head of $2.96 " \mathrm{H}_{2} \mathrm{O}$. Referring to data set 2 , the results of the probabilistic model $\left(\mathrm{H}=2.96 " \mathrm{H}_{2} \mathrm{O}\right)$ yields

$$
\text { Mean heat flow } \quad 125.707 \text { watts }
$$





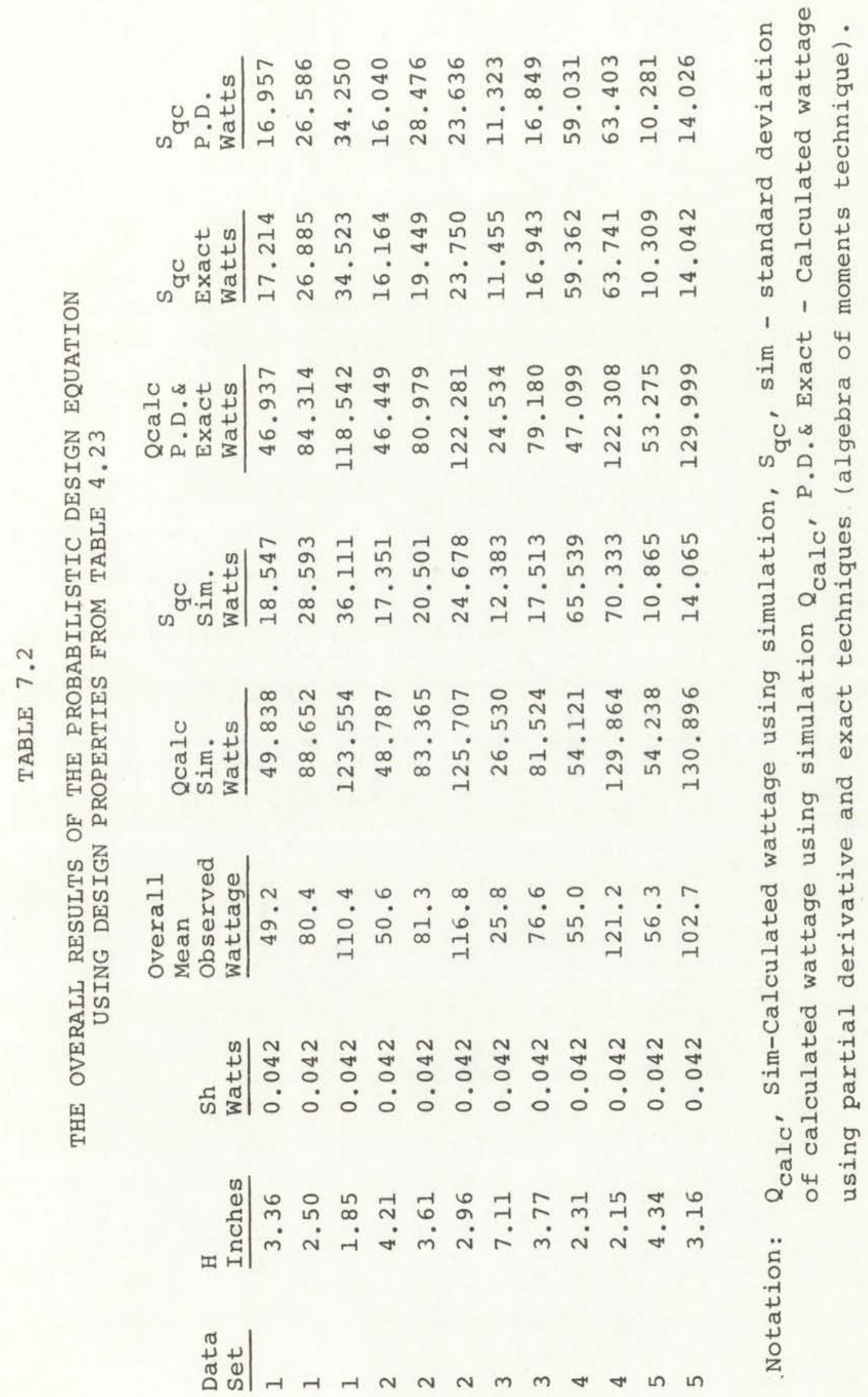





\section{Standard deviation 24.678 watts \\ Distribution \\ Normal (passes Kolmogorov significance test)}

Assuming the estimates of the mean and standard deviation to be perfect, the probability of failure for this heat pipe at 75 watts is

$$
\begin{aligned}
& \frac{125.707-75}{24.678}=2.06=.98 \\
& \begin{aligned}
1-.98 & =\text { probability of failure } \\
& =.02
\end{aligned}
\end{aligned}
$$

Since 30 samples were required for the estimation of the mean and standard deviation of the heat flows these estimates are by no means perfect. Due to the randomness of these estimates we will quote a maximum probability of failure at some confidence level. Using tolerance theory, ${ }^{17}$ we may conclude that the upper tolerance limit of the probability of failure for this heat pipe design is .10 at a confidence of $99 \%$, or that we are $99 \%$ confident that the probability of failure does not exceed .10. These tolerance limit values were computed from a table based on a given mean, standard deviation and sample size. This result indicates that the maximum amount of failures one might expect from 100 units of this design is 10 units. If this probability of failure is unacceptable, we can decrease the probability of failure by changing design parameters such that the meam heat flow is larger. For example, we can enlarge the wick area and one 

might calculate a heat flow of 150.00 watts at a standard deviation of 25 watts with a maximum probability of failure of .025 or 175 watts at a standard deviation of 30 watts with a .005 probability of failure. The difference between the mean calculation and the specification will indicate the risk one takes in designing a certain heat flow. The design distribution can be manipulated to minimize the risk of producing below specification. The reliability of this design is an initial start up reliability. An increase in failure probability may occur due to gas generation in the heat pipe. The resulting gas may block the condenser.

\subsection{Heat Pipe Temperature Drop}

The heat pipe thermal analog circuit appears in Figure 7.12. Applying this analysis to our low mass flow water heat pipes, we are allowed to neglect the evaporation temperature loss ( $\left.T_{\text {ew }}-T_{e v}\right)$, the vapor flow loss $\left(T_{e v}-T_{c v}\right)$ and the condensation temperature loss $\left(\mathrm{T}_{\mathrm{CV}}-\mathrm{T}_{\mathrm{CW}}\right)$. These conclusions were a result of inserting the maximum expected mass flow rate, $(.7$ $1 \mathrm{bm} / \mathrm{hr}$ ) into the pressure loss equation, 7.5 (derived from kinetic theory) and the clausius equation, 7.6.

$$
\begin{aligned}
& \Delta \mathrm{P}=\frac{\mathrm{m \alpha}}{\mathrm{g}_{\mathrm{C}}^{2 \pi r L}} \sqrt{\frac{2 \pi \mathrm{RTg} \mathrm{C}}{\mathrm{M}}} \quad \begin{aligned}
\text { where } \mathrm{R} & =\begin{array}{l}
\text { Universal Gas } \\
\text { Constant }
\end{array} \\
\mathrm{M} & =\text { Molecular Weight }
\end{aligned} \\
& \Delta \mathrm{T}=\mathrm{T} \Delta \mathrm{P} / \rho \mathrm{h}_{\mathrm{fg}} \mathrm{J}
\end{aligned}
$$

Figure 7.12 shows the general thermal analog circuit and our thermal circuit is reduced to

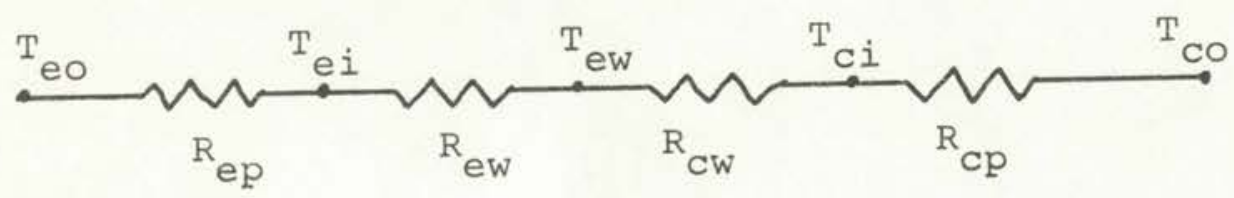



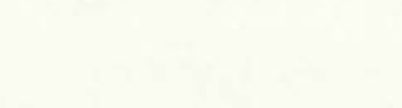

. 


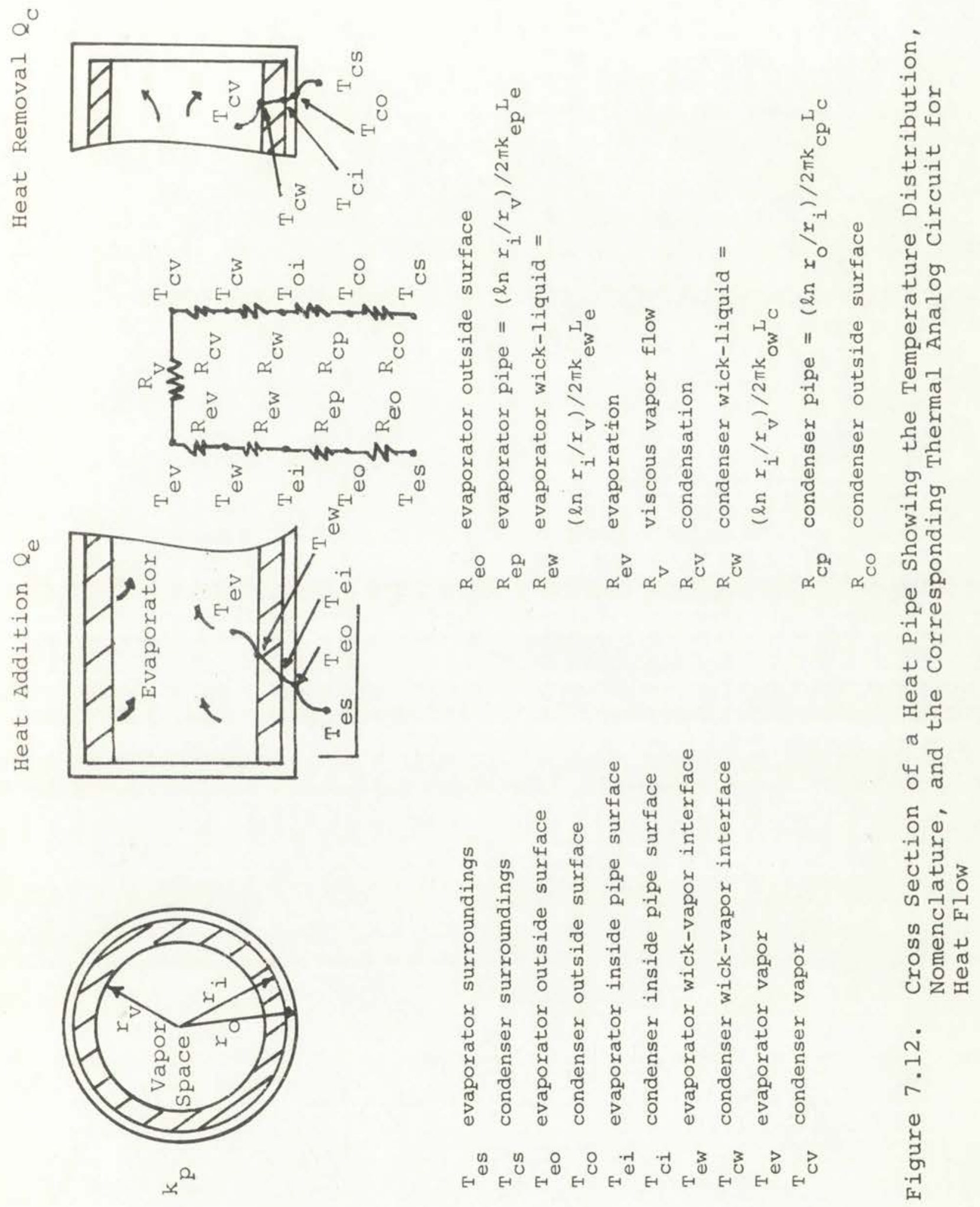



where

$$
\begin{aligned}
& R_{e p}=\ln \frac{r_{0} / r_{i}}{2 \pi k_{p} L_{E}} \\
& R_{c w}=\ln \frac{r_{i} / r_{v}}{2 \pi k_{w} L_{c}} \\
& R_{e w}=\ln \frac{r_{i} / r_{v}}{2 \pi k_{w} L_{E}} \\
& R_{c p}=\ln \frac{r_{0} / r_{i}}{2 \pi k L_{p}}
\end{aligned}
$$

This inodel should adequately describe temperature loss assuming the fully wetted wick. For the fully recessed situation near burn out, the evaporator wick resistance is modified as follows

$$
\begin{aligned}
& R_{E W}=R_{P R W} \times R_{F R W} / R_{P R W} \times R_{F R W} \\
& R_{P R W}=\ln r_{e} /\left(r_{0}+1 / 4\left(r_{i}-r_{0}\right)\right) / 2 \pi k_{l}\left(L_{e}-L_{f r}\right) \\
& R_{F R W}=\ln r_{i} /\left(r_{0}+.41\left(r_{i}-r_{0}\right) / 2 \pi k_{l}\left(L_{f r}\right)\right.
\end{aligned}
$$

It is assumed that the fully and partially recessed areas of the evaporator wick section combine in parallel to form a total resistance.

The thermal conductivity of the wick-fluid matrix is difficult to determine, but may be approximated by

$$
\mathrm{k}_{\mathrm{w}}=\varepsilon \mathrm{k}_{\ell}+(1-e) \mathrm{k}_{\mathrm{s}}
$$

assuming that the wick is well bonded to the pipe wall (little wick-pipe thermal resistance). This equation is inaccurate in 

our particular case because of the poor pipe-wick contact and oxide coatings which yield a high thermal resistance as shown in Figure 7.13. It is therefore assumed that the wick contact resistance with the wall is on the same order of magnitude as that of the fluid and thermal conductivity of the wick is essentially that of the liquid.

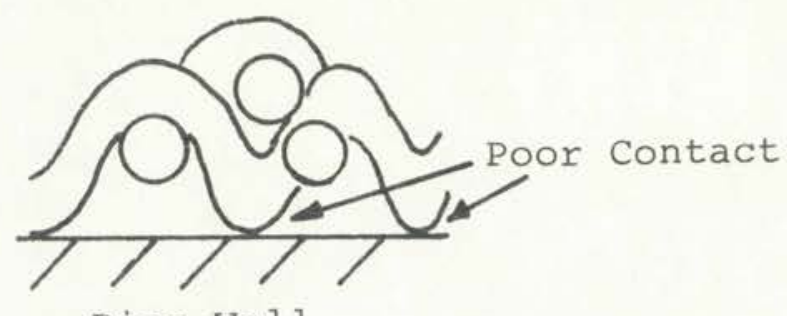

Pipe Wall

Figure 7.13. Wick Contact with Pipe Wall

As shown in Table 7.3 the stainless steel wick temperature loss predictions (using conductivity of the fluid as the wick conductivity) were always slightly higher than the observed temperature losses. The stainless steel wick has sufficient rigidity to allow some parallel heat paths to exist. However, the above assumption (conductivity of the wick equal to conductivity of the fluid) yields a conservative result and is more indicative of reality than the predictions of Equation 7. 11 .

The copper wicks, on the other hand, seemed to be described accurately by the fluid conductivity assumption. It is theorized that the copper wick lacks the rigidity for even mediocre thermal 



\section{TABLE 7.3}

TEMPERATURE LOSS PREDICTION (Recession Model)

\begin{tabular}{|c|c|c|c|c|c|}
\hline $\begin{array}{l}\text { Data } \\
\text { Set }\end{array}$ & Wattage & $\begin{array}{l}\text { Obs. } \\
\text { DT } \\
{ }^{\circ} \mathrm{F}\end{array}$ & $\begin{array}{l}\text { S obs. } \\
\text { DT } \\
{ }^{\circ} \mathrm{F}\end{array}$ & $\begin{array}{l}\mathrm{Calc} . \\
\mathrm{DT} \\
{ }^{\circ} \mathrm{F}\end{array}$ & $\begin{array}{l}\mathrm{S} C a l c \\
\mathrm{DT} \\
{ }^{\circ} \mathrm{F}\end{array}$ \\
\hline 1 & $42-59$ & 8.309 & 3.432 & 8.297 & 3.177 \\
\hline 1 & $70-90$ & 9.369 & 3.293 & 15.046 & 5.046 \\
\hline 1 & $100-130$ & 12.799 & 3.271 & 21.939 & 8.386 \\
\hline 2 & $42-59$ & 6.799 & 1.788 & 7.163 & 2.608 \\
\hline 2 & $70-90$ & 9.033 & 1.564 & 12.438 & 3.132 \\
\hline 2 & $100-130$ & 12.099 & 2.411 & 18.835 & 3.803 \\
\hline 3 & $20-30$ & 2.000 & 0.707 & 2.582 & 1.235 \\
\hline 3 & $60-80$ & 4.799 & 1.923 & 8.070 & 1.743 \\
\hline 4 & $50-60$ & 7.399 & 1.341 & 16.362 & 21.767 \\
\hline 4 & $100-130$ & 14.600 & 2.191 & 41.899 & 23.400 \\
\hline 5 & $45-55$ & 7.400 & 1.516 & 7.789 & 1.638 \\
\hline 5 & $90-120$ & 16.400 & 1.949 & 18.980 & 2.352 \\
\hline
\end{tabular}

Note: a) Obs DT - mean observed temperature loss

b) S obs DT - standard deviation of observed temperature loss

c) Calc. DT - calculated mean temperature loss using recession model

d) S calc. DT - standard deviation of the calculated temperature loss 

contact with the pipe wall and that essentially no parallel heat flow paths exist.

Figure 7.14 shows a typical wire mesh heat pipe temperature distribution. Refer to the appendix data sets for vapor temperature and temperature loss. 


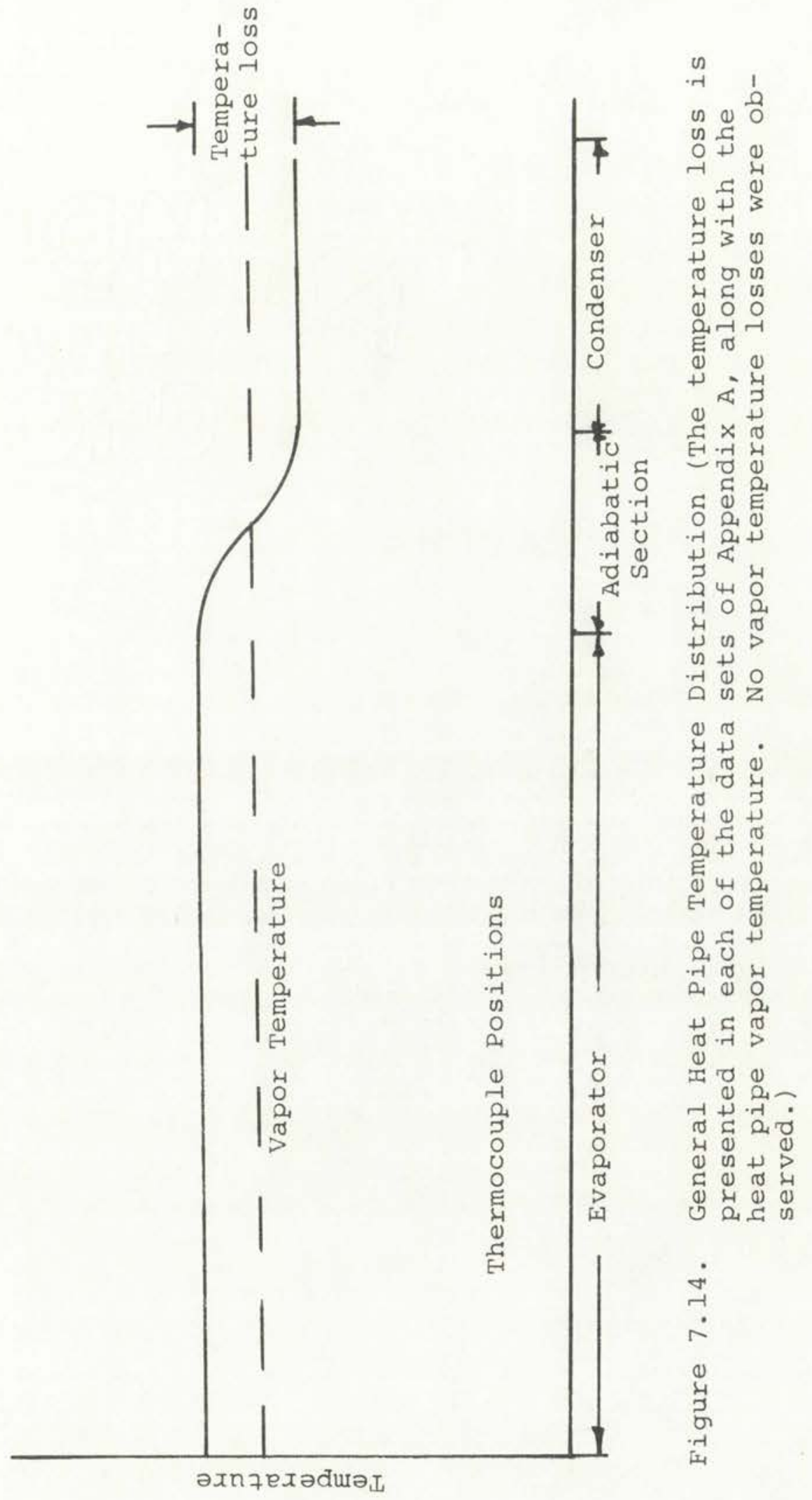



CHAPTER 8

CONCLUSIONS

8.1 Probabilistic Design

The probabilistic approach to design is illustrated in this work. For any given deterministic design equation,

$$
A=F\left(x_{1}, x_{2}, \ldots x_{n}\right)
$$

that describes the behavior of some physical phenomenon, we may transform into the probabilistic domain where

$$
\begin{aligned}
R A= & F\left(R_{x_{1}}, R_{x_{2}}, \cdots R_{x_{n}}\right) \\
& R \text { indicates the particular variable to be } \\
& \begin{array}{l}
\text { random and described by some probability } \\
\text { function }
\end{array}
\end{aligned}
$$

The random result of the probabilistic design equation, RA, indicates the uncertainty of the design quantity to be predicted as a function of the input parameter uncertainties. The value of the probabilistic design is that it eliminates the requirement for safety factors (which are arbitrarily conceived and may not describe the situation at hand) in favor of a quantitative measure of the range of a design results. One can therefore indicate the probability of manufacturing a successful design hence predict it's reliability. Three methods for the solution of the probabilistic design equations are mentioned. They are
a) Simulation
b) Algebra of moments
c) Taylor approximation 

These methods work well in prediction of most design function variabilities but caution must be exercised in the handing of certain functions such as $R A-R B$ and $1 / R A$ at large coefficients of variation.

\subsection{Heat Pipe Design}

The recession model is quite reliable in the prediction of the mean heat flow capability of the wire mesh wick heat pipe. The prediction of heat flow standard deviations was good at high heat flows (therefore low gravity components). At low heat flows the magnitude of the gravity and surface tension terms approach each other to form the classical numerical problem mentioned in chapter 6. At these low heat flows, prediction of the standard deviation is conservative. The recession model is by no means perfect and the descrepancy of standard deviation predictions at low heat flows is inherent to this particular model.

Uncertainty in the description of heat pipe wicking properties is discussed. A "rule of thumb" for predicting undertainties in heat pipe properties is listed below in Table 8.1 . The variability of these properties are a result of experimental and manufacturing variability. It should be mentioned that the property data generated in this work describes the wicks manufactured by the process mentioned in Chapter 3 . other types of wire mesh designs may have significantly different properties. 

TABLE 8.1

UNCERTAINTY OF WICK PROPERTIES

AS A O OF THE MEAN PROPERTY

\section{Property}

Permeability, $\mathrm{K}$

Critical radius, re

Wick cross sectional

area, A

Porosity, e

Tortuosity, b
Standard Deviation in of Mean

$10 \%$

$5 \%$

$3 \%$

$3 \%$

$10 \%$ 

1. Haugen, E. B., "Probabilistic Approaches to Design," Wiley \& Sons, 1968.

2. Kreith, F., "Principles of Heat Transfer," International Textbook Company, Scranton, Pennsylvania, 1965.

3. Haring, R. E., and Greenkorn, R. A., "A Statistical Model of a Porous Medium with Non-Uniform Pores," AICHE Journal, May 1970.

4. Holm, F. W., and Miller, P. L., "Thermal Scale Modeling of a Heat Pipe," ASME publication 70-ht/spT-14, March 26, 1970 .

5. Phillips, E. C., and Hinderman, J. D., "Determination of Properties of Capillary Media Useful in Heat Pipe Design," ASME-AICHE Heat Transfer Conference, Minneapolis, Minnesota, August 3-6, 1969.

6. Kemme, J. E., "Heat Pipe Design Considerations," ASMEAICHE Heat Transfer Conference, Minneapolis, Minnesota, August 3-6, 1969.

7. Feldman, K. T., "Analysis and Design of Heat Pipes," Lecture notes, UCLA, June 22-26, 1970.

8. Kunz, H. R., and Langston, L. A., "Vapor Chamber Fin Studies," NASA Contractor Report CR-812, June 1967.

9. Chun, K. R., "Some Experiments on Screen Wick Dry-Out Limits," ASME publication 71WA/HT-6, November 28, 1971.

10. Seban, R. A., and Abhat, A., "Steady and Maximum Evaporation from Screen Wicks," ASME Winter Annual Meeting, ASME Paper 71 WA/HT-12, November 23, 1971.

11. Chats, J. C., and Strevkert, J. H., "Performance of a Wick-Limited Heat Pipe," ASME-AICHE Heat Transfer Conference, Minneapolis, Minnesota, August 3-6, 1969.

12. Birnie, C., Jr., Private Communication, Department of Mechanical Engineering, The Pennsylvania State University, University Park, June 15, 1971.

13. Benner, R., Private Communication, Department of Mechanical Engineering, Lehigh University, Bethlehem, Pennsylvania, June 17, 1971. 

14. Kemme, J. E., Private Communication, Los Alamos Scientific Laboratory, Los Alamos, New Mexico, March 8, 1971.

15. Stoeker, University of Illinois, Urbana, September 15, 1971.

16. Brownlee, K. A., "Statistical Theory and Methodology in Science and Engineering," Wiley \& Sons, 1965.

17. Miller, I., and Freund, J. E., "Probability and statistics for Engineers," Prentice-Hall, Inc., New Jersey, 1965.

18. Davis, H. T., Private Communication, Department of Mathematics and Statistics, The University of New Mexico, Albuquerque, 19 .

19. Van Andel, E., "Heat Pipe Design Theory," EURATOM CCR, Direct Conversation Division, Ispra, Italy.

20. Roberts, C. C., and Feldman, K. T., "Predicting Performance of Heat Pipes at High Heat Flux," to be presented at ASME Winter Annual Meeting, New York, November 1972. 

APPENDIX A

BASIC RAW DATA

DATA NOMENCLATURE

The following is an explanation of data format.

\begin{tabular}{|c|c|c|}
\hline K & Wick permeability as described by Darcy & $\left(F t^{2}\right)$ \\
\hline SK & Standard deviation of permeability & $\left(F t^{2}\right)$ \\
\hline & $\begin{array}{l}\text { Effective capillary critical radius based } \\
\text { on two layers of screen }\end{array}$ & (inches) \\
\hline & Standard deviation of critical radius & (inches) \\
\hline & Flow area of the wick & $\left(F t^{2}\right)$ \\
\hline & Standard Deviation of flow area & $\left(F t^{2}\right)$ \\
\hline I LAYER & $\begin{array}{l}\text { Capillary pressure capability of one } \\
\text { layer of wire mesh }\end{array}$ & (in. $\mathrm{H}_{2} \mathrm{O}$ ) \\
\hline I LAYER & $\begin{array}{l}\text { Capillary pressure capability of two } \\
\text { layers of wire mesh }\end{array}$ & (in. $\mathrm{H}_{2}$ \\
\hline
\end{tabular}

SUB TEST FORMAT

VAPOR Heat pipe vapor temperature at equiTEMP librium

H Total gravity head loss experienced by heat pipe

(in. $\mathrm{H}_{2} \mathrm{O}$ )

SH

Standard deviation head loss

(in. $\mathrm{H}_{2} \mathrm{O}$ )

ALPP

Darcy effective flow length (L') for non recession model

$$
K=\frac{\mu L^{\prime} \dot{m}}{\rho A \Delta \bar{P}}
$$

SRALPP Standard deviation of Darcy effective flow length non recessed model

Note: Each of the standard deviations are a result of experimental error in determination of the particular properties 


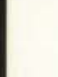


ALPPR

SRALPR

RL

SRL

CALC

WATTS $\mathrm{R}$

SWR

CALC

WATTS

SW

OBS

WATTS

DT CALC

SDT

OBS DT
Darcy effective flow length for recession model

flow length recession model
(Ft)

(Watts)

(Watts)

(Watts)

(Watts)

(Watts)

Experimentally observed wattage capability of a heat pipe with the above mentioned properties

Heat pipe wattage capability using non recessed model Eq( )

Standard deviation of CALC WATTS

Calculated temperature drop from evaporator surface to condenser surface. All

vapor temperature drops were negligible

Standard deviation of DT CALC

Experimentally observed temperature drop along a heat pipe with the above mentioned properties 

TEST DATA SHEET FOR DATA SET \#I

\begin{tabular}{|c|c|c|}
\hline SK & 1.9260 & E-10 \\
\hline $\mathrm{RE}$ & 4.0550 & $E-03$ \\
\hline SR & 1.0000 & $E-04$ \\
\hline A & 2.2830 & $E-04$ \\
\hline $\mathrm{SA}$ & 5.0400 & $E-06$ \\
\hline I LAYER & 5.0000 & \\
\hline II LAYER & 5.6250 & \\
\hline
\end{tabular}

18

5.2460

2. $8740=10$

$4.2470 \mathrm{E}-03$

$1.0000 \mathrm{E}-04$

2. 3750 E-04

5.2000 E-06

4.1250

5.3640

(42-59W)

SUB TEST)

\begin{tabular}{lr} 
VAPOR TEMP & \multicolumn{1}{l}{140} \\
H & 3.0600 \\
SH & 0.0417 \\
ALPP & 1.0400 \\
SRALPP & 0.0300 \\
ALPPR & 1.3260 \\
SRALPR & 0.0651 \\
RL & 1.0410 \\
SRL & 0.3210 \\
CALC WATTS R & 48.1120 \\
SWR & 5.3890 \\
CALC WATTS & 60.0870 \\
SW & 5.7640 \\
OBS WATTS & 55.0000 \\
DT CALC & 8.3830 \\
SDT & 1.0700 \\
OBS DT & 10.0000
\end{tabular}

140

3. 2700

0.0417

1.0400

0.0300

1. 3380

0.0769

1. 2080

0.4500

49.0530

7.9690

60.8100

8.4360

52.0000

8.6460

1. 6870

7.0000
146

3.7400

0.0417

1.0400

0.0300

1. 3430

0.0700

0.7910

0.2890

42.4140

5.6810

54.0170

6.3500

53.0000

7.1740

1.0530

8.0000

(CONTINUED) 



\section{(70 - $90 w$}

SUB TEST)

\begin{tabular}{lr} 
VAPOR TEMP & \multicolumn{1}{l}{165} \\
H & 2.5000 \\
SH & 0.0417 \\
ALPP & 1.0400 \\
SRALPP & 0.0300 \\
ALPPR & 1.3380 \\
SRALPR & 0.0748 \\
RL & 1.1240 \\
SRL & 0.4270 \\
CALC WATTS R & 67.0410 \\
SWR & 7.2360 \\
CALC WATTS & 83.7070 \\
SW & 8.0990 \\
OBS WATTS & 78.0000 \\
DT CALC & 11.9080 \\
SDT & 1.4090 \\
OBS DT & 15.0000
\end{tabular}

\section{6}

2. 2500

0.0417

1. 0400

0.0300

1. 3600

0.0965

1. 2080

0.5760

101.8750

14.4850

127.7850

18.4170

84.0000

18.2870

3. 0880

9.0000
182

2. 7600

0.0417

1. 0400

0.0300

1. 3440

0.0722

0.8330

0.2830

85.6470

9. 2860

100.4470

12.4160

80.0000

14.7720

1. 7190

8.0

$(100-130) \mathrm{W}$

SUB TEST)

\begin{tabular}{lr} 
VAPOR TEMP & \multicolumn{1}{l}{198} \\
H & 1.8000 \\
SH & 0.0417 \\
ALPP & 1.0400 \\
SRALPP & 0.0300 \\
ALPPR & 1.4140 \\
SRALPR & 0.1300 \\
RL & 1.2080 \\
SRL & 0.7490 \\
CALC WATTS R & 96.3000 \\
SWR & 12.0020 \\
CALC WATTS & 118.9330 \\
SW & 10.6320 \\
OBS WATTS & 110.0000 \\
DT CALC & 17.1850 \\
SDT & 2.2210 \\
OBS DT & 18.0000
\end{tabular}

\section{5}

1. 8700

0.0417

1. 0400

0.0300

1. 4280

0.1490

1. 2080

0.8100

136.1640

22.0540

169.8960

26.3460

110.0000

24.3230

4. 2000

13.0000
204

2. 0800

0.0417

1. 0400

0.0300

1. 3720

0.0696

0.8540

0.3270

122.2110

12.0210

155.1590

16.6560

100.0000

20.9000

2. 0280

10.0000 

TEST DATA SHEET FOR DATA SE' \#1

TEST \#

K

SK

RE

SR

A

$\mathrm{SA}$

I I,AYER

II LAYER
20

$\begin{array}{ll}5.2440 & \mathrm{E}-09 \\ 2.6850 & \mathrm{E}-10 \\ 4.9060 & \mathrm{E}-03 \\ 1.0000 & \mathrm{E}-04 \\ 2.5030 & \mathrm{E}-04 \\ 1.1040 & \mathrm{E}-05 \\ 4.2500 & \\ 4.6250 & \end{array}$

$5.2440 \quad \mathrm{E}-09$

4. $9060 \quad \mathrm{E}-03$

1. $0000 \quad \mathrm{E}-04$

2. $5030 \quad \mathrm{E}-04$

4.2500

4.6250
21

$\begin{array}{ll}5.4870 & \mathrm{E}-09 \\ 1.4950 & \mathrm{E}-10 \\ 4.3660 & \mathrm{E}-03 \\ 1.0000 & \mathrm{E}-04 \\ 2.4450 & \mathrm{E}-04 \\ 4.7900 & \mathrm{E}-05 \\ 4.5000 & \\ 5.2500 & \end{array}$

$(42-59 \mathrm{~W})$

SUB TEST)

VAPOR TEMP

138

147

$\mathrm{H}$

2. 9600

3. 7500

0.0417

0.0417

ALPP

1. 0400

1. 0400

SRALPP

0.0300

0.0300

ALPPR

1. 3340

1. 3260

SRALPR

0.0645

0.0648

1. 0410

0.9990

RI

0.3080

0.3070

CALC WATTS R 48.1020

41.9380

5.3550

4.9170

52.9920

CALC WATTS

60.1170

5.7160

SW

5.6620

OBS WATTS

DT CALC

43.0000

7.5660

43.0000

0.9680

6.4070

SDT

6.0000

0.7900

3.0000

(CONTINUED) 

TEST DATA SHEET CONTINUED FOR DATA SET \# 1

$(70-90 W$
SUB TEST)

VAPOR TEMP

$\mathrm{H}$

$\mathrm{SH}$

ALPP

SRALPP

ALPPR

SRALPR

RL

SRL

CALC WATTS

SWR

CALC WATTS

SW

OBS WATTS

DT CALC

SDT

OBS DT
178

2. $3900^{\circ}$

0.0417

1.0400

0.0300

1. 3630

0.0749

1. 1660

0.4370

R 78.5490

8.9850

97.8670

10.9480

87.0000

12.6340

1. 6100

8.0000
157

2.7300

0.0417

1. 0400

0.0300

1. 3310

0.0680

$0 . .9990$

0.3140

83.5200

7.0820

104.2500

7.6330

73.0000

12.9560

1.1420

7.0000

$(100-130) \mathrm{W}$

SUB TEST)

\begin{tabular}{lrr} 
VAPOR TEMP & \multicolumn{1}{c}{192} & 192 \\
H & 1.6000 & 1.9800 \\
SH & 0.0417 & 0.0417 \\
ALPP & 1.0400 & 1.0400 \\
SRALPP & 0.0300 & 0.0300 \\
ALPPR & 1.4110 & 1.3490 \\
SRALPR & 0.1300 & 0.0707 \\
RL & 1.1660 & 1.0830 \\
SRL & 0.7490 & 0.4390 \\
CALC WATTS R & 120.1130 & 129.5810 \\
SWR & 14.5570 & 10.555 \\
CALC WATTS & 149.8650 & 161.2640 \\
SW & 15.3920 & 9.3140 \\
OBS WATTS & 128.0000 & 104.0000 \\
DT CALC & 18.2170 & 20.0970 \\
SDT & 1.7020 & 1.5970 \\
OBS DT & 13.0000 & 10.0000
\end{tabular}



TEST DATA SHEET FOR DATA SET \#2

$\begin{array}{lcc}\text { TEST \# } & 22 & \\ \text { K } & 6.909 & \mathrm{E}-09 \\ \text { SK } & 4.862 & \mathrm{E}-10 \\ \mathrm{RE} & 4.139 & \mathrm{E}-03 \\ \mathrm{SR} & 1.000 & \mathrm{E}-04 \\ \mathrm{~A} & 2.475 & \mathrm{E}-04 \\ \text { SA } & 1.479 & \mathrm{E}-05 \\ \text { I LAYER } & 4.625 & \\ \text { I I LAYER } & 5.500 & \end{array}$

23

7.479 E-09

$2.634 \mathrm{E}-10$

$3.786 \mathrm{E}-03$

$1.000 \mathrm{E}-04$

$2.584 \quad \mathrm{E}-04$

$6.540 \mathrm{E}-05$

5.500

6.000
24

6.850 E-09

$3.748 \quad \mathrm{E}-10$

$3.645 \mathrm{E}-03$

$1.000 \mathrm{E}-04$

2. $555 \mathrm{E}-04$

$1.190 \mathrm{E}-05$

5.250

6.250

$(42-59 W)$

SUB TEST)

VAPOR TEMP 156.000

$\mathrm{H}$

$\mathrm{SH}$

ALPP

SRALPP

ALPPR

SRALPR

RL

SRL

CALC WATTS R36.840

SWR $\quad 7.502$

CALC WATTS 46.516

SW

OBS WATTS

DT CALC

SDT

OBS DT
43.300

0.042

1.040

0.030

1. 324

.064

.999

2846

46.516
8.743

46.090

5.571

1.272

5.000
156.000

4.740

0.042

1.040

0.030

1. 317

0.067

1.187

0.270

44.557

8.735

56.569

10.500

48.000

7.185

1.470

5.000
155.000

4.650

70.042

1.040

0.030

1.323

0.064

0.999

0.273

56.165

9.430

71.074

10.562

48.500

8.922

1.640

7.000

(CONTINUED) 

$(70-90 \mathrm{~W}$

SUB TEST)

$\begin{array}{lr}\text { VAPOR TEMP } & 192.000 \\ \text { H } & 3.840 \\ \text { SH } & 0.042 \\ \text { ALPP } & 1.040 \\ \text { SRALPP } & 0.030 \\ \text { ALPPR } & 1.327 \\ \text { SRALPR } & 0.067 \\ \text { RL } & 1.104 \\ \text { SRL } & 0.340 \\ \text { CALC WATTS R } & 62.268 \\ \text { SWR } & 10.270 \\ \text { CALC WATTS } & 77.506 \\ \text { SW } & 13.294 \\ \text { OBS WATTS } & 75.000 \\ \text { DT CALC } & 9.894 \\ \text { SDT } & 1.760 \\ \text { OBS DT } & 10.000\end{array}$

169.000

3. 760

0.042

1. 040

0.030

1. 329

0.069

1. 208

0.374

104.462

11.761

129.862

15.189

82.000

17.290

2. 024

8.000
189.000

3.890

0.042

1. 040

0.030

1. 330

0.068

1. 083

0.351

101.620

13.471

126.742

17.383

84.000

16.571

2. 362

8.000

$(100-130) \mathrm{W}$

SUB TEST)

$\begin{array}{lr}\text { VAPOR TEMP } & 198.000 \\ \text { H } & 2.850 \\ \text { SH } & 0.042 \\ \text { ALPP } & 1.040 \\ \text { SRALPP } & 0.030 \\ \text { ALPPR } & 1.357 \\ \text { SRALPR } & 0.077 \\ \text { RL } & 1.083 \\ \text { SRI } & 0.404 \\ \text { CALC WATTS R } & 127.166 \\ \text { SWR } & 15.435 \\ \text { CALC WATTS } & 158.640 \\ \text { SW } & 19.603 \\ \text { OBS WATTS } & 101.000 \\ \text { DT CALC } & 19.936 \\ \text { SDT } & 2.492 \\ \text { OBS DT } & 12.000\end{array}$

194.000

3. 130

0.042

1. 040

0.030

1. 348

0.069

1. 208

0.453

151.798

14.060

191.804

18.773

110.000

25.203

2. 299

12.000
187.000

2. 990

0.042

1. 040

0.030

1. 351

0.073

1. 020

0.430

158.986

16.870

199.124

21.956

114.000

25.577

2.743

10.000 
TEST DATA SHEET FOR DATA SET \#2

$\begin{array}{lll}\text { TEST \# } & 25 \\ \text { K } & & \\ \text { SK } & 8.379 & \mathrm{E}-09 \\ \mathrm{RE} & 5.015 & \mathrm{E}-10 \\ \mathrm{SR} & 4.265 & \mathrm{E}-03 \\ \mathrm{~A} & 1.000 & \mathrm{E}-04 \\ \mathrm{SA} & 2.336 & \mathrm{E}-04 \\ \text { I LAYER } & 1.124 & \mathrm{E}-05 \\ \text { I I LAYER } & 4.750 & \\ & 5.350 & \end{array}$

$(42-59 W)$

SUB TEST)

$\begin{array}{lrr}\text { VAPOR TEMP } & 159.000 & 156.000 \\ \text { H } & 4.300 & 4.160 \\ \text { SH } & 0.042 & 0.042 \\ \text { ALPP } & 1.040 & 1.040 \\ \text { SRALPP } & 0.030 & 0.030 \\ \text { ALPPR } & 1.329 & 1.391 \\ \text { SRALPR } & 0.057 & 0.101 \\ \text { RL } & 1.062 & 0.729 \\ \text { SRL } & 0.279 & 0.332 \\ \text { CALC WATTS R } & 43.536 & 49.895 \\ \text { SWR } & 7.900 & 8.098 \\ \text { CALC WATTS } & 53.920 & 68.235 \\ \text { SW } & 10.754 & 8.432 \\ \text { OBS WATTS } & 51.000 & 51.000 \\ \text { DT CALC } & 6.433 & 7.833 \\ \text { SDT } & 1.114 & 1.421 \\ \text { OBS DT } & 6.000 & 5.000 \\ & & \end{array}$

$\cdot 27$

$$
\begin{array}{ll}
7.184 & \mathrm{E}-09 \\
3.601 & \mathrm{E}-10 \\
4.053 & \mathrm{E}-03 \\
1.000 & \mathrm{E}-04 \\
2.558 & \mathrm{E}-04 \\
1.189 & \mathrm{E}-05 \\
4.000 & \\
5.675 &
\end{array}
$$$$
6.250 \text { E-09 }
$$$$
4.357 \mathrm{E}-10
$$$$
3.639 \mathrm{E}-03
$$$$
1.000 \mathrm{E}-04
$$$$
\text { 2. } 469 \mathrm{E}-04
$$$$
1.674 \text { E-05 }
$$$$
5.250
$$$$
6.250
$$

140.000
4.730
0.042
1.040
0.030
1.347
0.075
0.916
0.272
45.583
8.396
58.079
9.692
57.000
6.992
1.461
6.000

(CONTINUED) 



\section{$(70-90 \mathrm{~W}$ \\ SUB TEST)}

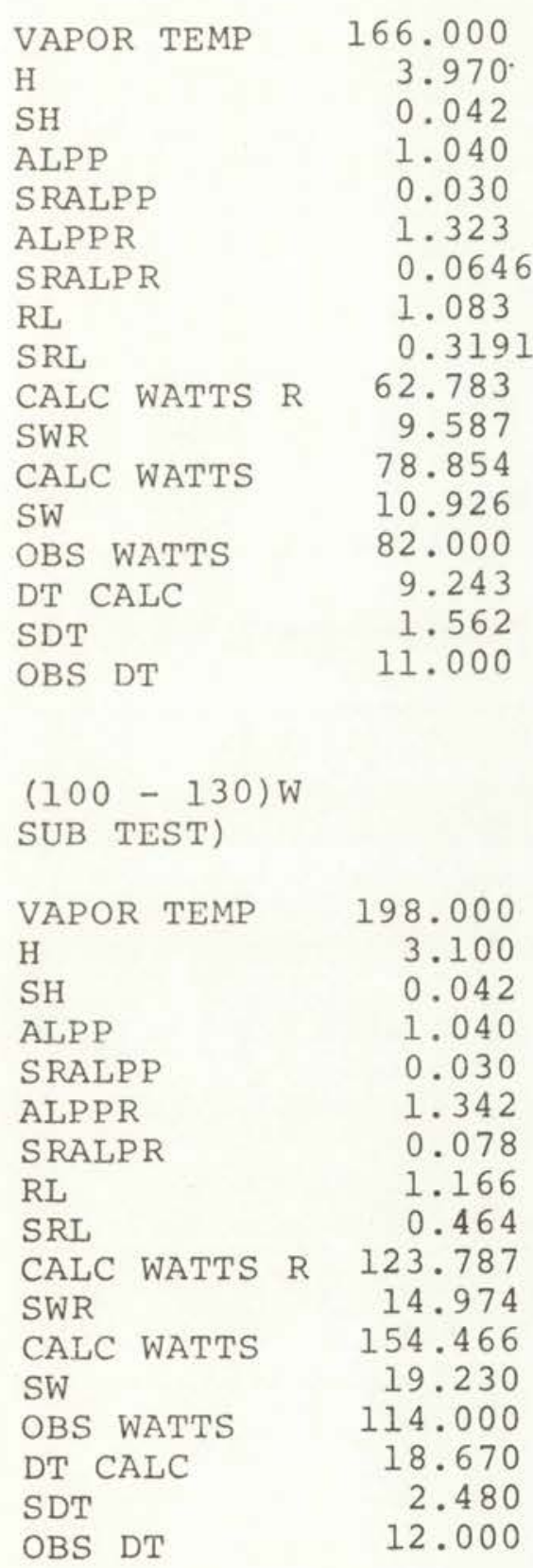

186.000

3. 760

0.042

1. 040

0.030

1. 382

0.105

0.749

0.330

76.951

11.413

99.996

14.798

85.000

12.118

1. 861

8.000

192.000

3.000

0.042

1. 040

0.030

1. 385

0.101

0.729

0.332

126.594

16.363

167.072

24.198

116.000

20.174

3.136

11.000
168.000

4.080

0.042

1. 040

0.030

1. 396

0.089

0.958

0.325

76.970

11.977

96.957

15.126

91.000

12.107

2.084

8.000
185.000

3.640

0.042

1. 040

0.030

1. 392

0.113

0.958

0.332

91.236

12.654

114.119

14.898

118.000

14.153

2. .008

12.000 

TEST DATA SHEET FOR DATA SET \#2

$\begin{array}{lll}\text { TEST \# } & 29 \\ \text { K } & 8.116 & \mathrm{E}-09 \\ \text { SK } & 4.052 & \mathrm{E}-10 \\ \mathrm{RE} & 3.961 & \mathrm{E}-03 \\ \mathrm{SR} & 1.000 & \mathrm{E}-04 \\ \mathrm{~A} & 2.441 & \mathrm{E}-04 \\ \text { SA } & 1.117 & \mathrm{E}-05 \\ \text { I LAYER } & 4.500 & \\ \text { II LAYER } & 5.750\end{array}$

30

6.081 E-09

$2.641 \mathrm{E}-10$

$3.958 \mathrm{E}-03$

$1.000 \mathrm{E}-04$

$2.402 \mathrm{E}-04$

$9.200 \mathrm{E}-6$

4.750

5.750
31

$6.326 \quad E-09$

$2.126 \mathrm{E}-10$

$3.859 \mathrm{E}-03$

$1.000 \mathrm{E}-04$

$2.359 \mathrm{E}-04$

7.890 E-06

4.750

5.900

$(42-59 \mathrm{~W})$

SUB TEST)

$\begin{array}{lrrr}\text { VAPOR TEMP } & 166.000 & 155.000 & 175.000 \\ \text { H } & 4.460 & 4.120 & 4.180 \\ \text { SH } & 0.042 & 0.042 & 0.042 \\ \text { ALPP } & 1.040 & 1.040 & 1.040 \\ \text { SRALPP } & 0.030 & 0.030 & 0.030 \\ \text { ALPPR } & 1.332 & 1.329 & 1.328 \\ \text { SRALPR } & 0.065 & 0.065 & 0.065 \\ \text { RL } & 0.895 & 0.958 & 0.958 \\ \text { SRL } & 0.271 & 0.279 & 0.289 \\ \text { CALC WATTS R } & 46.369 & 49.950 & 54.853 \\ \text { SWR } & 9.131 & 6.951 & 7.775 \\ \text { CALC WATTS } & 59.364 & 63.329 & 69.723 \\ \text { SW } & 10.683 & 7.892 & 8.965 \\ \text { OBS WATTS } & 54.000 & 58.000 & 8.000 \\ \text { DT CALC } & 7.011 & 7.501 & 1.089 \\ \text { SDT } & 1.478 & 1.133 & 10.000 \\ \text { OBS DT } & 6.000 & 3.000 & \end{array}$

(CONTINUED) 
$(70-90 \mathrm{~W}$
SUB TEST)

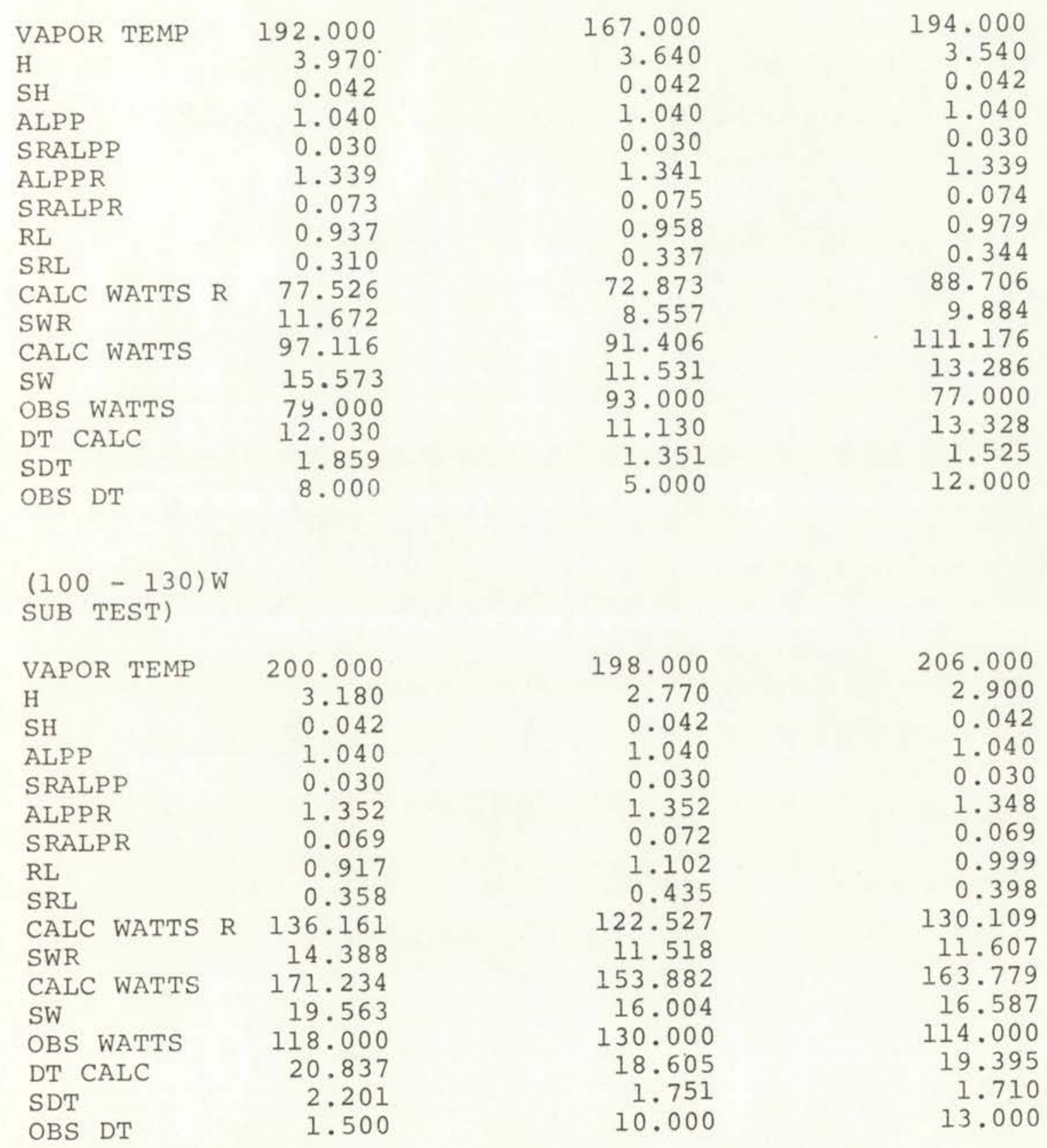





\section{TEST DATA SHEET FOR DATA SET \#2}

$\begin{array}{ll}\text { TEST \# } & 33 \\ \mathrm{~K} & 8.214 \mathrm{E}-09 \\ \mathrm{SK} & 4.302 \mathrm{E}-10 \\ \mathrm{RE} & 4.140 \mathrm{E}-03 \\ \mathrm{SR} & 1.000 \mathrm{E}-04 \\ \mathrm{~A} & 2.426 \mathrm{E}-04 \\ \mathrm{SA} & 8.500 \mathrm{E}-06 \\ \text { I LAYER } & 4.625 \\ \text { II LAYER } & 5.500\end{array}$

34

7. 324 E-09

2.834 E-10

$4.337 \mathrm{E}-03$

1. $000 \quad \mathrm{E}-04$

2. $294 \quad \mathrm{E}-04$

8.470 E-06

4.750

5. 250
35

8.154 E-09

$2.877 \quad \mathrm{E}-10$

$4.539 \mathrm{E}-03$

$1.000 \mathrm{E}-04$

$2.334 \quad \mathrm{E}-04$

6.270 E-06

4.625

5.000

(42-59W)

SUB TEST)

\begin{tabular}{lrr} 
VAPOR TEMP & \multicolumn{1}{r}{175} \\
H & 4.210 & \multicolumn{1}{r}{165} \\
SH & 0.042 & 3.390 \\
ALPP & 1.040 & 0.042 \\
SRALPP & 0.030 & 1.040 \\
ALPPR & 1.318 & 0.030 \\
SRALPR & 0.062 & 1.317 \\
RL & 1.062 & 0.068 \\
SRL & 0.238 & 1.187 \\
CALC WATTS & 47.540 & 0.259 \\
SWR & 8.899 & 40.836 \\
CALC WATTS & 60.319 & 6.668 \\
SW & 10.298 & 51.572 \\
OBS WATTS & 48.500 & 7.681 \\
DT CALC & 7.203 & 48.000 \\
SDT & 1.419 & 5.937 \\
OBS DT & 5.000 & 1.032 \\
& & 8.000
\end{tabular}

179

4.210

0.042

1. 040

0.030

1. 319

0.062

1.021

0.233

51.748

8.755

75.837

10.232

50.000

7.551

1. 331

8.000

(CONTINUED) 

$(70-90 W$
SUB TEST)

VAPOR TEMP 190

$\mathrm{H}$

$\mathrm{SH}$

ALPP

SRALPP

ALPPR

SRALPR

RL

SRL

CALC WATTS $R$

SWR

CALC WATTS

SW

OBS WATTS

DT CALC

SDT

OBS DT $3.830^{\circ}$

0.042

1.040

0.030

1. 324

0.065

1.083

0.263

66.836

9.729

82.935

12.166

80.000

10.388

1.522

8.000
182

3.660

0.042

1.040

0.030

1. 322

0.064

1.268

0.288

58.804

7.904

72.906

9.899

77.000

8.740

1.191

8.000
180

3.680

0.042

1.040

0.030

1.329

0.066

0.999

0.257

86.713

10.211

108.077

12.433

77.000

12.910

1.528

8.000

$(100-130) \mathrm{W}$

SUB TEST)

VAPOR TEMP 202

$\mathrm{H}$

3.250

$\mathrm{SH}$

0.042

ALPP

1.040

SRALPP

0.030

ALPPR

1.331

SRALPR

0.058

RL

1.104

SRL

0.304

CALC WATTS R 115.933

SWR

12.139

CALC WATTS 143.664

SW 14.569

OBS WATTS 118.000

DT CALC

17.809

SDT

1.813

OBS DT

13.000

194

$$
\begin{aligned}
& 2.970 \\
& 0.042 \\
& 1.040 \\
& 0.030 \\
& 1.335 \\
& 0.061 \\
& 1.208 \\
& 0.359
\end{aligned}
$$

101.329

9.497

125.615

11.017

109.000

14.895

1.388

10.000
189

3.18

0.042

1.040

0.030

1.333

0.050

1.042

0.290

123.185

11.304

153.237

13.306

114.000

18.203

1.607

10.000 

TEST DATA SHEET FOR DATA SET \#2

\begin{tabular}{|c|c|c|}
\hline TEST \# & 36 & \\
\hline K & 7.475 & $E-09$ \\
\hline SK & 5.334 & $E-10$ \\
\hline $\mathrm{RE}$ & 4.141 & $E-03$ \\
\hline SR & 1.000 & $E-04$ \\
\hline A & 2.421 & $E-04$ \\
\hline $\mathrm{SA}$ & 1. 300 & $E-05$ \\
\hline I LAYER & 5.000 & \\
\hline II LAYER & 5.500 & \\
\hline
\end{tabular}

(42-59W)

SUB TEST)
37
$6.698 \mathrm{E}-09$
$3.146 \mathrm{E}-10$
$3.870 \mathrm{E}-03$
$1.000 \quad \mathrm{E}-04$
2. 416 E-04
1. $022 \mathrm{E}-05$
5. 250
5.875

38

6.566 E-09

3. $085 \mathrm{E}-10$

$4.337 \mathrm{E}-03$

$1.000 \quad \mathrm{E}-04$

2. 401 E-04

8. 750 E-06

4. 675

5. 250
165.000

4.170

0.042

1. 040

0.030

1. 317

0.062

1.166

0.257

61.611

8.793

77.503

9.927

54.000

9.413

1. 471

7.000
180.000

3.730

0.042

1. 040

0.030

1. 318

0.063

1. 166

0.275

50.960

6.935

64.387

8.150

53.000

7.740

1.140

7.000

(CONTINUED) 

TEST DATA SHEET CONTINUED FOR DATA SET \# 2

$(70-90 W$
SUB TEST)

$\begin{array}{lrrr}\text { VAPOR TEMP } & 194.000 & 175.000 & 195.000 \\ \text { H } & 3.380 & 3.380 & 3.460 \\ \text { SH } & 0.042 & 0.042 & 0.042 \\ \text { ALPP } & 1.040 & 1.040 & 1.040 \\ \text { SRALPP } & 0.030 & 0.030 & 0.030 \\ \text { ALPPR } & 1.327 & 1.327 & 1.324 \\ \text { SRALPR } & 0.067 & 0.067 & 0.065 \\ \text { RL } & 1.208 & 1.187 & 1.208 \\ \text { SRL } & 0.332 & 0.332 & 0.305 \\ \text { CALC WATTS R } & 95.714 & 101.988 & 65.902 \\ \text { SWR } & 12.006 & 11.386 & 7.876 \\ \text { CALC WATTS } & 119.515 & 127.300 & 82.085 \\ \text { SW } & 15.745 & 13.903 & 10.315 \\ \text { OBS WATTS } & 75.000 & 77.000 & 76.000 \\ \text { DT CALC } & 14.956 & 15.862 & 10.206 \\ \text { SDT } & 2.086 & 1.850 & 1.249 \\ \text { OBS DT } & 10.000 & 9.000 & 12.000\end{array}$

$(100-130) \mathrm{W}$

SUB TEST)

$\begin{array}{lr}\text { VAPOR TEMP } & 195.000 \\ \text { H } & 2.940 \\ \text { SH } & 0.042 \\ \text { ALPP } & 1.040 \\ \text { SRALPP } & 0.030 \\ \text { ALPPR } & 1.338 \\ \text { SRALPR } & 0.063 \\ \text { RL } & 1.208 \\ \text { SRL } & 0.392\end{array}$

CALC WATTS R 126.022

SWR

14.558

CALC WATTS 155.837

$\mathrm{SW}$

OBS WATTS

DT CALC

SDT

OBS DT
17.116

110.000

19.456

2.273

10.000
205.000

2. 650

0.042

1.040

0.030

1.346

0.068

1.208

0.443

152.780

14.981

189.397

$1 ; .879$

119.000

23.582

2.344

14.000
205.000

2.86

0.042

1.040

0.030

1. 336

0.061

1.208

0.373

102.459

8.918

127.379

11.376

118.000

15.716

1.377

18.000 
TEST DATA SHEET FOR DATA SET \#2

$\begin{array}{lcccc}\text { TEST \# } & 39 & 40 & 41 \\ \text { K } & 7.192 \mathrm{E}-09 & 5.951 \mathrm{E}-09 & 6.235 \mathrm{E}-09 \\ \mathrm{SK} & 3.193 \mathrm{E}-10 & 3.363 \mathrm{E}-10 & 2.832 \mathrm{E}-10 \\ \mathrm{RE} & 4.051 \mathrm{E}-03 & 3.878 \mathrm{E}-03 & 3.877 \mathrm{E}-03 \\ \mathrm{SR} & 1.000 \mathrm{E}-04 & 1.000 \mathrm{E}-04 & 1.000 \mathrm{E}-04 \\ \mathrm{~A} & 2.392 \mathrm{E}-04 & 2.416 \mathrm{E}-04 & 2.363 \mathrm{E}-04 \\ \mathrm{SA} & 6.880 \mathrm{E}-06 & 1.134 \mathrm{E}-05 & 7.780 \mathrm{E}-06 \\ \text { I LAYER } & 5.000 & 5.250 & 4.750\end{array}$

(42-59W)

SUB TEST)

$\begin{array}{lrrr}\text { VAPOR TEMP } & 175.000 & 160.000 & 174.000 \\ \text { H } & 4.010 & 4.560 & 4.310 \\ \text { SH } & 0.042 & 0.042 & 0.042 \\ \text { ALPP } & 1.040 & 1.040 & 1.040 \\ \text { SRALPP } & 0.030 & 0.030 & 0.030 \\ \text { ALPPR } & 1.317 & 1.315 & 1.322 \\ \text { SRALPR } & 0.063 & 0.062 & 0.062 \\ \text { RL } & 1.187 & 1.146 & 0.979 \\ \text { SRL } & 0.260 & 0.228 & 0.225 \\ \text { CALC WATTS } & 58.780 & 34.876 & 46.413 \\ \text { SWR } & 8.036 & 6.665 & 7.214 \\ \text { CALC WATTS } & 74.435 & 44.341 & 59.278 \\ \text { SW } & 9.548 & 7.920 & 8.667 \\ \text { OBS WATTS } & 53.000 & 50.000 & 51.000 \\ \text { DT CALC } & 8.892 & 5.299 & 6.853 \\ \text { SDT } & 1.287 & 1.089 & 1.130 \\ \text { OBS DT } & 8.000 & 8.000 & 8.000\end{array}$

(CONTINUED) 

TEST DATA SHEET CONTINUED FOR DATA SET \# 2

$(70-90 \mathrm{~W}$

SUB TEST)

$\begin{array}{lr}\text { VAPOR TEMP } & 187.000 \\ \text { H } & 4.010 \\ \text { SH } & 0.042 \\ \text { ALPP } & 1.040 \\ \text { SRALPP } & 0.030 \\ \text { ALPPR } & 1.328 \\ \text { SRALPR } & 0.067 \\ \text { RL } & 1.208 \\ \text { SRL } & 0.341\end{array}$

CALC WATTS R 108.078

SWR $\quad 10.049$

CALC WATTS 134.972

SW

OBS WATTS $\quad 84.000$

DT CALC $\quad 16.639$

SDT

OBS DT

$(100-130) \mathrm{W}$

SUB TEST)

$\begin{array}{lr}\text { VAPOR TEMP } & 195.000 \\ \text { H } & 2.770 \\ \text { SH } & 0.042 \\ \text { ALPP } & 1.040 \\ \text { SRALPP } & 0.030 \\ \text { ALPPR } & 1.340 \\ \text { SRALPR } & 0.063 \\ \text { RL } & 1.208 \\ \text { SRL } & 0.402 \\ \text { CALC WATTS R } & 140.222 \\ \text { SWR } & 10.791 \\ \text { CALC WATTS } & 174.624 \\ \text { SW } & 13.838 \\ \text { OBS WATTS } & 115.000 \\ \text { DT CALC } & 21.447 \\ \text { SDT } & 1.665 \\ \text { OBS DT } & 14.000\end{array}$

175.000

3.900

0.042

1.040

0.030

1. 321

0.064

1.187

0.278

65.546

8.549

81.772

11.076

73.000

10.205

1. 384

10.000

10.000
180.000

3.630

0.042

1.040

0.030

1. 332

0.067

0.958

0.253

80.464

8.619

101.040

11.275

78.000

12.094

1. 327

10.000

$\begin{array}{rr}189.000 & 190.000 \\ 3.160 & 3.120 \\ 0.042 & 0.042 \\ 1.040 & 1.040 \\ 0.030 & 0.030 \\ 1.334 & 1.337 \\ 0.060 & 0.059 \\ 1.208 & 0.950 \\ 0.357 & 0.273 \\ 104.590 & 108.881 \\ 10.281 & 9.333 \\ 129.736 & 136.060 \\ 12.980 & 11.979 \\ 120.000 & 125.000 \\ 16.122 & 16.206 \\ 1.616 & 1.366 \\ 18.000 & 12.000\end{array}$


TEST DATA SHEET FOR DATA SET \# 2

\begin{tabular}{|c|c|c|}
\hline & 6.954 & E-09 \\
\hline SK & 3.122 & $E-10$ \\
\hline $\mathrm{RE}$ & 3.969 & $E-03$ \\
\hline SR & 1.000 & $E-04$ \\
\hline A & 2.426 & $E-04$ \\
\hline $\mathrm{SA}$ & 1.169 & $E-05$ \\
\hline I LAYER & 5.365 & \\
\hline II LAYER & 5.750 & \\
\hline
\end{tabular}

$(42-59 W)$

SUB TEST)
43

$\begin{array}{ll}7.483 & \mathrm{E}-09 \\ 4.465 & \mathrm{E}-10 \\ 4.140 & \mathrm{E}-03 \\ 1.000 & \mathrm{E}-04 \\ 2.382 & \mathrm{E}-04 \\ 1.236 & \mathrm{E}-06 \\ 4.750 & \\ 5.500 & \end{array}$

$7.483 \quad \mathrm{E}-09$

4.465 E-10

$1.000 \mathrm{E}-04$

2. $382 \quad \mathrm{E}-04$

4. 750

5.500

44

$6.081 \mathrm{E}-09$

2. $298 \mathrm{E}-10$

$3.969 \mathrm{E}-03$

1. $000 \mathrm{E}-04$

$2.353 \mathrm{E}-04$

$7.960 \mathrm{E}-06$

5.000

5.750

$$
\begin{array}{r}
185.000 \\
4.210 \\
0.042 \\
1.040 \\
0.030 \\
1.323 \\
0.059 \\
0.895 \\
0.229 \\
40.468 \\
8.214 \\
51.983 \\
9.800 \\
45.000 \\
5.986 \\
1.313 \\
8.000
\end{array}
$$

176.000

4.170

01042

1. 040

0.030

1. 322

0.059

0.894

0.224

45.587

6.703

58.509

8.129

45.000

6.683

1.049

5.000

(CONTINUED) 


\section{$(70-90 \mathrm{~W}$ \\ SUB TEST)}

$\begin{array}{lrrr}\text { VAPOR TEMP } & 185.000 & 192,000 & 198.000 \\ \text { H } & 3.810 & 3.490 & 3.420 \\ \text { SH } & 0.042 & 0.042 & 0.042 \\ \text { ALPP } & 1.040 & 1.040 & 1.040 \\ \text { SRALPP } & 0.030 & 0.030 & 0.030 \\ \text { ALPPR } & 1.327 & 1.343 & 1.341 \\ \text { SRALPR } & 0.065 & 0.077 & 0.760 \\ \text { RL } & 1.020 & 0.874 & 0.895 \\ \text { SRL } & 0.256 & 0.256 & 0.255 \\ \text { CALC WATTS } & 75.292 & 85.704 & 83.753 \\ \text { SWR } & 9.646 & 10.709 & 8.474 \\ \text { CALC WATTS } & 94.157 & 108.543 & 105.741 \\ \text { SW } & 12.601 & 14.156 & 11.220 \\ \text { OBS WATTS } & 86.000 & 88.000 & 72.000 \\ \text { DT CALC } & 11.656 & 13.420 & 12.483 \\ \text { SDT } & 1.561 & 1.702 & 1.305 \\ \text { OBS DT } & 8.000 & 10.000 & 8.000\end{array}$

$(100-130) \mathrm{W}$

SUB TEST)

VAPOR TEMP $\quad 190.000$

$\mathrm{H}$

3.140

$\mathrm{SH}$

ALPP

SRALPP

ALPPR

SRALPR

RL

SRL

CALC WATTS R 116.538

SWR

CALC WATTS

0.042

1. 040

0.030

1. 319

0.061

1. 020

0.285

SW

OBS WATTS

DT CALC

SDT

OBS DT
10.946

145.170

13.833

114.000

17.811

1. 715

8.000
205.000

3.000

0.042

1. 040

0.030

1. 333

0.064

0.854

0.264

118.852

12.124

149.571

15.507

121.000

17.700

1.846

15.000
198.000

3.070

0.040

1.040

0.030

1. 329

0.063

0.874

0.254

102.627

8.546

129.286

11.046

120.000

15.137

1. 245

10.000 

TEST DATA SHEET FOR DATA SET \#2

TEST \#

K
SK
RE
SR
A
SA
I LAYER
II LAYER

(42-59W)

SUB TEST)

\section{SUB TEST)}

$\begin{array}{lrrr}\text { VAPOR TEMP } & 168.000 & 170.000 & 179.000 \\ \text { H } & 4.078 & 4.280 & 4.140 \\ \text { SH } & 0.042 & 0.042 & 0.042 \\ \text { ALPP } & 1.040 & 1.040 & 1.040 \\ \text { SRALPP } & 0.036 & 0.030 & 0.030 \\ \text { ALPPR } & 1.317 & 1.325 & 1.346 \\ \text { SRALPR } & 0.058 & 0.060 & 0.064 \\ \text { RL } & 0.937 & 0.854 & 0.708 \\ \text { SRL } & 0.232 & 0.221 & 0.215 \\ \text { CALC WATTS R } & 65.462 & 40.704 & 44.146 \\ \text { SWR } & 9.656 & 7.538 & 7.281 \\ \text { CALC WATTS } & 83.766 & 52.739 & 57.578 \\ \text { SW } & 11.397 & 9.220 & 8.816 \\ \text { OBS WATTS } & 51.000 & 50.000 & 52.000 \\ \text { DT CALC } & 9.530 & 5.725 & 6.495 \\ \text { SDT } & 1.446 & 1.092 & 1.157 \\ \text { OBS DT } & 6.000 & 10.000 & 6.000\end{array}$

46

$\begin{array}{ll}8.702 & \mathrm{E}-09 \\ 3.439 & \mathrm{E}-10 \\ 4.143 & \mathrm{E}-03 \\ 1.000 & \mathrm{E}-04 \\ 2.337 & \mathrm{E}-04 \\ 6.280 & \mathrm{E}-06 \\ 4.875 & \\ 5.500 & \end{array}$

8. 338 E-09

$2.742 \mathrm{E}-10$

$4.140 \quad \mathrm{E}-03$

$1.000 \quad \mathrm{E}-04$

2.270 E-04

4.900 E-06

4.875

5.500

$6.427 \mathrm{E}-09$

$3.796 \mathrm{E}-10$

$4.051 \mathrm{E}-03$

$1.000 \mathrm{E}-04$

$2.387 \mathrm{E}-04$

$1.001 \mathrm{E}-05$

4.050

5.625

(CONTINUED) 
$(70-90 \mathrm{~W}$

SUB TEST)

$\begin{array}{lr}\text { VAPOR TEMP } & 185.000 \\ \text { H } & 3.460 \\ \text { SH } & 0.042 \\ \text { ALPP } & 1.040 \\ \text { SRALPP } & 0.030 \\ \text { ALPPR } & 1.337 \\ \text { SRALPR } & 0.075 \\ \text { RL } & 0.937 \\ \text { SRL } & 0.261 \\ \text { CALC WATTS R } & 99.720 \\ \text { SWR } & 10.273 \\ \text { CALC WATTS } & 125.386 \\ \text { SW } & 13.540 \\ \text { OBS WATTS } & 81.000 \\ \text { DT CALC } & 14.706 \\ \text { SDT } & 1.542 \\ \text { OBS DT } & 8.000\end{array}$

$$
\begin{array}{r}
200.000 \\
3.580 \\
0.042 \\
1.040 \\
0.030 \\
1.347 \\
0.077 \\
0.833 \\
0.244 \\
84.430 \\
9.422 \\
106.740 \\
12.510 \\
83.000 \\
12.143 \\
1.354 \\
10.000
\end{array}
$$$$
\begin{array}{r}
190.000 \\
3.480 \\
0.042 \\
1.040 \\
0.030 \\
1.367 \\
0.082 \\
0.687 \\
0.228 \\
78.652 \\
9.171 \\
101.497 \\
12.328 \\
83.000 \\
11.786 \\
1.433 \\
10.000
\end{array}
$$

$(100-130) W$

SUB TEST)

$\begin{array}{lr}\text { VAPOR TEMP } & 190.000 \\ \text { H } & 2.970 \\ \text { SH } & 0.042 \\ \text { ALPP } & 1.040 \\ \text { SRALPP } & 0.030 \\ \text { ALPPR } & 1.326 \\ \text { SRALPR } & 0.067 \\ \text { RL } & 0.916 \\ \text { SRL } & 0.270 \\ \text { CALC WATTS R } & 135.919 \\ \text { SWR } & 10.797 \\ \text { CALC WATTS } & 170.892 \\ \text { SW } & 13.992 \\ \text { OBS WATTS } & 112.000 \\ \text { DT CALC } & 19.941 \\ \text { SDT } & 1.538 \\ \text { OBS DT } & 12.000\end{array}$

$$
\begin{array}{r}
205.000 \\
2.680 \\
0.042 \\
1.040 \\
0.030 \\
1.337 \\
0.066 \\
0.812 \\
0.260 \\
149.236 \\
10.381 \\
189.573 \\
13.625 \\
130.000 \\
21.276 \\
1.423 \\
13.001
\end{array}
$$

$$
\begin{gathered}
190.000 \\
2.910 \\
0.042 \\
1.040 \\
0.030 \\
1.356 \\
0.0679 \\
0.666 \\
0.227 \\
109.447 \\
10.220 \\
140.463 \\
13.463 \\
125.000 \\
16.187 \\
1.512 \\
14.000
\end{gathered}
$$



$(70-90 \mathrm{~W}$

SUB TEST)

\begin{tabular}{|c|c|c|c|}
\hline VAPOR TEMP & 18900 & 180000 & 190000 \\
\hline $\mathrm{H}$ & $3.580^{\circ}$ & 2.950 & $\begin{array}{r}190.000 \\
3.310\end{array}$ \\
\hline $\mathrm{SH}$ & 0.042 & 0.042 & 0.042 \\
\hline ALPP & 1.040 & 1.040 & 1.040 \\
\hline SRALPP & 0.030 & 0.030 & 0.030 \\
\hline ALPPR & 1.349 & 1.352 & 1.348 \\
\hline SRALPR & 0.077 & 0.080 & 0.078 \\
\hline RL & 0.812 & 0.812 & 0.833 \\
\hline SRL & 0.233 & 0.260 & 0.254 \\
\hline CALC WATTS R & 82.475 & 113.993 & 71.195 \\
\hline SWR & 8.437 & 9.536 & 6.899 \\
\hline CALC WATTS & 104.588 & 145.198 & 90.239 \\
\hline & 11.175 & 12.906 & 9.238 \\
\hline OBS WATTS & 80.000 & 89.000 & 80.000 \\
\hline DT CALC & 12.401 & 16.294 & 10.092 \\
\hline SDT & 1.282 & 1.435 & 0.998 \\
\hline OBS DT & 10.000 & 10.000 & 10.000 \\
\hline \multicolumn{4}{|l|}{$\begin{array}{l}(100-130) \mathrm{W} \\
\text { SUB TEST) }\end{array}$} \\
\hline VAPOR TEMP & 192.000 & 192.000 & 190.000 \\
\hline $\mathrm{H}$ & 3.040 & 2.700 & 2.540 \\
\hline SH & 0.042 & 0.042 & 0.042 \\
\hline ALPP & 1.040 & 1.040 & 1.040 \\
\hline SRALPP & 0.030 & 0.030 & 0.030 \\
\hline ALPPR & 1.337 & 1.337 & 1.339 \\
\hline SRALPR & 0.064 & 0.066 & 0.066 \\
\hline RL & 0.791 & 0.812 & 0.792 \\
\hline SRI & 0.236 & 0.262 & 0.261 \\
\hline CALC WATTS R & 111.588 & 133.755 & 110.377 \\
\hline SWR & 8.870 & 9.888 & 7.484 \\
\hline CALC WATTS & 141.818 & 169.661 & 140.466 \\
\hline SW & 11.636 & 12.848 & 9.801 \\
\hline OBS WATTS & 121.000 & 110.000 & 110.000 \\
\hline DT CALC & 16.592 & 18.949 & 15.487 \\
\hline SDT & 1.270 & 1.402 & 1.040 \\
\hline & 12.000 & 10.000 & 15.000 \\
\hline
\end{tabular}



TEST DATA SHEET FOR DATA SET \#2

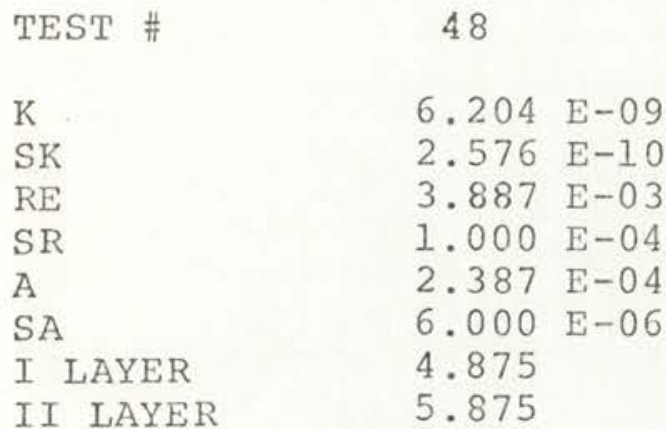

(42-59W)

SUB TEST)
49
8. 246 E-09
$2.674 \quad \mathrm{E}-10$
$4.257 \mathrm{E}-03$
$1.000 \mathrm{E}-04$
2. 261 E-04
$7.510 \mathrm{E}-06$
4.500
5.365

50

$6.412 \mathrm{E}-09$

1. $968 \mathrm{E}-10$

$4.257 \mathrm{E}-03$

$1.010 \mathrm{E}-04$

$2.236 \mathrm{E}-04$

$6.290 \mathrm{E}-06$

4.500

5.365

$\begin{array}{lr}\text { VAPOR TEMP } & 176.000 \\ \text { H } & 4.210 \\ \text { SH } & 0.042 \\ \text { ALPP } & 1.040 \\ \text { SRALPP } & 0.030 \\ \text { ALPPR } & 1.331 \\ \text { SRALPR } & 0.061 \\ \text { RL } & 0.812 \\ \text { SRL } & 0.216 \\ \text { CALC WATTS R } & 54.535 \\ \text { SWR } & 7.240 \\ \text { CALC WATTS } & 70.427 \\ \text { SW } & 8.826 \\ \text { OBS WATTS } & 49.000 \\ \text { DT CALC } & 8.067 \\ \text { SDT } & 1.127 \\ \text { OBS DT } & 6.000\end{array}$

174.000

3.780

0.042

1. 040

0.030

1. 330

0.062

0.833

0.235

61.828

7.782

79.545

9. 459

58.000

8,728

1. 188

10.000
176.000

3.870

0.042

1. 040

0.030

1. 330

0.062

0.830

0.233

43.227

5.839

55.724

7.127

43.000

6.031

0.862

7.000

(CONTINUED) 

TEST DATA SHEET FOR DATA SET \#2

TEST \#

K

SK

RE

SR

A

SA

I LAYER

II LAYER
51

8. 337 E-09

$3.730 \mathrm{E}-10$

$4.140 \quad \mathrm{E}-03$

1. $000 \quad \mathrm{E}-04$

$2.373 E-04$

$6.270 \quad \mathrm{E}-06$

5.000

5.500
52

7. $463 \mathrm{E}-09$

$1.382 \mathrm{E}-10$

$4.140 \quad \mathrm{E}-03$

1. $000 \mathrm{E}-04$

2. $324 \quad \mathrm{E}-04$

$5.320 \mathrm{E}-06$

4.750

5.500
53

$7.775 \mathrm{E}-09$

$3.343 \mathrm{E}-10$

$4.245 \mathrm{E}-03$

$1.000 \quad \mathrm{E}-04$

2. $392 \mathrm{E}-04$

9.780 E-06

4. 500

5. 365

$(42-59 W)$

SUB TEST)

VAPOR TEMP 168.000

$\mathrm{H}$

$\mathrm{SH}$

4.160

0.042

ALPP

1. 040

SPALPP

0.030

ALPPR

1. 315

SRALPR

0.057

RL

0.999

SRL

0.235

CALC WATTS R 50.830

8.118

SWR

CALC WATTS

64.889

9.722

SW

48.000

7.529

DT CALC

1. 255

OBS DT

8.000

184.000

4.020

0.042

1. 040

0.030

1. 323

0.059

0.896

0.232

50.886

7.406

65.495

9.112

54.000

7.362

1.116

6.000
185.000

3.980

0.042

1.040

c. 030

1. 330

0.061

0.833

0.233

49.416

8.126

63.716

9.813

49.000

7.378

1.297

5.000

(CONTINUED) 

$(70-90 \mathrm{~W}$

SUB TEST)

$\begin{array}{lr}\text { VAPOR TEMP } & 177.000 \\ \text { H } & 3.610 \\ \text { SH } & 0.042 \\ \text { ALPP } & 1.040 \\ \text { SRALPP } & 0.030 \\ \text { ALPPR } & 1.330 \\ \text { SRALPR } & 0.073 \\ \text { RL } & 0.979 \\ \text { SRL } & 0.260 \\ \text { CALC WATTS R } & 86.563 \\ \text { SWR } & 9.649 \\ \text { CALC WATTS } & 108.494 \\ \text { SW } & 12.643 \\ \text { OBS WATTS } & 86.000 \\ \text { DT CALC } & 13.060 \\ \text { SDT } & 1.466 \\ \text { OBS DT } & 10.000\end{array}$

192.000

3.560

0.042

1. 040

0.030

1. 343

0.076

0.874

0.247

79.212

8.123

99.799

10.782

82.000

11.655

1. 202

6.000
194.000

3. 660

0.042

1. 040

0.030

1. 347

0.077

0.833

0.245

69.306

9.610

87.654

12.113

85.000

10.487

1.416

8.000

$(100-130) \mathrm{W}$

SUB TEST)

$\begin{array}{lr}\text { VAPOR TEMP } & 189.000 \\ \text { H } & 2.860 \\ \text { SH } & 0.042 \\ \text { ALPP } & 1.040 \\ \text { SRALPP } & 0.030 \\ \text { ALPPR } & 1.324 \\ \text { SRALPR } & 0.063 \\ \text { RL } & 0.950 \\ \text { SRL } & 0.287 \\ \text { CALC WATTS R } & 140.225 \\ \text { SWR } & 11.067 \\ \text { CALC WATTS } & 175.901 \\ \text { SW } & 14.331 \\ \text { OBS WATTS } & 18.000 \\ \text { DT CALC } & 20.936 \\ \text { SDT } & 1.606 \\ \text { OBS DT } & 10.000\end{array}$

202.000

2. 990

0.042

1.040

0.030

1. 332

0.064

0.854

0.256

116.434

8. 609

147.187

11.205

125.000

16.966

1. 209

10.000
202.000

2. 990

0.042

1. 040

0.030

1. 337

0.065

0.812

0.257

116.188

10.409

146.990

13.472

125.000

17.341

1.559

10.000 

TEST DATA SHEET FOR DATA SET \#3

TEST \#

$K$
SK
RE
SR
A
SA
I LAYER
II LAYER

(20-30W)

SUB TEST)

$\begin{array}{lr}\text { VAPOR TEMP } & 152.000 \\ \text { H } & 7.230 \\ \text { SH } & 0.042 \\ \text { ALPP } & 1.040 \\ \text { SRALPP } & 0.030 \\ \text { ALPPR } & 1.227 \\ \text { SRALPR } & 0.055 \\ \text { RL } & 0.937 \\ \text { SRL } & 0.180 \\ \text { CALC WATTS R } & 26.665 \\ \text { SWR } & 6.529 \\ \text { CALC WATTS } & 32.035 \\ \text { SW } & 7.399 \\ \text { OBS WATTS } & 26.500 \\ \text { DT CALC } & 2.878 \\ \text { SDT } & 0.779 \\ \text { OBS DT } & 2.000\end{array}$

55

56

$\begin{array}{ll}2.584 & \mathrm{E}-09 \\ 1.483 & \mathrm{E}-10 \\ 2.396 & \mathrm{E}-03 \\ 1.000 & \mathrm{E}-04 \\ 1.579 & \mathrm{E}-04 \\ 5.390 & \mathrm{E}-06 \\ 7.000 & \\ 9.500 & \end{array}$

$2.584 \quad \mathrm{E}-09$

2.845 - -10

$2.336 \quad \mathrm{E}-03$

1. $000 \mathrm{E}-04$

$1.614 \quad \mathrm{E}-04$

1. $294 \mathrm{E}-05$

8.000

9.750
$3.796 \mathrm{E}-09$

$6.949 \mathrm{E}-10$

$2.525 \quad \mathrm{E}-03$

$1.000 \mathrm{E}-04$

$1.688 \mathrm{E}-04$

$8.570 \mathrm{E}-06$

(CONTINUED)

$\begin{array}{rr}146.000 & 164.000 \\ 7.100 & 7.010 \\ 0.042 & 0.042 \\ 1.040 & 1.046 \\ 0.030 & 0.030 \\ 1.239 & 1.225 \\ 0.056 & 0.055 \\ 0.729 & 0.999 \\ 0.148 & 0.193 \\ 20.406 & 25.080 \\ 4.382 & 8.379 \\ 24.953 & 30.116 \\ 5.118 & 9.191 \\ 25.000 & 25.400 \\ 2.136 & 2.779 \\ 0.479 & 0.976 \\ 1.000 & 2.000\end{array}$



$(70-90 \mathrm{~W}$

SUB TEST)

$\begin{array}{lrrr}\text { VAPOR TEMP } & 150.000 & 192.000 & 200.000 \\ \text { H } & 2.860 & 3.620 & 3.980 \\ \text { SH } & 0.042 & 0.042 & 0.047 \\ \text { ALPP } & 1.040 & 1.040 & 1.040 \\ \text { SRALPP } & 0.030 & 0.030 & 0.030 \\ \text { ALPPR } & 1.257 & 1.255 & 1.255 \\ \text { SRALPR } & 0.075 & 0.069 & 0.074 \\ \text { RL } & 0.854 & 0.749 & 1.083 \\ \text { SRL } & 0.377 & 0.216 & 0.498 \\ \text { CALC WATTS } & 92.933 & 74.076 & 99.119 \\ \text { SWR } & 13.026 & 7.632 & 20.465 \\ \text { CALC WATTS } & 110.930 & 88.276 & 117.492 \\ \text { SW } & 15.865 & 9.227 & 23.810 \\ \text { OBS WATTS } & 78.000 & 70.000 & 75.000 \\ \text { DT CALC } & 10.231 & 7.952 & 11.474 \\ \text { SDT } & 1.588 & 0.839 & 2.384 \\ \text { OBS DT } & 4.000 & 3.000 & 4.000\end{array}$


TEST DATA SHEET FOR DATA SET

TEST \#

K

SK

RE

SR

A

SA

I LAYER

II LAYER

(20-30W)

SUB TEST)

VAPOR TEMP

$\mathrm{H}$

$\mathrm{SH}$

AJPP

SRALPP

ALPPR

SRALPR

RL,

SRL

CALC WATTS R

SWR

CALC WATTS

SW

OBS WATTS

DT CALC

SDT

OBS DT
57

$\begin{array}{ll}2.798 & \mathrm{E}-09 \\ 9.819 & \mathrm{E}-11 \\ 2.162 & \mathrm{E}-03 \\ 1.000 & \mathrm{E}-04 \\ 1.677 & \mathrm{E}-04 \\ 6.440 & \mathrm{E}-06 \\ 9.250 & \\ 0.250 & \end{array}$

2. 798 E-09

$9.819 \mathrm{E}-11$

$2.162 \quad \mathrm{E}-03$

$1.000 \mathrm{E}-04$

$1.677 \mathrm{E}-04$

6.440 E-06

10.250

162.000

7. 360

0.042

]. 040

0.030

1. 222

0.055

1. 100

0.181

34.337

6.742

41.373

7.892

29.000

3. 842

0.797

3.000
58

3. 171 E-09

$2.146 \mathrm{~L}-10$

2. $603 \mathrm{E}-03$

1. 000 E-04

$1.682 \mathrm{E}-04$

7. 860 E-06

7. 350

8.750
175.000

6.850

0.042

1. 040

0.030

1. 222

0.055

1. 062

0.070

18.559

5.653

22.590

6.496

24.000

2. 060

0.659

2. 000

(CONTINUED) 


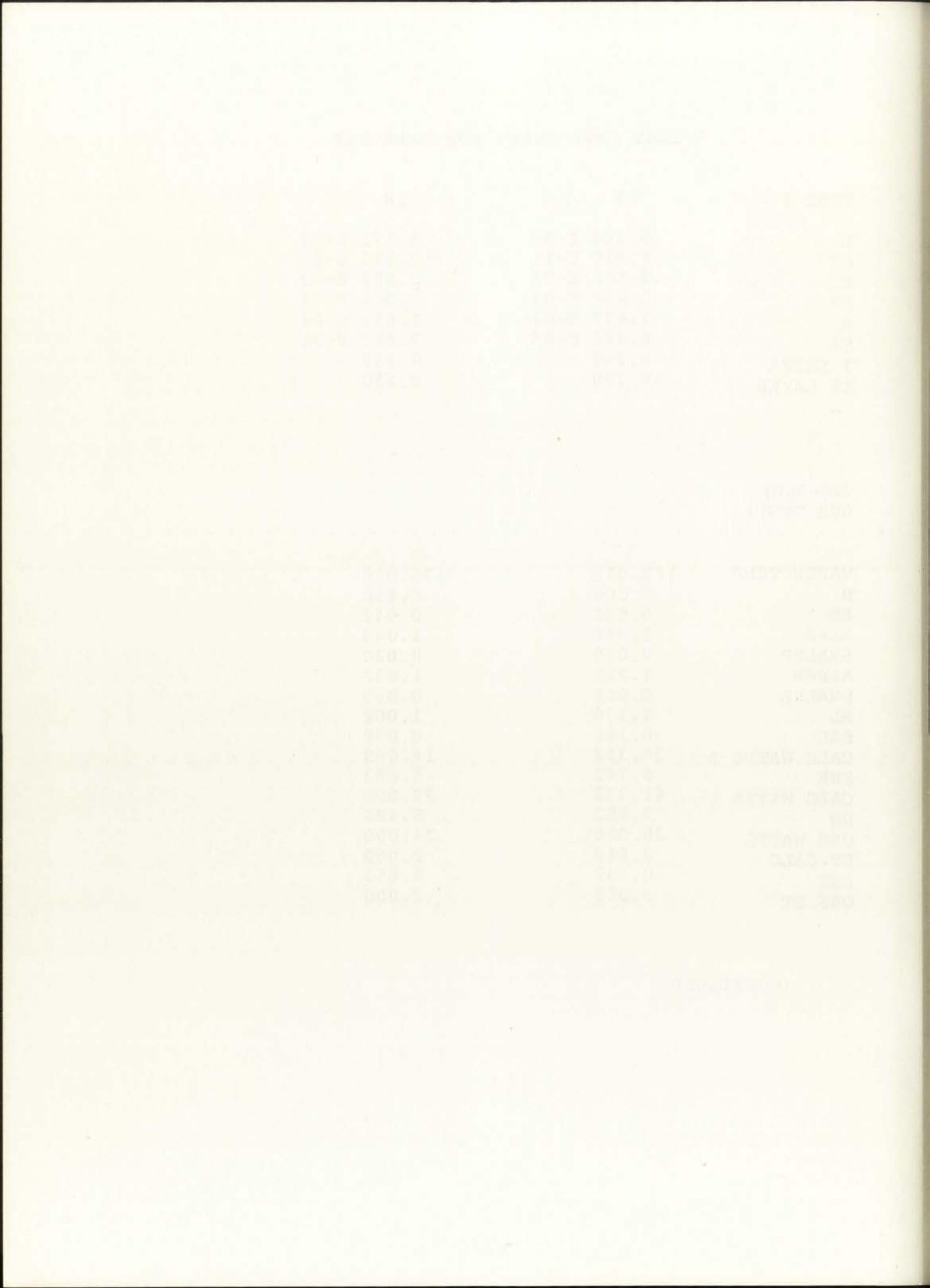


$(60-80 W)$

SUB TEST)

$\begin{array}{lrr}\text { VAPOR TEMP } & 203.000 & 194.000 \\ \text { H } & 4.350 & 4.050 \\ \text { SH } & 0.042 & 0.042 \\ \text { ALPP } & 1.040 & 1.046 \\ \text { SRALPP } & 0.030 & 0.030 \\ \text { ALPPR } & 1.244 & 1.242 \\ \text { SRALPR } & 0.067 & 0.067 \\ \text { RL } & 1.208 & 1.083 \\ \text { SRL } & 0.376 & 0.314 \\ \text { CALC WATTS R } & 92.092 & 75.657 \\ \text { SWR } & 9.862 & 9.050 \\ \text { CALC WATTS } & 107.954 & 89.044 \\ \text { SW } & 11.745 & 10.827 \\ \text { OBS WATTS } & 81.000 & 79.000 \\ \text { DT CALC } & 10.581 & 8.688 \\ \text { SDT } & 1.168 & 1.082 \\ \text { OBS DT } & 5.000 & 8.000\end{array}$



TEST DATA SHEET FOR DATA SET \# 4

TEST \#

K
SK
RE
SR
A
SA
I LAYER
II LAYER

(50-60W)

SUB TEST)

VAPOR TEMP

$\mathrm{H}$

$\mathrm{SH}$

ALPP

SRALPP

ALPPR

SRALPR

RI

SRL

CALC WATTS $R$

SWR

CALC WATTS

SW

OBS WATTS

DT CALC

SDT

OBS DT
59

$\begin{array}{ll}2.729 & \mathrm{E}-08 \\ 1.339 & \mathrm{E}-09 \\ 7.921 & \mathrm{E}-03 \\ 1.000 & \mathrm{E}-04 \\ 5.314 & \mathrm{E}-04 \\ 1.890 & \mathrm{E}-05 \\ 2.365 & \\ 2.875 & \end{array}$

$2.729 \mathrm{E}-08$
$1.339 \mathrm{E}-09$

$7.921 \mathrm{E}-03$

$1.000 \quad \mathrm{E}-04$

5. $314 \quad \mathrm{E}-04$

1.890 E-05

2. 875

60

3. $209 \mathrm{E}-08$

1. $381 \mathrm{E}-09$

8. $278 \mathrm{E}-03$

1. $000 \mathrm{E}-04$

5.203 E-04

$2.091 \mathrm{E}-06$

2. 365

2.750

61

3. $291 \mathrm{E}-08$

1. 265 E-09

$8.675 \mathrm{E}-03$

1. $000 \mathrm{E}-04$

$5.406 \mathrm{E}-04$

1. 860 E-06

2. 000

2. 625
182.000

2. 480

0.042

1.040

0.030

1. 328

0.064

1.041

0.403

35.003

26.410

44.122

30.879

55.000

.10 .778

8.668

8.000
195.000

2. 290

0.042

1. 040

0.030

1. 328

0.063

1. 166

0.439

68.111

32.289

85.004

37.535

56.000

21.366

10.562

8.000
188.000

2. 250

0.042

1. 040

0.030

1. 342

0.076

0.916

0.442

38.561

31.797

48.406

37.576

56.000

11.904

10.533

8.001

(CONTINUED) 


$\begin{array}{lr}\text { VAPOR TEMP } & 200.000 \\ \text { H } & 2.250 \\ \text { SH } & 0.042 \\ \text { ALPP } & 1.040 \\ \text { SRALPP } & 0.030 \\ \text { ALPPR } & 1.348 \\ \text { SRALPR } & 0.085 \\ \text { RL } & 1.083 \\ \text { SRL } & 0.440 \\ \text { CALC WATTS R } & 133.845 \\ \text { SWR } & 29.706 \\ \text { CALC WATTS } & 163.944 \\ \text { SW } & 40.669 \\ \text { OBS WATTS } & 115.000 \\ \text { DT CALC } & 45.000 \\ \text { SDT } & 10.006 \\ \text { OBS DT } & 18.000\end{array}$

$$
\begin{array}{r}
200.000 \\
2.230 \\
0.042 \\
1.040 \\
0.030 \\
1.345 \\
0.082 \\
1.117 \\
0.449 \\
286.371 \\
32.232 \\
103.088 \\
44.143 \\
120.000 \\
28.965 \\
10.608 \\
14.000
\end{array}
$$$$
200.000
$$$$
2.100
$$$$
0.042
$$$$
\text { 1. } 040
$$$$
0.030
$$$$
\text { 1. } 364
$$$$
0.098
$$$$
0.937
$$$$
0.464
$$

118.182

33.356

144.277

45.878

123.000

40.421

11. 280

14.000 



\section{TEST DATA SHEET FOR DATA SET \#4}

TEST \#

K

SK

$\mathrm{RE}$

SR

A

$\mathrm{SA}$

I LAYER

II LAYER

(50-60W)

SUB TEST)

VAPOR TEMP

$\mathrm{H}$

$\mathrm{SH}$

ALPP

SRALPP

ALPPR

SRALPR

RL

SRL

CALC WATTS R

SWR

CALC WATTS

SW

OBS WATTS

DT CALC

SDT

OBS DT
62

$2.822 \mathrm{E}-08$

8. $494 \mathrm{E}-10$

8.675 E-03

$1.000 \quad E-04$

5.438 E-0 4

$1.001 \mathrm{E}-05$

1. 875

2.625
63

3.231 E-08

$9.071 \mathrm{E}-10$

$8.675 \mathrm{E}-03$

$1.006 \mathrm{E}-04$

5.295 E-04

1. $100 \mathrm{E}-05$

2. 250

2.625
176.000

2.300

0.042

1.040

0.030

1. 355

0.084

0.791

0.432

23.412

23.637

30.089

30.476

53.000

.7 .027

8.365

8.000
170.000

2.240

0.042

1.040

0.030

1. 331

0.065

1.124

0.448

158.707

29.374

73.392

34.452

55.000

18.544

9.631

8.000

(CONTINUED) 



$\begin{array}{lrr}\text { VAPOR TEMP } & 195.000 & 184.000 \\ \text { H } & 2.030 & 2.120 \\ \text { SH } & 0.042 & 0.042 \\ \text { ALPP } & 1.040 & 1.040 \\ \text { SRALPP } & 0.030 & 0.030 \\ \text { ALPPR } & 1.378 & 1.351 \\ \text { SRALPR } & 0.108 & 0.087 \\ \text { RL } & 0.812 & 1.124 \\ \text { SRL } & 0.458 & 0.471 \\ \text { CALC WATTS R } & 147.351 & 123.177 \\ \text { SWR } & 27.892 & 29.889 \\ \text { CALC WATTS } & 183.923 & 149.780 \\ \text { SW } & 38.544 & 40.569 \\ \text { OBS WATTS } & 122.000 & 126.000 \\ \text { DT CALC } & 50.058 & 41.568 \\ \text { SDT } & 9.374 & 9.913 \\ \text { OBS DT } & 12.006 & 15.000\end{array}$



TEST \#

K

SK

$\mathrm{RE}$

$\mathrm{SR}$

A

SA

I LAYER

II LAYER
64

$\begin{array}{ll}6.737 & \mathrm{E}-09 \\ 2.587 & \mathrm{E}-10 \\ 3.888 & \mathrm{E}-03 \\ 1.000 & \mathrm{E}-04 \\ 3.092 & \mathrm{E}-04 \\ 9.650 & \mathrm{E}-06 \\ 5.750 & \\ 5.875 & \end{array}$

$(45-55 \mathrm{~W})$

SUB TEST)

VAPOR TEMP

$\mathrm{H}$

$\mathrm{SH}$

ALPP

SRALPP

ALPPR

SRALPR

RL

SRL

CALC WATTS R

SWR

CALC WATTS

SW

OBS WATTS

DT CALC

SDT

OBS DT
175.000

4.310

0.042

1.040

0.030

1.308

0.055

1. 208

0.245

61.077

9.506

77.575

11.395

53.000

9.561

1.587

7.000
65

6.031 E-09

4. 131 E-10

$3.888 \mathrm{E}-03$

1.000 E-0 4

2. 759 E-04

1. 719 E-05

5.250

5.875
66

6.421 E-09

$4.344 \mathrm{E}-10$

$3.888 \mathrm{E}-03$

1.000 E-04

2.939 E- 04

1. 053 E-05

5.250

5.875
185.000

4.490

0.042

1.040

0.030

1. 305

0.055

1. 145

0.735

45.768

10.015

58.129

11.815

55.000

6.803

1. 650

8.000

(CONTINUED) 
$(90-120 \mathrm{~W}$

SUB TEST)

VAPOR TEMP

$\mathrm{H}$

$\mathrm{SH}$

ALPP

SRALPP

ALPPR

SRALPR

RL

SRL

CALC WATTS $R$

SWR

CALC WATTS

$\mathrm{SW}$

OBS WATTS

DT CALC

SDT

OBS DT
185.000

3.550

0.042

1. 040

0.030

1. 327

0.068

1. 208

0.308

112.410

11.538

140.247

15.031

104.000

17.930

1.911

15.000
201.000

3.590

0.042

1.040

0.030

1. 328

0.068

1.208

0.315

94.374

12.657

118.145

16.431

105.000

13.421

1.985

15.000
180.000

3.750

0.042

1.040

0.030

1. 327

0.068

1.200

0.302

87.366

11.942

109.325

15.490

110.000

13.764

1.997

19.000 

TEST DATA SHEET FOR DATA SET \#5

TEST \#

K
SK
RE
SR
A
SA
I LAYER
II LAYER

(45-55W

SUB TEST)

$\begin{array}{lrr}\text { VAPOR TENP } & 190.000 & 186.000 \\ \text { H } & 3.950 & 4.380 \\ \text { SH } & 0.042 & 0.042 \\ \text { ALPP } & 1.040 & 1.040 \\ \text { SRALPP } & 0.030 & 0.030 \\ \text { ALPPR } & 1.308 & 1.308 \\ \text { SRALPR } & 0.055 & 0.055 \\ \text { RL } & 1.124 & 1.208 \\ \text { SRL } & 0.263 & 0.240 \\ \text { CALC WATTS R } & 71.543 & 52.877 \\ \text { SWR } & 10.360 & 9.568 \\ \text { CALC WATTS } & 90.255 & 67.271 \\ \text { SW } & 12.109 & 11.431 \\ \text { OBS WATTS } & 55.000 & 55.000 \\ \text { DT CALC } & 10.302 & 7.715 \\ \text { SDT } & 1.710 & 1.487 \\ \text { OBS DT } & 8.000 & 9.000\end{array}$

\section{8}

$$
\begin{array}{ll}
6.400 & E-09 \\
3.475 & E-10 \\
3.971 & E-03 \\
1.000 & E-04 \\
2.836 & E-04 \\
1.474 & E-05 \\
5.165 & \\
5.750 &
\end{array}
$$

$$
\begin{array}{ll}
6.577 & \mathrm{E}-09 \\
3.111 & \mathrm{E}-10 \\
3.888 & \mathrm{E}-03 \\
1.000 & \mathrm{E}-04 \\
2.893 & \mathrm{E}-04 \\
1.037 & \mathrm{E}-05 \\
5.250 & \\
5.875 &
\end{array}
$$

(CONTINUED) 

$(90-120 \mathrm{~W}$

SUB TEST)

VAPOR TEMP

$\mathrm{H}$

$\mathrm{SH}$

ALPP

SRALPP

ALPPR

SRALPR

RL

SRL

CALC WATTS $R$

SWR

CALC WATTS

SW

OBS WATTS

DT CALC

SDT

OBS DT
195.000

3.650

0.042

1.040

0.030

1. 327

0.068

1.208

0.301

91.632

11.601

114.474

15.102

95.000

13.395

1.822

15.000
186.000

3.490

0.042

1.040

0.030

1. 328

0.067

1.020

0.279

113.258

11.854

141.463

15.440

100.000

16.866

1.857

18.000 



\section{APPENDIX B}

COMPUTER PROGRAM

52.05

in 0 in J) TIME=10, G?

RDBERTS, CHARLES

DIMFNSION AAN(400), F(400), DEF $(400)$, DIFF $(400), \times(400)$

COHMUN RHOF, IJL, AL, HIL, RE, SR, HFG, AK, SK, SAL

ก) 681 II $=1,10$

REAC, RV

REAL, SIRV

$R V=R V / ?$.

$S R V=S .2 V / 2$.

FEL $A D, H 1 L$

$\vdash 1 L=H 1 L / 12$.

REAC, AL

RE.AD, SAI.

REAE, AK

READ, SK

REAC, HF

REAC, St:

READ 100 , RHCF, HFG

REAO 100 , SISMA.UL

READ $100, H, S H$

READ $100, T T$, ALPF

100 FJRMAT $(-23.7, F 20.7)$

200 FORNAT $(-20.7, F .20 .7, E 20.7)$

WIR I TF $(6,102)$

102

FORNAT $(C X$, , AK

WRITE $(0,1,1)$ AK,SK, RF, SO,H,SH

101 FORNAT $(2 X, 1$ PE $12.5,4 X, 1 P E 12 \cdot 5,4 X, 1 P E 12.5,4 X, 1 P E 12.5,4 X, 1 P E 1 ? .5$.

$14 \times, 1 P E 12.5,11$

SRALPD $=.03$

DO $400 \mathrm{KL}=1.3$

WR I TE $(0,103)$

103 FIF MAT $(6 \times$, ALFPP, $/ 1)$

WRITE $(5,104)$ ALFP

104 FUPNAT $(2 \times, 1 F E 12.5 . /)$

PR INT, SRALPF

WRITE $(6,105)$

165 FORMAT( $5 \mathrm{X}$, , TEMP・, / )

WRITE $(5,165)$ TT

166 FORNAT( $2 X, 1$ PE $12.5, /)$ 
$3= \pm-1 \div 3$

$C C=32.1+4$

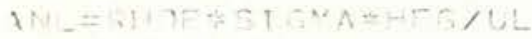

$C=3 r+67 .+17.57$

NRIT: $(1,1=5)$

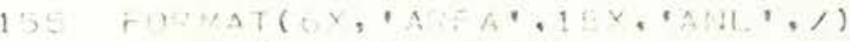

NEITF( , ISA) AL, A:L

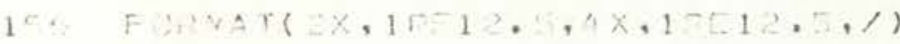

Di: I:T, : $: 4$

$\ln I T_{1}=(\ldots 201)$

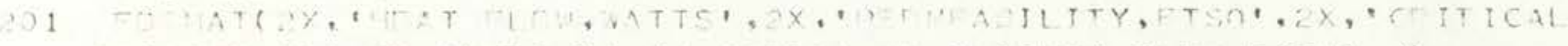

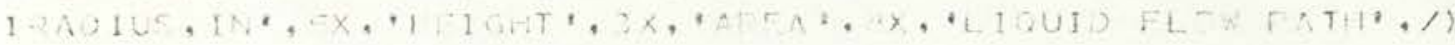

$\mathrm{i}=\sin 0$

$x \times \times \times=\therefore:(2.3723)$

1) $\div 13 \quad 1=1$,

$3:=(5+1)(0)+S x)+A p$

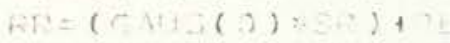

$|2|=(1 ; 0,13)-\cdots)+1+$

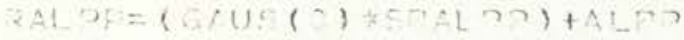

$B A L=(C N U ;()+,A L)+A L$

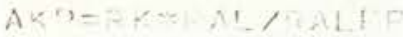

GF $1=0+\ldots$

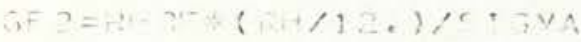

$\mathrm{CHC} A=31-7,2$

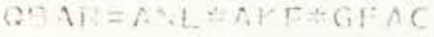

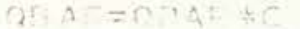

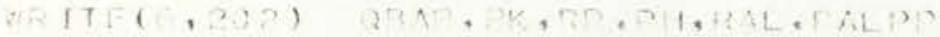

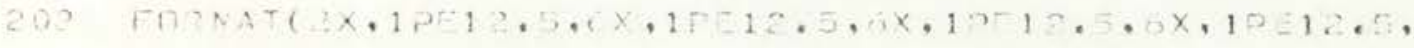

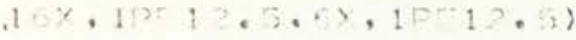

$x(1)=2 . \quad \therefore$

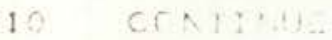

P: $1: T$,

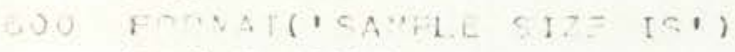

I. T $\because 10$,

10 FONAT(1H,

$z=s$

S.1. $=2$.

$\begin{array}{rl}130 & 56 \times=51+x(32)\end{array}$

$2 \times 3+1=5(14):$

50, $30=0$

Dot 1 is $+1-1, x$

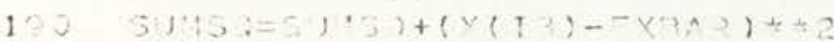

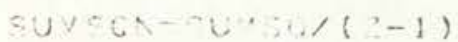

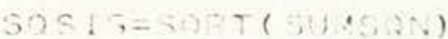

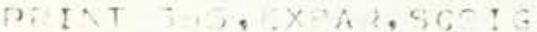

535 FWM

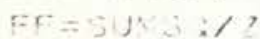

$\mathrm{x}_{1}=\mathrm{C}$.

$x:=0$.

$\times 3=;$

$x+1=$.

Dii $2 x \quad I=1$,

$\times 1=(1+x(1)$

$x_{2}=x^{2}+x^{2}(1)$

$x 3=x 3+\wedge(1)$

$\because x=x+x(!)$ 
$\left(13=\times 3 / 7-3 *\left(x_{2} / 7\right) \div(\times 1 / 7)+2 *(\times 1 / 7) * 3\right.$

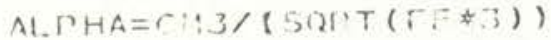

PIXINT HER.ALPHAB

(1), FIJIMAT ( / OCOEFFICITNT TF SKEWNFSS = . F $20.3 / 1)$

$C A 4=x 4 / 2-4 *(\times 1 / 2) *(\times 3 / Z)+5 *(x 2 / Z) *(\times 1 / Z) * * 2-3 *(\times 1 / Z) * * 4$

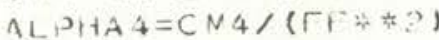

PRTINT ZOOO, AI PHA

300

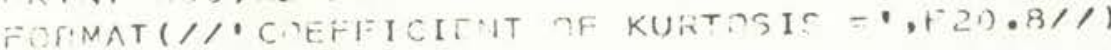

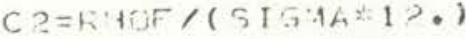

C $3=2+$

$\mathrm{a}=\mathrm{C} * A \mathrm{AL} *(A K * A \mathrm{Al} / \mathrm{AL} \Gamma \mathrm{F}) *(\mathrm{C} ; / \mathrm{R} E-\mathrm{C} 2 * H)$

1). INT, ?

$\Delta_{4}=\mathrm{AK} \neq \mathrm{AL}$

$A S=A 4 / A I . P P$

A $3=C 3 / 2:-C ?+11$

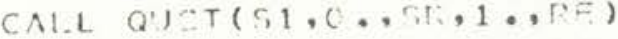

$S 1=51$ t $\mathrm{S}, \mathrm{s}$

$52=\mathrm{C} 2 * 5 \mathrm{H}$

CAL.L SUMTIt $(53,51,52)$

CALL PHOO (S.4, SK, $A \mathrm{AL}, \mathrm{AK}, \mathrm{AL}$ )

CALL OU T ( $5.54,50 A L D P, A 4, A L P P)$

CALL W OT $35, .55,5,3,45 . A ?)$

$S t=C * \wedge: 1+5 t$

F+R INT, ; F;

$\mathrm{QB}=\mathrm{C} 3 / \mathrm{QS}-\mathrm{C} \cdot \mathrm{S}^{\mathrm{x}} \mathrm{H}$

$P \cap W A=C \simeq A N L *(A K / A L F P) \div 2 !$

$D O W K=C * A N L *(A L . / A L F: P)$ *OL

$P Q W L P=-C * A+L *(A L * A K /(A L P P * * 2)) * Q F 3$

$\triangle C=C * A F L *(A K * A L / A L \Gamma P)$

$P O W H=Q C *(-C ?)$

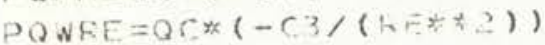

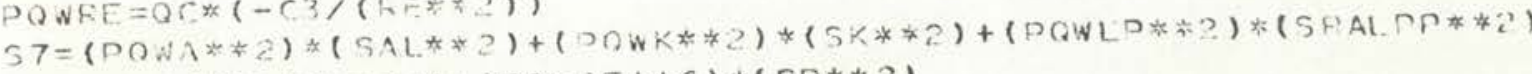

$1+(P O N H * 2) \neq(5 H+2 * ?)+(P O W ? F * 2) *(S R * * 2)$

$S 7=S G t^{2} T(57)$

ORINT,, 37

CALL HESLSS (FX

AI $\Gamma P=A L P P$ N

$S R A L P I=S<A L P N$

PRINT, S1,AL.FP

CAIL OULTAT(IV, CIV , XBAD, S.ST G)

4 (i) CRNTIN:I

E.31 CONTINUE.

CALL FXIT

END 

EIINCT IH:N ;AUS $(K)$

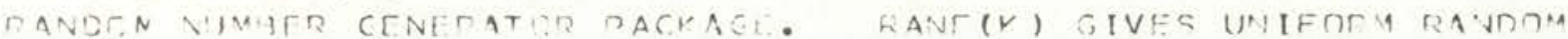

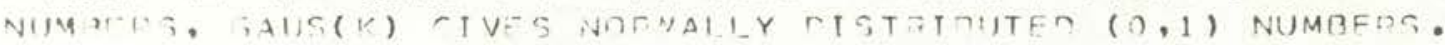

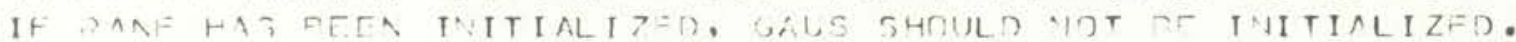

I) ATA I; T T T

DATA T'UT'T/. ?331:/

IF ( ISET) 1 $, 10,20$

$1 \cap \quad \mathrm{I}, \mathrm{T}=1$

$A=\xi G H \cdot T(-2 \cdot+\Lambda) \cap G(H A N F(K)))$

$3=A N F(3) * T$ TODI

$\mathrm{G} A()_{5}=\Delta * 5 \mathrm{I} \cup\left({ }^{\prime 2}\right)$

STPOF=A+CRS(T)

CLTIJRN

s? I $3: T=0$

TAUS = CT $\because$

KETUTON

F(N!) 

FUNCTION TANT (N)

FRRTFAY RTUTINE TC GENFOATF FLOATING RANDOM NUMBEPB OVTU THF RANGE DF 0.0 TO $1: 0$.

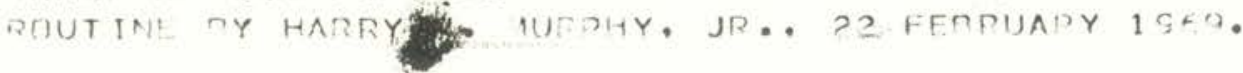

FOUIVAL-NCF $(T \times, P X)$

DATA TX/7:2771/

1 If $(\Lambda) 4,2,$,

$2 \quad I X=N+)(10 \geqslant 1 * I X+3,104 ? 575)$

R $\triangle N F=F L \cap A T(I X) / 1040 E 76.1)$

RETUPA

$3 \quad[x=\operatorname{vec}(N, 104,27,7)$

4 RAIVF $=F X$

RETUI:A

FN) 


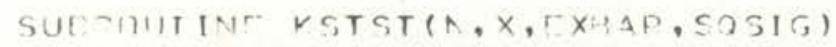

DI UFA TOA: AAY $(400)$, F: $(4: 0))$, COF $(400)$, DIFF $(400), \times(400)$

) $3 \in 1=1, \mathrm{~N}$

36 $F(I)=C$.

$1=N+1$

$M=i v+10$

()) $114 \quad \mathrm{I}=\mathrm{L}$.

$14 \times(I)=C$.

$\mathrm{U}= \pm \times 3 \mathrm{~A}^{2}$

$\mathrm{S}=\mathrm{S}$ GS IG

PRIAT $>77, N$

FROMAT( I, SAMPLF SIZF= , I 5)

$Z=-1 \cdot 0 n t+10$

$Y=0$.

Dח? $\mathrm{I}-1, \mathrm{~N}$

IF $(x($ I $)-Z) \quad 1$ ? , ?

$1 \quad k=1-1$

$x(K)=x(I)$

$x(1)=$ ?

$Y=1$.

$r=x(I)$

IT (Y) $5,5,4$

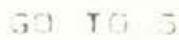

COI:T TNJ:

$p=0$.

Dก 51 I $=1,1$

$\curvearrowright=1$.

$K=I+1$

If $(x(I))$, $0,51,60$

IF $(x(T)-x(k)) \quad 31,32,21$

Dก $5: J=I, N$

$\mathrm{L}=\mathrm{J}+\mathrm{I}$

L $2=j+i$

$x(L)=x(L ?)$

$0=0+1$.

$O=\sigma+1$.

IF $(X(I)-X(K))>1,30, ? 1$

37 CON.T1 10

$F(\mathrm{I})=\mathrm{A}$

CONTNH

$L=1$

$M=N-L$

RF $7=0$.

ग) $71 \quad I=1, \mathrm{~N}$

$\Gamma=N$

$513<F=F(I) / 3$

OF $7=O F Z+O 3 S T$

71 TRF (I) $=M . F Z$

DO $41 \mathrm{I}=1$, M

(Ii) $=(x(I)-(1)) / 5$

$R=0$.

IF (UC) $1 \geq 1,131,132$

$131 U U=\operatorname{AH}(U)$

R=1.

CONTINII:

$Z U=1 \cdot /($ SQRT $(6 \cdot 28312) * E \times P(U U * * 2 / ?)$.

$T=1 . /(1 .+.33267 *$ Uし $)$ 

$P X=1 .-(.436133 * * T-.120167 *(T * 2)+.9372900 *(T * * 3)) * Z U$

IF (13) $134,134,135$

$p X=1 \cdot->x$

CDN TNय

$\operatorname{AAN}(1)=i) X$

$D()-\{1 \quad I=1, H$

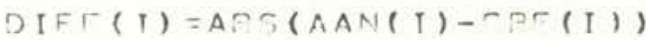

31 CONTINIF-

PRIT,T 300

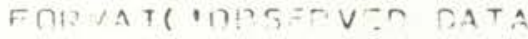

1 NOMAM EIINCTION

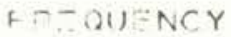

ก) 4 it $I=1$, *

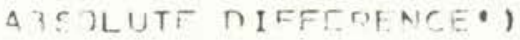

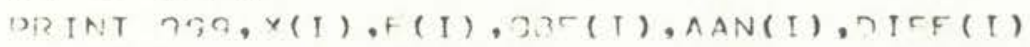

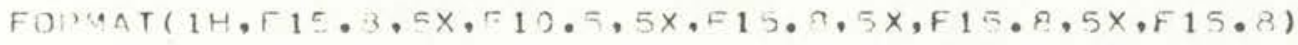

DIF $v x=$ ).

กn $\varphi=I=1 . \prime$

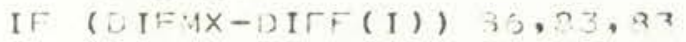

1) IF $n=$ J) IFF (I)

33 CINTINII:

CRINT A ID, CIFNX

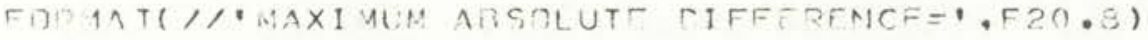

TEST $=1$ - B B $/$ SGRT $(\theta))$

DOINT $403, T$, TIT

407 FIOMAT( /, KOLAOCORIV CRITICAL VALUE AT OD DFRCT CL=",F15. $3 /$ ) PFTURN.

[N] 
SUBRCLTINF DELTAT (RV, SRV, G, TO)

DIMICNCITN OT(120)

CANVCA /CFLK/RECESL, SRFSSL

C $1=50.117 .57$

$\mathrm{\gamma}=\mathrm{C} 1 \leqslant 0$

$\mathrm{SQ}=\mathrm{C} \cdot \mathrm{I}+\mathrm{SQ}$

DKM-. ZOE

री $1=.43 / .332$

$\mathrm{N}=1<\mathrm{C}$

रKD $=3.13$.

$P L 5=1+\cdot 3 / 12$.

HI. $C=7,12$.

DO $5 \mathrm{I}=1, \mathrm{~N}$

$R P V=(\operatorname{CNUS}(0) * S R V)+P V$

$R V C=(.393-0 V) *((6 A C 5(0) * 013)+.25)+5.5 V$

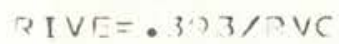

DTVER=(.303-nRV) $+((; 1)=(0) \div .03)+.41)+R R V$

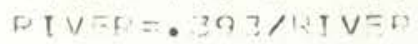

RECL $=(G A U S(0)$ + SRESSL ) + RECES1.

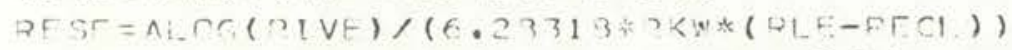

RESFH= LOO

२I VC $=.303 /$ R.V.V

$P J=(; A(1 \leq(\partial) * S \cap)+0$

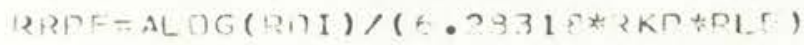

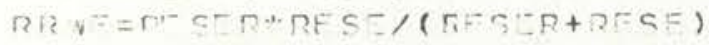

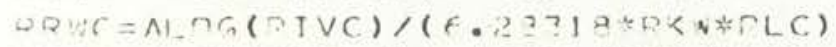

$R P P C=A L C G(\Omega \cap 1) /(6.23316+2 \mathrm{KO}$ * RLC

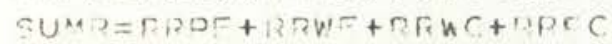

nT $(T)=22 *$ SIJiA

CALL V:AN(N, DT, OCT, SDT)

गम 1 IT $100,00 T$, OกT

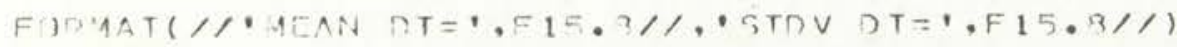
RETURA

FN? 

SU:3:JUTINE AKVAL (A, X. AL, SAL, AK, SK)

DIMENSION! $\times(400)$

PRINT ;OI

501 FOIPAT( 'DATA IS')

DC $14 \mathrm{~J}-1$. N

DRINT $5: 1, \times(J)$

FOP.MAT ( 1 H, F 15.3)

PIRIAT 16

FOLMAT( ISAMDLF SIZF TS*)

PRIAT 510,2

10 FDR MAT ( 1 H, IS)

$D O=3 \quad \mathrm{I}=1, \mathrm{~N}$

$A=(G A \cup S(0)+S A L)+M L$

$32 \times(T)=6 \cdot 132=-04 *(2.0 / x(1))+(2.205 F-03 / A) *(1 . / 62.265) *(2 \cdot 16 ? \cdot 265) *$

$1(1 . / 32.2)$

$\mathrm{Z}=\mathrm{N}$

SUM $=0$.

D) $1: 1 \quad \mathrm{~T} ?=1, \mathrm{~N}$

$C U N=C L 1+X(1 ?)$

$F \times A R=S U M / Z$

SU⿻ $6=0$ ?

Di) 1 : 1 + $+3=1, N$

$\operatorname{sim} S G=51 M C \cdot Q+(X(13)-\approx X B A D) * * 2$

SUNEOR= UUNS: $/(2-1)$

SOSIC- ThIT (SIJMSON)

PRINT 126. PXAAR, $563 I G$

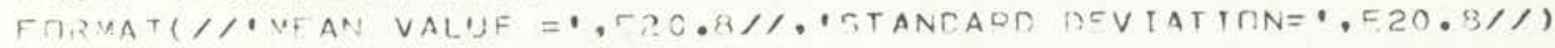

$A F=$ รUม

$x_{1}=0$.

$\times 2=0$.

$\times 3=1$.

$\times 4=11$.

() $₹ 1 \quad 1=1, \mathrm{~N}$

$x_{1}-x_{1}+x($ I $)$

$\times 2=x z+x(1) *+?$

$x 3=x_{3}+\times(1)+x^{2}$

$x_{4}=x^{4}+x($ I $) \neq 4$

CM $3-x, 2 / z-3 *(\times 2 / Z)+(\times 1 / Z)+2 *(\times 1 / 7) * 2 * 3$

AL. DHA.?=CH $3 /(50 ? T(A F+\div 3))$

ORIAT 203 , ALFHA?

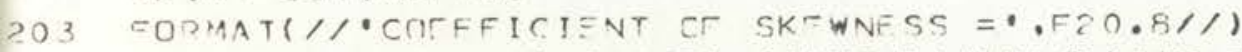

$C M A=x 4 / Z-4 *(x 1 / Z) *(x 3 / Z)+5 *(x ? / 7) *(x 1 / 7) * * 2-3 *(x 1 / 7) * * 4$

ALPHA $4=C \times 4 /(A F * * ?)$

PRINT 301 , ALPHA 4

301 1 FORMAT( $/$ COEFFICIENT CFF KURTOSIS $=$, F20.8/1)

$A K==x+3 A=$

$S K=S Q \subseteq 1$,

RETURA

END 


UPRCIT INE MVALU(A,X, AL, SAL).

I $M E A S I \cap N \times(400)$

RINT 500

NDNAT('SAMTLE SIZE IS')

RINT $\triangle 1 \cap, A$

W. 2 - AT ( $1 \mathrm{H}, \mathrm{T} 5)$

$\mathrm{I}=3.1+150 / 575$.

$1=.7 \varepsilon 6$

in $3=1, N$

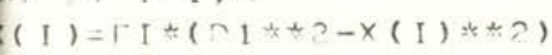

$=\mathrm{N}$

$U \cdot 1=$ ) .

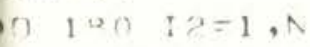

$113=5(1+x(12)$

$X \cap A R=\Im, U H / Z$

SU⿺C $=7$.

$130 \quad \mathrm{I} 3=1, \mathrm{~N}$

$U_{N} \subseteq Q=S U N=O+(X(I 3)-F X E A R) *$ \#

SUM Sก $N=\sin 1.42 /(Z-1)$

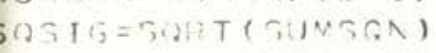

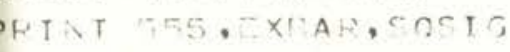

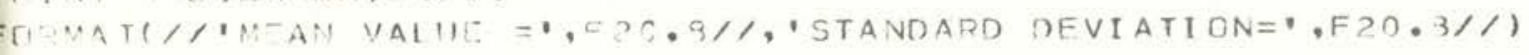

$F=-11, \cdots, 0,2$

$1=0$.

$2=0$

$3=0$

$4=2$.

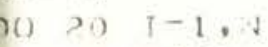

$\ll 1=x 1+x(I)$

$r ?=x ?+x(1) * x+3$

$83=x j+x(I) \neq 3$

$<4=x 4+x(1)+2+4$

$M 3=x \geq / Z-z+(X 2 / 7) *(\times 1 / Z)+2 *(\times 1 / Z) * * 3$

AL. FHA $-C * 3 /($ SORT $(F F * 3))$

DRINT ORE, ALPHAB

$=02 \times A T(/ /$ CUFFFICITNT RF SKE ANFSS = ,F20.8/1)

$6 * 4=x 4 / 2-4 *(x 1, Z) *(x 3 / 2)+6 *(x 2 / Z) *(x 1 / Z) * * 2-3 *(x 1 / 7) * * 4$

$A L F+A A=C M 4 /(F F \div 2)$

DP TNT 300 , ALPHAL

URNAT( / C COFFICIINT CF KUFTCSTS $=\cdot$, F20.8//)

$\mathrm{AL}_{1}=\mathrm{S} \cap \mathrm{S}_{\mathrm{I}} \mathrm{S}$

$A L=X E A$

RETURA 
SUHGOLTINE MEAN $A, X, F X$ XR, SGSIG)

DIMFR.STCN $\times(400)$

PRIAT 500

DO FOQMATI. SAMPLE SITF IS')

DRINT S10, N

10 FORMAT( 1 H. I 5 )

$Z=N$

SUN $=$ ? .

D० $180 \quad \mathrm{I} ?=1, \mathrm{~N}$

SUN $=S U \cdot 1+X(12)$

$E \times B A F=S U M / Z$

$\sin \sin =0$.

Dก 1 \%० $13=1, \mathrm{~N}$

Q0 $S U M S C=S(M S Q+(\times(I 3)-E \times B A R) * * 2$

SUMSON= SUM $30 /(Z-1)$

SQCTG SORT ( SUMSGN)

DRINT 535,5 XBAR, SOSIG

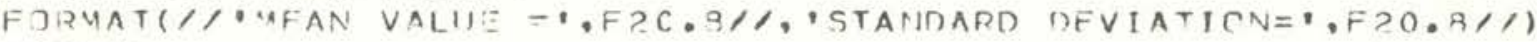
RFTUPA

END 

TUI3TOUTINF PFCESS(, , SO, ALFPN, SRAL.PN,H, SH)

DI MENSION Y $(200)$

COMNUN THOF,UL, AL, HIL, RL, SR, HFG, AK, SK, SAL

CONMCA /CPLK/RECESL, SRESSL

$A M O=(G * 00562 /(H F C \star 50)$.

$S A M O=S Q * 05692 /(H F G * 6,0$.

$E L=14.5 / 12$.

$\mathrm{S} \mathrm{FI}_{\mathrm{I}}=.03$

$\mathrm{FH}=+/ 1$ ?

CFHI $=$ I $/ 12$.

$x=?$.

$D X=.25112$.

$C 1=(L L * .5 * A \vee 0) /((F H \cap F * 2) * 32.2 * A K * A L)+(9.5 / 24) * F$.

$A=(A M O * U$ ) $) /(A K * 32 \cdot 2 *(2 H \cap F * 2) * E L * 3 . A L / 4 \bullet)$

$\mathrm{a}=\mathrm{FH} / \mathrm{C}$.

$N=5 ?$

DO $\supset \mathrm{I}=1, \mathrm{~N}$

$x=x+n \cdot x$

$D \eta=-\Delta, \cdot *(x * ?)+(F L * A+3) * x+C 1$

IF $(P \mathrm{C}-\mathrm{H}-1 \mathrm{~L}) 5,5,5$

$5 \quad \cap P D=P D$

गKINT,OT

$n x=x$

$3 \quad$ CONTINUI

5) $\quad$ QFCFSL $=\tau L-D X$

$A L F F N=2 F C E S L * 2 /(5.25 * 5 L)+? * E L / 3 .+.5$

$N N=1 \cap 0$

Oก $\rightarrow \quad \mathrm{I}=1, \mathrm{NN}$

$R K=(G A U S(0) * S K)+A K$

$\supset A=(G A U \subseteq(O) * S A L)+A L$

$R A M)=(G A U S(O) * S A M O)+A M O$

$\mathrm{RH}=($ : $A U S(O) * S T H)+F H$

RTH $=($ GAUS $(0) * . C 52)+.75$

$R C=(U \mathrm{~L} * 5 * \mathrm{RANO}) /((\mathrm{PHCF} * 2) * 32.2 * \Gamma K * \mathrm{PA})+(7.5 / 34) * R$.

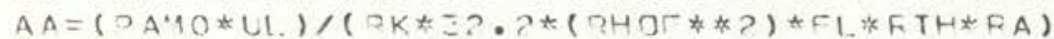

$125=P \vdash / 2$.

$R P C=-(A \wedge / P \cdot) \neq(J X * 2)+(F L * A \wedge+2 B) * n X+R C$

$Y(I)=\operatorname{Ron})$

CONTINUE

CAIL N AN(NA, Y,XBAF, SX)

$P D=X S A$ ?

$S P D=C X$

$S L D P F=-A * O X+F L * A+B$

$A B=S \cap n * * 2+S H * *$ ?

SRFCSL = CQRT (CE)/SLCPF

गO $10 \mathrm{~J}=1, \mathrm{HN}$

RRFCSL-(GAUS $(0)$ \& SE $5 S L)+R E C E S L$

$R T H F O=(; A U S(0) * .014)+.10$

REI $=($ CAIIS $(0)+S E L)+[1$.

RTTH $=($ GAUS (0) $* 043)+2 \cdot 13$.

RAL $\cdot D N=(F R F C S L *$ ? $) * F T H R D / R E L+D T T H * R E L+.5$

$10 \quad Y($ I $)=R A L P P N$

CALL NEAN $(N N, Y, X B A D, C X)$

SRALPN $=S X$

PRINT, SRAL TN

PRIAT, $\cap X$

PR INT, SRFSSI

\section{RerTUR}

MND 
SU $3 R C U T I N E$ SUNDIF(SA.SF, SC)

$S A=\subseteq B * 2+S C * * 2$

$S A=S Q R T(S A)$

RF. TURN

END

SUBFCUTINE GUDT (SA,SB, SC, EEAR, CGAR)

$S A=((C L A R * 2) *(S 3 * 2)+(B B A D * 2) *(S C * 2)) /(C B A R * 4)$

$S A=S G R T$ (SA)

RETURA.

[ND

SU:BFCUT INF PQOC (SA.S3,SC, GIAR, CBAR)

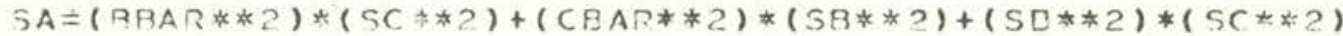

$S A=S \cap T(S A)$

TETURN

END

SUBRTITINE XSQAFE( $5 \times 2, S X, X 3 A R)$

$S \times 2=4 * * X$ A R *XEAR*SX*5X+2**5X**4

$\mathrm{S} \times \mathrm{S}=\mathrm{S}$ OP $\mathrm{T}(\mathrm{S} \times \mathrm{S})$

RFTURN

END 



\section{APPENDIX C}

\section{HEAT PIPE EXPERINIENTAL TEST PROCEDURES}

The following is a step-by-step procedure for the testing of a water heat pipe.

1. The heat pipe is thoroughly cleaned using trichloroethylene, alcohol, and water.

2. A wick is saturatec with fresh distilled water and inserted into the pipe.

3. The wick is inserted with the seam facing down and is forced against the evaporator plug.

4. The pipe is then filled with distilled water to further saturate the clearance area between the wick and the pipe wall.

5. The water is drained and $30 \mathrm{cc}$ of excess water is injected.

6. The condenser plug is inserted and sealed.

7. The pipe is then evacuated to 23 inches of Hg.

8. The evaporator is lowered and full power (100 watts) applied. The start up is observed to avoid premature burnout.

9. When the pipe pressure reaches 0 psi, the condenser valve is opened to vent any non-condensible residual gases.

10. After venting and resealing, the calorimeter is turned on and the system allowed to reach an equilibrium at the particular power level to be tested.

11. The evaporator is raised in increments of one fourth inch until a wick burnout is attained. A burnout is defined 
as a sudden temperature rise of more than $10^{\circ} \mathrm{F}$ at the extreme end of the evaporator after equilibrium is reached.

12. A second measurement is made to determine the burnout height within one eighth inch of the true height.

13. Data recorded at this time are:
a. Heat pipe temperature distribution
b. Calorimeter flow and temperature rise
c. Pipe vapor pressure
d. Burnout height

14. The power is now disengaged and the evaporator seal broken.

15. The gravity head is measured at the various burnout heights, as shown in Figure 3.5 .

16. The permeability is measured, as described in Figure 3.9. Thirty flow readings are recorded. Permeability is calculated according to the formula $K=u L ' \dot{m} / \rho A \Delta p$, where $\Delta p$ is assumed to be the linear head loss through the wick.

17. The wick is removed from the pipe and portions of it are placed in the wick apparatus, as described in Figure 3.12. If five consecutive identical readings are observed, they are considered to be the mean and the standard deviation is chosen to be one half the least count of the instrument. $r_{f r}$ is calculated as: $r_{f r}=2 \sigma / \rho \mathrm{GH}$.

18. The data are compiled for reduction. The procedure for wire mesh wick manufacture is as follows. 1. The raw wire mesh is cut to size and the retainer rod is welded to an edge. 
2. The wire mesh is inserted into the mandrel, wrapped in the wrapping apparatus (Figure 3.15) and welded.

4. The wick is cleaned as follows:
a. Ultrasonic cleaner with alkanox.
b. Rinse with tirchloroethylene.
c. Rinse in methanol.
d. Rinse in distilled water.

5. The wick is oxidized in air at $850^{\circ} \mathrm{F}$ for two hours. 6. Storage is under distilled water. 

Mr. Charles C. Roberts was born in New Bedford, Massachusetts on the 6 th of May, 1944. In 1966, his BS degree in Mechanical Engineering was received from Worcester Polytechnic, and in 1967, the MS degree in Mechanical Engineering was received from the same institution. Honors include election to the Sigma Tau Honor Society and to Outstanding Young Men of America, 1970. 


